\title{
Republic of Mozambique
}

\section{Agriculture Public Expenditure Review: \\ Assessment and Result-Focused \\ Expenditure Management}

May 2019

Agriculture Global Practice

Africa Region 


\section{Standard Disclaimer}

This Draft Report is a product of the staff of the International Bank for Reconstruction and Development/ The World Bank. The findings, interpretations, and conclusions expressed in this Interim Report do not necessarily reflect the views of the Executive Directors of The World Bank or the governments they represent. The World Bank does not guarantee the accuracy of the data included in this work. The boundaries, colors, denominations, and other information shown on any map in this work do not imply any judgment on the part of The World Bank concerning the legal status of any territory or the endorsement or acceptance of such boundaries. 


\section{Acknowledgments}

This Report was produced by a team from the World Bank Group led by Norman Piccioni (Senior Agriculture Economist), Aniceto Bila (Senior Agriculture Specialist) and Pedro Arlindo (Agriculture Economist. The technical team was comprised of: Richard Anson (lead consultant); Joao Mutundo (Associate Professor of Agricultural Economics, University of Eduardo Mondlane); Helder Zavale (Senior Lecturer of Agricultural Economics, University of Eduardo Mondlane); Ms. Gaby Mandlate (Junior Lecturer of Agricultural Economics, University of Eduardo Mondlane) and Carlos Mucavele (Senior Economist). Mark Austin (Program Leader, EACMM), and Holger Kray (Lead Agricultural Economist, GFA13) contributed useful insights as peer reviewers; Mark Lundell (Country Director, AFCS2), Raymond Bordeaux (Program Leader) provided additional strategic guidance at various stages of the report's preparation. Dina Umali-Deininger (Practice Manager) provided overall oversight for the work. Federica Ricaldi (Economist, GPSJ), Elliot W. Mghenyi (Sr. Agriculture Economist), Shireen Mhadi (Country Economist) Gustavo Abath, Consultant, (GFA07), Isabel Ramos (Consultant, Senior Climate Change Specialist) and Gabriella Morandi (Consultant, Communications Specialist) provided comments and editorial support; and Marina Mwanga (Team Assistant) provided administrative and logistical support; John Barnes, provided editorial support.

The team would like to thank the Ministry of Agriculture and Food Security staff, (MASA); the Ministry of Economy and Finance (MEF), the Ministry of Land, Environment and Rural Development (MITADER), the Ministry of Industry and Trade (MIC); and local governments in country for excellent collaboration, including organization of the various missions and meetings, and provision of the information and inputs requested. Finally, the team would like to thank all the contacts in the various public ministries, departments, agencies, non-governmental agencies, and donor organizations who have contributed to and otherwise supported the development of this review.

Special appreciation is conveyed to the counterpart Technical Team of this study, namely: from MASA, the former director of DPCI, llidio Massinga, for his leadership during the conceptual stage; DPCl's current director, Delfim Vilissa, as well as Acubar Batista (Minister's advisor) and Fatima Bibi. From MITADER, the Director of Rural Development/MITADER Olegário Banze and his team members, and the FNDS Administrator, Júlio Costa and his team, for their useful comments and contributions, and for their support during consultations and completion. Appreciation is extended to Júlio Filimone from MEF, Virgilio António from MOPHRH, Alberto Macia from MITADER, Tomé Sualei from MIC, Fernando Momade and Castilho Bande from MIMAIP and other staff members of the above listed ministries who provided information/inputs for the elaboration of this study.

Appreciation is also expressed to officials from other key stakeholder groups who collaborated in providing useful information, feedback and insights on the results of this study. These stakeholder groups included the other related Government Ministries (especially the Ministry of Land, Environmental, and Rural Development/MITADER; the Ministry of Economy and Finance (MEF); the Ministry of Industry and Trade (MIC); the Ministry the Sea, Interior Water and Fisheries (MMAIP); and the Ministry of Public Works, Housing, and Water Resources); the Authorities and other stakeholders from three Provinces (Gaza, Manica and Nampula) who were consulted; the Technical officers from the development partner agricultural working group (Agriculture and Rural Economic Development AGRED); and representatives from the private sector, civil society, and academia. 
Appreciation is expressed to:

(i) the Department of International Development of the United Kingdom (DFID), for providing funding support and technical advice throughout the study (together with the complementary study, "Strategy for Expanding the Role of the Private Sector in Transforming the Agrarian Sector"), under the leadership of Shahnila Azher (Team Leader) Catriona Cluna, and Sérgio Dista;

(ii) FAO for making available valuable human resources and technical backstopping, in particular Alberta Mascaretti (Chief, Africa Region) and Olman Serrano (Country Representative); and

(iii) AGRA, through it's country representative, Paolo Mole, for its continued collaboration and for providing useful insights. 


\section{Currency Equivalent}

Exchange rate effective as of May 3024, 2019

\begin{tabular}{|l|l|}
\hline Currency unit & (MZM) \\
\hline US\$1.00 & $=$ MTZ62.4 \\
\hline
\end{tabular}




\section{Acronyms and Abbreviations}

\begin{tabular}{|c|c|}
\hline AgGDP & Agricultural Gross Domestic Product \\
\hline AgPER & Agricultural Public Expenditure Review \\
\hline $\mathrm{AU}$ & African Union \\
\hline BdPES & Economic and Social Plan Balance \\
\hline CAADP & Comprehensive Africa Agricultural Development Program \\
\hline CCSA & Agricultural Sector Coordinating Committee \\
\hline CFMP & Medium Term Fiscal Scenario \\
\hline CGE & Mozambique National Account \\
\hline COFOG & Classification of Functions of the Government \\
\hline DFID & United Kingdom Department for International Development \\
\hline DP & Development Partner \\
\hline FAO & Food and Agriculture Organization of the United Nations \\
\hline FTE & Full Time Equivalent \\
\hline GDP & Gross Domestic Product \\
\hline GoM & Government of Mozambique \\
\hline$|A|$ & Integrated Agricultural Survey \\
\hline IIAM & Mozambique Agricultural Research Institute \\
\hline IIP & Mozambique Fisheries National Research Institute \\
\hline INE & Mozambique Statistics National Institute \\
\hline MASA & Ministry of Agriculture and Food Security \\
\hline$M \& E$ & Monitoring and Evaluation \\
\hline MEF & Ministry of Finance and Economy \\
\hline MIC & Ministry of Industry and Trade \\
\hline MIMAIP & Ministry of Sea, Interior Waters and Fisheries \\
\hline MITADER & Ministry of Land, Environment and Rural Development \\
\hline MOPHRH & Ministry of Public Works, Housing and Water Resources \\
\hline MT & Metric ton \\
\hline MTEF & Medium Term Expenditure Framework \\
\hline NAIP & National Agricultural Investment Plan \\
\hline NEPAD & New Partnership for Africa's Development \\
\hline NGO & Non-Governmental Organization \\
\hline O\&M & Operation and Maintenance \\
\hline $\mathrm{OE}$ & Mozambique State Budget \\
\hline PDO & Program Development Objective \\
\hline PEDS & Strategic Plan for Sustainable Development \\
\hline PEDSA & Strategic Plan for Agricultural Development \\
\hline PEFP & Strategic Plan for Public Finance \\
\hline PES & Economic and Social Plan \\
\hline PESOD & District Economic and Social Plan \\
\hline PNISA & National Agricultural Investment Plan \\
\hline PQG & Five-year Government Program \\
\hline PPP & Public Private Partnership \\
\hline RA & Result Area \\
\hline RF & Results Framework \\
\hline SETSAN & Technical Secretariat for Food Security \\
\hline SISTAFE & State Financial Management System \\
\hline SSA & Sub-Saharan Africa \\
\hline ToC & Theory of Change \\
\hline UGB & Beneficiary Management Unity \\
\hline USAID & United States Agency for International Development \\
\hline WDI & World Development Indicator \\
\hline ZRC & Zonal Research Center \\
\hline ZRC & Zonal Research Center \\
\hline
\end{tabular}




\section{Glossary of Key Terms}

\begin{tabular}{|c|c|}
\hline Agrarian Sector & $\begin{array}{l}\text { Refers to major subsectors of crops, livestock, fisheries and other } \\
\text { functions that directly contribute to agricultural production, and } \\
\text { value chain development and directly supporting rural } \\
\text { infrastructure; consistent with the African Union's broader } \\
\text { definition of "agricultural sector" (COFOG "plus") Refers to major } \\
\text { subsectors of crops, livestock, fisheries and other functions that } \\
\text { directly contribute to agricultural production, and value chain } \\
\text { development and directly supporting rural infrastructure; } \\
\text { consistent with the African Union's broader definition of } \\
\text { "agricultural sector" (COFOG "plus") }\end{array}$ \\
\hline $\begin{array}{l}\text { Allocative efficiency of public } \\
\text { expenditures }\end{array}$ & $\begin{array}{l}\text { Analysis that permits an understanding of the priorities and } \\
\text { balance of public expenditures. It consists of the analysis of } \\
\text { economic and functional composition of expenditures. }\end{array}$ \\
\hline Budget estimates & $\begin{array}{l}\text { Budget allocation approved by the Mozambican Parliament at the } \\
\text { beginning of each fiscal year }\end{array}$ \\
\hline Capital expenditures & $\begin{array}{l}\text { Investments where the benefit continues over a long period rather } \\
\text { than being exhausted in a short period. Such expenditure is of a } \\
\text { non-recurring nature and results in acquisition of permanent } \\
\text { assets }\end{array}$ \\
\hline $\begin{array}{l}\text { Economic composition of public } \\
\text { expenditures }\end{array}$ & $\begin{array}{l}\text { Assessment of balance between wages, non-wage recurrent, and } \\
\text { capital expenditures }\end{array}$ \\
\hline $\begin{array}{l}\text { Functional composition of public } \\
\text { expenditures }\end{array}$ & $\begin{array}{l}\text { Assessment of allocation of public expenditure by main functions } \\
\text { and alignment of this composition with policies, strategies, growth } \\
\text { diagnostics, and other priorities }\end{array}$ \\
\hline Non-wage recurrent expenditures & $\begin{array}{l}\text { Recurrent expenditure less expenditure on wages, salaries, and } \\
\text { supplements }\end{array}$ \\
\hline Public goods and Services & $\begin{array}{l}\text { They are characterized as having the properties of non-rival } \\
\text { consumption and non-exclusion, which have the consequence that } \\
\text { the market by itself, will either not produce these goods and } \\
\text { services, or only an insufficient amount. Hence the rational for } \\
\text { provision of public goods and services by the public sector. }\end{array}$ \\
\hline Recurrent expenditures & $\begin{array}{l}\text { Expenditure that does not result in the creation or acquisition of } \\
\text { fixed assets. It consists mainly of expenditure on wages, salaries } \\
\text { and supplements, purchase of goods and services, operations and } \\
\text { maintenance of fixed assets, interest payments, subsidies, and } \\
\text { transfers }\end{array}$ \\
\hline Revised estimates & $\begin{array}{l}\text { Revised budget allocation approved by the Mozambican } \\
\text { Parliament during mid-term review }\end{array}$ \\
\hline Wage expenditures & Recurrent expenditure on wages, salaries, and supplements \\
\hline
\end{tabular}




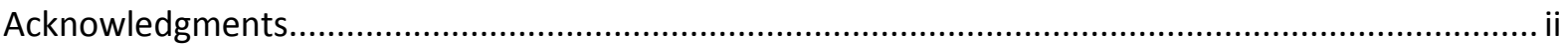

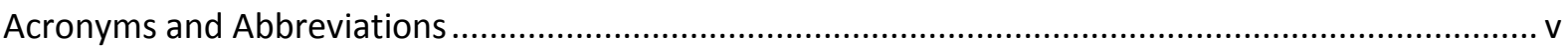

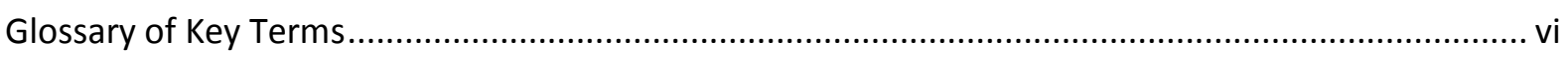

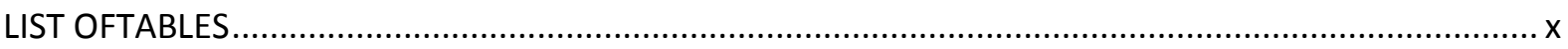

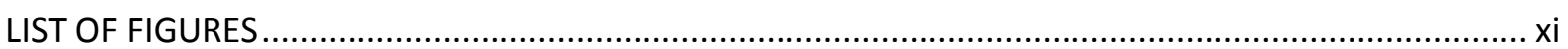

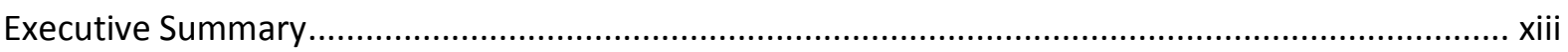

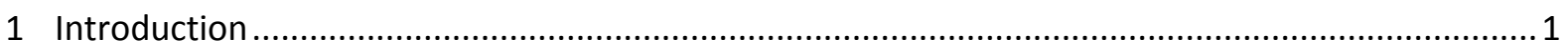

1.1 Macro Context and Implications for the Agricultural Sector............................................. 1

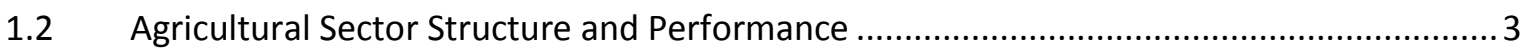

1.3 CAADP Process: Commitment and Compliance ...........................................................

1.4 Synthesis of Challenges, Lessons Learned and Good Practices of Agricultural Public Expenditure Reviews in Sub Saharan Africa ................................................................ 7

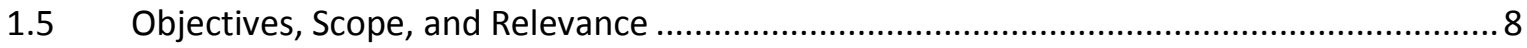

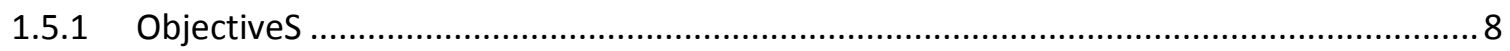

1.5.2 Scope

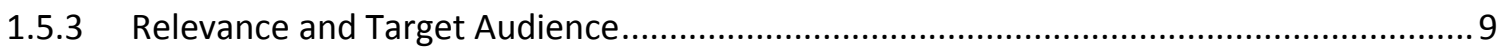

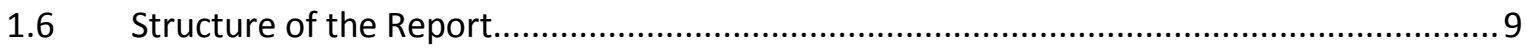

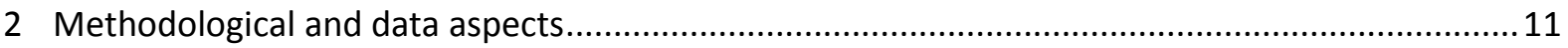

$2.1 \quad$ Definitions of Key Concepts and Tools .......................................................................... 11

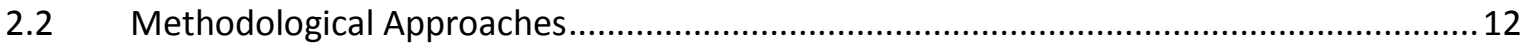

2.2.1 Theory of Change and Results Framework ................................................................ 12

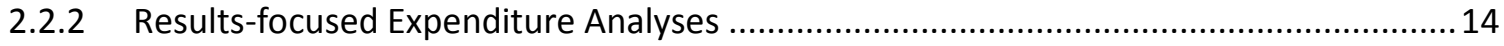

2.3 Criteria for Selection of Key PNISA programs and Provinces ...........................................16

2.4 Data and Information Requirements, Sources and Challenges........................................16

3 BUDGETARY PROCESSES AND INSTITUTIONAL ARRANGEMENTS AND ROLES: CURRENT PRACTICES

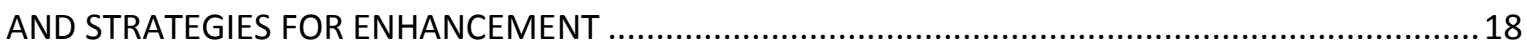

3.1 Overview of Agrarian Sector Budgetary Cycle and Processes: Gap between "Theory

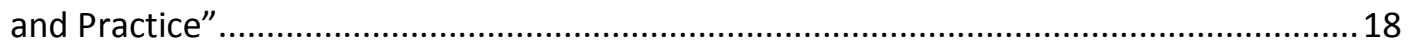

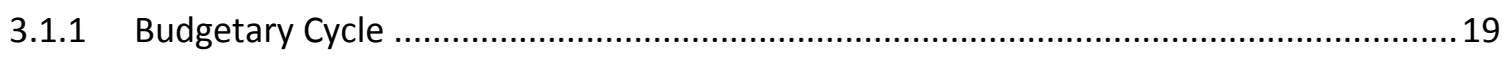

3.1.2 Budgetary Processes at National and Subnational Levels ............................................2 21

3.2 Assessment of Institutional Roles, Arrangements, Capacities and Prioritized

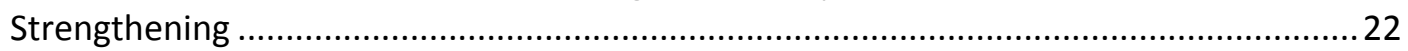

3.3 Summary of Emerging Issues and Priority Recommendations.........................................2 24

4 Trends, composition and performance of agricultural public expenditure ....................................26

4.1 Macro Fiscal Structure of Government Budget Allocations ...............................................2 26 


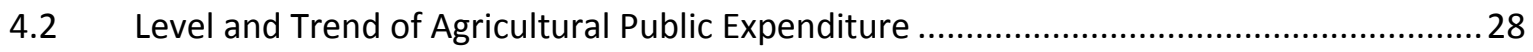

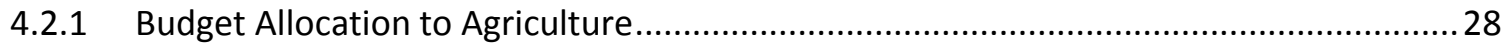

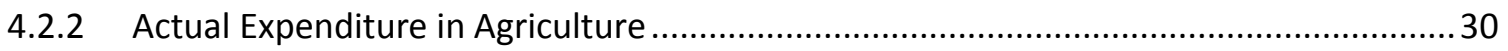

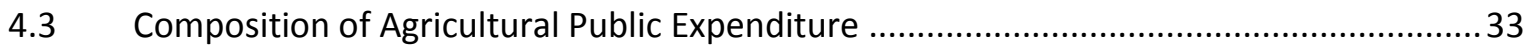

4.3.1 Actual Expenditure in Agriculture by Economic Classification........................................33

4.3.2 Funding Sources of Public Expenditure in Agriculture .................................................. 37

4.3.3 Public Expenditure in Agriculture by Administrative Level............................................... 38

4.3.4 Public Expenditure in Agriculture by PNISA Result Area.................................................. 40

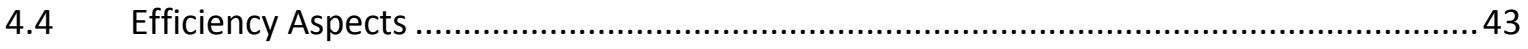

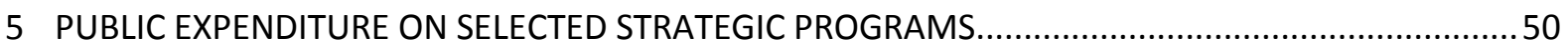

5.1 Overview and Rationale for Selected Strategic Programs ..................................................5 50

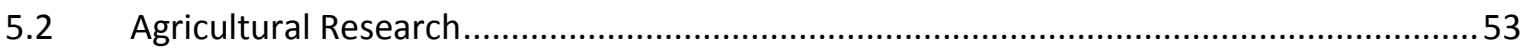

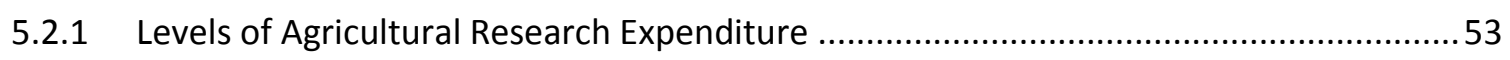

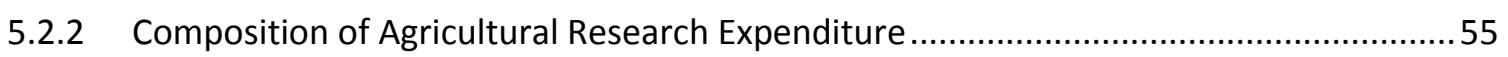

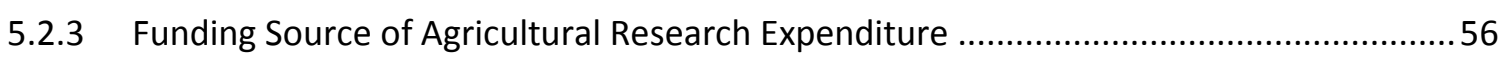

5.2.4 Agricultural Research Public Expenditure by Administrative Level .................................57

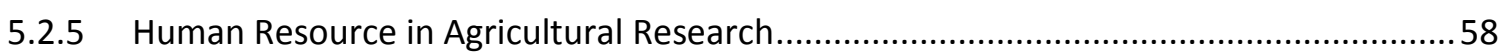

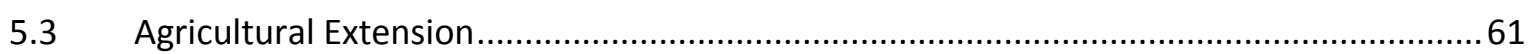

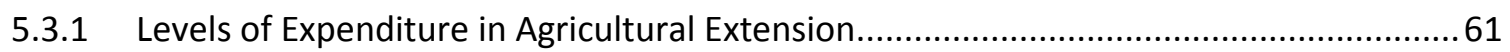

5.3.2 Composition of Expenditure in Agricultural Extension ................................................... 63

5.3.3 Funding Source of Expenditure in Agricultural Extension................................................ 64

5.3.4 Agricultural Extension Public Expenditure by Administrative Level ................................65

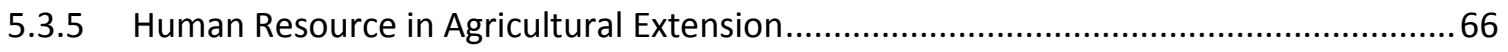

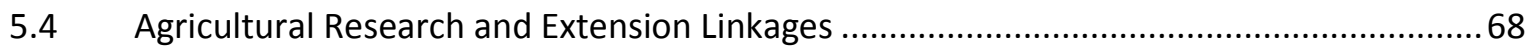

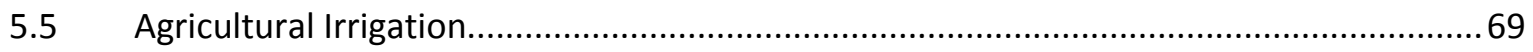

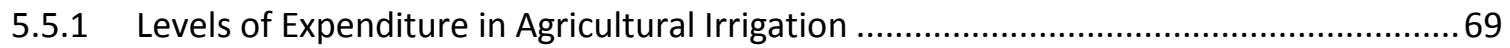

5.5.2 Composition of Expenditure in Agricultural Irrigation ................................................... 71

5.5.3 Funding Source of Expenditure in Agricultural Irrigation ................................................ 72

5.5.4 Agricultural Irrigation Public Expenditure by Administrative Level ................................. 73

5.5.5 Framework of Emerging Benefits from Irrigation Investments ....................................... 74

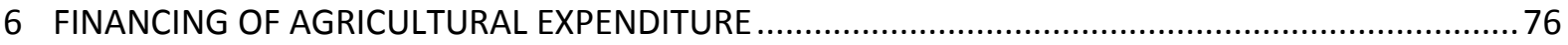

6.1 Overview of Financing Strategy and Main Sources ......................................................... 76

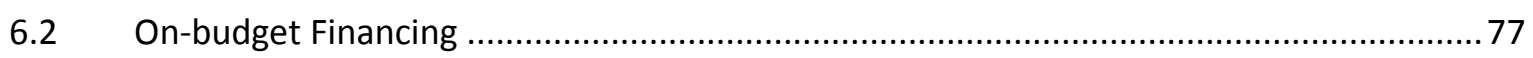

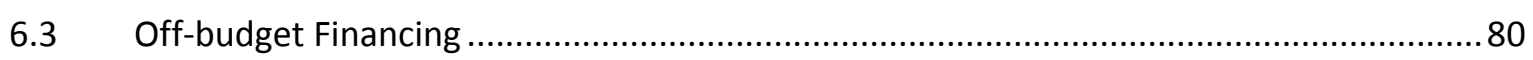

6.4 Private Sector Financing: Levels, Sources, Constraints and Emerging Strategy for Expanded Private Sector Role. 
6.5 Framework for Expanded Role of Private Sector for Promoting Agrarian Sector

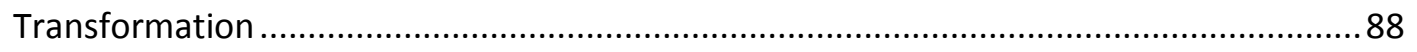

7 ASSESSMENT OF FORWARD AGRICULTURAL EXPENDITURE ALLOCATIONS ..................................90

7.1 Overview of MTEFF/CFMP Processes and Emerging Issues ............................................. 90

7.2 Assessment of MTEFF at the Sector Ministry Level....................................................... 93

7.3 Synthesis of Good Practices and Lessons from Selected African Countries........................99

7.4 Alignment between Priority Targets and Programs and Proposed Forward

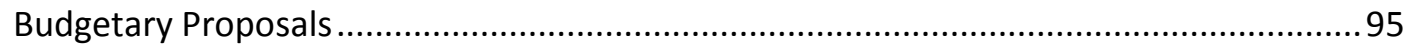

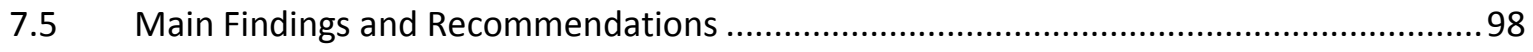

8 ROADMAP: STRATEGIC CONCLUSIONS, PRIORITIZED RECOMMENDATIONS AND WAY FORWARD 100

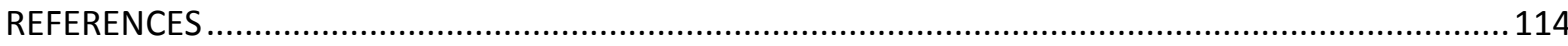

A. Strategic objectives and targets for the agricultural sector: PQG (2015-2019) and PNISA (2013 2017)

B. The AgPERs in Sub Saharan Africa: Synthesis of Relevant Challenges, Lessons and Good Practices

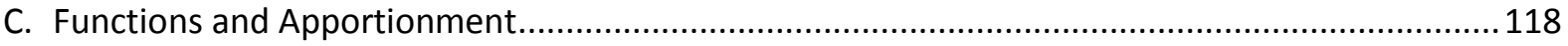

D. Institutional roles and Budgetary Planning documents ...........................................................120

E. Results-Focused Agrarian Sector Public Expenditure Action Plan ("RASPEAP”) .............................122 


\section{LIST OFTABLES}

Table 1.1 Structure of the Economy and Sector Contributions to GDP $(2013-2017)$.......................... 1

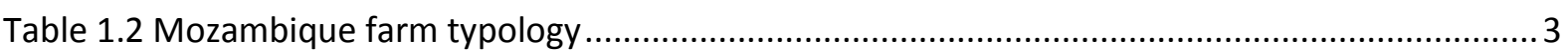

Table 2.1 Summary of the PNISA Structure: Result Areas and Programs............................................ 15

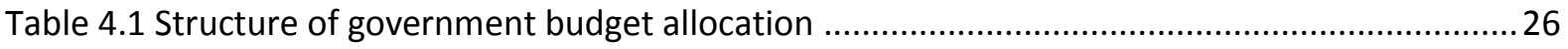

Table 4.2 Government budget allocation to agriculture by ministry (million MZN) ............................22

Table 4.3Actual public expenditure in agriculture by ministry (million MZN) .....................................31

Table 4.4Recurrent and capital expenditure in the agriculture (real million MZN, $2009=100$ ) ..........34

Table 4.5Actual expenditure in agriculture by wage and non-wage expenditure (real million MZN,

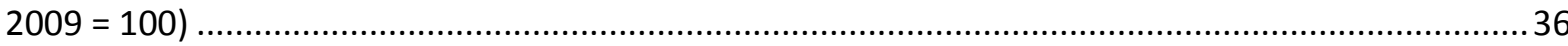

Table 4.6Actual expenditure in agriculture by administrative level (real million MZN, $2009=100$ ) $\ldots 39$

Table 4.7 Actual expenditure in agriculture by PNISA result area (real million MZN, $2009=100$ ) $\ldots . . .42$

Table 4.8 Actual expenditure as share of approved budget by ministry ............................................ 44

Table 4.9 Expenditure in agriculture, GDP, agricultural GDP and rural population by province: 2013-

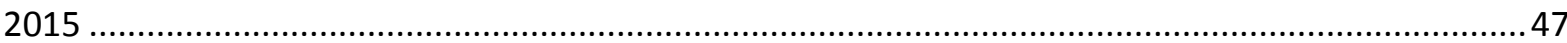

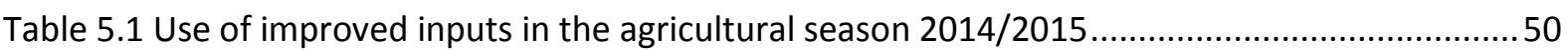

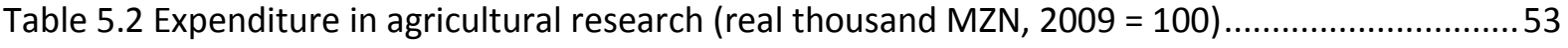

Table 5.3Full-time-equivalent (FTE) agricultural researchers by degree ..............................................59

Table 5.4 Expenditure in agricultural extension (real thousand MZN, $2009=100$ ) ...........................62

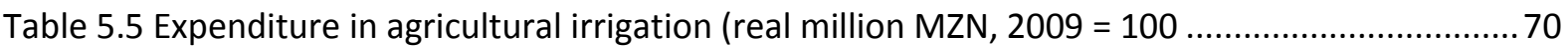

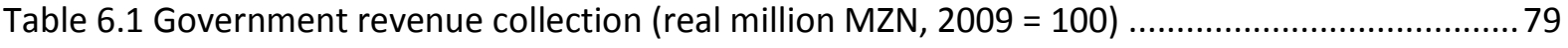

Table 6.2 Off-budget and government expenditure in agriculture (real million MZN, $2009=100$ ).. .82

Table 6.3 Foreign direct investment by sector (real million MZN, $2009=100$ ) ............................... 87

Table 7.1 Forecasted and actual budget (million MZN) .................................................................. 92

Table 7.2 Forecasted total investment by ministry (million MZN) ..................................................... 94

Table 7.3 Share of internal and external predicted investment by ministry (\%) .................................94

Table 7.4 Forecasted investment budget by result area in the agricultural sector $(2019-2021)$...... 96

Table 7.5 Forecasted investment budget by result area $(2019-2021)$............................................... 97

Table C.1 Expenditure apportionment assumptions for Mozambique's agricultural sector .............119 


\section{LIST OF FIGURES}

Figure 2.1 Theory of change and results framework for Mozambique agricultural sector

Figure 2.2 Framework of Flow from Policies to Expenditure to Results............................................ 14

Figure 3.1 Public expenditure decision-making and the factors influencing decisions ....................... 18

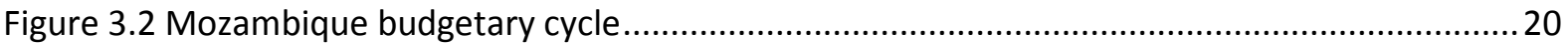

Figure 3.3 The evolving planning and budget processes in Mozambique ..........................................22

Figure 4.1 Central and provincial government shares in total government budget allocation............28

Figure 4.2 Share of total government budget allocated to the agricultural sector..............................30

Figure 4.3Share of total government actual expenditure accounted for by agriculture.......................32

Figure 4.4 Expenditure on agriculture as share of total governement expenditure and of agricultural GDP

Figure 4.5 Recurrent and investment expenditure as share of total expenditure by ministry ............35

Figure 4.6 Agricultural expenditure by subsidy and non-subsidy expenditure ..................................37

Figure 4.7 Investment expenditure in agriculture by source fo funds by ministry...............................38

Figure 4.8 Share of expenditure at central and povincial levels in total expenditure by ministry ....... 40

Figure 4.9 Distribution of PNISA proposed budget over the period 2013 to 2017 ............................ 41

Figure 4.10 Actual expenditure in agriculture as a share of PNISA budget by PNISA result area ........ 43

Figure 4.11 Budget execution rate by administrative level ........................................................... 45

Figure 4.12 Budget execution rate for investment expenditure ....................................................... 46

Figure 4.13 Intensity of expenditure in agriculture by province over the period 2013 to 2015 ..........48

Figure 4.14 Expenditure in agriculture relative to agricultural GDP by province over the period 2013

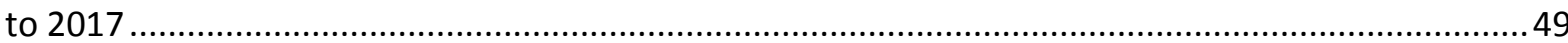

Figure 5.1 Maize yield among adopters and non-adopters of improved inputs ................................52

Figure 5.2 Expenditure on agricultural research as share of PNISA proposed budget for research ....54

Figure 5.3 Public expenditure in agricultural research as a share of agricultural GDP.........................55

Figure 5.4 Public expenditure in agricultural research by cost categoory.........................................56

Figure 5.5 Capital public expenditure in agricultural research by funding source ..............................57

Figure 5.6 Public expenditure in agricultural research by administrative level...................................58

Figure 5.7 FTE agricultural researchers by degree ........................................................................... 59

Figure 5.8 FTE agricultural researcher by zonal research center (ZRC) by degree .............................60

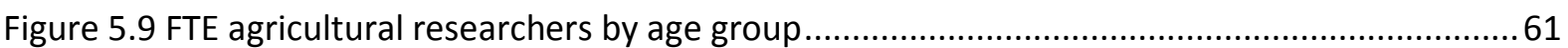

Figure 5.10 Expenditure on agricultural extension as share of PNISA proposed budget for extension 
Figure 5.11 Public expenditure in agricultural extension by cost categoory.

Figure 5.12 Capital public expenditure in agricultural extension by funding source ..........................65

Figure 5.13 Public expenditure in agricultural extension by administrative level...............................66

Figure 5.14 Number of extension officers by service provider.......................................................67

Figure 5.15 Demonstration plots and assisted farmers per extension officer ..................................67

Figure 5.16 Expenditure on agricultural irrigation as share of PNISA proposed budget for irrigation 71

Figure 5.17 Public expenditure in agricultural irrigation by cost categoory...................................... 72

Figure 5.18 Public capital expenditure in agricultural irrigation by funding source ........................... 73

Figure 5.19 Public expenditure in agricultural irrigation by administrative level................................. 74

Figure 6.1 On-budget public expenditure in agriculture by financing source .................................. 78

Figure 6.2 On-budget agricultural public expenditure by source of financing by ministry .................. 79

Figure 6.3 Actual collected revenue as a share of government forescated revenue .......................... 80

Figure 6.4 Agricultural expenditure funded by donors by funding chanel ........................................ 81

Figure 6.5 Breakdown of off-budget expenditure in agriculture during 2013 to 2017 ...................... 83

Figure 6.6 Most problematic factors for doing business in Mozambique: 2013 - 2017 ....................... 84

Figure 6.7 Contribution of selected sectors to total credit among those sectors ............................... 85

Figure 6.8 Agricultural sector credit by agricultural subsector between 2013 and 2017 .................. 86

Figure 6.9 Foreign direct investment in agriculture by country of origin between 2013 and $2017 \ldots . .87$

Figure 7.1 The driving factors and the objectives of CFMP .............................................................. 91

Figure 7.2 The five steps for the improvement of CFMP ............................................................. 92

Figure 7.3 PNISA budget and CFMP budget by PNISA result area ...................................................98

Figure 8.1 Interconnectivity and Synergies of Core Elements of Agricultural Sector Expenditure ....101 


\section{Executive summary}

\section{Background}

Mozambique is still one of the poorest countries in the world - ranking 187 out of 192 countries. With a population of about 27 million people, $46.1 \%$ of the population were poor in 2015. Poverty, including stunting, remains much higher in rural areas (53.1\%) compared to urban areas (40.7\%). The reduction of poverty depends on the good performance of the country's economy. Mozambique's GDP growth rate has been high, 7\% per annum (pa) in the period 2011-15, decreasing to about $3 \%$ pa in recent years, mainly due to the economic crisis and unsustainable debt. The recovery and sustained growth of the country's economy and reduction of pervasive poverty is largely dependent on the performance of the agricultural sector which employs the majority (about 80\%) of the active population. Moreover, empirical studies have shown that agriculture has the largest poverty elasticity $(-2.6 \%)$, more than three times higher than that of other sectors.

However, the contribution of agriculture to the Mozambican economy has been mixed. Although it was the major single sector contributor, with an average contribution of $23 \%$ to GDP during the period 2013 to 2017, the agricultural sector's annual growth rate has been low and erratic in recent years $(1.9 \%-4.3 \% \mathrm{pa})$, and well below the target annual growth rate of $6 \%$ established under CAADP. This is because of low agricultural productivity influenced by: (i) low use of improved inputs; (ii) inadequate agricultural support services, including extension, research and financial services; (iii) high reliance on variable rainfall in predominantly rain-fed agriculture; (iv) unsustainable land use practices, such as widespread slash and burn agriculture, resulting in significant threats to the sustainability of natural resources, particularly soil and water, exacerbating low productivity levels; ( $v$ ) limited accessibility to input and output markets, especially in the northern and central regions; road networks provide access to only about $33 \%$ of the rural population; (vi) lack of formal land property rights; (vii) lack of other key rural infrastructure (particularly storage, water storage and irrigation, with only small area under irrigation (only about $3 \%$ of the cultivated area and potentially irrigable area); and (viii) fragmentation of institutional arrangements and roles, at central and sub-national levels.

\section{Objectives and scope}

These challenges, coupled with limited efficiency and effective use of scarce fiscal resources, pose a major for improving sector performance. This study aims to (a) generate sound, evidenced-based findings and recommendations for enhancing the efficiency, effectiveness and sustainable results of agricultural public expenditure, focusing on PNISA's more "strategic" programs; and (b) provide strategic inputs for the forthcoming formulation of the proposed updated agrarian sector policy, strategy and investment program.

This study covers the period 2013 to 2017 and the forward budget period until 2021. It adopts a "hybrid" approach in terms of period, depth, coverage, frequency, and costs, although there has been effective demand for comprehensive scope. The study includes in-depth analysis of three strategic programs: Research, Extension and Irrigation. They are the engine of Mozambique's agrarian sector transformation. Geographically the study covers the entire country while visiting three "representative" provinces (Gaza, Manica and Nampula) for in-depth analysis of budgetary processes and priorities. This exercise is also consistent with the Comprehensive Africa Agriculture Development Program (CAADP) processes of periodic updating of country's level agrarian sector policy, strategy, and investment program. 


\section{Main results}

\section{Budgetary Cycle and Processes}

The budgetary cycle and processes in Mozambique are, in overall terms, sound, providing the agricultural sector, and its Ministries and Departments at central and provincial levels, with vital tools to ensure sound expenditure allocations. Yet, two cross-cutting issues impede realizing the expected benefits of the management of the budgetary cycle and support processes, managed by MEF, namely (a) capacity constraints, which need to be addressed at various levels; and (b) uncertainty regarding budgetary ceilings, which impact planning and prioritization.

CFMP and PNISA are misaligned in the forward budget: (a) in terms of budget allocation, in result area 1 (agricultural production and productivity), the annual PNISA budget is significantly superior to the forecasted budget for the CFMP (2019-2021). On the other hand, PNISA allocation emphasizes value chain development, while food and nutritional security is getting more attention in terms of forecasted funds under CFMP (even in actual expenditure).

\section{Levels \& Trends of Agricultural Sector Expenditures}

The main findings for levels and trends are as follows: (a) MASA dominates budget allocations, comprising about $48 \%$ of total sectoral allocations, with a similar pattern for expenditure at Provincial level; (b) Agricultural budgetary allocations are erratic and decreasing among all ministries, with the exception of MITADER, especially in 2017, which saw a sharp upward trend in its allocation; (c) The budgetary allocation to the agricultural sector averages $6.4 \%$ of the total budget, well below the $10 \%$ expenditure target under the MAPUTO/MALABO commitment, and misaligned with the relative importance of the sector's share of GDP estimated at 23\% pa); (d) Actual expenditure follows similar patterns to that of budget allocations, but with different magnitudes; (e) There is a clear dominance of central government (in all relevant ministries) as compared to local governments, although a sizable share of central expenditure is for jointly planned activities being implemented at sub-national levels.

With respect to expenditure classification, the main results are as follows: (a) Recurrent and investment expenditure allocations vary significantly across ministries. However agricultural performance does not match the investment levels; (b) Expenditure is often misclassified; and (c) The appropriate balance between recurrent/investment, wage/non-wage, and internal/external expenditure have to be determined by each ministry and specific functions, based on efficiency-based benchmarks.

For the PNISA Result Areas (RAs), the main results show that: (a) although RA1 is a driver to achieve key PNISA targets, which PNISA recognized (78\% of PNISA total budget), it is significantly underfunded in all of its 8 programs; (b) The food and Nutrition Security RA revealed a significant increase in expenditure allocations; and (c) There is overfunding of the Institutional Reform/Strengthening RA, with lack of tangible evidence of sustainable results, while recognizing the importance of enhanced capacities to better manage the sector.

Regarding the efficiency of agricultural expenditure, the results show that: (a) There are overall high budget execution rates $(80 \%)$ in the agricultural sector, and for internal vs. external funds. The timing of disbursement is crucial with higher execution rates being "forced" to meet end-of-year expenditure targets; (b) This pattern may suggest misalignment between donor and government procurement procedures, and higher budget unpredictability for external funds; (c) Provinces that contribute a 
higher share to GDP are receiving relatively lower public expenditure in the sector and (d) This misalignment suggests the need for MEF (at central and provincial levels) to ensure appropriate criteria for the allocation of expenditure consistent with the relative importance of the sector in the respective province.

\section{Expenditure on Selected Strategic Programs}

Three programs, namely agricultural research, extension and irrigation were analyzed in detail as they comprise the engine for the transformation of the agrarian sector. With respect to the Agricultural Research Program, results reveal : (a) the dominance of MASA in public expenditure for agricultural research (about $70 \%$ of total); (b) significant underfunding of agricultural research, about $0.43 \%$ of the agricultural GDP and well below the KHARTOUM target of 1\%; (c) a need to explore appropriate publicprivate partnerships for expanded agricultural research, especially involving high value-chains; (d) a low and shrinking capital investment share in agricultural research public expenditure, coupled with limited operating funds, are constraining the potential and tangible benefits of highly specialized agricultural researchers; (e) a low share of researches with a doctorate. (6\%); (f) A dominance of researchers with a Ph.D. aged 50 or older, coupled with limited knowledge-sharing mechanisms, results in limited pathways for enabling younger researchers to assume expanded agricultural research responsibilities and roles, in order to deliver on the country's future research agenda.

Regarding the Agricultural Extension Program, the results indicate the following: (a) Although operating funds are significant, it is not clear that this is being translated into improved and effective extension services, contributing to expected outputs and outcomes (e.g. adoption rates; crop yields; \$/adopter), per PNISA assessment (2017); (b) There is a need, as in the case of research, to explore appropriate public-private partnerships for expanded extension services, especially involving high value commodities/value-chains; and (c) There is a large dependence on external funding sources (about $70 \%$ ), raising questions about scalability and sustainability in providing improved extension services, and securing sustained increases in agricultural productivity.

The results for the irrigation program show : (a) that there has, and continues to be, significant underfunding of irrigation, ranging from 2.5 to $25 \%$ of the original PNISA budget (with a $25 \%$ share in 2017); (b) significant underfunding of agricultural irrigation, except in 2017, primarily from external funds; and (c) a need to explore appropriate cost-recovery levels and public-private partnerships for expanded agricultural irrigation infrastructure, especially involving high value crop production and value chains.

\section{Financing of Agricultural Expenditures}

The main sources of financing for the sector are the government, development partners and the private sector. Regarding the government budget, financing is mainly on-budget including for funds from other sources such as development partners. The results reveal that for On-Budget Financing, there is (a) erratic financing levels and sources: Government (52-72\% of total financing); External Loans (7-32\%); and External Grants (8-20\%); (b) a dominance of government revenues (about 70\%) and increasing external borrowing; and (c) internal funding sources are linked to improved revenue collection and are more predictable than external funds. For agricultural expenditure funded by donors, on-budget sources vary from $58-68 \%$ and off-budget sources vary from $32-42 \%$. The private sector share of agricultural finance is very small (varying between $5.5-7.5 \%$ of total private sector financing). Although the agriculture sector has the largest impact on poverty reduction, and makes a sizable contribution to GDP, the sector receives a small share of the total private sector finance/credit. Various constraints impede access to credit for agricultural development (land security; collateral; 
high interest rates). The agriculture sector ranks $4^{\text {th }}$ in terms of Foreign Direct Investment (FDI), despites its higher importance; a considerable share of FDI for industry is agro-based.

\section{Assessment of Forward Agricultural Expenditure Allocations}

The Cenário Fiscal do Médio Prazo (CFMP) provides a good basis for budgetary planning and is used to define the annual PES targets and provides an instrument to mobilize donor funding. The main challenges include: (a) changing and uncertain ceilings require several iterations in the preparation of medium and annual budgets by national and sub-national governments; (b) indicative ceilings established by MEF based on the CFMP are well above the actual budgets; (c) the absence of clear prioritizing criteria, and the actual allocations, do not reflect sound expenditure priorities; and (d) the CFMP is ambitious as it aims to be both a fiscal and a budgetary framework - there is need to reconcile/harmonize their objectives.

\section{Strategic conclusions and priority recommendations}

The Government has sound medium-term and annual expenditure frameworks and processes. However, agricultural sector ministries and provincial institutions need to enhance their effective application and utilization of funds with a focus on sharper management, especially with respect to prioritization and accountability, to help ensure better strategic results.

Chapter 8 provides a roadmap for the way forward. Annex E outlines a proposed prioritized action plan. Below is a summary of the 8 emerging strategic outcomes, supported by recommended priority core and secondary actions. These outcomes are inter-connected, and therefore there are some priority actions which are needed in more than one strategic outcome.

Strategic Outcome \#1: Macro-Sectoral "Enablers" Strengthened. Sound policy framework at both macro and sectoral levels and clear and effective institutional roles will determine the scope and pace of agrarian sector transformation.

\section{Core recommendations:}

a) Ensure updated and effective implementation of the PQG \& MTEF as guiding planning and expenditure tools for each sectoral ministry, also reflecting high priority for agrarian sector;

b) Ensure formulation, approval and implementation of updated agrarian sector policy, strategy and investment program.

\section{Secondary recommendations:}

- Improve agrarian sector performance to be more consistent and to achieve realistic targets, while addressing the relevant constraints;

- Revitalize the role of the agrarian sector to contribute to core objectives of the Government's PQG and targets;

- Tap underutilized potential for intensifying and diversifying Mozambique's sources of growth;

- Promote stronger institutional coherence fragmentation in the agrarian sector;

- Expand role of an inclusive private sector to accelerate agrarian sector transformation;

- Update and track appropriate and prioritized investments by both public and private sectors to help realize strategic sector targets; and 
- Tap the large poverty elasticity of the agrarian sector.

Strategic Outcome \#2: Results Framework (RF) and Theory of Change (ToC) utilized effectively for assessing and prioritizing the efficiency and effectiveness of sectoral public expenditure.

A sound results framework, underpinned by a solid theory of change, provides a useful TOOL for assessing the efficiency and effectiveness of sectoral public expenditure, for both backward and forward-looking assessments. While this tool has been absent, the sharpening and operationalization of a RF provides planners, decision-makers and implementors with a tool and roadmap for agrarian transformation.

\section{Core recommendation:}

Ensure effective use of sound RF and other relevant tools to:

- formulate updated agrarian policy, strategy and investment program

- support mid-term reviews of on-going and design of proposed projects

\section{Secondary recommendations:}

MASA, and other sectoral ministries, take a proactive role to: (a) Engage with MEF; (b) Work together;

\section{Strategic Outcome \#3: Budget Management Cycle Fortified: Sound Processes and Prioritization Criteria Applied and Effective Sectoral Coordination to Ensure Strategic Results.}

There is a gap between the theory and practice of the agricultural budgetary cycle and supporting processes. The budgetary process and institutional roles at national and sub-national levels are elaborate and similar; there are greater capacity constraints at sub-national levels; and there is a comprehensive budgetary cycle process, which exhibits uncertain and changing budgetary ceilings.

\section{Core recommendations:}

(a) Apply enhanced prioritization criteria, at each stage of the budgetary cycle for the agrarian sector, namely (i) Strength of alignment with relevant PQG and sector objectives and targets; (ii) Contribution to inclusive sources of agricultural growth and poverty reduction, especially with respect to increased crop yields and value-chain development, increased climate change resilience, and consistent with "public" goods and services, to ensure appropriate roles); (iii) Contribution to "catalyzing" expanded and inclusive private sector investment; and (iv) Demonstrated evidence of good institutional performance and governance (including functional M\&E systems)

(b) Ensure effective functioning of a strengthened CCSA

\section{Secondary recommendations:}

Strengthen the effectiveness of the sectoral budgetary cycle in the three major phases of Planning, Implementation and M\&E, as follows:

Planning Phase:

- Allow adequate time and scenarios;

- Strengthen capacities and the use of relevant tools;

- Sound prioritization with final ceilings; and 
- Expand Private Sector Role.

Implementation Phase: (i) Streamline procurement and financial management (FM); (ii) Ensure Development Partners (DPs) alignment and harmonization; and (iii) Provide interim technical support.

M\&E Phase: (i) Enhance sectoral M\&E systems (and not just for each Ministry); (ii) Operationalize performance indicators; (iii) Strengthen expenditure data/e-SISTAFE systems; (iv) Ensure Effective use of M\&E results; and ( $v$ ) Conduct strategic studies and implement relevant findings/recommendations.

\section{Strategic Outcome \#4: Expenditure technical efficiencies and levels of public expenditure in the agrarian sector progressively increased.}

The agricultural sector accounts for approximately $23 \%$ of GDP and has the highest poverty elasticity $(-2.6 \%)$, more than three times higher than other sectors. However, the sector was substantially underfunded in the period 2013-2017 (averaging only 6.5\% of the total government budget allocation, and $5^{\text {th }}$ in allocations relative to other government functions/sectors).

\section{Core recommendations:}

Improve the execution rates and especially prioritization in order to ensure better quality of expenditure allocations in agrarian sector, as pre-condition to increase expenditure levels in the agrarian sector (towards the Maputo Declaration expenditure target of 10\%);

\section{Secondary recommendation:}

Develop and use efficiency-based unit costs/benchmarks.

\section{Strategic Outcome \#5: Composition/Quality and Allocative Efficiencies of Agrarian Sector Expenditures Significantly Enhanced.}

The study found that there was a substantial difference between wages and non-wage expenditures, with wage expenditure dominating agricultural public expenditure. There is also substantial underfunding of the 3 strategic programs - agricultural research, extension and irrigation infrastructure -- well below PNISA targets and established international standards/targets (e.g., agricultural research expenditure intensity of $0.43 \%$ of AgGDP, vs. the AU target of $1 \%$ of Ag. GDP); an imbalance in allocations for recurrent and capital expenditure (especially to ensure that agricultural researchers and extension workers, and irrigation schemes, have adequate operational funds and capital "assets" to perform productively and to generate the expected results).

\section{Core recommendations:}

a) Apply the agreed enhanced four (4) prioritization criteria:

- Strength of alignment with relevant PQG and agrarian sector objectives and targets;

- Contribution to inclusive sources of agricultural growth and poverty reduction;

- Contribution to "catalyzing" expanded inclusive private agrarian sector investments; and

- Demonstrated evidence of good institutional performance and governance 
b) Strengthen and effectively use Agrarian Sector M\&E system (ministry, provincial and sectoral levels)

\section{Secondary recommendations:}

- Develop/use efficiency-based expenditure for achieving sound "balance" and unit costs;

- Increase funding for 3 strategic programs (agricultural research, agricultural extension and irrigation); and

- Enhance quality and results of 3 strategic programs.

\section{Strategic Outcome \#6: Level and Quality of Decentralized Agricultural Expenditure Significantly Strengthened.}

Decentralization policies and expenditure are in the early stages of implementation, and there is significant scope for proactively strengthening the quality and effectiveness of decentralized programs and their expenditure, especially for strategic programs. The results show that the larger share of agricultural expenditure is managed at central level, although it is being also used to purchase goods and services to be used at provincial level, and there is a misalignment between expenditure allocations and agricultural potential.

\section{Core Recommendation:}

Align annual and medium term strategic agrarian sector provincial expenditure plans in line with enhanced prioritization criteria and timeline

\section{Secondary Recommendations:}

During the budgetary planning phase and cycle, MEF and sectoral ministry budgetary officers need to give increased attention to ensuring:

(a) Improved stability in funding levels and shares;

(b) Improved alignment between sectoral allocations and importance/potential; and

(c) Strengthened technical capacities including:

- planning officers in the use of enhanced and relevant planning and implementation tools and application of prioritization criteria (to be consistent with national entities): and

- M\&E officers in the design and implementation of M\&E systems at various levels, and relevant performance indicators (consistent with the sectoral results framework).

\section{Strategic Outcome \#7: Role and Strategy of the Private Sector Expanded for Accelerating Agrarian Sector Transformation}

There is a VITAL need to improve financing strategies and to diversify/increase financing sources for the agricultural sector, especially to better align off-budget funding and to expand the role of an inclusive private sector in the transformation of the sector. The results show that: (i) There are risks of relying excessively on external funding vs. adequate and stable internal funding; (ii) There is misalignment of off-budget funding with key Government priorities; (iii) There are constraints to, and limited funding for, and from, the Private Sector; and an expanded role for of the private sector and investment is a "game changer" for agricultural transformation, but is at an infant stage.

\section{Core Recommendation:}


Approve, Adopt and Implement Proposed Private Sector Strategy for the Agrarian Sector. MASA, MIMAIP, MITADER, MIC, and MOPHRH together with other stakeholders, to review, validate/update, adopt and implement the emerging recommendations of the parallel private sector strategy for agrarian sector transformation. This emerging strategy complements the Ag. PER, is comprised of seven inter-linked strategic objectives/outcomes, and is to be operationalized through prioritized supporting strategic actions, with a strong results-orientation:

1. Improved Policy/Regulatory Environment;

2. Increased Smallholder Intensification/Performance;

3. Strengthened Value Chain Competitiveness;

4. Expanded Land Access/Security;

5. Expanded Access to Finance;

6. Strengthened private-public partnerships (PPPs); and

7. Effective Institutional Arrangements/Mechanisms.

\section{Secondary Recommendation:}

Strengthen expenditure alignment during the budgetary cycle, to catalyze expanded private sector investment;

Strategic Outcome \#8: MTEF as an Instrument and Process for Expenditure Alignment Enhanced.

The Medium-Term Expenditure Fiscal Framework (MTEF) is a powerful but underutilized tool for the planning and budgetary cycle and for promoting enhanced levels and composition of expenditure. There is scope for substantial improvement in the effective application and use of the CFMP, at national and sub-national levels, to help ensure better alignment of expenditure and strategic results. The results show that there is a misalignment between the CFMP and PNISA.

\section{Core Recommendation:}

Ensure each sectoral ministry strengthens the quality and effective use of its MTEF, including application of enhanced prioritization criteria and of expenditure scenarios (High, Medium, and Low)

\section{Secondary Recommendations:}

Improve the MTEF/CFMP processes (by MEF and sectoral ministries), including:

- $\quad$ separate fiscal \& budgetary frameworks, while ensuring complementarity;

- improve revenue forecasting \& use expenditure scenarios (High, Medium, Low);

- strengthen institutional coordination/reactivate an effective CCSA;

- use sector program working groups, as part of CCSA system.

Finally, to ensure that tangible benefits arise from this expenditure review, it is vital that MASA together with other sectoral Ministries and stakeholders, review, adopt and coordinate the implementation of the agreed priority actions. This should ensure effective prioritization and implementation of agrarian sector public expenditures during the expenditure cycle, with a strong results-orientation. 


\section{Introduction}

\subsection{Macro Context and Implications for the Agricultural Sector}

During the period 2011 - 2015, Mozambique's growth in gross domestic product (GDP) was amongst the highest in Sub-Saharan Africa (SSA), averaging 7\% per year. In subsequent years, the scenario changed to a downward trend, mainly due to an economic crisis provoked by unsustainable debt. Consequently, GDP growth decelerated to $3.8 \%$ in 2016 and 3.7\% in 2017. Additionally, annual average inflation increased from $3.6 \%$ in 2015 to $18.0 \%$ in 2016, decreasing slightly to $15.5 \%$ in 2017. Moreover, small and medium-size enterprise profitability levels, and capacity to generate employment, have also decreased. The balance of payments for the current account fluctuated from a negative 2.2 billion USD in 2011, to a negative 498 million USD in 2017. This change was mainly due to a decrease in imports, influenced by limited availability of funds for purchasing foreign products and services. Also, limited funds were in part due to the withdrawal of development partners from the funding government activities, and to invest in Mozambique, resulting in a decrease in foreign direct investment (FDI) levels from an average of 4.8 billion USD per year during the period from 2011 to 2015, to 3.1 billion USD in 2016, and 2.3 billion USD in 2017. This slowing and erratic macroeconomic performance has adversely affected Government revenues and a fiscal imbalance, and a decrease in external assistance and public expenditure for all sectors and functions of Government.

However, the contribution of agriculture to the economy did not change significantly and its contribution to GDP remained stable at about 23\% during the period 2013 - 2017 (Error! Reference source not found.). Apart from service sector, which is composed of several economic activities/subsectors, agriculture is the main contributor to the GDP. The relative importance of the agricultural sector is even greater when other related sectors (industry, manufacturing and services) are taken into consideration, and which are directly driven by the agricultural sector, as well as by the fact that approximately $80 \%$ of the total labor force in the country is employed in agricultural or related activities.

Table 1.1 Structure of the Economy and Sector Contributions to GDP (2013 - 2017)

\begin{tabular}{lccccc}
\hline Sector & 2013 & 2014 & 2015 & 2016 & 2017 \\
\hline Agriculture & 24 & 23 & 23 & 23 & 21 \\
Manufacturing & 9 & 9 & 9 & 9 & 9 \\
Industry. & 8 & 10 & 11 & 11 & 16 \\
Services & 59 & 58 & 57 & 57 & 54 \\
\hline
\end{tabular}

Source: INE (2019)

Pervasive and Structural Poverty. ${ }^{1}$ The macro-economic pressures/shocks described above are exacerbated by continued pervasive poverty. According to the International Monetary Fund (IMF), World Economic Outlook (October 2018), Mozambique is still one of the poorest countries in the world, ranking 187 out of 192 countries. With a population of c. 27 million, $46.1 \%$ of the population were poor in 2015. However, poverty levels have fallen from $70 \%$ in 1996 to $46 \%$ in 2015 . In 2014,

\footnotetext{
${ }^{1}$ Various excerpts were taken from the World Bank report, "Mozambique Rural Income Diagnostic (RID) Study: Constraints and Opportunities for Faster Rural Poverty Reduction" (slides, February, 2019). The overarching question guiding this report is: "What are the income pathways which offer a sustainable path out of rural poverty"?
} 
about $63 \%$ of the population lived on less than US\$ 1.90 per day, and large proportions of the population suffered from stunting and wasting (44\% for under-fives in 2015). About 8 out of 10 residents in rural areas are poor. Poverty, including stunting, remains much higher in rural areas (53.1\%) compared to urban areas (40.7\%), and poverty is becoming geographically concentrated in some provinces. In the provinces of Niassa, Nampula, Zambezia and Gaza over $50 \%$ of the population is classified as "poor", with poverty incidence at $60.6 \%, 57.1 \%, 56.5 \%$ and $51.2 \%$, respectively. In the light of these poverty levels, the Government of Mozambique, with significant financial and technical support from development partners, has implemented significant poverty reduction efforts. While there is positive progress in reducing the scope and extent of poverty, the underlying structural causes still pose significant challenges requiring more intense and coordinated efforts, increased and prioritized public expenditure, and an expanded role for an inclusive private sector. It is significant that the Rural Income Diagnostics (RID) Study has highlighted that the growth elasticity of poverty in agriculture is the highest of any sector in the economy and other poverty-reducing sources of growth. It is therefore very relevant to assess the efficiency and effectiveness of public expenditure allocations in the agriculture sector.

The main guiding policies and strategies pursued by the Government to ensure accelerated, stable and inclusive macro-economic growth, for poverty reduction, are:

- The National 5 Year Development Plan (Plano Quinquenal de Governo, PQG, 2015 2019);

- Decentralization policy overseen by the State Financial Management System (SISTAFE). The SISTAFE applies to all government entities and establishes and harmonizes rules and procedures for the programming, management, execution and control of public expenditure and producing data and information in an integrated and timely manner, concerning the administration of financial resources by public institutions. The Government is progressively increasing the level and scope of political and financial decentralization, with varying levels of efficiency and effectiveness, given institutional and funding weaknesses at provincial and district levels;

- The Strategic Plan for Public Finance (2016 - 2019)2, which aims to ensure the mobilization, control allocation and the judicious, transparent, efficient and prudent application of public funds in the public interest and to promote inclusive economic growth and harmonious and sustainable development. One of the plan's six strategic objectives seeks to increase internal revenue and savings, with a target of increasing internal revenues up to be $32.5 \%$ of GDP by 2019 , to improve the adequacy of expenditure standards, and improved judicious channeling and application of all internal and external resources through the state budget and treasury account.

In summary, a macro-economic assessment shows progress in, and the challenges of, meeting key macro-economic objectives of inclusive growth, reduced poverty, stable inflation, and effective management of increased fiscal resources and associated expenditure levels. These macro-economic structural factors and trends pose significant challenges to achieving accelerated and inclusive growth in the agrarian sector. The Government generally has sound framework documents to guide these processes. The challenge is to translate them into sound operational and results-focused actions.

\footnotetext{
2 Plano Estratégico das Finanças Públicas: 2016 - 2019, Ministério da Economia e Finanças, Agosto, 2017.
} 


\subsection{Agricultural Sector Structure and Performance}

Structure/Role of the Sector. Agriculture is the largest economic sector in Mozambique (see Table 1.1), and more so, when considering direct and indirect linkages with other key sectors/activities. On average, the agriculture sector has accounted for $23 \%$ of direct GDP in the last five years and employs about $80 \%$ of the labor force. However, the majority of the population is engaged in smallholder, rainfed, subsistence agriculture which frequently suffers from climate-induced shocks, with significant negative impacts on overall economic growth and poverty reduction. Only $15 \%$ of a total of 36 million hectares of arable land is currently under cultivation. In the 2013/2014 agricultural season, there were about 4 million farmers in Mozambique, of which $99 \%$ were smallholders (with average farm size of 1.3 ha.), with only $1 \%$ medium- and large-scale commercially oriented farmers involved in competitive value chains, primarily for cash crops (see Table 1.2). These features reveal important implications for the roles of the public and private sectors working together to further develop the sector, and especially in the management of the state agricultural budget. As the agricultural sector is dominated by smallholders, it is important to direct the majority of the agricultural budget to boosting their production and productivity through promoting their transformation into market-oriented farmers. Therefore, the state agricultural budget should give priority to the intensification of production and the development of competitive value chains, with an active role for smallholder producers and traders, linked by competitive value chains.

Table 1.2 Mozambique farm typology

\begin{tabular}{lll}
\hline Farmer category & Number & $\%$ \\
\hline & \multicolumn{1}{l}{ Number of farmers } \\
Small farmers (thousand) & 3,999 & $98.91 \%$ \\
Medium farmers (thousand) & 44 & $1.08 \%$ \\
Large farmers & 436 & $0.01 \%$ \\
Total (thousand) & 4,043 & $100.00 \%$ \\
\hline & Cultivated area (ha) \\
Small farmers (thousand) & 5,207 & $96.69 \%$ \\
Medium farmers (thousand) & 117 & $2.17 \%$ \\
Large farmers (thousand) & 61 & $1.14 \%$ \\
Total (thousand) & 5,386 & $100.00 \%$ \\
\hline Source: & \multicolumn{2}{c}{}
\end{tabular}

Source: IAI 2014

The predominance of smallholder farmers relying mainly on rain-fed agriculture, using traditional, low productivity agricultural technologies, has significantly limited the performance of the agriculture sector. The annual growth rate of the sector has been erratic and significantly lower than the established Malabo growth target (6\% per year) and PNISA target (7\% per year) fluctuating from $1.9 \%$ in 2013 to $4.3 \%$ in 2017. This fluctuation reflects the climate and precipitation dependency of the agricultural sector, which implies the need for the expansion of climate resilient agricultural technologies and low-cost irrigation infra-structure/schemes.

Potential and Sources for Expanded and Diversified Growth. Mozambique has favorable natural conditions for intensifying and diversifying its agricultural production and value-chain development in the majority of the country through increased productivity and agribusiness-driven investment. Based 
on the recent World Bank (WB) study, the main sources of agricultural growth include: ${ }^{3}$ productivity growth in existing food and cash crops; expanded commercialization levels, enabled by increased market integration; a shift toward high value crops (especially cotton, sesame, tobacco and sugar cane) and animal products (e.g., poultry); and expanded rural infrastructure (especially irrigation and rural/feeder roads). Irrigation has the potential to significantly enhance smallholder agricultural productivity. Mozambique has a potential to irrigate 3 million hectares enabling increased productivity and diversification. However, only about 180,000 hectares $(6 \%)$ are equipped with irrigation infrastructure, and only about $50 \%$ of this infrastructure is currently fully operational. Thus, only about $3 \%$ of the country's irrigation potential is currently being used.

The recent growth in commercial agriculture and out-grower schemes, from a low base, points to the country's untapped agribusiness investment potential. Emerging value chains include poultry, soy, sesame and cashew, and there is significant scope to intensify and expand sustainable cultivation of agricultural land and domestic food processing. Thriving value chains in agriculture and forestry could form the backbone of the rural economy by creating jobs, increasing rural incomes, strengthening food security, and facilitating better nutrition. ${ }^{4}$ The realization of this agricultural and value-added potential will require an expanded role of an inclusive private sector, catalyzed by enhanced and appropriate agricultural policies/regulations, institutional reforms and prioritized public investment. ${ }^{5}$

\section{Pervasive and Structural Constraints.}

Low agricultural productivity is a binding and dominant constraint to Mozambique's economic growth and poverty reduction. The country's agriculture productivity levels are lower than the average for low- income countries in Southern Africa, particularly for maize and rice, key food crops. Key constraints to realizing Mozambique's significant agricultural sector and income growth potential (in production and value-chain development) include: ${ }^{6}$

- low levels of crop productivity, for both food and cash crops;

- crop production patterns characterized by low input usage/intensity (of improved seeds, chemical fertilizers): less than $3 \%$ of farmers use improved crop varieties; less than $5 \%$ of farmers use fertilizers; less than 9.5\% of farmers used animal traction in 2014;

- inadequate agricultural support services, including extension services; there are only 1,200 agricultural extension officers employed by the public sector, resulting in a high farmer to extension officer ratio; this is exacerbated by low technology adoption rates by most farmers;

- high reliance on variable rainfall in predominantly rain-fed agriculture, with increasing climate change threats; Mozambique is ranked the third most vulnerable country to climate change in Africa;

\footnotetext{
${ }^{3}$ Refer to the WB report, "Mozambique Rural Income Diagnostic" study (2019).

${ }^{4}$ There are a series of value chain studies being carried out by the WB-supported Let's Work Program, including: Cashew Value Chain Development Strategy; Cassava Value Chain Strategy; and Plantation Forestry Value Chain Strategy. The findings of these studies illustrate the potential for expanded agricultural growth, and the main types of constraints to be addressed.

${ }^{5}$ There is an on-going parallel study on: Private Sector Strategy for the Agricultural Sector (draft report, March, 2019). This report integrates relevant emerging findings and recommendations from this parallel study.
}

${ }^{6}$ Many of these constraints are identified in the recent Rural Income Diagnostic Study (WB, draft 2019). 
- unsustainable land use practices, such as widespread slash and burn agriculture, resulting in significant threats to the sustainability of natural resources, particularly soil and water, exacerbating low productivity levels;

- limited accessibility to input and output markets, especially in the northern and central regions; road networks provide access to only about $33 \%$ of the rural population;

- lack of formal land property rights, limited access to finance (less than $5 \%$ of smallholders), and low levels and rates of agricultural investments and economic diversification;

- lack of other key rural infrastructure (particularly storage, water storage and irrigation, with only small area under irrigation, with only about $3 \%$ of the cultivated area and potentially irrigable area;

- smallholder farmers' integration in value chains is modest, reflecting the cumulative effects of the above constraints; and

- fragmentation of institutional arrangements and roles, at central and sub-national levels (further detailed below).

Fragmentation of Institutional Arrangements/Roles. The institutional arrangements and roles in the "agricultural sector" (see below for broader definition, equivalent to the "agrarian sector") for promoting accelerated and inclusive agricultural development in Mozambique are fragmented, involving five ministries ${ }^{7}$ at central government level, coupled with Provincial (11) and District (about 150 ) institutions, involved in the Government's on-going decentralization policies and services. The complex interplay between central and sub-national governments is especially important for the agricultural sector in terms of their roles in policy formulation and implementation, institutional reforms, and the formulation, implementation and tracking of agricultural sector public expenditure, including the effective provision of key services to rural households. The fragmented institutional arrangements have major implications for ensuring coherent and coordinated policies and programs, including the public expenditure management cycle (planning/allocations, execution and accountability mechanisms). ${ }^{8}$

The Ministry of Agriculture and Food Security (MASA) is the lead institution for agriculture development, although there are important functions and investments assumed by the Ministry for Land, the Environment and Rural Development (MITADER, established in 2016). MASA is responsible for formulating and implementing agricultural policy at national level, including agricultural services, crop development, livestock, irrigation, forestry, and food security. MASA has outlined its strategy and investment priorities, geared towards raising rural incomes and improving food security, in the Strategic Plan for Agricultural Development (PEDSA 2011-20), the National Agriculture Investment Plan (PNISA 2013-2017, now extended to end of 2019); and the PES, the annual plan to implement the PQG 2015-2019.

7

These five central government ministries involve: Ministry of Agriculture and Food Security (MASA); Ministry of Land, Environment and Rural Development (MITADER); Ministry of Industry and Trade (MIC); Ministry of Sea, Interior Waters and Fisheries (MMAIP), and Ministry of Public Works, Housing and Water Resources (MOPHRH).

8

Currently, the Government, under the leadership of the Ministers and senior staff of MASA and MITADER, is making arrangements for reactivating a multi-stakeholder and institutional Conselho de Coordenação do Sector Agrário (CCSA). It will be supported by a Technical Secretariat, and by multi-stakeholder program-based implementation teams, to help ensure more effective and timely coordination at the sectoral level. Similar coordination arrangements are needed at the Provincial/District levels. 
MITADER, has articulated a vision to promote integrated and sustainable rural development in its comprehensive Programa Estratégica para Desenvolvimento Rural Integrado e Sustentável (Integrated Sustainable Rural Development Program, "SUSTENTA"), 2015-2019, focused on five strategic priorities. ${ }^{9}$

The Ministry for the Sea, Interior Waters and Fisheries (MIMAIP) is responsible for promoting fishery development, involving both on and off-shore fishery resources (for an extensive coastline of c.2,500 $\mathrm{Km}$ ), and increasing the role of aquaculture in diversifying rural livelihoods and nutrition involving large numbers of rural households.

The Ministry of Industry and Trade (MIC) provides and oversees important aspects of policy formulation and implementation for trade and investment including for the agricultural sector, and therefore close coordination with MASA and MITADER is essential.

The Ministry of Public Works, Housing and Water Resources (MOPHRH) is responsible for the construction/rehabilitation of rural/feeder road networks which play a key role in enhancing agricultural competitiveness.

The decentralization policy involves an expanded role for Provinces in providing key agricultural services, especially important for smallholders, subsistence and evolving commercial farmers. These key services involve coordination with central government agencies, especially MASA, and involve veterinary, phytosanitary, and agricultural extension and training services, and strategic linkages with agricultural research.

Central Role of the "Infant" Private Sector. Similar to other countries, both developed and developing, the private sector plays a CENTRAL role in ensuring accelerated and sustainable agricultural transformation. Therefore, public policies and investments should aim to catalyse an expanded role for the private sector, especially in tapping the significant potential for the development of numerous value chains. However, the role of the private sector in Mozambique is currently at an infant stage. A parallel study is formulating a comprehensive assessment and strategy, and supporting an action plan for expanded private sector development in Mozambique's agricultural sector. ${ }^{10}$ Section 6.4 highlights some of the trends, constraints and strategy elements for accelerating private sector development in the agricultural sector.

Key Sectoral Policies, Targets and Performance. To address the important role of the agricultural sector and the constraints and potential, Annex A summarizes the main policy/strategy elements, the development objectives, or the PNISA and the corresponding targets (proposed and actual performance) established in the PQG and the PNISA. Annex Error! Reference source not found. also includes additional details regarding PNISA indicators with respect to: support programs, and their corresponding targets - proposed and progress (actual vs targets); and Sector Ministries, considering their mandates and corresponding targets, respectively. These objectives and targets provide a key

\footnotetext{
${ }^{9}$ These programs are located in both rural and urban areas, and include: (i) knowledge and technology transfer (Mais Saber); (ii) market-related infrastructure (Via Rural); (iii) access to finance and financial services (Um Distrito, Um Banco); (iv) improved water supply (Agua Viva); and (v) expanded energy supply (Quinta da Energia) in rural areas.

${ }^{10}$ See the forthcoming study on: Expanding the Role of the Private Sector For Accelerating Agrarian Sector Transformation (draft report expected in May, 2019). DFID is providing funding, with WB-selected consultant team.
} 
reference point and framework for assessing the soundness, alignment and effectiveness of public expenditure allocations and expenditure with respect to expected and actual results (see Chapters 3 $-7)$.

Erratic and Uneven Agricultural Sector Performance. Overall, the performance of the agricultural sector has been erratic and below expectations/targets in relation to sectoral growth rates, reduction in rural poverty, increased employment, increased productivity, commodity diversification, and competitive value chain development. Annex A highlights these indicators and targets and their corresponding erratic performance. While establishing attribution of this erratic performance is always a challenge, these findings highlight structural constraints in the sector and the serious challenges involved in ensuring appropriate and consistent agricultural policies and sound agricultural public expenditure. These relationships and implications are further examined in Chapters 4 to 7 .

\subsection{CAADP Process: Commitment and Compliance}

African leaders have developed and implemented the Comprehensive African Agricultural Development Program (CAADP) framework and agenda to help accelerate agricultural sector growth and reduce poverty. African Heads of State have affirmed their commitment to meet common development strategic as reflected in the MAPUTO Declaration (2003) and reaffirmed in the MALABO Declaration (2014). Mozambique has demonstrated consistent commitment to complying with and carrying out the CAADP agenda and agreed targets, reflected in the formulation and implementation of PEDSA and PNISA. However, the performance has been erratic for similar reasons outlined above, and further detailed in the independent assessment of Mozambique's PNISA. ${ }^{11}$ The CAADP processes, strategic priorities, biennial reports on core performance indicators and targets, comparative experiences with other African countries and forward-looking strategy and investment frameworks together provide a relevant roadmap, tools and "peer-level" incentives for encouraging stronger performance by Mozambique --- both backward and forward looking. Mozambique's next cycle of agrarian sector policies, strategies (known as PEDSA II) and national agricultural investment program (known as PNISA II) provide an opportunity for sectoral leaders to revitalize its sector performance and to draw on relevant good practices from other countries complying with the CAADP agenda and targets.

\subsection{Synthesis of Challenges Lessons Learned and Good Practices of Agricultural Public Expenditure Reviews in Sub Saharan Africa}

Based on a review of relevant AgPERs and Light AgPERs prepared for Sub-Saharan (SSA) countries, Annex Error! Reference source not found., Error! Reference source not found. summarizes the main challenges, lessons and good practices which were taken into account in the design and implementation of this current exercise for Mozambique.

The thrust of good practices reveals the following elements drive the design, implementation and follow-up actions of a sound and useful AgPER:

- Appropriate and agreed definition of the "agricultural sector";

11 See PNISA Assessment (November, 2017). 
- Sound results framework for the "agricultural/agrarian sector";

- Solid and realistic scope of the terms of reference of the Ag. PER, agreed by the relevant stakeholders, including strategic inputs for the forthcoming formulation of an updated agricultural policy, strategy and investment program (see below);

- Strong ownership by relevant stakeholders, ensuring the focus addresses relevant expenditure issues, and fosters stronger professionalism and technical capacities of the relevant officers;

- Identification of key expenditure data requirements and formulate corresponding template tables which can be institutionalized, and data recommendations as part of the periodic enhanced expenditure analyses;

- Recommend improved coordination arrangements, mechanisms and processes for an enhanced expenditure management cycle.

\subsection{Objectives, Scope, and Relevance}

\subsubsection{Objectives}

In the light of the above context, there are two objectives of this Agricultural Public Expenditure Review (AgPER):

(a) to generate sound, evidenced-based findings and recommendations, including a detailed action plan, for enhancing the efficiency, effectiveness and sustainable results of agricultural public expenditure, focusing on PNISA's more "strategic" programs; and

(b) to provide strategic inputs for the forthcoming formulation of the proposed updated agrarian sector policy, strategy and investment program.

This study was carried out together with a companion document: "Strategy for Expanding the Role of the Private Sector in Transforming the Agrarian Sector". Both documents aim to support the Government of Mozambique in generating a new cycle of Policy, Strategy and Investment plan for the Agrarian Sector.

\subsubsection{Scope}

The original scope of the analysis was to conduct a "Light"12 Ag. PER, but given the operational requirements for broader coverage of expenditure programs as key inputs for formulating the next phase of Mozambique's agrarian sector strategy and investment program, the scope of the review evolved into a "hybrid" approach between a "light" and "comprehensive" Ag. PER. Accordingly, the study covers the period 2013 - 2017 (using available expenditure data), and also assessed the proposed budget allocations for 2019, 2020 and 2021 (based on available expenditure data). In the spirit of conducting a "hybrid" approach, the team reviewed the efficiencies and effectiveness of 3 strategic programs (out of 21 programs supported by PNISA), namely: agricultural research, extension and irrigation programs. Also, to account for important evolving decentralized programs, the study team selected three "representative" provinces (Nampula in the North; Manica in the center; and

\footnotetext{
12"Light" refers to a focused/limited scope, analytical depth, time-period, taking into account available information and evidenced-based studies, and limited available funding and human resources (Ag PER Light Guide, World Bank, 2016). The World Bank has developed a guide for "Light" AgPERs (2016), based on applying the methodology for 5 countries in Africa, and which were taken into account during this exercise. The more "strategic" programs of PNISA (out of a total of 21 programs) will include those programs which play a vital role in the generation of key results (at impact and outcome levels), as reflected in the updated Results Framework used for the assessment of PNISA (in 2017).
} 
Gaza in the south), in order to integrate a "provincial lens" in the expenditure assessment and recommendations.

\subsubsection{Relevance and Target Audience}

The relevance of this study includes the timely need:

a) To encourage the use of the study's public expenditure assessment tools, including indicators, emerging findings and recommendations, and proactive and enhanced practice of carrying out evidenced-based expenditure analyses and recommendations during the entire budgetary cycle on the part of participating Ministries/Provinces and their technical officers; these outputs also will contribute to the CAADP agenda in Mozambique (see above);

b) To provide development partners with inputs for aligning and harmonizing their technical and financial assistance in accordance with the Government's expenditure priorities and lessons learned (as outlined in their enhanced MTEF and annual budget proposal); and

c) To provide strategic inputs for the forthcoming formulation of the policy, strategy, and investment program of the agrarian sector: "3 Pillars of Agrarian Sector Transformation".

Four main stakeholder groups are therefore engaged as the target audience, in terms of providing inputs, consultation feedback and users of the report findings and recommendations/action plan:

a) Key Government officials and their corresponding ministries/agencies at national ${ }^{13}$ and provincial levels, which are directly involved in agricultural sector policy formulation, planning, implementation, and monitoring and evaluation of agricultural sector policies, regulations and programs;

b) Private sector actors who are directly involved in one or more aspects of agricultural and value chain development, including investors/entrepreneurs, financing institutions, input suppliers, traders of both imports and exports, suppliers of agricultural technologies and representatives of the private sector (e.g., farmers' organizations, chamber of commerce); ${ }^{14}$

c) Development partners (DP) stakeholders and their agencies who are directly involved in the provision of technical and/or financial assistance to the agrarian sector; and

d) Civil society, farmer groups/associations and selected members of relevant Parliamentary committees who are involved in promoting, advocating for, and accountability in agricultural sector expenditure and performance.

\subsection{Structure of the Report}

The structure of the report reflects the sequence of topics which comprise the theory of change (ToC) and supporting results framework (RF) with respect to achieving sustainable results from prioritized agricultural public expenditures, through addressing the following key questions:

Why? Chapter 1 outlines the main macro and sectoral challenges which underpin the rationale for carrying out the Ag. PER. Annex 1 provides further details on various aspects of this chapter.

\footnotetext{
${ }^{13} \mathrm{At}$ the national level, there are five central government ministries directly involved in different aspects of the "agrarian sector": MASA, MITADER, MIC, MIMAIP, MOPHRH (for further details, see Section 1.2 and Annex 1).

${ }^{14}$ Also includes stakeholders which have been involved in the on-going Private Sector Strategy for the Agricultural sector.
} 
How? Chapter 2 outlines the methodological aspects, including the theory of change (ToC) and supporting results framework (RF), and key sectoral policies/strategies/targets which provide a sound conceptual and empirical framework for assessing agricultural expenditure; appropriate definition of the "Agricultural Sector"; descriptive, quantitative and qualitative analyses of agricultural expenditure levels/trends, composition, relevant measures of efficiency, effectiveness and value of money; criteria for defining the scope of the study with respect to thematic programs covered and for selecting 3 Provinces for in-depth assessment; data requirements and limitations;

How and Who Managed? Chapter 3 outlines the Government's budgetary cycle, processes and practices at central and provincial levels, based on relevant budgetary decrees/circulars that guide budgetary priorities and allocations for annual and medium-term agricultural sector expenditure, and management aspects, and for assessing the actual practices followed;

What and When? Chapter 4 conducts a backward assessment through an analyses of the levels, trends, composition, and performance of agricultural expenditure (on-budget, and where possible, off-budget expenditures), including the efficiency, effectiveness and emerging results of agricultural public expenditure, for the period 2013-2017; Chapter 5 synthesizes the expenditure performance of three strategic programs: agricultural technology (research and extension, and research-extension linkages); and irrigation, while also considering aspects related to decentralization and adaptation to climate change. Given limited public resources, the study team also conducted a rapid review of subsidies for the agricultural sector, based on available expenditure data;

Chapter 7 takes a forward-looking approach to the expenditure assessment by outlining: (a) key elements, processes and emerging issues of the Government's Medium Term Fiscal Framework (MTEFF); (b) the approach used by agricultural sector ministries for estimating and using their medium term expenditure framework; (c) good practices of the MTEF for the agricultural sector derived from relevant countries, and their implications for Mozambique; and (d) alignment between the forward sectoral expenditure and priority agricultural sector policies and targets;

How Financed? Chapter 6 highlights: the financing strategy and main sources of finance; onbudget and off-budget aspects; the role, scope, levels/trends and sources of private sector financing in the agricultural sector, and their key determinants. The chapter also highlights some of the strategic linkages with a parallel private sector strategy study for the agrarian. Sector.

So What? Chapter 8 synthesizes the main findings and priority recommendations in the form of a roadmap, including a supporting proposed results-focused agriculture expenditure action plan ("RASEAP"). During the consultation phase of this exercise, these strategic recommendations were presented to key stakeholders according to six strategic areas and supporting priority actions. The action plan also emphasizes ways to "institutionalize" strategic recommendations as part of an enhanced budgetary cycle and as a basis for generating improved expenditure performance and results. 


\section{Methodological and data aspects}

\subsection{Definitions of Key Concepts and Tools}

The detailed scope and methodological aspects of this expenditure review are guided by key concepts and principles outlined in Annex C. Key concepts are synthesized below.

(a) Agrarian sector" refers to the key functions/programs which contribute directly to agricultural development, comprised of two broad components:

(i) Subsectors defined by the International Classification of Functions of Government (COFOG) - namely crops, livestock, forestry and fisheries; and

(ii) Crosscutting components which comprise functions and activities which involve the provision of public "good and services" contributing directly to agricultural growth and poverty reduction. These functions are detailed in Annex $C$.

Based on the AU guide, ${ }^{15}$ each country is required to estimate an appropriate apportionment of costs/expenditure for each of the specified crosscutting functions. In the case of Mozambique, as stated above, the agricultural sector will involve the following five government entities (both central and sub-national levels), and their corresponding functions: the Ministry of Agriculture and Food Security (MASA); the Ministry for Land, the Environment and Rural Development (MITADER); the Ministry for Trade and Industry (MIC); the Ministry for the Sea, Interior Waters and Fisheries (MIMAIP); and the Ministry for Public Works, Housing and Water Resources (MOPHRH).

(b) Apportionment refers to the percentage of expenditure for functions/expenditure from relevant ministries to ensure that expenditure are providing "direct" support to agricultural development (agricultural growth and rural poverty reduction), and therefore, included in the estimation of "agricultural sector" expenditure (for example, rural roads provide multi-sectoral benefits, and therefore there is a need to apportion an appropriate percentage of the total expenditure to the agricultural sector). Table C.1 in Annex $C$ shows the expenditure apportionment assumptions employed in this report with respect to Mozambique's relevant government entities and their respective functions/mandates, taking into account apportionment assumptions in other countries in Sub-Sahara Africa;

(c) Agricultural Public Expenditure Review (AgPER), involving both quantitative and qualitative analyses to assess the efficiency and effectiveness of public expenditures;

(d) "Light" and "Hybrid" AgPER: refers to a "simplified" version of an AgPER, with respect to the scope, depth, frequency, coverage of expenditure, on and off-budget analyses and attribution of expenditures-results. It is also important to recognize that a "Light" approach needs to be customized to country conditions and requirements, and also aims to suggest an approach which can be updated on a regular basis to support the medium-term and annual budgetary planning cycle as stated above, in this instance, the team carried out a "hybrid" scope, especially given the sector's operational requirements during 2019 and 2020;

(e) On-budget: refers to public expenditure which is reflected in the Government's annual and medium-term budget, including internal and external funds. There are also two other aspects of on-budget funds: "ON-CUT" and "OFF-CUT", as reflecting whether the funds are integrated

15 See AU Guide on the Level and Quality of Agricultural Public Expenditures (AU, 2016). 
in the Government's single treasury account (CUT) that require different procedures for the release of, and access to, funds by implementing ministries. "OFF-CUT" funds would be managed by the central Bank, and enable greater ease in access to required public funds, while ensuring accountability of its use;

(f) Off-budget: refers to public expenditure which is not reflected in the Government's annual and medium-term budget, and which are normally funded by development partners on a grant basis, and channeled directly to the implementing ministry/agency;

(g) "Public" goods and services: refers to the intended role of public sector/funding, to generate social benefits;

(h) "Private" goods and services; refers to goods/services generating private benefits

(i) Subsidy: private good funded by Government, often driven by policy objectives;

(j) Efficiency: there are two components, with important implications for the utilization and benefits of scarce public expenditure -technical and allocative efficiency;

(i) Technical Efficiency: refers to the effectiveness with which a given set of inputs is used to produce an output. A farm/firm is said to be technically efficient if it is producing the maximum output from the minimum quantity of inputs, such as land, labor, capital, and/or technology;

(ii) Allocative Efficiency: refers to "an optimal distribution of goods and services, taking into account consumer's preferences; or equivalent to the "appropriate" allocation of funds for different programs.

The focus of allocative efficiency analysis is on answering the question of whether public financing is being allocated for the right things. Stated otherwise, it is part of "congruence analysis": to what extent have budget allocations been aligned to the specific sector objectives and strategy to achieve these objectives.

(k) Effectiveness: refers to the capability of producing a desired result, with respect to its objectives and targets (e.g., output, outcome, impact); the results framework can provide a useful roadmap and reference;

(I) Cost Effectiveness or Value for Money: refers to expenditure that represent "good value", where the benefits and usage are worth at least what is paid for them; often, comparisons are made to assess the good value (e.g., cost per kilometer of comparable road constructed; cost per hectare of irrigation (new or rehabilitated, using "efficiency-based" unit prices as a target benchmark for expenditures);

(m) Results: In the context of agricultural public expenditure, results refer to the impacts, outcomes and outputs arising from agricultural public expenditure.

\subsection{Methodological Approaches}

\subsubsection{Theory of Change and Results Framework}

The methodology applied for this exercise is based on a theory of change (ToC) and supporting results framework (RF), customized for the case of Mozambique. Error! Reference source not found. Counterclockwise flow reflects a good practice planning approach, to ensure strategic impacts, outcomes and outputs help guide and prioritize the financing of the most strategic activities. The clockwise flow reflects the normal implementation sequence of the prioritized activities, which will help generate the envisioned strategic outputs, outcomes and contribute to the target impacts. Key aspect to operationalize this approach is to establish and maximize an evidenced-based approach to maximizing expenditure-results linkages. 
Theory of Agrarian Sector Change: In summary, in the context of the role and results of agricultural public expenditure in Mozambique, refers to the prioritization of expenditure activities relating to key public sector goods and services (inputs, such as research trials for improved crop varieties) which generate the most relevant set of strategic outputs (results of relevant research trials and recommendations), which contribute to the strategic outcomes (increased farmer adoption of improved varieties, and resulting increases in crop yields, together with crop diversification toward higher value and competitive value chains), which in turn contribute to the expected impacts referring to accelerated and sustained agricultural sector growth, increased farm-level profitability levels, corresponding increased rural household incomes, and reduced household poverty levels. The ToC and supporting RF is comprised of prioritized "public" AND "private" goods and services which, combined will contribute to the higher-level impacts, driven by clear and appropriate roles of public and private sectors. Accordingly, this ToC and corresponding RF is used as a methodological tool to help assess budgetary processes, past and proposed allocations of agricultural public expenditures, especially to the extent to which past and future agricultural public expenditure are prioritized.

Figure 2.1 Theory of change and results framework for Mozambique agricultural sector

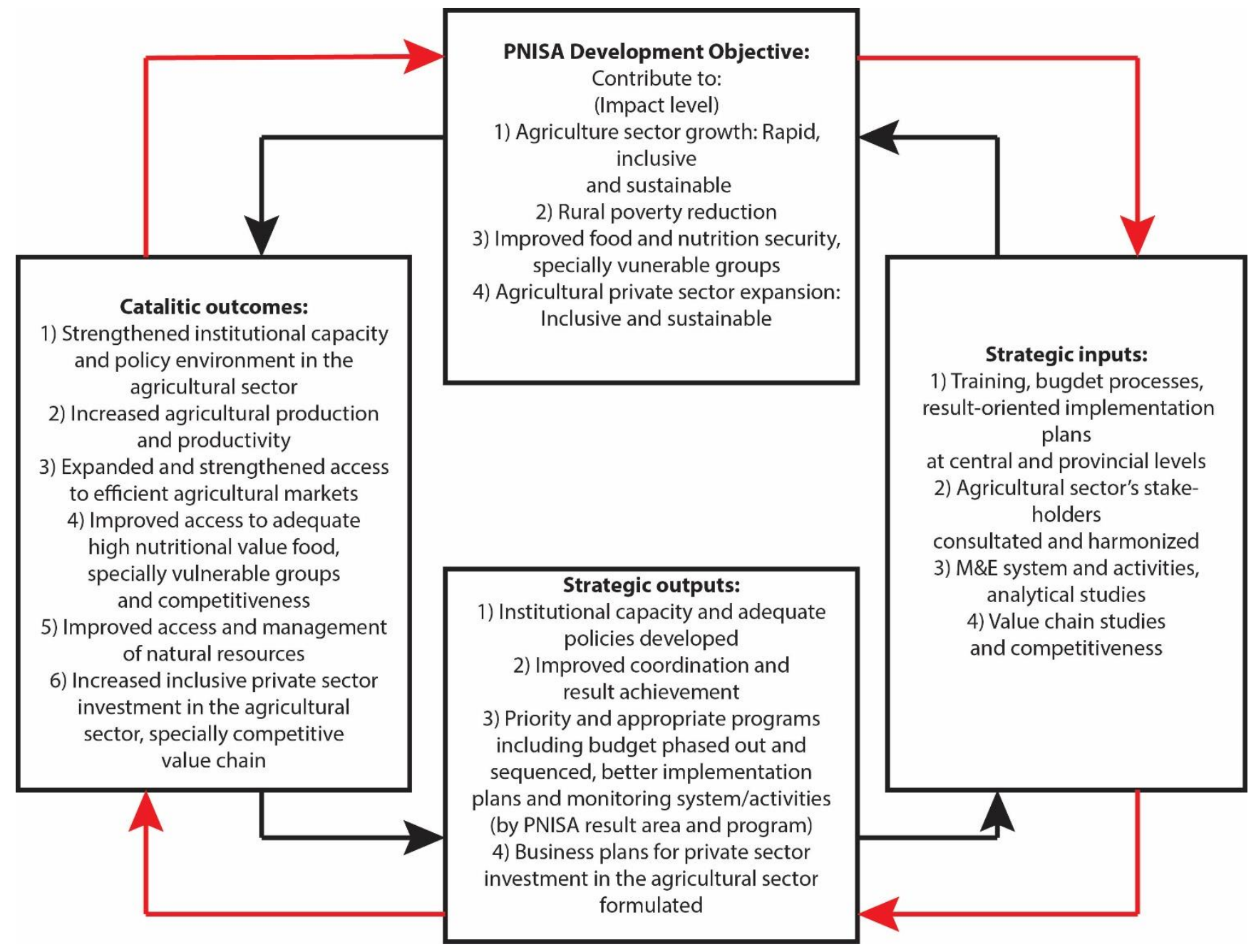




\subsubsection{Results-focused Expenditure Analyses}

Error! Reference source not found. illustrates the desired flow of country-level macro and sectoral development objectives and targets, which helps determine and prioritize the required level and composition of agricultural expenditures, coupled with the appropriate role of the private sector. Given expenditure elasticities, these public and private sector interventions should generate/contribute to the expected results (impacts, outcomes and outputs), to be reaped by the relevant target groups.

Figure 2.2 Framework of Flow from Policies to Expenditure to Results

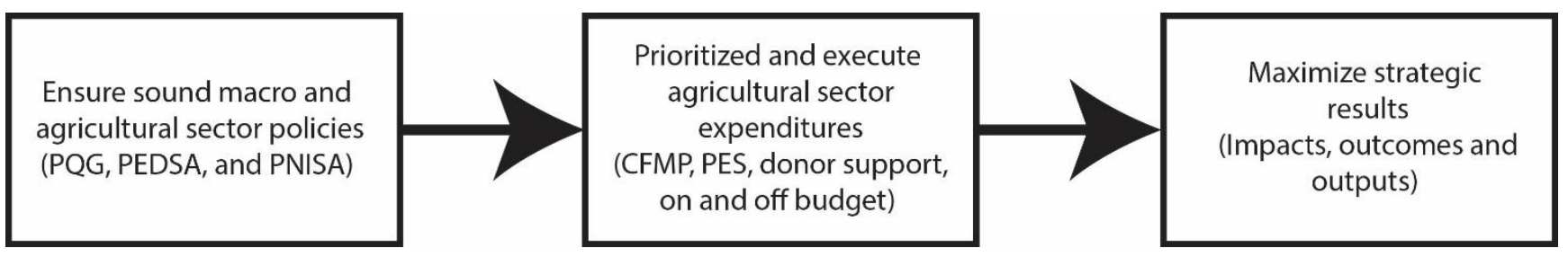

This expenditure analysis uses a combination of quantitative and qualitative methods to assess backward and forward expenditure, including the following elements (and tools) during the budgetary cycle:

(a) Budgetary Processes and Cycle: Good practice for ensuring agricultural public expenditure allocations involve the application of sound budgetary processes and management practices throughout the budgetary planning and implementation cycle, as directed by the Ministry of Economy and Finance (MEF) to ensure consistency across Government entities.

(b) Trends and Composition: The analysis of the trends and composition of Agricultural Public expenditure is disaggregated according to three classifications, providing a "lens" to assess expenditure, consistent with good practice. The priority classification categories are as follows: ${ }^{16}$

(i) Institutional and Recurrent/Capital;

(ii) Function/Program: expenditure classified according to the PNISA's 5 Result Areas (RAs) and 21 component programs (see Table 2.1);

(iii) Administration; and

(iv) "Private" and "public" goods and services.

(c) Performance and Emerging Results of Agricultural Public Expenditures: Based on the results of the descriptive analysis of the agricultural expenditure data, this section derives relevant ratios and performance indicators involving efficiency, effectiveness and value for money, drawing on good methodological practice and benchmarks. The main indicators derived in this assessment include (at aggregated and disaggregated levels):

i) Efficiency Measures:

- Actual expenditure as a percentage of approved expenditures;

- Actual expenditure as a percentage of disbursed expenditures;

16 The expenditure cclassification systems would still need to be based on expenditure data from each relevant Institution or Ministry. Given the "light" and hybrid scope followed in this exercise, it was not possible to classify and assess the expenditure according to public or private goods. 
- Budgetary releases/disbursements for the agricultural sector and strategic programs as a percentage of approved expenditures;

- Recurrent and capital expenditure as a percentage of total expenditures;

- Non-wage recurrent expenditure as a percentage of total recurrent expenditure, recognizing that there is a need to ensure a sound "balance" and appropriate interpretation of the figures/trends in both absolute and percentage terms;

- Procurement efficiency: extent of deviation of actual procurement from target procurement timeframe; extent to which the procurement processes resulted in lower unit and total expenditures;

- Cost effectiveness measures:

- Average cost of goods and services provided (e.g. actual cost per kilometer of feeder road construction; number of rural households supported by one extensionist; actual unit cost per hectare of irrigation rehabilitated and constructed;

Table 2.1 Summary of the PNISA Structure: Result Areas and Programs

\begin{tabular}{|c|c|}
\hline Component/Result Area (RAs) & Program \\
\hline $\begin{array}{l}\text { 1. Agricultural Production and } \\
\text { Productivity } \\
\text { (8 programs) }\end{array}$ & $\begin{array}{l}\text { Food Crop (1); Cash Crop (2); Fishery (3); Livestock (4) } \\
\text { Agricultural Research (5); Agricultural Extension (6); } \\
\text { Agricultural Irrigation (7); and Agricultural Mechanization (8) }\end{array}$ \\
\hline $\begin{array}{l}\text { 2. Access to Market } \\
\text { (5 programs) }\end{array}$ & $\begin{array}{l}\text { Postharvest Management and Marketing (9); Financial Services } \\
\text { (10); Agribusiness Development (11); Rural Roads (12); and } \\
\text { Information Systems and Agricultural Statistics (13) }\end{array}$ \\
\hline $\begin{array}{l}\text { 3. Food \& Nutritional Security } \\
\text { ( } 2 \text { programs) }\end{array}$ & $\begin{array}{l}\text { Multisectoral Monitoring and Coordination (14); and Improved } \\
\text { Access to and Use of High Nutritional Value Food (15) }\end{array}$ \\
\hline $\begin{array}{l}\text { 4. Natural Resource Management } \\
\text { (4 programs) }\end{array}$ & $\begin{array}{l}\text { Land for Agricultural Purpose (16); Forestry and Wildlife (17); } \\
\text { Institutional Development of the DNTF (18); and Mapping and } \\
\text { Remote Sensing (19) }\end{array}$ \\
\hline $\begin{array}{l}\text { 5. Institutional Reform and } \\
\text { Strengthening } \\
\text { (2 programs) }\end{array}$ & Institutional Reform (20) and Institutional Strengthening (21) \\
\hline $\begin{array}{l}\text { Cross-cutting issues: Gender, } \\
\text { environment, other sector policies, } \\
\text { on-going plans, decentralization }\end{array}$ & $\begin{array}{l}\text { They are not stand-alone, hence lack budget of their own. They } \\
\text { are intended to be integrated into the } 5 \text { components/RAs and } \\
\text { corresponding } 21 \text { programs. }\end{array}$ \\
\hline
\end{tabular}

ii) Effectiveness Measures: ${ }^{17}$ (with respect to approved and actual expenditures)

- Public expenditure on agriculture as a share of agriculture's value-added (Agricultural GDP), at both national and provincial levels;

- Public expenditure on agriculture per capita (rural population) and number of households at provincial level;

17 These are based on the indicators suggested by the Light Guide of Ag. PER (2016). 
- Sub-sector expenditure as a percentage of sub-sectors' GDP (subject to being included in the classification of expenditures);

- Research intensity: $:^{18} R \& D$ expenditure as a percentage of agriculture GDP,

- Expenditure on the "agriculture sector" as a percentage of total government expenditure (ensuring that the numerator contains only items that are also included in the denominator);

- Extent to which strategic programs are making good progress toward meeting their objectives and targets;

(d) Decentralization Analyses: This section analyzes the trends and composition of agricultural expenditure analysis at the provincial level, showing the breakdown of expenditure between central and provincial level governments,

\subsection{Criteria for Selection of Key PNISA programs and Provinces}

(a) Criteria for selecting three strategic programs include:

- Contribution to key sources of growth and the Theory of Change (ToC) \& Results Framework (RF);

- Major expenditure program; and

- Available analytical studies.

Based on these criteria, the following three programs were selected for in-depth assessment:

- Agricultural technology:

- Agricultural research;

- Agricultural extension and training;

- Agricultural research and extension linkages;

- Irrigation;

(b) Criteria for selecting provinces:

- One province in each region;

- Provinces with "major" agricultural investments;

- Demonstrates variations among Provinces.

Based on these criteria, the following three provinces were selected to introduce and apply a decentralization "lens" for the expenditure analysis:

- Nampula in Northern Mozambique;

- Manica in Central Mozambique; and

- Gaza in Southern Mozambique

\subsection{Data and Information Requirements, Sources and Challenges}

(a) Data and information requirements and availability: These include expenditure data with respect to:

- Key sector strategies and policies, ministry strategic plans, and corresponding sector and ministry targets;

${ }^{18}$ CAADP recommends African countries spending one percent of Ag GDP on research and extension. 
- Expenditures:

- Targets and Results:

(b) Main Data Sources: These include:

- Annual Ministry/program performance reports ("Balanço de Programas e Ministérios" for each year);

- Total and sectoral expenditure from Central Government Ministries (MEF, Sectoral Ministries) and Provincial Governments (MEF, Provincial Governments);

- Annual Performance Reports prepared by the main Ministries;

- Analytical studies and progress reports for the 3 programs being assessed;

- $\quad$ Project performance reports, especially prepared by Development Partners (DP), including Mid-Term Reports;

(c) Data Coverage, Reliability and Challenges: These include:

- Data on total and agricultural expenditure (on-budget) according to the ministries, PNISA program, recurrent vs capital, and Provincial is generally complete and reliable;

- Data on total and agricultural expenditure (off-budget) according to the ministries, PNISA program, recurrent vs capital, and Provincial, and development partner sourced are generally partial and somewhat "unreliable". This highlights the need to ensure both onbudget and off-budget resources are captured and recorded, to ensure strong alignment and prioritization of ALL expenditures, regardless of funding source, since all of these resources need to contribute to priority objectives and targets;

- Results by program are variable and somewhat unreliable, depending on the program. 


\section{Budgetary processes and institutional arrangements and roles: current practices and strategies for enhancement}

\subsection{Overview of Agrarian Sector Budgetary Cycle and Processes: Gap between "Theory and Practice"}

This chapter discusses the budgetary cycle, processes and institutional arrangements, roles and capacities of the "agrarian sector" in Mozambique focusing on identification of the limiting factors and provision of strategic recommendations which can contribute to enhance strategic results. In the case of Mozambique, these key functions are carried out by the following 5 ministries, including their respective provincial and district level entities/Departments: MASA, MITADER, MIMAIP, MIC, and MOPHRH. Therefore, the discussion presented here focuses on the budgetary cycle, processes and arrangements in these institutions at all levels (central, provincial and district). As presented below, there is a gap between the theory and practice, resulting in some inefficiencies, especially in the composition and strategic results of the expenditure. Figure 3.1 below presents these determinants, namely budget processes generally issued by MEF, recognizing the difference between intended and actual practices followed; characteristics of the investments; the degree of influence by key actors and their "incentives" to "influence" the budgetary allocations; and the main factors affecting the political and governance "environment" which also could influence investment decisions and allocations and level of accountability.

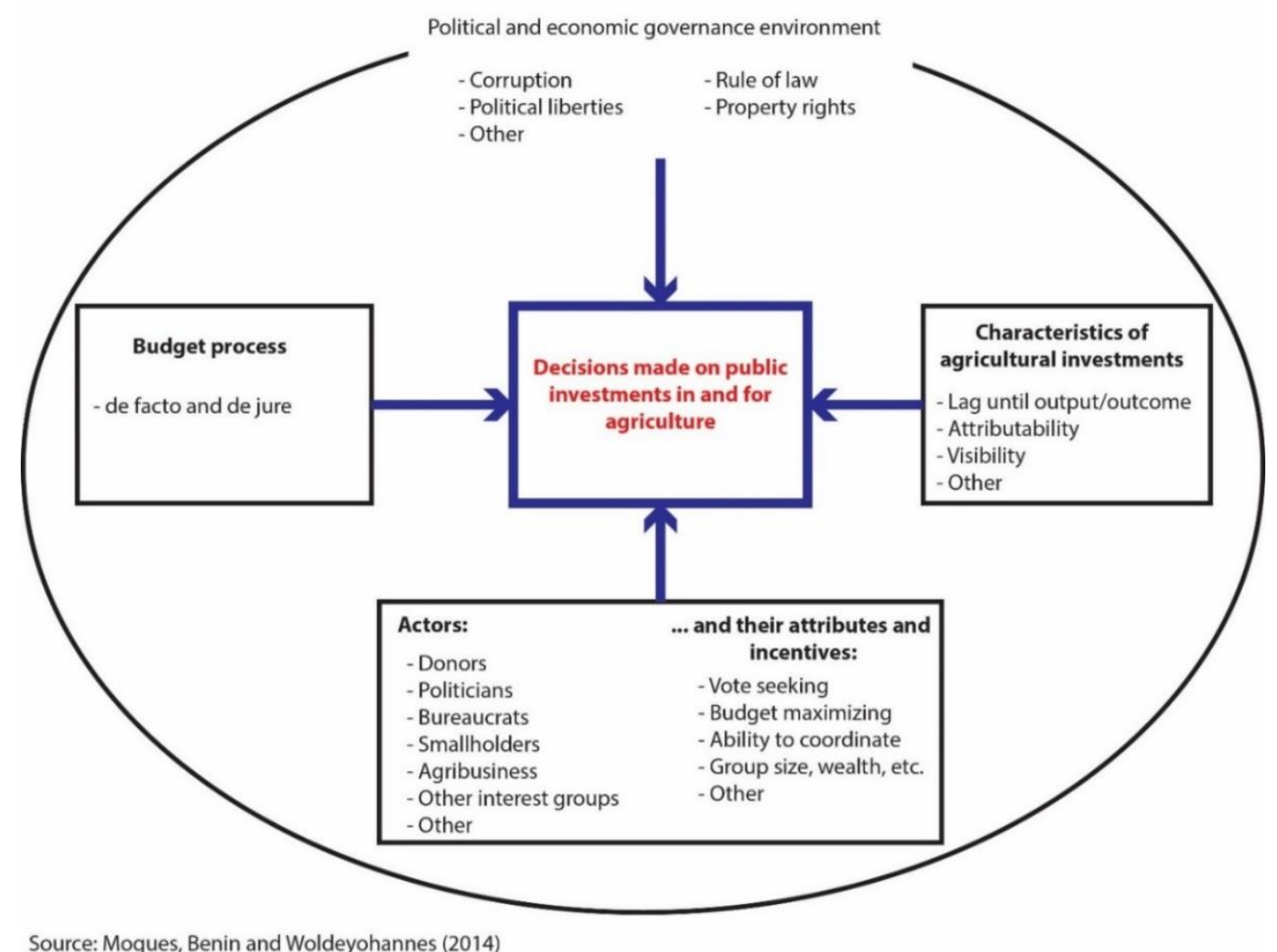

Figure 3.1 Public expenditure decision-making and the factors influencing decisions 
In general, these broad factors or determinants are applicable to Mozambique, but with varying degrees of influence to reflect the "political-economy" of the country At all levels, the budgetary process is the key factor, then followed by the characteristics and requirements of the investments.

The relative high importance of the budgetary process is because it is guided by several instruments in Mozambique, such as the methodology for the elaboration of Economic and Social Plan, methodologies for the elaboration of the Medium-Term Expenditure Fiscal Framework (MTEFF), commonly known in Mozambique as Cenário Fiscal de Médio Prazo (CFMP); it is used to establish the budget ceiling. These instruments are instructive and provide all elements for planning and the production of the budget, and therefore comprise the main elements for generating the final budget. The influence of key stakeholders, such as civil society and private sector actors, is minimal since the budget is approved by the government entities at provincial and central level, before the final approval from the national parliament. The key stakeholders are consulted partially during the budgetary process. This budgetary assessment "lens" would be revisited in the chapters below, based on assessing expenditure data and qualitative inputs from various stakeholders. The MTEFF will be assessed further in Chapter 7, which reviews the forward budgetary planning processes and allocations which are actually followed by the sectoral Ministries.

\subsubsection{Budgetary Cycle}

The public budget management cycle is carried out by institutions receiving directly funds from the government through MEF. In Mozambique, the public budget is channeled to three types of institutions, namely: (i) central government institutions, including the Office of the President, Office of Prime Minister, National Parliament, Courts and Ministries; (ii) Institutions of the central government geographically decentralized (provincial and district levels); and (iii) institutions with legal administrative and financial autonomy. Therefore, the budgetary cycle and processes described in this chapter involve the government and autonomous agricultural sector institutions at all levels.

Figure 3.2 depicts the Mozambican budgetary cycle. It starts at the beginning of the calendar year with the preparation and approval of the Economic and Social Plan Balance (BdPES), and the Budget Execution Report of the previous fiscal year, which are supposed to be submitted to MEF by the end of January of each year. In the same period, the MEF issues a budgetary circular to all government institutions at the central and provincial levels, which outlines the methodology for the elaboration of CFMP ${ }^{19}$; the budget proposals are supposed to be completed and submitted to MEF by May of each year. The CFMP was introduced by MEF as a tool to help plan and prioritize expenditure over a three-year period. While sectoral Ministries recognized the merits of this tool, there were various emerging weaknesses, which resulted in discontinuing the use of this tool. ${ }^{20}$ The CFMP, BdPES and Budget Execution Report are used by MEF to establish the budget ceiling for each institution at all levels, which are communicated to these entities by May 31 of each year, along with the orientation for the elaboration of the PES (central and provincial PES) and the District Economic and Social Plan, commonly known as the Plano Económico e Social do Distrito (PESOD).

19 Besides including the expected revenues and expenses, the CFMP includes also the matrix of activities of the Economic and Social Plan for the forthcoming three years.

20

See: "The Mozambique CFMP - Creating an Effective Tool for Fiscal and Budgetary Planning", World Bank, 2018.

The main problems were identified to include: (1) the CFMP is issued with ceilings which are received in December, but then significantly lower ceilings are issued for the OE in May, and therefore Ministries and agencies have to redo all the work ..."; (2) "There is a lot of wasted effort and it is very frustrating for the staff.."; (3) "Coordination inside MEF also seems to be weak: we receive conflicting messages from different Directorates. 
Using the budget ceiling and guidelines for the preparation of PES and PESOD provided by MEF, the institutions at all levels prepare the proposals of PES/PESOD and OE (orçamento estatal) by June of each year, and submit to the MEF the final proposal up to the end of July ${ }^{21}$. Due to budget limitations, planning units are supposed to have criteria for prioritizing activities during the preparation of PES and PESOD. However, there are no specific criteria to define priorities during the preparation of PES/PESOD and OE at all levels.

Role of e-SISTAFE. The introduction of e-SISTAFE in the budget preparation cycle has been viewed as a significant improvement of the efficiency of registering the budget and producing the respective budgetary reports. The process has also been seen as efficient because since 2016 , the sectors are allowed to reallocate the approved funds among the approved activities through e-SISTAF, needing only the approval of the respective Minister without a need to seek permission from MEF. However, the e-SISTAFE system is not available for all users, since some districts: do not benefit from this platform; have limited access to electricity and availability of human resources to use and solve specific problems of its functionality. Therefore, it is recommended that MEF formulate and impart to the relevant target groups a training module in the use of e-SISTAFE. This training would contribute to improvements in the effective and efficient use of this expenditure platform, and resulting improvements in the expenditure allocations.

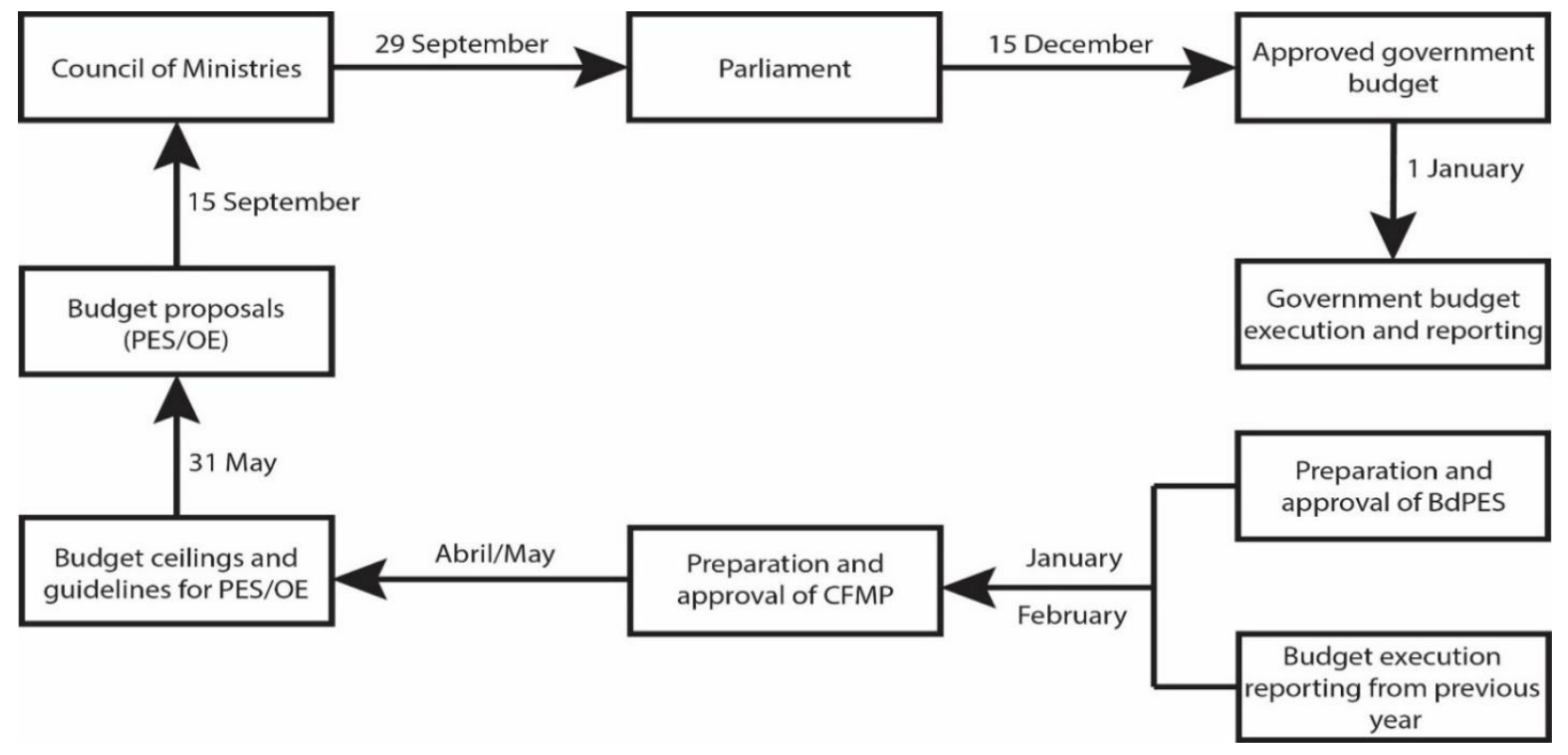

Figure 3.2 Mozambique budgetary cycle

The above described budget cycle is clear and known by the planners. The limiting factors during budgetary cycle include:

- Adjustments/prioritization of the activities, due to limited financial resources, coupled with the absence of clear and sound prioritization criteria;

- Delayed disbursements due to limited availability of funds, including shortfalls/delayed revenue inflow to MEF;

21 The PESOD and district OE is submitted to the province (provincial secretariat) up to August 10 and the provincial PES and OE is submitted to MEF by August 30. 
- Possible reallocation of funds for activities that were not planned;

- Inadequate integrated and coordinated planning among the agricultural sector institutions. This constraint is also associated with lack of effective involvement of key entities as well as stakeholders [coordinating councils/committees, such as agricultural sector coordinating committee (CCSA), development partners, private sector, and civil society] in decision-making processes during the budgetary cycle. It is important to note that the calendar of the budget cycle foresees meeting with development partners to take place in September of each year. However, these meetings use to take place at national level (MEF), but not at Ministry and local government (province and district) levels. Moreover, at provincial level, there are similar weaknesses, but at a greater scope and intensity, reflecting greater capacity weaknesses; and

- Development Observatory Forum, the Private Sector Forum, and the Provincial Parliaments. However, those organs do not have decision-making roles during the budgetary cycle.

Table D.1 in Annex D summarizes the strengths and weaknesses of the key elements of budgetary cycle involving various actors at national and subnational levels.

\subsubsection{Budgetary Processes at National and Subnational Levels}

Error! Reference source not found. illustrates the budgetary processes in Mozambique, with respect to the agricultural sector, at national and subnational levels. Overall, the budgetary processes have been improving over time, and there is scope for further improvements to help ensure prioritized and quality expenditure results, consistent with the cited weaknesses (and summarized in Table D.1 in Annex D). There are two distinct budgetary processes: one at central level (right hand side of Error! Reference source not found.); and the others at the provincial level (left hand side of the Error! Reference source not found.). As shown at the bottom of Error! Reference source not found., these two processes are supported by the sectoral strategic documents and cited in Table D.2 of Annex $\mathrm{D}$. The preparation and the contents of these strategic documents also are influenced by the regional (African) strategic documents such as the Comprehensive Africa Agriculture Development Program (CAADP), as well as the national guiding document (PQG and PES). ${ }^{22}$ 


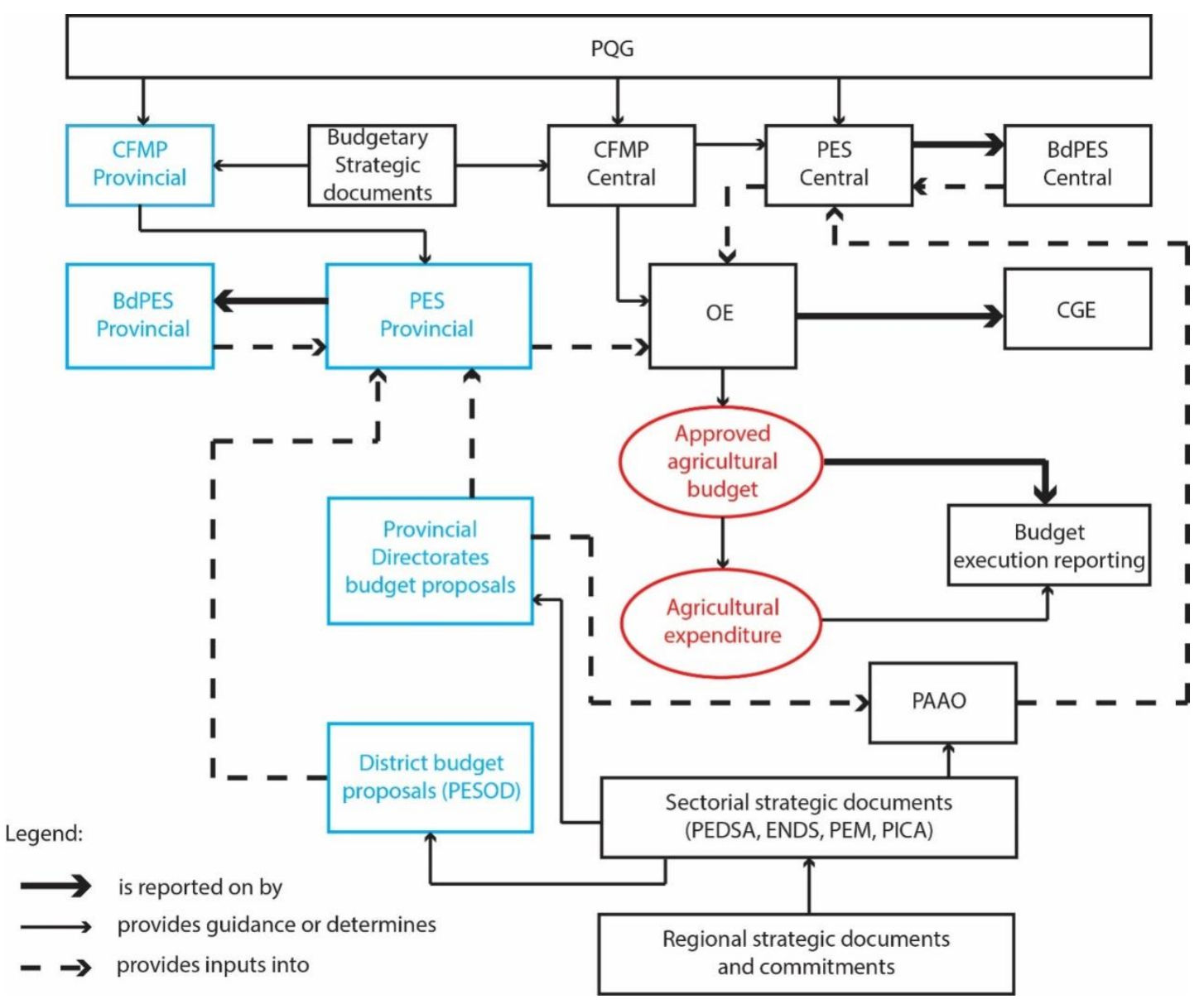

Figure 3.3 The evolving planning and budget processes in Mozambique

A major conclusion of the budgetary planning processes is that, while generally sound and progressively improving, and guided by numerous strategy and planning documents (see Annex D, Table D.2), there are variable capacities to absorb and implement effectively the guidelines. Moreover, there is an absence of clear and sound prioritization criteria and supporting objective tools to ensure sound prioritization during an iterative process of budgetary adjustments, given that the original budgetary ceilings are progressively adjusted (downwards). It is recommended to:

- Streamline the guidelines into user-friendly guidelines;

- Ensure clear and sound prioritization criteria;

- Provide adequate time to allow budgetary adjustments, including consultations with relevant stakeholders;

- Ensure the M\&E systems are generating relevant results which are incorporated in the forward medium and annual budgetary planning processes.

\subsection{Assessment of Institutional Roles, Arrangements, Capacities and Prioritized Strengthening}

As stated at the beginning of this chapter, the budgetary processes involve government institutions at national (Ministries) and subnational (district and provincial) levels, both coordinated by Central and Provincial level MEF. All institutions at national and subnational levels have planning and finance administration officers at all directorates and departments responsible for the planning and 
execution of the budget, respectively. These established organs interact during the budgetary cycle through providing inputs and reporting to MEF. Specifically, the district budget planning and execution officers interact with the provincial secretary, and the Provincial Directorate of Economy and Finance, with their counterparts at provincial level and the provincial sectors report to Provincial Secretary, and the Provincial Directorate of Economy and Finance and their counterparts at central (Ministry) level. The provincial government, through the Provincial Directorate of Economy and Finance (DPEF) reports to MEF. At central level, within a given Ministry, there are departments of planning and budget execution for each directorate which report to the respective internal planning and budget execution directorates and these directorates report to MEF. The interaction among counterparts is mainly for planning activities, while the budget execution and reporting are reported directly to MEF. Also, there are institutions having financial and administrative autonomy and these also have budget planning and execution departments which report directly to MEF. The current roles of these institutions at different levels are summarized in Table D.1 in Annex D.

Emerging constraints. The capacities of these institutions are constrained mainly in terms of number and technical skills of the human resources. From 2015 up to now, the government stopped hiring public officers, except in strategic economic and social activities (education, health and agriculture) due to macro-economic fiscal crisis faced by the country. This situation has substantially limited the number of technicians working on the budgetary process (planning, execution and reporting). In addition, technical skills of the existing officials are constrained, thereby making it difficult for the effective, efficient and timely implementation of MEF's recommendations. This capacity constraint is compounded with the frequent staff turnover due to high staff mobility. This situation has required MEF, with its Provincial Directorates, to implement training sessions at all levels for each budgetary cycle.

Another constraint is related to the lack of sound mechanisms of interaction between the budget planning officers and the budget execution officers, which prevents the planning officers from knowing the extent of budget execution to cover expenses of the planned activities. This limitation is exacerbated by the lack of standardized monitoring and evaluation mechanisms, which can guide data collection, analysis and reporting at all levels. The existing monitoring and evaluation mechanisms vary among the involved institutions at all levels, which generates inconsistent and variable results. Moreover, the existing mechanisms are not integrated among institutions and therefore each institution plans individually with its respective departments and other lower level layers. Also, the planning officers report the level of achievement of planned activities and the accomplishment of envisioned targets, while the finance officers report on budget execution without a synchronization aiming to assess the value for money (i.e. the level of accomplishment of the targets taking into account the respective expenditures). Finally, during the planning process there is no effective inclusion of actions/funding (e.g., off-budget) carried out by government institutions, mainly development partners, NGOs and private sector, which limits the completeness of the execution and expenditure reports. This is mainly due to limited interaction between the government institutions and these other stakeholder institutions.

Taking into account the above constraints, it is recommended that priority should be given to the training of the budget planning and implementation officers, mainly on the interpretation and application of the MEF recommendations related to enhanced budget management as well as in the monitoring and evaluation (data collection, analysis and reporting). Special efforts should be placed in the establishment and strengthening of effective monitoring and evaluation systems at all levels (national and subnational) and institutions in order to better assess the value of money through inclusion of relevant efficiency and effectiveness indicators. The summary of emerging issues and the respective recommendation are presented in the next section. 


\subsection{Summary of Emerging Issues and Priority Recommendations}

Taking into account the above findings, the study team recommends the following priority actions to enhance the budgetary cycle, with a stronger expenditure results-orientation:

a) Planning Phase:

- Request MEF (at National and Provincial levels) to issue the call for budget proposals (medium and annual) with adequate time for technical preparation and for consultations with stakeholders, and with 3 scenarios (high, medium and low), varying according to resource availabilities and Government priorities;

- Request MEF and strengthened sectoral Ministries (at National and Provincial levels) to introduce (in the call for budget) and apply consistently sound planning tools (e.g., updated results framework, efficiency, effectiveness and value for money measures), and explicit prioritization criteria; the following 4 prioritization framework is recommended (drawing on good practices, using simple weighting system for applying the criteria in the budgetary planning phase) ${ }^{23}$ (and to be applied for on-budget and off-budget sources of funding to ensure consistency of priorities):

- Strength of alignment with relevant PQG and sector objective and targets with respect to the agriculture sector;

- Contribution to inclusive sources of agricultural growth and poverty reduction, especially with respect to increased crop yields and value chain development, production climate change resilience, and consistent with "public" goods and services (to ensure appropriate roles);

- Contribution to "catalyzing" expanded inclusive private sector investments;

- Demonstrated evidence of good institutional performance and governance (including functional M\&E systems);

- Sectoral Ministries to ensure the final budgetary ceiling issued by MEF is used as the guide for the proposed allocations, based on the application of enhanced prioritization criteria, and adequate stakeholder consultation processes;

- Strengthening the planning capacities and performance at national and subnational levels, evidenced with better quality plans and results;

- Government to ensure the establishment and effective functioning of improved coordination mechanisms and processes for the agricultural sector (e.g., the proposed re-activation of the Coordination Committee for the Agricultural Sector/CCSA) to review and adjust the proposed budgetary allocations of the relevant institutions (national and subnational levels), from the perspective of ensuring strong complementarity between institutions, with respect to achieving agricultural sector objectives and targets;

b) Implementation Phase:

23

These criteria are consistent with findings and recommendations from the Rural Income Diagnostics Study. 
- Ensure the effective functioning of the enhanced CCSA, coupled with the required technical support (e.g. Technical Secretariat for the Agrarian Sector), supported by periodic meetings and ensuring timely implementation of the agreed actions;

- Streamline procurement and financial management processes to ensure a strengthened Government procurement system is functional at national and subnational levels, and that development partner procurement requirements are aligned with the Government systems at national and subnational levels; in the interim, to ensure adequate technical support is being provided to the implementing agencies;

c) M\&E:

- Ensure the effective functioning and strengthening of the M\&E systems at the National, subnational and sectoral levels (especially the 5 sectoral institutions comprising the CCSA), developing and using the relevant performance indicators for promoting enhanced efficiencies, effectiveness and value-for money, to support effective and timely implementation and enhanced coordination of prioritized public expenditures (including midyear adjustments and rolling 3-year plans), and to ensure appropriate support for ensuring expanded and inclusive private sector for promoting agricultural development, consistent with appropriate roles between public and private sectors;

- Ensure recommended improvements in the quality and reliability of expenditure data for the e-SISTAFE expenditure data base;

- Ensuring the relevant findings of the M\&E systems are utilized as strategic inputs for the planning cycle (rolling 3-year and annual plans) for and by the relevant ministries/directorates for the agricultural sector, at national and subnational levels; and

- Identify relevant strategic studies to be carried out which assess strategic expenditure issues (e.g. subsidies in the agricultural sector; effectiveness of the agricultural technology systems, others arising from the M\&E studies). 


\section{Trends, composition and performance of agricultural public expenditure}

\subsection{Macro Fiscal Structure of Government Budget Allocations}

Table 4.1 presents proportions of the total government budget allocated to specified functions based on the Classification of the Functions of the Government (COFOG). This table shows that the structure of the government budget allocation is erratic, with shares of all functions fluctuating across years during the period 2013 -2017. Economic affairs with $26 \%$, defense with $13 \%$, education with $12 \%$ and health with $11 \%$ are among the government functions with the highest average shares of the budget allocation during this period. ${ }^{24}$ The "Agricultural sector" - comprising of crops, livestock, forestry, and fisheries, and also including complementary services and apportionment of other relevant crosscutting expenditure whose main purpose is to directly promote agricultural growth and contribute to poverty reduction - ranks consistently fifth in terms of share of government budget allocations ${ }^{25}$ receiving, on average, $6 \%$ of the total government budget over the period 2013 to 2017.

Table 4.1 Structure of government budget allocation

\begin{tabular}{|c|c|c|c|c|c|c|}
\hline \multirow[b]{2}{*}{ Function } & \multicolumn{5}{|l|}{ Year } & \multirow[b]{2}{*}{ Total } \\
\hline & 2013 & 2014 & 2015 & 2016 & 2017 & \\
\hline Defense & $10.5 \%$ & $18.0 \%$ & $12.1 \%$ & $9.7 \%$ & $14.3 \%$ & $12.9 \%$ \\
\hline Economic affairs & $27.4 \%$ & $26.9 \%$ & $23.8 \%$ & $26.0 \%$ & $26.3 \%$ & $26.1 \%$ \\
\hline Agriculture & $6.5 \%$ & $6.8 \%$ & $7.3 \%$ & $5.1 \%$ & $6.5 \%$ & $6.4 \%$ \\
\hline Health & $13.0 \%$ & $8.2 \%$ & $10.5 \%$ & $9.1 \%$ & $10.9 \%$ & $10.2 \%$ \\
\hline Education & $12.7 \%$ & $11.4 \%$ & $12.9 \%$ & $10.3 \%$ & $11.4 \%$ & $11.6 \%$ \\
\hline Social protection & $1.6 \%$ & $1.9 \%$ & $2.6 \%$ & $1.8 \%$ & $2.5 \%$ & $2.1 \%$ \\
\hline Other & $28.3 \%$ & $26.9 \%$ & $30.8 \%$ & $38.1 \%$ & $28.1 \%$ & $30.7 \%$ \\
\hline Total & $100.0 \%$ & $100.0 \%$ & $100.0 \%$ & $100.0 \%$ & $100.0 \%$ & $100.0 \%$ \\
\hline
\end{tabular}

Source: e-SISTAFE

This finding suggests that the agricultural sector was significantly underfunded during the period 2013 -2017 , given that the agrarian sector: (a) contributes $23 \%$ of GDP, and when considering the indirect contributions, through agricultural and related agro-based activities and services, the broader agricultural sector probably contributes closer to $50 \%$ of GDP; and (b) has the highest poverty elasticity compared with any other sector of the economy ${ }^{26}$. These trends suggest a relatively higher impact on poverty reduction from agricultural productivity gains by smallholders if spending on the sector is translated into effective and efficient delivery of services and goods, aimed at strengthening agricultural productivity and inclusive and competitive value-chain development. Furthermore, the

\footnotetext{
${ }^{24}$ According to COFOG, economic affairs also encompass agriculture; however, the study team separated agriculture from economic affairs to illustrate the agriculture share in the total government budget allocation.

${ }^{25}$ As mentioned earlier, relevant ministries which have agriculture-related functions include MASA, MITADER, MIC, MOPHRH and MIMAIP. When a new president came into office in January 2015, the then Ministry of Agriculture (MINAG) was split to form MASA and MITADER. The newly formed MITADER also assumed all functions of the then Ministry for Coordination of Environmental Affairs (MICOA) which was dissolved in 2015. Hereinafter, public budget allocated to MITADER and MITADER actual expenditure between 2013 and 2014 come from MICOA.
}

${ }^{26}$ Refer to the Rural Income Diagnostics Study for Mozambique (World Bank, 2019). 
benefits of agricultural productivity gains stemming from effective and efficient expenditure in the agricultural sector could reach a higher number of households given that about $70 \%$ of Mozambique's population live in rural areas, of which about $80 \%$ have agriculture as their main livelihood. Furthermore, anecdotal evidence suggests that the agricultural sector receives a relatively lower share of the total government budget allocation because the sector is characterized by low productivity, and also perceived to perform poorly. This suggests a perception (by MEF) that spending on agriculture might not be effectively and efficiently translated into the delivery of efficient services and goods that will improve agricultural productivity, and lead to higher return for scarce public resources. Moreover, supporting the effective generation, dissemination and adoption of appropriate climate-smart technologies by Mozambican smallholders can also enhance the expenditure supply and poverty reduction elasticities, in line with other country experiences. Therefore, it is vital to demonstrate that public funding for improved agricultural technologies will be translated into improved agricultural productivity.

Decentralization Trends and Challenges. Mozambique has introduced a number of changes in terms of decentralization since 1992. The Local Government Act (LOLE) was approved in 2003 and more recently the Decentralization Policy and Strategy (PED) was approved by the Council of Ministers in 2012. ${ }^{27}$ Decentralization could be more effective in contributing to poverty reduction by enhancing local ownership because resources are allocated to local governments giving them more control and accountability over how they are prioritized and used to address local priorities of constituencies. On the other hand, decentralization presents challenge in terms of better alignment between central government (ministries) and sub-national government (provincial directorates and district services), and the institutional capacity in sub-national government to use the allocated resources in a more effective and efficient manner, while recognizing there is an absence of a strong civil society to help ensure transparency and accountability of allocations and expenditures.

Figure 4.1 shows the distribution of the State Budget between central and provincial government entities. Provincial government share of the total government budget allocation increased from $26 \%$ in 2013 to $37 \%$ in 2016 but then fell to $23 \%$ in 2017. These erratic trends show that Mozambique is still in transition to devolution and deconcentration, which could negatively influence the efficiency and effectiveness with which relevant services are delivered to sustainably increase agricultural productivity. This transitional phase of decentralization could also promote lack of accountability between central and provincial government entities because the decentralization guidelines do not outline a clear division of operational and functional responsibilities between central and provincial government entities.

\footnotetext{
${ }^{27}$ Maschietto (2016) documents that there exists two types of decentralization: Devolution representing the transfer of power and resources to democratically elected sub-national authorities, and deconcentration, denoting the transfer of authorities to sub-national branches of the central government. Mozambique has experienced both devolution of political power to municipalities (currently Mozambique has 53 municipalities) and deconcentration of administrative responsibilities to the provinces and districts. This year, the government has a new law proposal (still to be submitted to Parliament for approval) under which provincial governors will be chosen from the head of the winning party or group of people for the provincial parliament elections, but nominated by the country president, and the administrative responsibilities of the provincial governors will also change.
} 


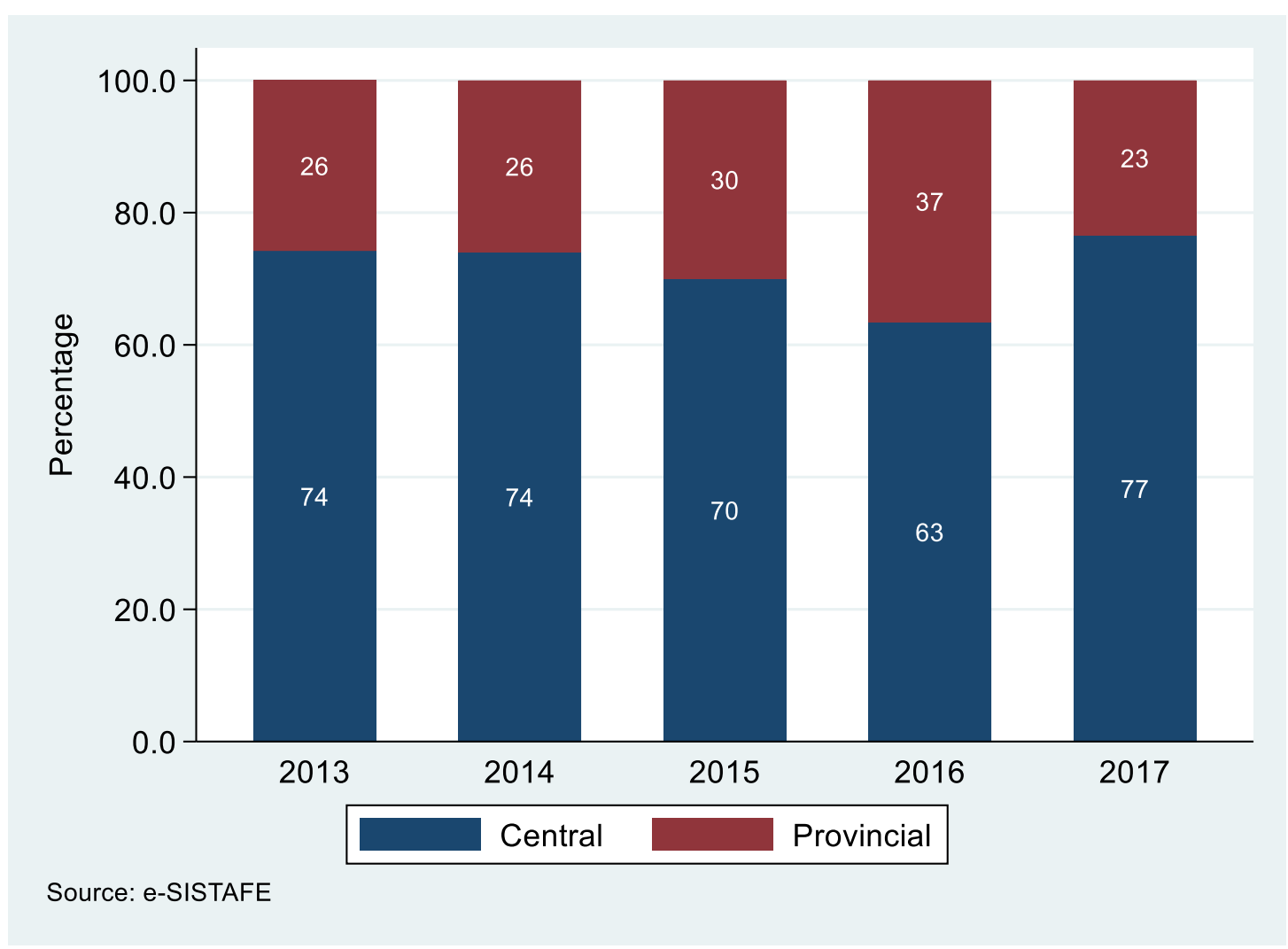

Figure 4.1 Central and provincial government shares in total government budget allocation

\subsection{Level and Trend of Agricultural Public Expenditure}

\subsubsection{Budget Allocation to Agriculture}

Table 4.2 summarizes government budget allocations to the "agriculture sector" by relevant ministries between 2013 and 2017. Government budget allocation should be a reflection of policy priorities as well as political commitments and agreements/compromises. Table 4.2 shows that government budget allocation to agriculture increased in real terms from 8.5 billion MZN in 2013 to 10.8 billion MZN in 2014. Since 2014, the expenditure trends have been downward falling to 6.9 billion MZN in 2017, equivalent to a $36 \%$ decline. Similar patterns are observed in all relevant ministries except MITADER. Contrary to other relevant ministries that experienced budgetary reductions, the government budget allocated to MITADER increased in real terms from 436 million MZN in 2013 to 1.5 billion MZN in 2017, an increase of 239\%. At an aggregate level, the annual government budget allocated to the agriculture sector dropped in real terms from an average of 9.6 billion MZN between 2013 and 2014 to 8.1 billion MZN between 2015 and 2017, representing a decline of 16\%. This decline in the government budget allocation to agriculture coincides with the withdrawal by Development Partners from direct budget support initiated in 2015 after revelations of hidden debts which triggered a significant economic downturn. 
Table 4.2 Government budget allocation to agriculture by ministry (million MZN)

\begin{tabular}{|c|c|c|c|c|c|c|}
\hline \multirow[b]{2}{*}{ Year } & \multicolumn{5}{|c|}{ Ministry } & \multirow[b]{2}{*}{ Total } \\
\hline & MASA & MITADER & MIC & MOPHRH & MIMAIP & \\
\hline & Nomina & & & & & \\
\hline 2013 & 4,995 & 436 & 395 & 3,155 & 1,391 & 10,372 \\
\hline 2014 & 6,060 & 382 & 564 & 5,020 & 1,482 & 13,510 \\
\hline 2015 & 5,946 & 548 & 495 & 3,758 & 1,778 & 12,526 \\
\hline 2016 & 5,746 & 623 & 365 & 2,721 & 1,799 & 11,254 \\
\hline 2017 & 5,422 & 1,479 & 429 & 2,149 & 1,999 & 11,479 \\
\hline \multirow[t]{2}{*}{ Average } & 5,634 & 694 & 450 & 3,361 & 1,690 & 11,828 \\
\hline & \multicolumn{5}{|c|}{ Real $(2009=100)$} & \\
\hline 2013 & 4,082 & 356 & 323 & 2,578 & 1,137 & 8,477 \\
\hline 2014 & 4,826 & 305 & 449 & 3,998 & 1,180 & 10,758 \\
\hline 2015 & 4,536 & 418 & 378 & 2,867 & 1,356 & 9,556 \\
\hline 2016 & 3,917 & 425 & 249 & 1,855 & 1,226 & 7,671 \\
\hline 2017 & 3,275 & 893 & 259 & 1,298 & 1,208 & 6,933 \\
\hline Average & 4,127 & 479 & 332 & 2,519 & 1,222 & 8,679 \\
\hline
\end{tabular}

Source: e-SISTAFE

Government budget allocation to the agricultural sector varies among relevant ministries, with MASA taking the largest share. Between 2013 and 2017, annual budget allocations to the agricultural sector in real terms averaged 8.7 billion MZM of which, $48 \%$ went to MASA, $29 \%$ to MOPHRH, and $14 \%$ to MIMAIP. The MIC and MITADER accounted individually for less than $6 \%$ of average annual government budget allocated to agriculture during the same period.

The total government budget allocated to the agricultural sector increased from $6.5 \%$ in 2013 to $7.3 \%$ in 2015 , declined by $5.1 \%$ in 2016 before increasing by $6.5 \%$ in 2017 . The sizable decline registered from 2015 and 2016 could be associated with two factors. First, as mentioned, DPs withdrew direct support to the State Budget in 2015. Second, the new government five-year program (PQG) launched in 2015 set new government priorities and gave higher priority to other key sectors. Table shows that the share of the total government budget allocated to the agricultural sector averaged $6.4 \%$ over the period 2013 to 2017. This share reflects the above trends where there are other sectors which received a higher share of total government expenditures.

Although government budget allocations reflect government's intentions as well as priorities, the Ministry of Economy and Finance (MEF) does not release the full approved budget allocations due to at least two factors. First, shortfalls in the revenue collected in comparison to that which was projected at the time of budget formulation. Second, delays in disbursement of committed funds by DPs also constraint MEF's capacity to disburse funds according to approved budget allocations. These two factors usually lead to delays in the disbursement of funds to relevant ministries to the last quarter of the year. ${ }^{28}$ Furthermore, the capacity of the relevant ministries' in terms of financial execution coupled

28 It is worth pointing out that MEF has improved revenue collection in the recent years. Data from National Accounts (CGE) show collected revenue rose in nominal terms from 190.6 billion MZN in 2013 to 226.5 billion MZN in 2016, representing an increase of $19 \%$. However, revenues collected in 2013 are comparable in real terms to that collected in 2016 (155.7 billion MZN versus 154.4 billion MZN), but it is worth noting that collected revenue increased in real terms from 155.7 billion in 2013 to 190.4 billion MZN in 2014; and then it dropped to 154.4 billion MZN in 2016. Data from CGE 
with cumbersome procurement procedures for goods and services, budget accounting, reporting and auditing procedures, lead to shortfalls between approved budget allocation and actual expenditure. Actual expenditure, rather than budget allocations, in terms of both quantity and more importantly quality, and timing could be translated into actions on the ground to deliver goods and services aimed at strengthening performance of the agricultural sector.

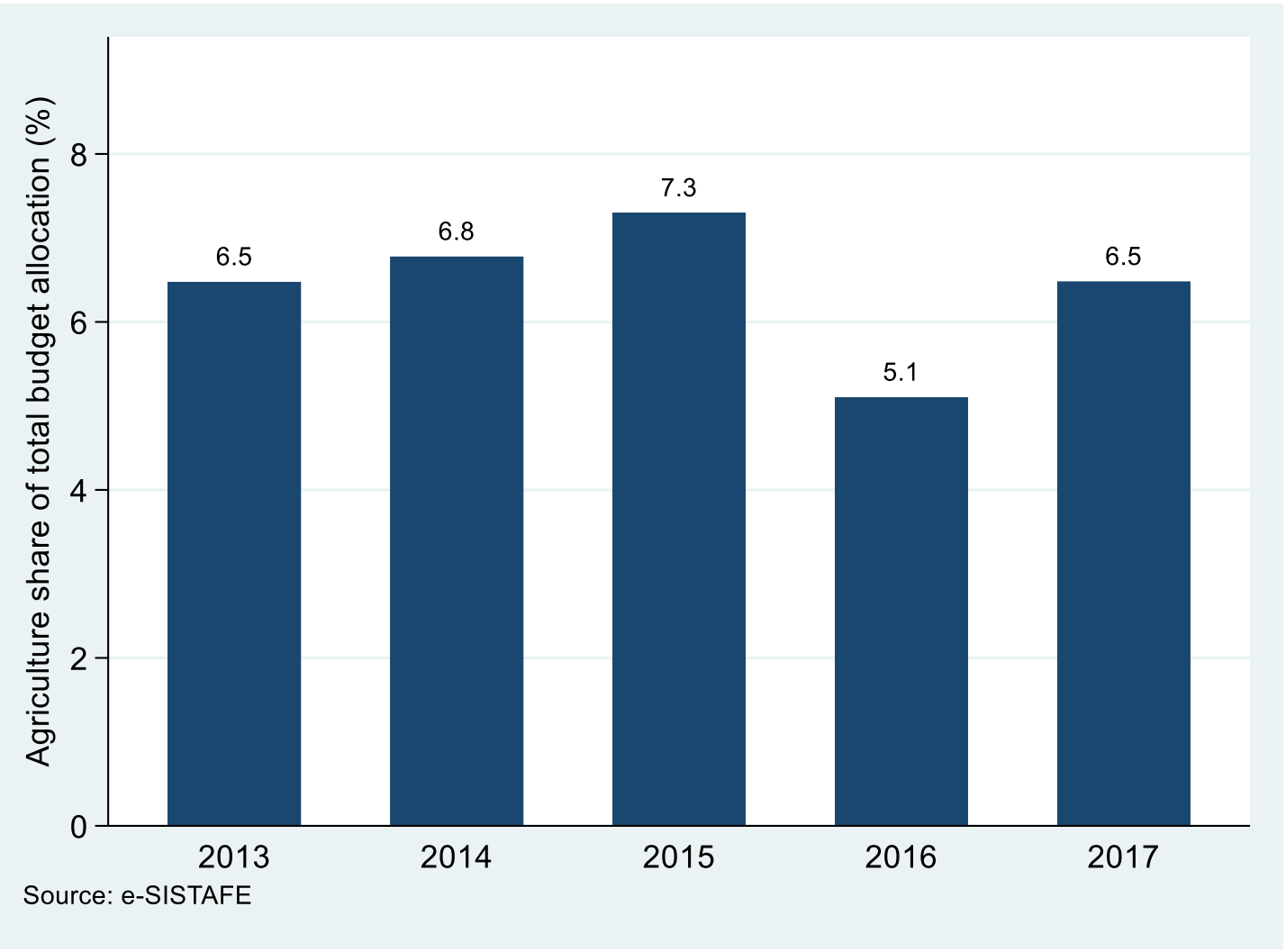

Figure 4.2 Share of total government budget allocated to the agricultural sector

\subsubsection{Actual Expenditure in Agriculture}

Table 4.3 summarizes actual government expenditure in agriculture by ministry. This table illustrates that actual public expenditure in agriculture fluctuated significantly and without a clear trend between 2013 and 2017. Actual spending in agriculture rose in real terms from 7.2 billion MZN in 2013 to 9.1 billion MZN in 2014 followed by a reduction of 52\%, falling to 4.4 billion MZN in 2016 and an increase of $24 \%$, rising to 5.4 million MZN in 2017. Like budget allocation, actual public expenditure in agriculture in real terms declined on average from 8.1 billion MZN during the period 2013-2014 to 5.8 billion MZN during the period 2015-2017, representing a 28\% decline. Levels and trends of actual expenditure vary among ministries. For instance, between 2014 and 2017, real actual expenditure for MITADER trended upward. On the contrary, real expenditure for MIC declined and for MASA showed no clear trend. Over the period 2013-2017, government spend in real terms averaged 6.8 billion MZN per year, of which MASA accounted for $48 \%$, MOPHRH for $31 \%$, MIMAIP for $12 \%$, MITADER for $5 \%$

indicate that collected revenue as a share of projected revenue averaged $94 \%$ for internal sources of funding and $89 \%$ for external sources. 
and MIC for $4 \%$. This ranking of relevant ministries based on actual spending is consistent with that based on budget allocation (see Table 4.2).

Table 4.3Actual public expenditure in agriculture by ministry (million MZN)

\begin{tabular}{|c|c|c|c|c|c|c|}
\hline \multirow[b]{2}{*}{ Year } & \multicolumn{5}{|l|}{ Ministry } & \multirow[b]{2}{*}{ Total } \\
\hline & MASA & MITADER & MIC & MOPHRH & MIMAIP & \\
\hline & Nominal & & & & & \\
\hline 2013 & 4,099 & 293 & 371 & 3,013 & 1,006 & 8,783 \\
\hline 2014 & 4,752 & 303 & 483 & 4,668 & 1,239 & 11,445 \\
\hline 2015 & 5,219 & 397 & 379 & 2,976 & 1,126 & 10,096 \\
\hline 2016 & 3,518 & 481 & 327 & 972 & 1,103 & 6,402 \\
\hline 2017 & 4,241 & 1,042 & 324 & 2,110 & 1,257 & 8,974 \\
\hline \multirow[t]{2}{*}{ Average } & 4,366 & 503 & 377 & 2,748 & 1,146 & 9,140 \\
\hline & Real $(20 c$ & & & & & \\
\hline 2013 & 3,350 & 239 & 303 & 2,463 & 822 & 7,178 \\
\hline 2014 & 3,784 & 241 & 385 & 3,717 & 987 & 9,114 \\
\hline 2015 & 3,982 & 303 & 289 & 2,270 & 859 & 7,702 \\
\hline 2016 & 2,398 & 328 & 223 & 663 & 752 & 4,364 \\
\hline 2017 & 2,561 & 629 & 196 & 1,275 & 759 & 5,420 \\
\hline Average & 3,215 & 348 & 279 & 2,077 & 836 & 6,756 \\
\hline
\end{tabular}

Source: e-SISTAFE

To enable African countries to achieve a $6 \%$ annual growth in agricultural GDP, African Heads of State committed (in 2003) to allocate at least $10 \%$ of total government budgetary resources to the agriculture sector by 2008 and thereafter. This commitment is referred to as the "MAPUTO Declaration". Partly due to poor performance of most African countries in meeting this expenditure target, and to re-emphasize the importance of the agricultural sector and the CAADP, in 2014 the Heads of State formally re-affirmed their commitment to meeting the $10 \%$ expenditure target (and was known as the "MALABO Declaration"). The MALABO Declaration also emphasized the importance of ensuring good quality of public expenditure in agriculture, and the gathering of empirical evidence to track the quality of expenditure. Figure 4.3 shows share of total public spending (on- and offbudget) going to agriculture between 2013 and 2017. This figure illustrates that the share of total government expenditure on the agricultural sector (on-budget) experienced an upward trend between 2013 and 2015, rising from 6.0\% in 2013 to 6.7\% in 2015. It then sharply fell by about 50\% reaching $3.6 \%$ in 2016 , followed by a sizable increase of about $65 \%$ reaching $5.7 \%$ in 2017 . This pattern is similar to that of the agriculture share of total government budget allocations shown in Figure 4.2. Over the period 2013 to 2017 , the agricultural sector accounted on average for $5.7 \%$ of the total government actual expenditure (on-budget) and $6.4 \%$ of the total government budget allocations. These findings reveal that Mozambique fell significantly below the MAPUTO/MALABO Declaration target of allocating at least $10 \%$ of the total government expenditure to the agricultural sector. Even with the inclusion of off-budget expenditures, the share of expenditure for the agricultural sector are still well below the $10 \%$ expenditure target as illustrated in Figure 4.3 . 


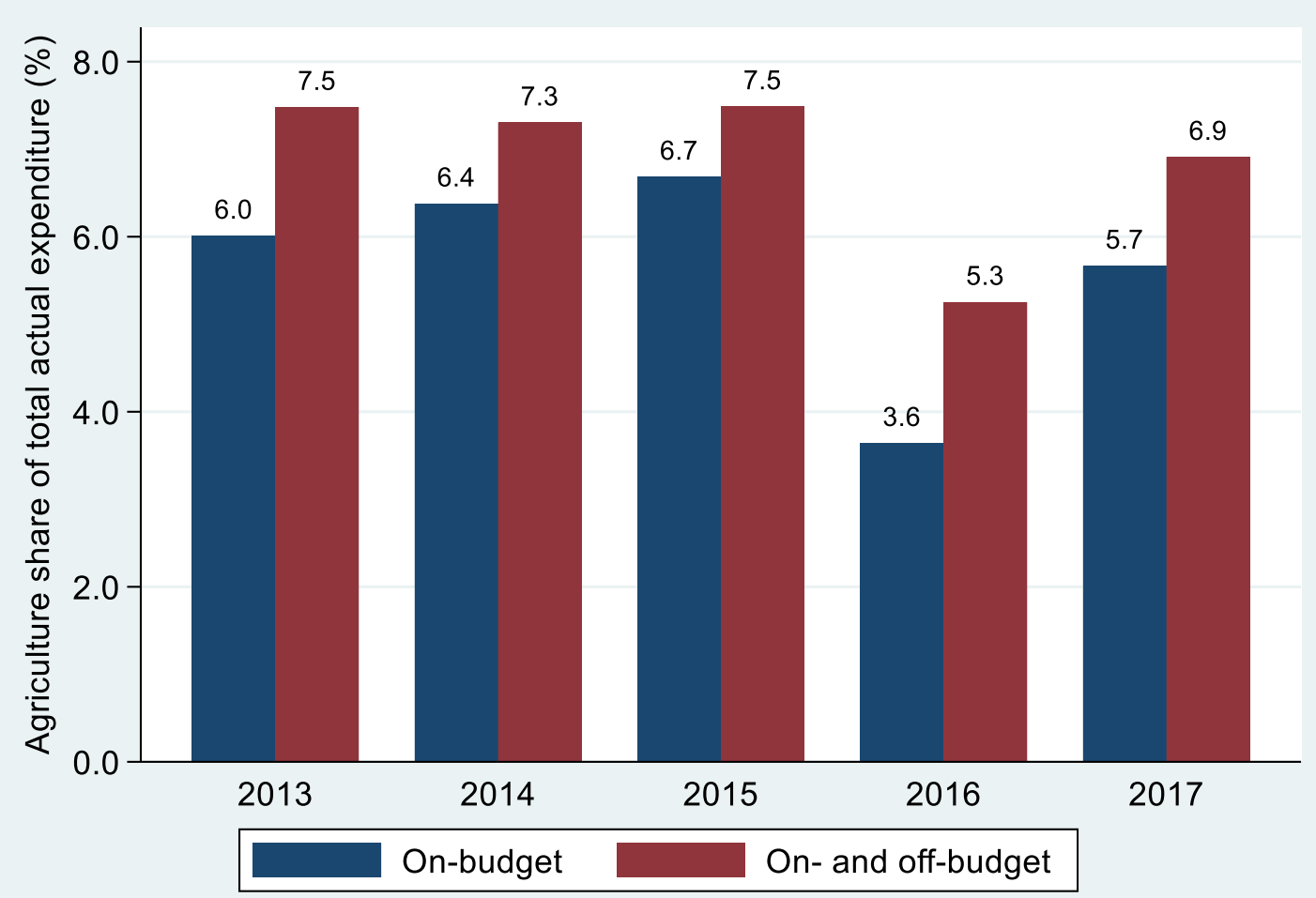

Source: e-SISTAFE and ODAMOZ

Figure 4.3Share of total government actual expenditure accounted for by agriculture

However, as argued by Mogues et al. (2008), allocating $10 \%$ of total government expenditure to agriculture may be appropriate in a country where agriculture accounts for $10 \%$ of the country's economy, but it is unlikely to be appropriate in a country where agriculture makes up about $60 \%$ of economy, and about $70 \%$ of the labor force. To evaluate the adequacy of the magnitude of public spending on agriculture relative to the importance of the sector in the economy, many empirical studies compare the share of total government actual expenditure going to agriculture with the public expenditure in agriculture as a share of agricultural GDP (AgGDP). This comparison is illustrated in Figure 4.4 below. This figure shows that expenditure in agriculture as a proportion of total government expenditure and as a proportion of AgGDP basically follow similar trends, but with different magnitudes over the period 2013 through 2017. In all years, except 2017, over the same period, the share of public spending on agriculture in AgGDP is greater than the share of total government expenditure accounted for by the agricultural sector. On the other hand, the average share of GDP accounted for by agriculture sector is greater than the average share of total government expenditure going to agriculture over the period 2013 to 2017 (23.0\% versus 6\%).These findings suggest that the proportion of total government expenditure going to agriculture should be increased to approximate the relative importance of the sector in the economy, and certainly, warrants at least $10 \%$ of total public expenditure. It is noted that despite the fact that the share of GDP accounted for by agriculture slightly trended downward, falling from $24.2 \%$ in 2013 to $22.5 \%$ in 2017, the agriculture sector still ranks first in terms of contribution to GDP, especially when considering the indirect linkages with other sectors of the economy. This feature underscores the importance of the agriculture sector in the economy. Furthermore, about $70 \%$ of the population live in rural areas, predominantly depending on agriculture for livelihood and employment. These comparisons are illustrated in Figure 4.4. 


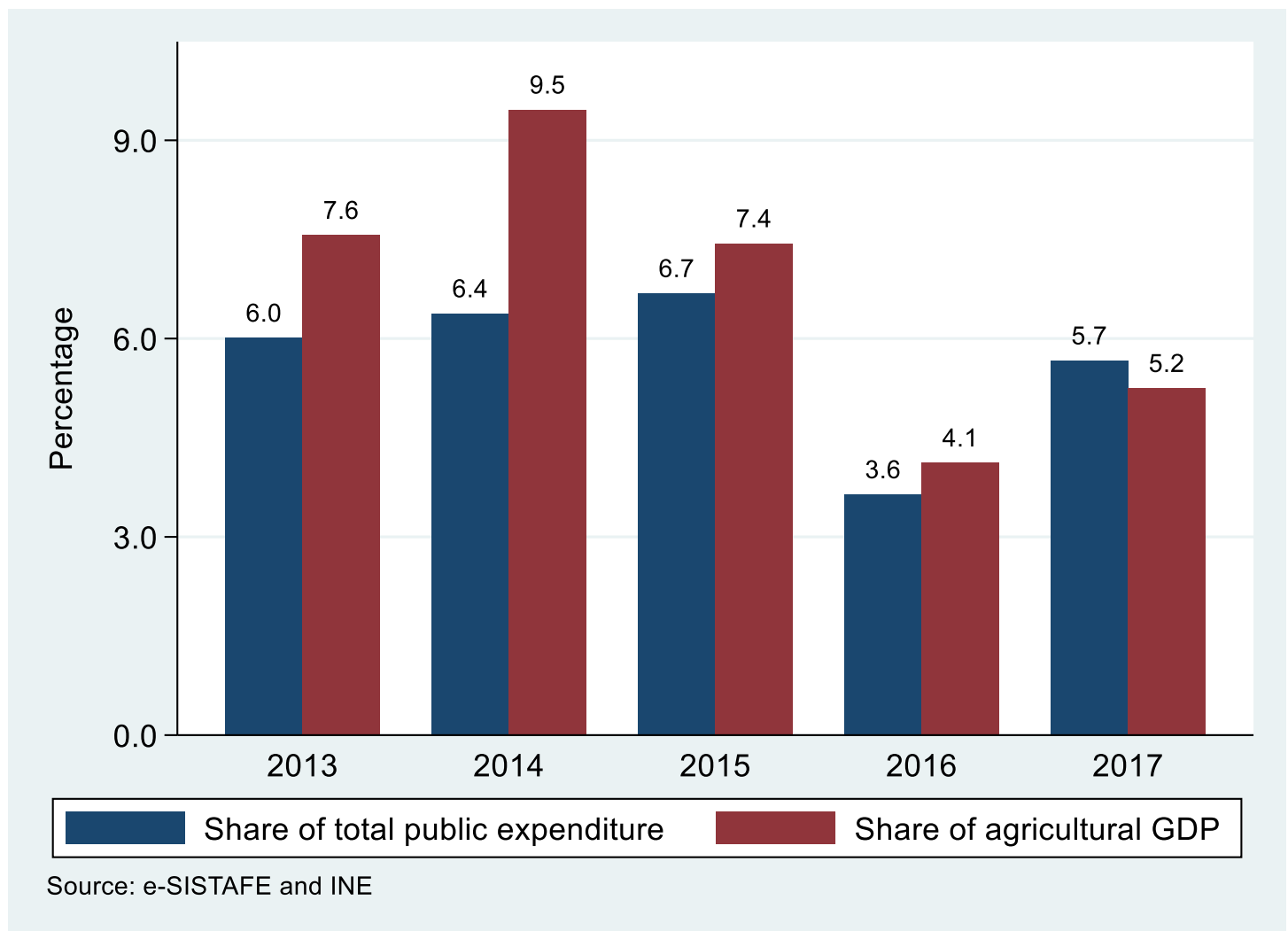

Figure 4.4 Expenditure on agriculture as share of total governement expenditure and of agricultural GDP

\subsection{Composition of Agricultural Public Expenditure}

Composition of agricultural public expenditure matters as much as the amount actually spent. Expenditure on different functions can result in very different outcomes in terms of both performance of the agricultural sector and ultimately impact on households' welfare.

Consistent with international good practices, public expenditure in agriculture is classified in four different ways: a) economic classification; b) source of funding; c) administrative level; and d) PNISA result area and program. Given that these four classification systems provide relevant insights into the efficiency and effectiveness of public expenditure in the agricultural sector, findings emerging from these classification systems will generate relevant recommendations that together would contribute to enhanced composition and quality (and consequently results) of expenditure in agriculture.

Recurrent/Capital Expenditures. Table 4.4 provides breakdown of actual expenditure in recurrent and investment based on the economic classification used in the National Accounts (e-SISTAFE). This economic classification should be interpreted with caution because in a non-negligible fashion, some recurrent expenditure was classified as investment expenditure, and vice-versa. For instance, during the period 2013 to 2017, 25\% of the total amount of salaries and remunerations, amounting to 2.2 billion MZN paid in the agricultural sector, were classified as "investment" expenditure.

\subsubsection{Actual Expenditure in Agriculture by Economic Classification}

Table 4.4 shows that recurrent expenditure in agriculture in real terms trended upward between 2013 and 2015, jumping from 1.4 billion MZN in 2013 to 1.8 billion MZN in 2015. Since then, it moved downward, falling to 1.5 billion MZN in 2016 and 1.2 billion MZN in 2017. On the other hand, after 
registering an increase from 5.7 billion MZN in 2013 to 7.4 billion MZN in 2014, investment expenditure experienced a sharp decline of $62 \%$, dropping to 2.5 billion MZN in 2016. It then rose to 4.2 billion MZN in 2017.

Table 4.4Recurrent and capital expenditure in the agriculture (real million MZN, $2009=$ 100)

\begin{tabular}{|c|c|c|c|c|c|c|}
\hline \multirow[b]{2}{*}{ Expenditure type } & \multicolumn{5}{|c|}{ Ministry } & \multirow[b]{2}{*}{ Total } \\
\hline & MASA & MITADER & MIC & MOPHRH & MIMAIP & \\
\hline \multicolumn{7}{|l|}{2013} \\
\hline Recurrent & 871 & 104 & 149 & & 324 & 1,447 \\
\hline Investment & 2,480 & 135 & 154 & 2,463 & 499 & 5,731 \\
\hline Total & 3,350 & 239 & 303 & 2,463 & 822 & 7,178 \\
\hline \multicolumn{7}{|l|}{2014} \\
\hline Recurrent & 1,042 & 116 & 171 & & 361 & 1,690 \\
\hline Investment & 2,742 & 125 & 214 & 3,717 & 626 & 7,424 \\
\hline Total & 3,784 & 241 & 385 & 3,717 & 987 & 9,114 \\
\hline \multicolumn{7}{|l|}{2015} \\
\hline Recurrent & 1,151 & 119 & 169 & & 356 & 1,796 \\
\hline Investment & 2,830 & 184 & 120 & 2,270 & 503 & 5,906 \\
\hline Total & 3,982 & 303 & 289 & 2,270 & 859 & 7,702 \\
\hline \multicolumn{7}{|l|}{2016} \\
\hline Recurrent & 907 & 158 & 155 & & 321 & 1,540 \\
\hline Investment & 1,492 & 170 & 68 & 663 & 431 & 2,824 \\
\hline Total & 2,398 & 328 & 223 & 663 & 752 & 4,364 \\
\hline \multicolumn{7}{|l|}{2017} \\
\hline Recurrent & 665 & 162 & 137 & & 253 & 1,217 \\
\hline Investment & 1,897 & 467 & 58 & 1,275 & 506 & 4,203 \\
\hline Total & 2,561 & 629 & 196 & 1,275 & 759 & 5,420 \\
\hline \multicolumn{7}{|l|}{ Average } \\
\hline Recurrent & 927 & 132 & 156 & & 323 & 1,538 \\
\hline Investment & 2,288 & 216 & 123 & 2,077 & 513 & 5,218 \\
\hline Total & 3,215 & 348 & 279 & 2,077 & 836 & 6,756 \\
\hline
\end{tabular}

Source: e-SISTAFE

Recurrent expenditure averaged 1.5 billion MZN and investment expenditure averaged 5.2 billion MZN between 2013 and 2017. Over this same period, the share of total expenditure in agriculture accounted for by investment expenditure ranged from $65 \%$ in 2015 to $81 \%$ in 2014, with an average of $76 \%$. However, the magnitude of the proportion of investment expenditure in total expenditure in agriculture varies among relevant ministries (see Figure 4.5). This figure shows that the share of total expenditure in agriculture made up by investment expenditure varied from $30 \%$ in 2017 to $56 \%$ in 2014 in the case of MIC and from 62\% in 2016 to 74\% in 2017 in the case of MASA. Figure 4.5 also indicates that in all ministries, except MIC, the share of total expenditure in agriculture going to investment expenditure fluctuates from year to year. MIC is the only ministry in which the proportion of spending on agriculture in total spending on agriculture experienced a clear downward trend over time falling from $51 \%$ in 2013 to $30 \%$ in 2017 . The relatively high allocation of expenditure for recurrent expenditure reflects the tendency for development partners to include significant amounts of funding to support vital recurrent expenditures, but which are misclassified as capital expenditures. 
Future allocations from development partners should endeavor to show a more appropriate classification of expenditure in terms of recurrent vis-à-vis investment expenditures.

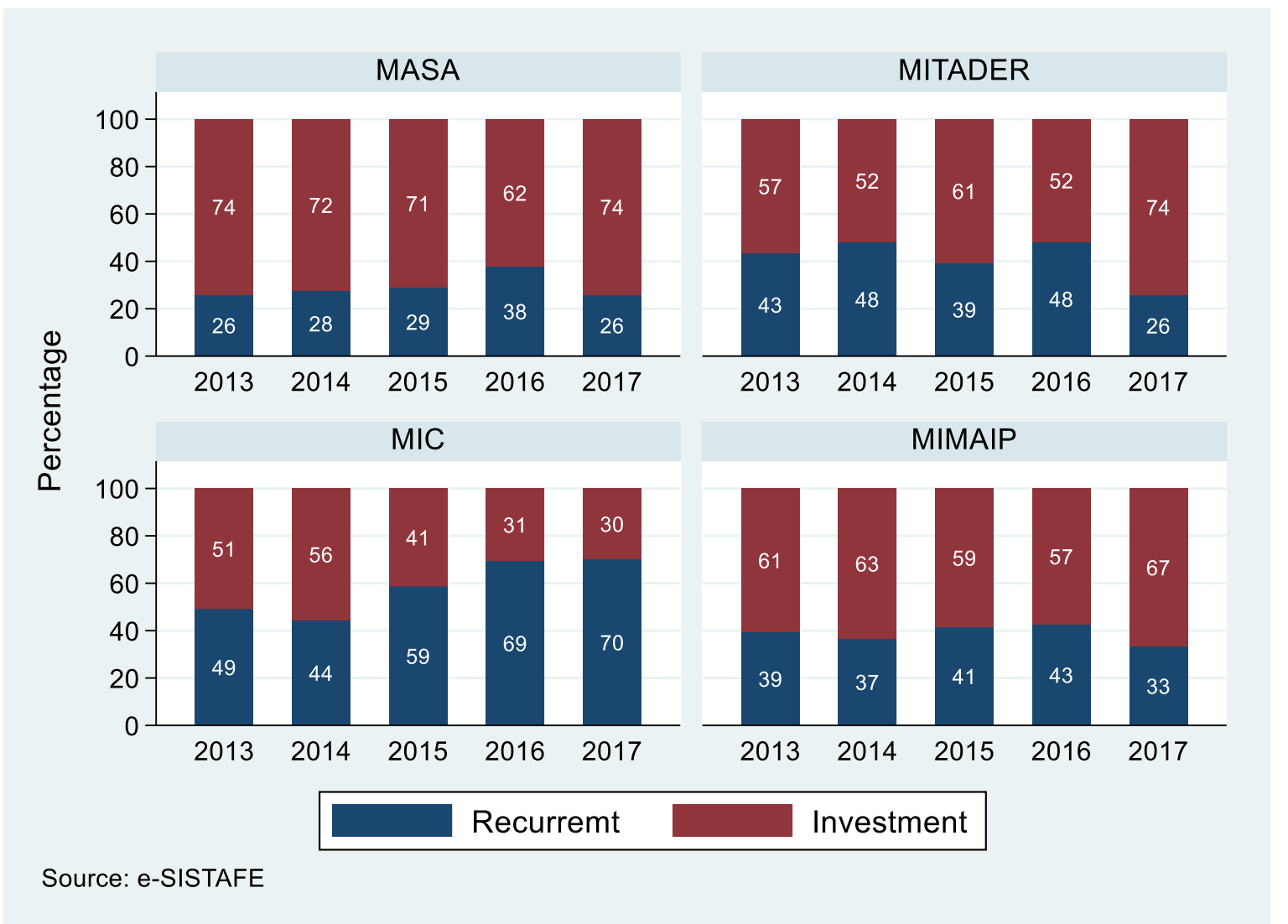

Figure 4.5 Recurrent and investment expenditure as share of total expenditure by ministry

Table 4.5 breaks down total expenditure in agriculture into wage and non-wage expenditure by ministry. This table shows that wage expenditure in agriculture experienced an upward trend in real terms from 1.2 billion MZN in 2013 to 1.5 billion MZN in 2015, representing a 22\% increase. This was followed by a downward trend, falling to 1.3 billion in 2017. Average wage expenditure in agriculture was in real terms higher during the period 2013 to 2015 than during the period 2016 to 2017 (1.4 billion MZN per year versus 1.3 billion MZN per year). This lower average wage expenditure in the last two years under analysis could be a reflection of decreased real wages compared with the period 2013-2015. Over the period 2013 to 2017, wage expenditure in agriculture averaged in real terms 1.3 billion MZN compared with an average of 5.4 for non-wage expenditure. This suggests that wage expenditure contributed on average to $21 \%$ of total public expenditure in agriculture; ranging from $15 \%$ in 2014 to $30 \%$ in 2016. Our findings indicate that the share of wage expenditure out of total expenditure in agriculture varies among ministries. Excluding MOPHRH in which wage accounts for less than one percent of total expenditure in agriculture between 2013 and 2017, MIC (45\%) and MITADER (38\%) are among the ministries with largest average wage share, while MIMAIP (35\%) and MASA (25\%) are among the lowest. 
Table 4.5Actual expenditure in agriculture by wage and non-wage expenditure (real million MZN, 2009 = 100)

\begin{tabular}{|c|c|c|c|c|c|c|}
\hline \multirow[b]{2}{*}{ Type of expenditure } & \multicolumn{5}{|c|}{ Ministry } & \multirow[b]{2}{*}{ Total } \\
\hline & MASA & MITADER & MIC & MOPHRH & MIMAIP & \\
\hline \multicolumn{7}{|l|}{2013} \\
\hline Wage & 780 & 92 & 93 & 0 & 272 & 1,237 \\
\hline Non-wage & 2,570 & 148 & 210 & 2,462 & 551 & 5,941 \\
\hline Total & 3,350 & 239 & 303 & 2,463 & 822 & 7,178 \\
\hline \multicolumn{7}{|l|}{2014} \\
\hline Wage & 847 & 101 & 132 & 0 & 282 & 1,363 \\
\hline Non-wage & 2,937 & 140 & 253 & 3,717 & 705 & 7,751 \\
\hline Total & 3,784 & 241 & 385 & 3,717 & 987 & 9,114 \\
\hline \multicolumn{7}{|l|}{2015} \\
\hline Wage & 952 & 115 & 129 & 0 & 307 & 1,503 \\
\hline Non-wage & 3,030 & 187 & 160 & 2,270 & 552 & 6,199 \\
\hline Total & 3,982 & 303 & 289 & 2,270 & 859 & 7,702 \\
\hline \multicolumn{7}{|l|}{2016} \\
\hline Wage & 721 & 151 & 127 & 0 & 298 & 1,296 \\
\hline Non-wage & 1,678 & 178 & 96 & 663 & 454 & 3,068 \\
\hline Total & 2,398 & 328 & 223 & 663 & 752 & 4,364 \\
\hline \multicolumn{7}{|l|}{2017} \\
\hline Wage & 705 & 169 & 112 & 6 & 270 & 1,262 \\
\hline Non-wage & 1,857 & 460 & 83 & 1,269 & 489 & 4,158 \\
\hline Total & 2,561 & 629 & 196 & 1,275 & 759 & 5,420 \\
\hline \multicolumn{7}{|l|}{ Average } \\
\hline Wage & 801 & 125 & 119 & 1 & 286 & 1,332 \\
\hline Non-wage & 2,414 & 223 & 160 & 2,076 & 550 & 5,423 \\
\hline Total & 3,215 & 348 & 279 & 2,077 & 836 & 6,756 \\
\hline
\end{tabular}

Source: e-SISTAFE

Governments could support agricultural production through payments for "private" rather than "public" goods and services with the stated objective of increasing access to agricultural inputs in order to boost agricultural production and productivity. However, expenditure on "private" goods and services does not provide incentives to the beneficiaries of those "private" good and services to sustainably increase their agricultural production and productivity. Figure 4.6 breaks down public expenditure in the agricultural sector by subsidy ("private" goods and services) and non-subsidy ("public" goods and services) expenditure. In this case, subsidies refer to payments made by government to providers of agricultural inputs - such as seed and fertilizers which are "private" goods - to make agricultural inputs more accessible, given their subsidized prices, to smallholder farmers. Figure 4.6 shows that the share of public agricultural expenditure accounted for by subsidy declined from 8\% in 2013 to 2\% in 2015 and then increased to 5\% in 2017 and showing an average of $4 \%$ during the period 2013-2017. Although the share of public agricultural expenditure accounted for by subsidies did not follow a clear pattern over the period 2013-2017, its magnitude is small, especially when compared with countries like Malawi with average share of about $15 \%$ and Zambia with average share of about $30 \%$. This reveals that Mozambique did not implement a large-scale agricultural input subsidy program between 2013 and 2017. Also, it is important to ensure that subsidies do not undermine the Government's overall policy of expanding the role of the private sector, in both input 
and output markets. While there are low levels of usage of fertilizer by the majority of smallholders, it is important to address the actual causes (inappropriate technologies and low profitability and farmer adoption levels), rather than distort markets with input subsidies.

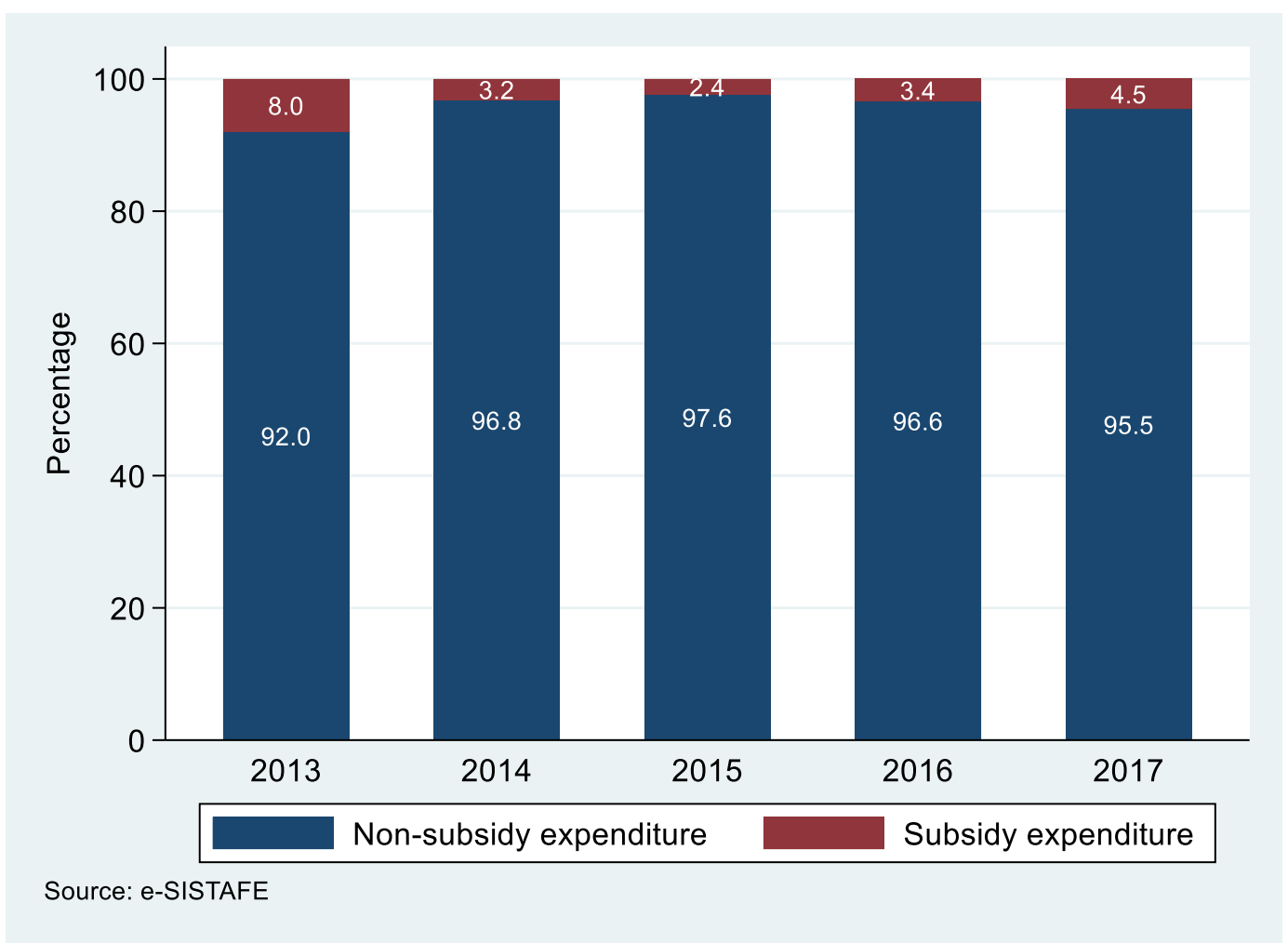

Figure 4.6 Agricultural expenditure by subsidy and non-subsidy expenditure

\subsubsection{Funding Sources of Public Expenditure in Agriculture}

Investment expenditure is the only expenditure type for which data broken down by source of funding (internal versus external) is available. The study findings show that the share of total expenditure in agriculture using external funds was fairly stable at about 60\% between 2013 and 2016, but then dropped substantially to $38 \%$ in 2017. As stated earlier, this fall is consistent with the withdrawal of DPs from direct budget support initiated in 2015. Figure 4.7 displays investment expenditure by source of funds and by ministry over the period under analysis. This figure indicates that the importance of external sources in terms of contribution to total expenditure in agriculture varies considerably among ministries. Ministries with the highest average share of total expenditure funded from external sources over the period 2013-2017 include MIMAIP (66\%), MOPHRH (54\%) and MITADER (50\%). In the remaining two ministries (MASA and MIC), external sources of funding contributed to less than $25 \%$ of total expenditure. Higher dependence on external funding is associated with higher budget unpredictability because lower disbursement rates, usually related to procurement procedures required by DPs and associated ministry capacity constraints - as discussed later in this chapter characterizes funding from DPs in the agriculture sector in particular, and in all sectors of the economy in general. Furthermore, anecdotal evidence suggests that internal sources of funding are relatively less erratic than external sources. 


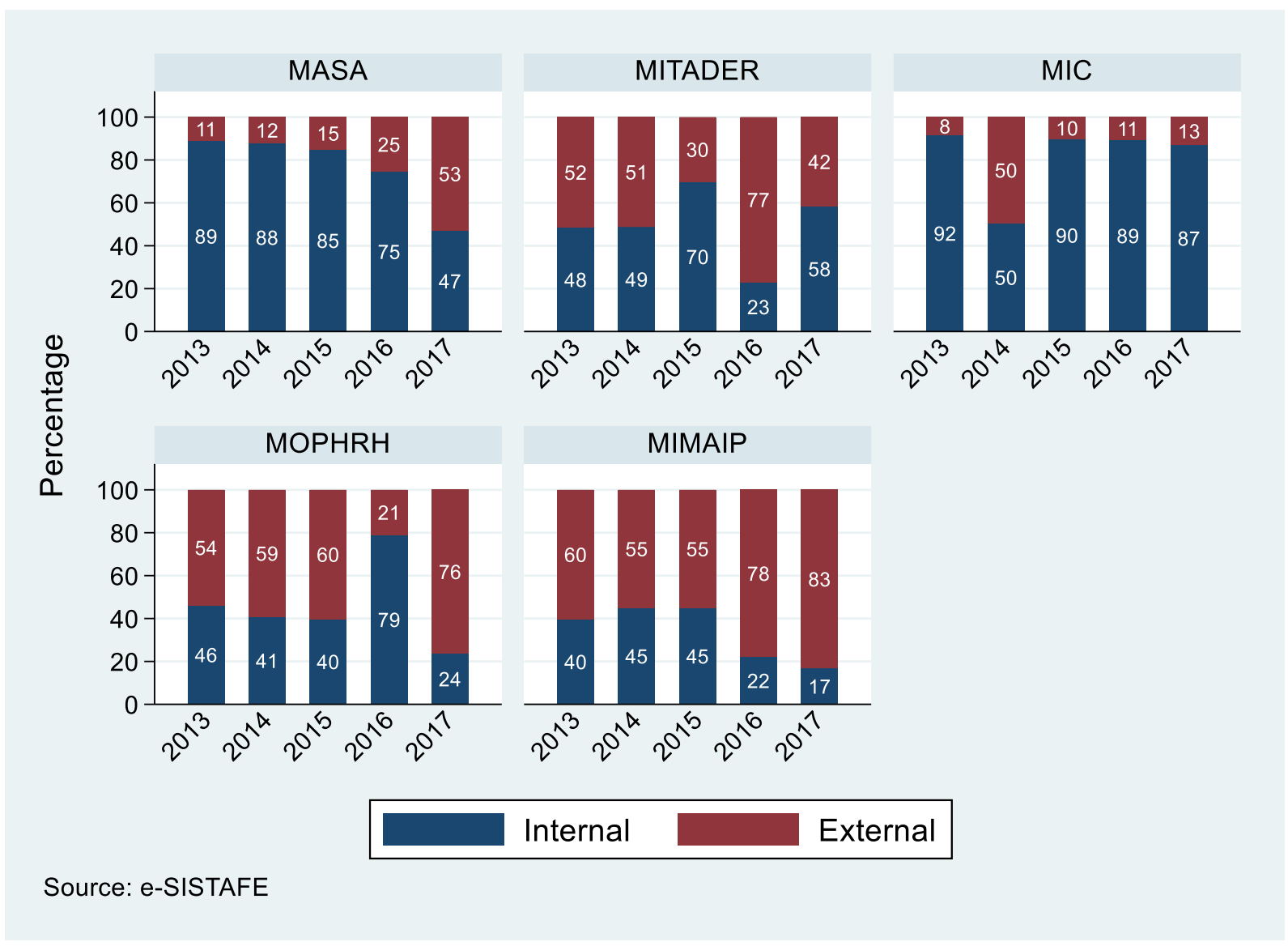

Figure 4.7 Investment expenditure in agriculture by source fo funds by ministry

\subsubsection{Public Expenditure in Agriculture by Administrative Level}

Table 4.6 summarizes actual expenditure in agriculture by administrative level. This table shows that public spending on agriculture at provincial level increased in real terms from 1.5 billion MZN in 2013 to 1.9 billion MZN in 2015, representing an increase of $27 \%$. It then dropped to 1.5 billion MZN in 2017, representing a decline of $20 \%$. Up to 2016, expenditure in agriculture at central level followed similar pattern to that of expenditure at provincial level, but with a difference in magnitude. Contrary to provincial level, expenditure in agriculture at central level increased in real terms by $39 \%$ from 2.8 billion MZN in 2016 to 3.9 billion MZN in 2017.

Between 2013 and 2017, public spending on agriculture at provincial level, in real terms, averaged 1.6 billion MZN compared with 5.1 billion MZN at central level. Our findings show that with an average of $26 \%$ over the period 2013 to 2017, the share of total expenditure in agriculture accounted for by provincial level rose from $21 \%$ in 2013 to $35 \%$ in 2016 before falling to $28 \%$ in 2017 . These trends suggest: (a) that a larger share of total government expenditure in agriculture is being channeled to provincial government over time; (b) increased commitment by the GoM to decentralization (both devolution and deconcentration); and (c) central government (ministries) - accounting for about 75\% of total expenditure in agriculture - still dominate actual expenditure in agriculture over the period 2013-2017. However, it is worth pointing out that a sizable share of the central government expenditure is incurred to ensure that provincial directorates execute on-the-ground activities jointly planned with the central government. 
Table 4.6Actual expenditure in agriculture by administrative level (real million MZN, 2009 $=100)$

\begin{tabular}{|c|c|c|c|c|c|c|}
\hline \multirow[b]{2}{*}{ Administrative level } & \multicolumn{5}{|c|}{ Ministry } & \multirow[b]{2}{*}{ Total } \\
\hline & MASA & MITADER & $\mathrm{MIC}$ & MOPHRH & MIMAIP & \\
\hline \multicolumn{7}{|l|}{2013} \\
\hline Central & 2,333 & 140 & 208 & 2,461 & 561 & 5,705 \\
\hline Provincial & 1,017 & 99 & 95 & 2 & 261 & 1,474 \\
\hline Total & 3,350 & 239 & 303 & 2,463 & 822 & 7,178 \\
\hline \multicolumn{7}{|l|}{2014} \\
\hline Central & 2,503 & 142 & 283 & 3,716 & 698 & 7,342 \\
\hline Provincial & 1,281 & 99 & 102 & 1 & 289 & 1,772 \\
\hline Total & 3,784 & 241 & 385 & 3,717 & 987 & 9,114 \\
\hline \multicolumn{7}{|l|}{2015} \\
\hline Central & 2,634 & 209 & 183 & 2,268 & 513 & 5,806 \\
\hline Provincial & 1,348 & 94 & 106 & 2 & 346 & 1,896 \\
\hline Total & 3,982 & 303 & 289 & 2,270 & 859 & 7,702 \\
\hline \multicolumn{7}{|l|}{2016} \\
\hline Central & 1,331 & 251 & 137 & 660 & 446 & 2,826 \\
\hline Provincial & 1,067 & 77 & 86 & 3 & 305 & 1,538 \\
\hline Total & 2,398 & 328 & 223 & 663 & 752 & 4,364 \\
\hline \multicolumn{7}{|l|}{2017} \\
\hline Central & 1,541 & 525 & 117 & 1,267 & 449 & 3,899 \\
\hline Provincial & 1,021 & 104 & 78 & 7 & 311 & 1,521 \\
\hline Total & 2,561 & 629 & 196 & 1,275 & 759 & 5,420 \\
\hline \multicolumn{7}{|l|}{ Average } \\
\hline Central & 2,068 & 254 & 186 & 2,074 & 533 & 5,115 \\
\hline Provincial & 1,147 & 94 & 93 & 3 & 303 & 1,640 \\
\hline Total & 3,215 & 348 & 279 & 2,077 & 836 & 6,756 \\
\hline
\end{tabular}

Source: e-SISTAFE

MOPHRH is the ministry with the lowest share of expenditure at provincial level out of total expenditure for the agricultural sector with less than $1 \%$ of total expenditure during the period 2013 to 2017. Figure 4.8 shows the contribution of expenditure at central and provincial levels in relation to total expenditure by ministry. This figure shows that expenditure at provincial level, as a share of total expenditure for agriculture, has increased in all ministries except MITADER. For instance, the proportion of expenditure in total agriculture accounted for by expenditure at provincial level rose from 30\% in 2013 to $40 \%$ in 2017 in the case of MASA, and from 32\% in 2013 to $41 \%$ in 2017 in the case of MIMAIP. On the contrary, in the case of MITADER, the share of provincial level expenditure dropped substantially from $41 \%$ in 2013 to $17 \%$ in 2017 . Our findings point out that at central level, the largest share of total expenditure goes to investment expenditure with an average of $85 \%$. By contrast, at provincial level, the largest share goes to recurrent expenditure, with an average of $51 \%$. The share of total expenditure in agriculture made up by investment expenditure varies among ministries at both central and provincial levels. At central level, MASA exhibited an average of $53 \%$ over the period 2013 to 2017 and it is the ministry with the largest investment expenditure in proportion to total expenditure. MIC is the ministry with the smallest share, with an average of $22 \%$. Consistent with this finding, at provincial level over the same period, MIC is the ministry with the 
largest share of total expenditure accounted for by recurrent expenditure (with an average of 78\%) and MASA is the ministry with the smallest share, with average of $47 \%$.

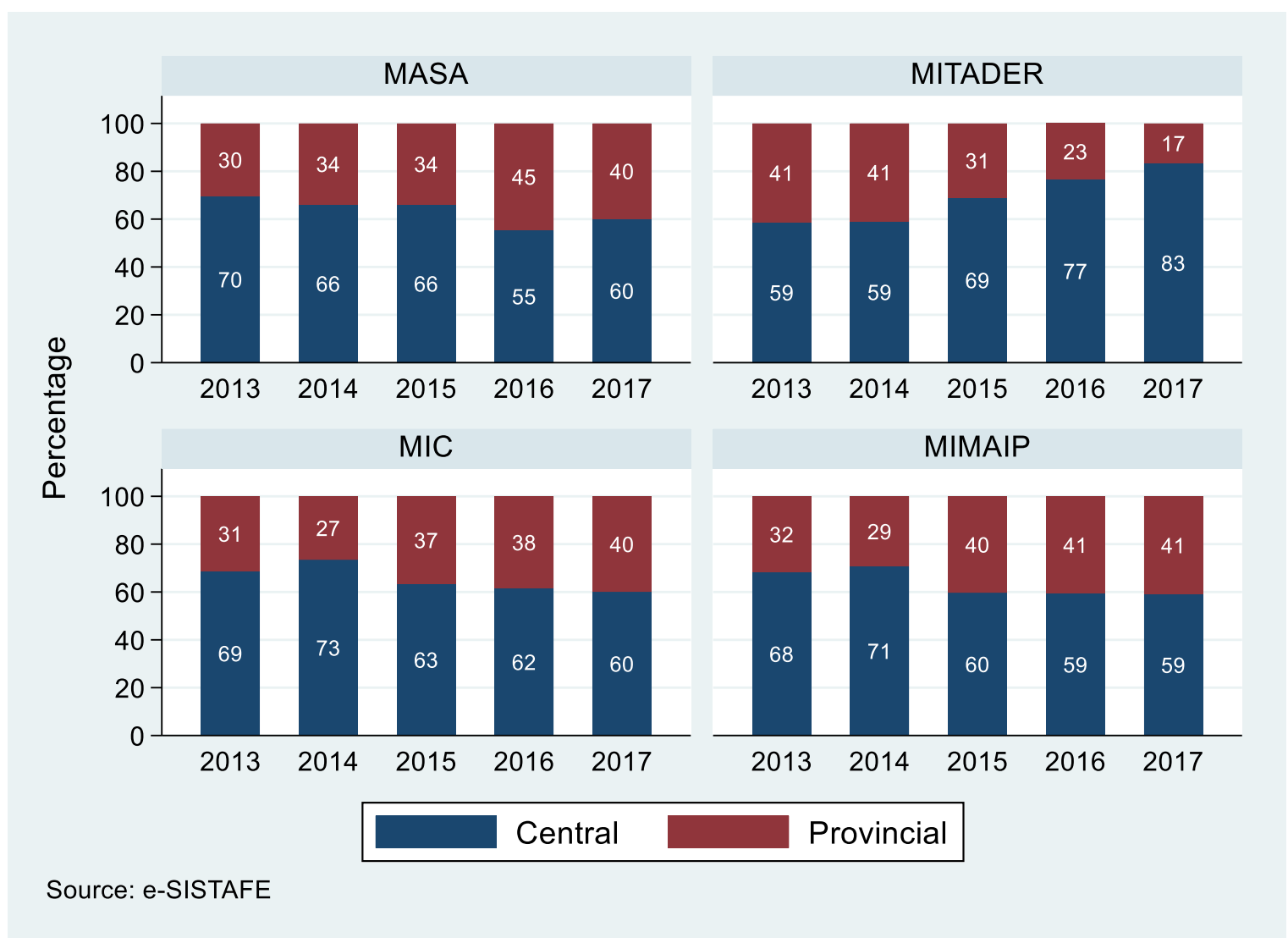

Figure 4.8 Share of expenditure at central and povincial levels in total expenditure by ministry

\subsubsection{Public Expenditure in Agriculture by PNISA Result Area}

The National Agricultural Investment Plan (NAIP) 2013-2017, (Plano de Investimento no Sector Agrário -PNISA), is a national program which aims to operationalize the Strategic Plan for Agricultural Sector Development, 2010-2020 (Plano Estratégico para o Desenvolvimento do Sector Agrário - PEDSA). PNISA is structured in five result areas (RAs), namely agricultural production and productivity, access to market, food and nutritional security, natural resource management, and institutional reform and strengthening. There are 21 programs supporting the realization of the objectives and targets of each RA. Based on a "requirement" approach to meet objectives and targets, PNISA proposed a budget totaling 112.4 billion MZN for the period 2013 - 2017. The relative importance of each result area is summarized in Figure 4.9. This figure shows the following shares: production and productivity with $77 \%$, access to market with $15 \%$ and institutional reform and strengthening with $5 \%$. These three RAs are the most important ones in terms of contribution to PNISA proposed budget over the period 2013 through 2017. 


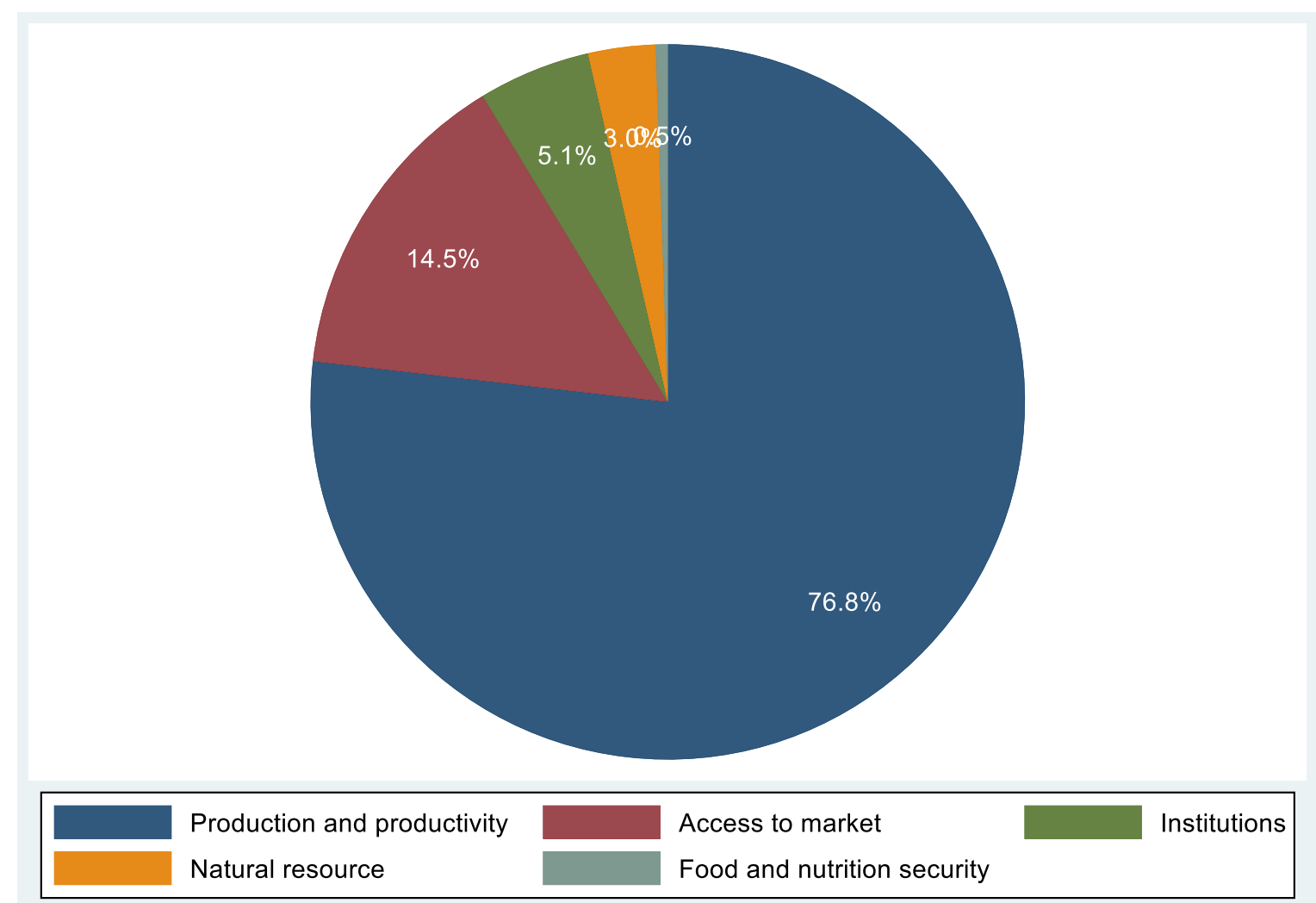

Source: PNISA

Figure 4.9 Distribution of PNISA proposed budget over the period 2013 to 2017

Table 4.7 below breaks down actual expenditure by PNISA result area. This table shows that the most important PNISA result areas in terms of contribution to total expenditure in agriculture between 2013 and 2017 include: Access to Market with an average of 2.6 billion MZN, Institutional Reform and Strengthening with 1.8 billion MZN, and Agricultural Production and Productivity with 1.7 billion MZN. These three PNISA RAs together contributed to $91 \%$ of average total agricultural expenditure during the period 2013-2017: Access to Market accounting for 37\%, Institutional Reform and Strengthening for $27 \%$ and Agricultural Production and Productivity with 27\%. This ranking, based on actual expenditure and consistent across all years between 2013 and 2017, is not aligned with PNISA priorities based on share of PNISA proposed budget. According to actual expenditure, Agricultural Production and Productivity is equally important as Institutional Reform and Strengthening (27\% versus 27\%); however, based on PNISA proposed budget, Agricultural Production and Productivity is five times more important than Institutional Reform and Strengthening (77\% versus $15 \%$ ).

The study findings reveal that MOPHRH accounted for $79 \%$ of the total expenditure in agriculture spent on Access to Market result area. MOPHRH spending on Access to Market result area is dominated by construction and maintenance of roads which have multi-sectoral objectives/benefits, including support for agricultural marketing. Excluding $\mathrm{MOPHRH}$, the average expenditure on Access to Market result area over the period 2013 to 2017 drops from 2.6 billion MZN to 526 million MZN; a reduction of about $80 \%$. Without expenditure incurred by $\mathrm{MOPHRH}$, Institutional Reform and Strengthening and Agricultural Production and Productivity - contributing individually to $38 \%$ of the average expenditure in agriculture between 2013 and 2017 - undoubtedly stand out as the most important PNISA result areas in terms of share of total public spending on agriculture. Excluding expenditure from MOPHRH, average expenditure on Access to Market result area becomes 
comparable to that on Natural Resource Management result area (528 million MZN versus 526 million $M Z N$ ), each accounting individually to $11 \%$ of the average public expenditure in agriculture. It is worth pointing out that between 2013 and 2017, MASA contributed to $82 \%$ of the total expenditure on Agricultural Production and Productivity result area and $58 \%$ of the total expenditure on Institutional Reforms and Strengthening.

Table 4.7 Actual expenditure in agriculture by PNISA result area (real million MZN, $2009=$ 100)

\begin{tabular}{|c|c|c|c|c|c|c|c|}
\hline \multirow[b]{2}{*}{ Year } & \multicolumn{6}{|c|}{ PNISA result area } & \multirow[b]{2}{*}{ Total } \\
\hline & $\begin{array}{l}\text { Agricultural } \\
\text { production } \\
\text { and } \\
\text { productivity }\end{array}$ & $\begin{array}{l}\text { Access } \\
\text { market }\end{array}$ & to & $\begin{array}{l}\text { Food and } \\
\text { nutritional } \\
\text { security }\end{array}$ & $\begin{array}{l}\text { Natural } \\
\text { resource } \\
\text { managemen } \\
\mathrm{t}\end{array}$ & $\begin{array}{l}\text { Institutional } \\
\text { reform and } \\
\text { strengtheni } \\
\text { ng }\end{array}$ & \\
\hline 2013 & 1,952 & 2,782 & & 23 & 455 & 1,965 & 7,178 \\
\hline 2014 & 2,093 & 4,215 & & 40 & 622 & 2,144 & 9,114 \\
\hline 2015 & 1,863 & 2,861 & & 55 & 825 & 2,098 & 7,702 \\
\hline 2016 & 1,187 & 1,190 & & 55 & 348 & 1,584 & 4,364 \\
\hline 2017 & 1,754 & 1,952 & & 111 & 382 & 1,221 & 5,420 \\
\hline Average & 1,770 & 2,600 & & 57 & 526 & 1,802 & 6,756 \\
\hline
\end{tabular}

Source: e-SISTAFE

Actual public expenditure in agriculture over the period 2013 to 2017 totaled 32 billion MZN. This represents a significant shortfall of $72 \%$ vis-à-vis the total PNISA proposed budget. This shortfall is about the same magnitude as that at the outset of PNISA in 2013 (72\% versus 85\%), suggesting that little progress was made in mobilizing funds to close the significant financial gap at the outset of PNISA. Furthermore, it is challenging to meet PNISA's original objectives and targets with this significant shortfall. Moreover, the targets were never revised downwards during implementation, and the assessment study in 2017 recommended the need to revise downwards the relevant targets. ${ }^{29}$ The financial gap - measured as the difference between PNISA proposed budget and actual expenditure varies across result areas (see Figure 4.10). Figure 4.10 illustrates that Agricultural Production and Productivity result area experienced the largest financial gap - varying from $84 \%$ in 2017 to $90 \%$ in 2016 - despite being the most important result area according to the results framework (see Error! Reference source not found.) and the share of PNISA proposed budget. Agricultural Production and Productivity is also the result area with the most direct channel through which expenditure in agriculture could be translated into agricultural productivity gains, and the base for value chain development, while also contributing to poverty reduction.

Figure 4.10 suggests that progress has been made to mobilize funds to close the financial gap for the Food and Nutritional Security result area. The financial gap for the Food and Nutritional Security result area dropped considerably from $76 \%$ in 2013 to $8 \%$ in 2015. Since then, spending on the Food and Nutritional Security result area outpaced PNISA proposed budget by $15 \%$ in 2016 and $46 \%$ in 2017 . This could be due to several factors and initiatives: a reflection of the strong partnership of SETSAN with various development partners (FAO, IFAD, UNICEF, WFP, WHO, USAID, and others); signing up to the Scaling Up Nutrition Movement (SUN); and the creation of the Nutrition Partners Forum (NPF). Our study findings reveal that Institutional Reform and Strengthening is the only result area in which

${ }^{29}$ Assessment of the PNISA: 2013 - 2017 (2017). 
actual expenditure exceeded PNISA proposed budget in all years, except 2015, during the period 2013 through 2017. This combined with higher ranking compared to agricultural production and productivity suggests that institutional reform and strengthening appears to be overfunded. At the same time, it is difficult to compile relevant evidence and attribution of this institutional strengthening being translated into better quality of expenditure and "management" of the agricultural sector. It is recommended to construct relevant performance indicators for each of the RAs and the component programs to assess the quality and results of increased expenditures.

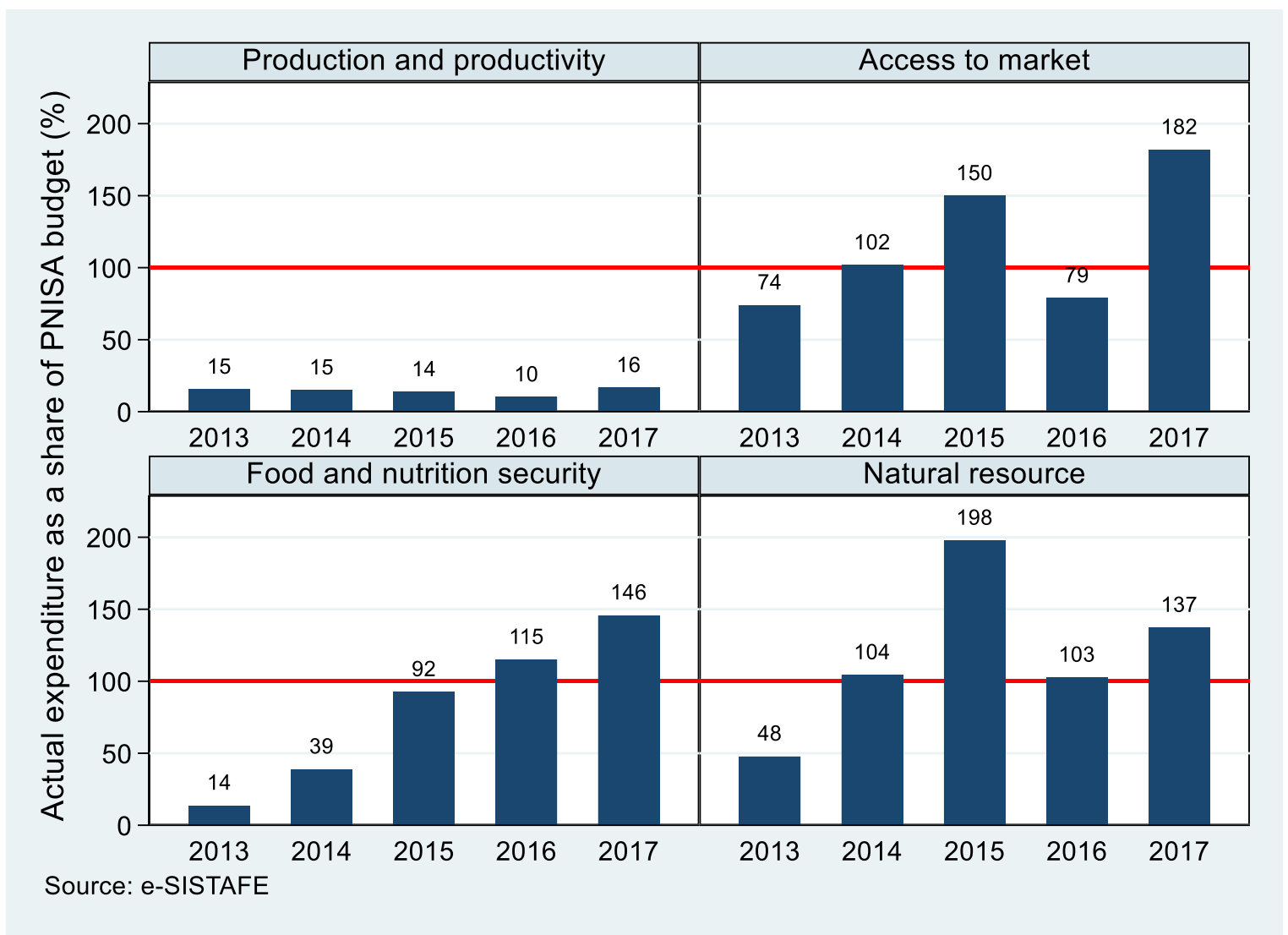

Figure 4.10 Actual expenditure in agriculture as a share of PNISA budget by PNISA result area

\subsection{Efficiency Aspects}

The efficiencies of the budgetary expenditure allocations and actual expenditure present a mixed picture, although there is limited expenditure data to demonstrate the extent of inefficiencies.

In line with international practices, the study team employed actual expenditure as a share of approved budget allocation as one of the key indicators of expenditure efficiency. This indicator should be interpreted with caution, due to several underlying factors, not necessarily related to efficiency, which could explain the deviation between approved budget allocation and actual expenditure including late release of funds as a result of delays in accounting for previously released funds by the implementing agencies, delayed disbursement of funds from DPs, readjustment of budget allocations after the announcement of the approved budget, shortfalls in government revenue collections and hence MEF's cash-flow constraints, and cumbersome procurement procedures and procurement implementation capacities. Table 4.8 summarizes actual expenditure in agriculture as a share of approved budget allocation by ministry. This table shows that the share of expenditure as a 
share of budget allocation was quite stable, fluctuating between $85 \%$ in 2013 and $81 \%$ in 2015 . It then sharply dropped to $57 \%$ in 2016 and then increased to $78 \%$ in 2017. The sharp decline registered in 2016 could be related to two factors. First, withdrawal from direct-budget support by DPs initiated in 2015. Second, large shortfall in government revenue collection in 2016. Collected revenue as a share of projected revenue stood at $84 \%$ in 2016, compared with 93\% in 2015 and $97 \%$ in 2013.

Table 4.8 Actual expenditure as share of approved budget by ministry

\begin{tabular}{|c|c|c|c|c|c|c|}
\hline \multirow[b]{2}{*}{ Year } & \multicolumn{5}{|c|}{ Ministry } & \multirow[b]{2}{*}{ Total } \\
\hline & MASA & MITADER & MIC & MOPHRH & MIMAIP & \\
\hline 2013 & $82.1 \%$ & $67.2 \%$ & $93.9 \%$ & $95.5 \%$ & $72.4 \%$ & $84.7 \%$ \\
\hline 2014 & $78.4 \%$ & $79.1 \%$ & $85.6 \%$ & $93.0 \%$ & $83.6 \%$ & $84.7 \%$ \\
\hline 2015 & $87.8 \%$ & $72.3 \%$ & $76.5 \%$ & $79.2 \%$ & $63.3 \%$ & $80.6 \%$ \\
\hline 2016 & $61.2 \%$ & $77.2 \%$ & $89.7 \%$ & $35.7 \%$ & $61.3 \%$ & $56.9 \%$ \\
\hline 2017 & $78.2 \%$ & $70.4 \%$ & $75.4 \%$ & $98.2 \%$ & $62.9 \%$ & $78.2 \%$ \\
\hline Average & $77.5 \%$ & $73.2 \%$ & $84.2 \%$ & $80.3 \%$ & $68.7 \%$ & $77.0 \%$ \\
\hline
\end{tabular}

Table 4.8 reveals that the proportion of budget expenditure as a share of budget approval/allocation in expenditure averaged 77\% over the period 2013 - 2017. This discrepancy suggests there is scope for improvement. Over the same period, the average share of actual expenditure in approved budget allocation in agriculture varies considerably among ministries in the agricultural sector - fluctuating between $69 \%$ for MIMAIP and $84 \%$ for MIC. Improved collaboration among ministries in the agricultural sector could potentially be a pathway through which these ministries could learn from one another to improve the proportion of the approved budget actually executed. Figure 4.11 shows that budget execution rates are slightly higher at central level than at provincial level in all years under analysis except for 2015 and 2016. Over the period, average budget execution rate at central level is comparable to that at provincial level ( $77 \%$ for central level versus $76 \%$ for provincial level). In the event the share of budgetary allocations increases at the sub-national level, it is likely the expenditure efficiency will be lower, due to capacity constraints.

Another measure for expenditure efficiencies could be using efficiency-based unit costs for major programs and services (e.g., cost per hectare of irrigation; cost per km. of rural roads; cost of generating agricultural technologies; extension cost of disseminating new technology messages). It is recommended that MASA's and other Ministry's performance M\&E system derive and use relevant efficiency-based measures. These measures will provide an improved tool for enhancing expenditure management decisions and targets. 


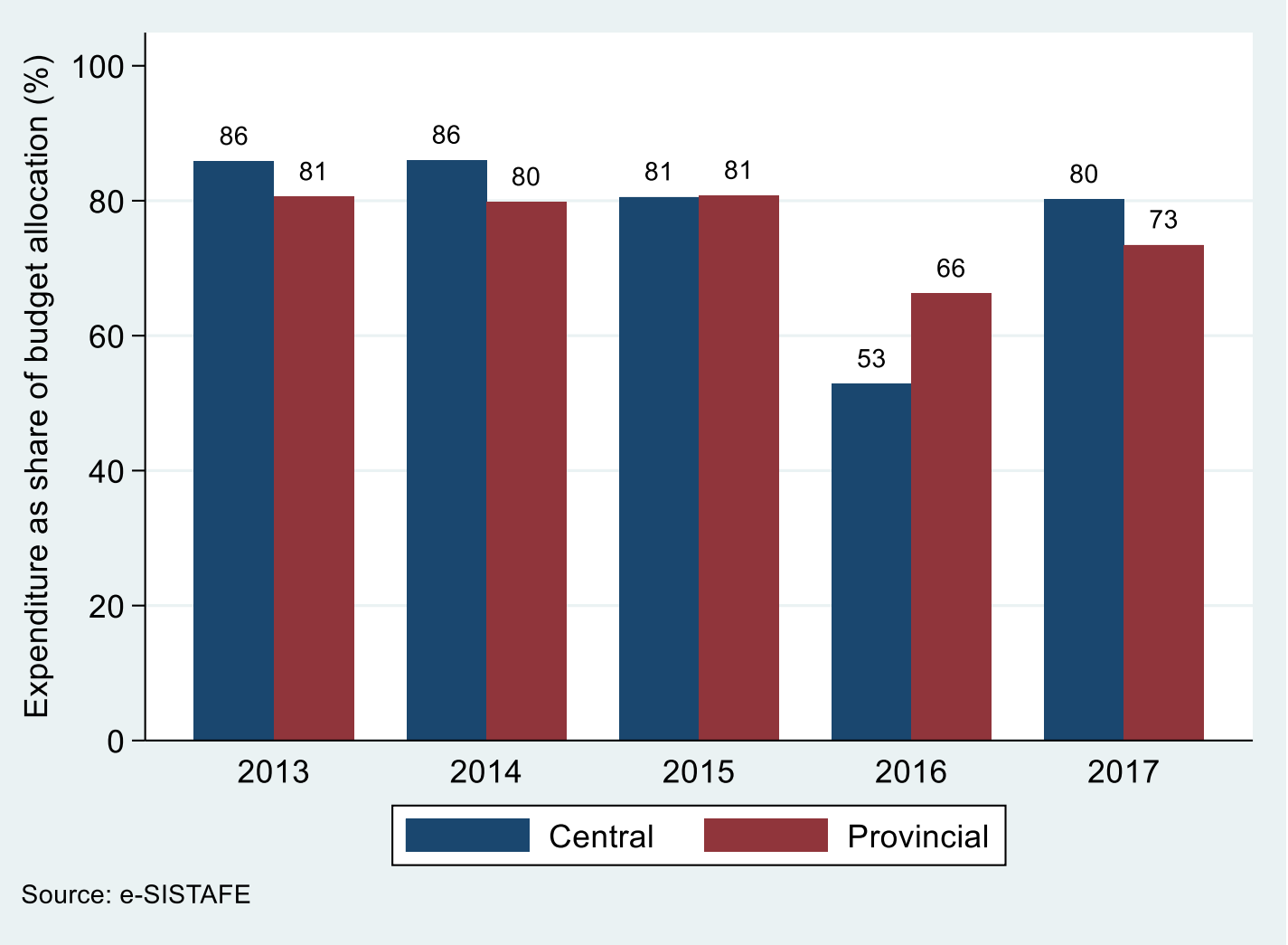

Figure 4.11 Budget execution rate by administrative level

Investment Expenditure as Share of Budget Allocation. Figure 4.12 shows actual investment expenditure as a share of budget allocation. This figure illustrates that in all years between 2013 and 2016, the share of approved investment budget executed was higher for funding coming from internal sources than for funding coming from external sources. During the same period, the share of budget investment allocation accounted for by actual investment expenditure ranged from $98 \%$ to $75 \%$ for internal sources, and from $71 \%$ to $28 \%$ for external sources. This relatively low budget execution rate - actual investment expenditure as a share of budget investment allocation - suggests higher budget unpredictability for externally sourced funding, compared with internally sourced funding; as discussed earlier. This high unpredictability makes it difficult to implement activities as planned, usually leading to ad-hoc decision-making when considerable portion of funding are not forthcoming. 


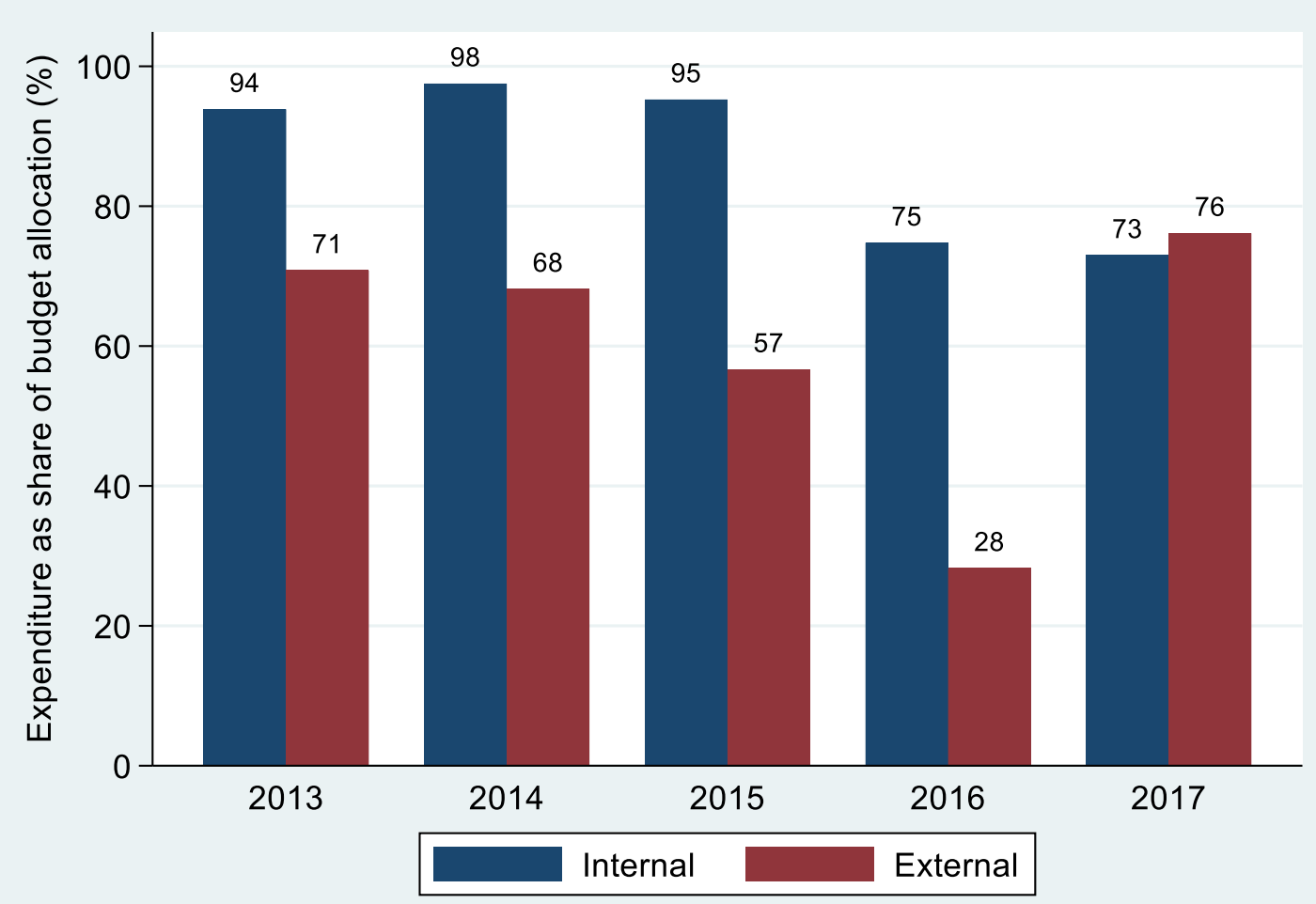

Source: e-SISTAFE

Figure 4.12 Budget execution rate for investment expenditure

Variable Execution Rates. Our findings suggest that budget execution rates for investment varies considerably among ministries in the agricultural sector (MASA, MITADER, MIC, MOPHRH, and MIMAIP) during the period 2013 - 2017. During this period, budget execution rates for internal sources is quite stable - but with different magnitudes - for all ministries in the agricultural sector. However, budget execution rates for external sources varies considerably among ministries. MOPHRH with $72 \%$ and MITADER with $64 \%$ stood out as the ministries with the greatest average share of investment budget allocation accounted for by investment expenditure for external sources. Average execution rates for external sources in the remaining ministries ranged from $39 \%$ for MIC and $50 \%$ for MIMAIP.

Allocations by Province. As another measure of expenditure efficiency, the study team analyzed expenditure in agriculture disaggregated by province to assess whether expenditure in agriculture was aligned with agricultural "potential". Given data availability, this analysis covers the period 2013 $2015^{30}$. Table 4.9 breaks down expenditure in agriculture, GDP and rural population by province during the period 2013 - 2015. This table shows that Nampula with 16\%, Zambezia with 14\% and Gaza with $14 \%$ are the provinces with the largest share of expenditure in agriculture between 2013 and 2015. On the other hand, Zambezia with $23 \%$, Nampula with $21 \%$ and Inhambane with $13 \%$ account for the largest proportion of agricultural GDP during the same period. Zambezia (22\%) and Nampula (20\%) together accounted for $42 \%$ of total rural population; and the remaining provinces account individually for less than $10 \%$. The two most important provinces (Zambezia and Nampula) in terms of agriculture's contribution to GDP and share of the rural population received the largest share of public

30 Cultivated area at province level is only available for the period 2013 through 2015. 
expenditure in agriculture. This suggests an alignment between expenditure in agriculture and agricultural potential, for at least these two provinces. These two provinces are also the most important ones in terms of the size of cultivated area, Zambezia accounting for an average of $20 \%$ of the total cultivated area during the period 2013 - 2017 and Nampula for $18 \%$.

Table 4.9 Expenditure in agriculture, GDP, agricultural GDP and rural population by province: 2013-2015

\begin{tabular}{|c|c|c|c|c|c|c|c|}
\hline Province & $\begin{array}{l}\text { Expenditure } \\
\text { in } \\
\text { agriculture } \\
\text { (million } \\
\text { MZN) }\end{array}$ & $\begin{array}{l}\text { Expenditure } \\
\text { in } \\
\text { agriculture } \\
\text { share }\end{array}$ & $\begin{array}{l}\text { GDP } \\
\text { (million } \\
\text { MZN) }\end{array}$ & $\begin{array}{l}\text { Agriculture } \\
\text { GDP } \\
\text { (million } \\
\text { MZN) }\end{array}$ & $\begin{array}{l}\text { Agriculture } \\
\text { GDP share }\end{array}$ & $\begin{array}{l}\text { Rural } \\
\text { population } \\
\text { (million) }\end{array}$ & $\begin{array}{l}\text { Rural } \\
\text { population } \\
\text { share }\end{array}$ \\
\hline Niassa & 160 & $7.4 \%$ & 15,718 & 5,948 & $4.8 \%$ & 1.222 & $7.1 \%$ \\
\hline Cabo Delgado & 158 & $7.3 \%$ & 25,619 & 11,207 & $9.0 \%$ & 1.417 & $8.3 \%$ \\
\hline Nampula & 340 & $15.7 \%$ & 78,349 & 25,952 & $20.9 \%$ & 3.338 & $19.5 \%$ \\
\hline Zambezia & 294 & $13.5 \%$ & 53,355 & 28,845 & $23.2 \%$ & 3.723 & $21.7 \%$ \\
\hline Tete & 140 & $6.4 \%$ & 33,550 & 6,891 & $5.5 \%$ & 2.092 & $12.2 \%$ \\
\hline Manica & 169 & $7.8 \%$ & 19,314 & 6,422 & $5.2 \%$ & 1.419 & $8.3 \%$ \\
\hline Sofala & 240 & $11.1 \%$ & 55,487 & 8,987 & $7.2 \%$ & 1.274 & $7.4 \%$ \\
\hline Inhambane & 134 & $6.2 \%$ & 42,611 & 16,369 & $13.2 \%$ & 1.126 & $6.6 \%$ \\
\hline Gaza & 296 & $13.6 \%$ & 24,456 & 8,518 & $6.9 \%$ & 1.034 & $6.0 \%$ \\
\hline Maputo & 241 & $11.1 \%$ & 186,771 & 5,150 & $4.1 \%$ & 0.493 & $2.9 \%$ \\
\hline Total & 2,171 & $100.0 \%$ & 535,229 & 124,288 & $100.0 \%$ & 17.137 & $100.0 \%$ \\
\hline
\end{tabular}

Source: e-SISTAFE and INE

However, it is worth pointing out that although Gaza is a province with considerably less importance of agriculture' contribution to GDP and the size of rural population compared with Zambezia (7\% versus $23 \%$ for agriculture GDP share and $6 \%$ versus $22 \%$ for rural population), the share of agricultural expenditure accounted for by Gaza is comparable to that accounted for by Zambezia. Furthermore, Tete received the smallest share of expenditure in agriculture (6\%), but Tete ranks third in terms of the size of rural population and seventh in terms of agriculture's contribution to GDP. These rankings are higher than those for Maputo (3\% versus $12 \%$ for the size of rural population and $4 \%$ versus $6 \%$ for agriculture's contribution to GDP) but Maputo contributed to higher share of expenditure in agriculture ( $11 \%$ versus $6 \%)$. The share of the total cultivated area accounted for by each province is also much higher for Tete than for Maputo ( $11 \%$ versus $6 \%$ ). This suggests that with the exception of Zambezia and Nampula provinces, the size of expenditure in agriculture appears to be disproportionate to agricultural role and potential.

Assessing Appropriate Level of Expenditures. Looking at alignment between agricultural potential and the relative share of expenditure in agriculture as summarized in Table 4.9 could be misleading because the relative expenditure shares are not adjusted to reflect relevant indicators consistent with the current and potential role of agriculture sector, including: the size of rural population or the number of smallholder farmers or the size of the total cultivated area or the size of agricultural GDP. Figure 4.13 summarizes spending on agriculture per smallholder farmer and per rural capita by province over the period 2013 to 2015. This figure illustrates that Gaza with 1,413 MZN, Sofala with $906 \mathrm{MZN}$, Niassa with $861 \mathrm{MZN}$ and Maputo with $728 \mathrm{MZN}$ are among the provinces with the largest expenditure per smallholder farmer. By contrast, Nampula with 462 MZN, Cabo Delgado with 404 MZN, Tete with $388 \mathrm{MZN}$ and Zambezia with $343 \mathrm{MZN}$ are among the provinces with the smallest 
expenditure per smallholder farmer. However, the agriculture sector is more important in terms of contribution to GDP in the latter provinces (Nampula, Cabo Delgado and Zambezia) than in the former (Gaza, Sofala, Niassa and Maputo). Figure 4.13 also shows that a similar pattern is observed when expenditure in agriculture per person living in rural areas is compared across provinces. The study team findings also reveal a similar pattern when expenditure in agriculture per hectare of cultivated area is compared across provinces. For instance, expenditure in agriculture per hectare of cultivated area averaged $840 \mathrm{MZN}$ in Maputo, $788 \mathrm{MZN}$ in Gaza and $520 \mathrm{MZN}$ in Sofala - compared with averages of 267 MZN in Nampula, 205 MZN in Zambezia and 200 MZN in Cabo Delgado - during the period 2013 through 2015. These findings suggest that the size of expenditure in agriculture is disproportionate to the importance of the agricultural sector and current potential.

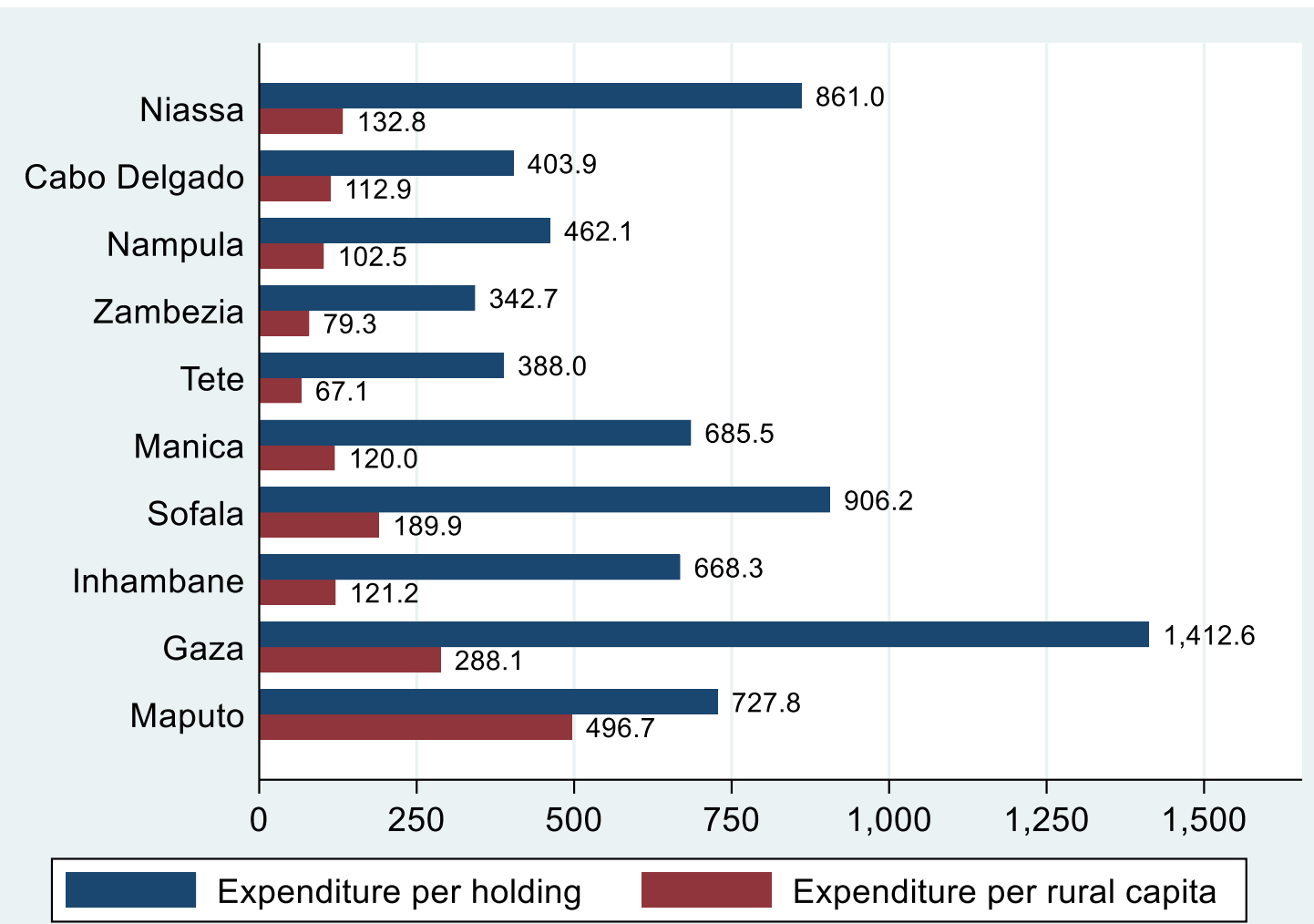

Source: e-SISTAFE and INE

Figure 4.13 Intensity of expenditure in agriculture by province over the period 2013 to 2015

Figure 4.14 shows expenditure in agriculture as share of agricultural GDP by province between 2013 and 2015. This figure indicates that intensity of expenditure in agriculture relative to agricultural GDP is greater in the provinces of Maputo, Gaza, Niassa and Sofala where agriculture is less important than in the provinces of Cabo Delgado, Nampula, Zambezia and Inhambane where agriculture is more important. For instance, between 2013 and 2015, Maputo and Gaza spent on average respectively 4.7 and 3.5 MZN on agriculture for every $100 \mathrm{MZN}$ of agricultural GDP, while Nampula and Zambezia spent on average 1.3 and $1.0 \mathrm{MZN}$ for every $100 \mathrm{MZN}$ of agricultural GDP. This points out that provinces where agriculture is more important spent disproportionately less on agriculture, measured in terms of units of agricultural GDP, than provinces where agriculture is less important. These findings are consistent with findings reported above regarding the intensity of expenditure in agriculture in terms of the size of smallholder farmers, the size of rural population and the size of cultivated area. It is 
recommended that the Planning Offices of MASA and Departments of Agriculture (at the Provincial level) adopt and apply prioritization criteria (as suggested above in Chapter 3 ) which also reflect the relative importance and alignment of the agricultural sector in meeting strategic growth and rural poverty reduction targets.

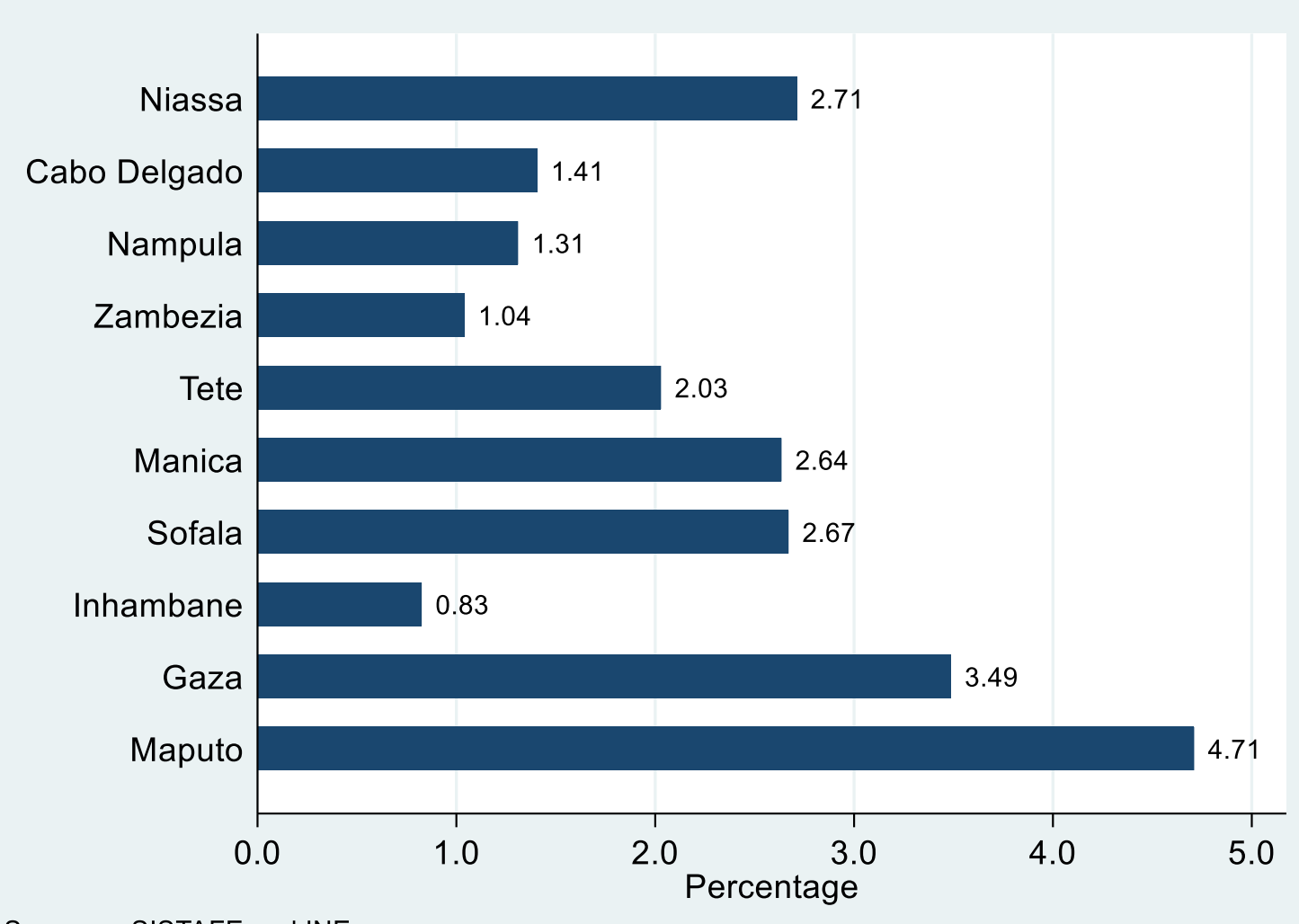

Source: e-SISTAFE and INE

Figure 4.14 Expenditure in agriculture relative to agricultural GDP by province over the period 2013 to 2017

In summary this Chapter has highlighted the significant underfunding of the agrarian sector, especially the agricultural and productivity result area, coupled with an erratic expenditure trend and uneven quality of expenditures. With respect to decentralization, this expenditure assessment suggests that it is in its early stage, with expenditures concentrated at the central level. Further aspects of decentralization are addressed later. 


\section{PUBLIC EXPENDITURE ON SELECTED STRATEGIC PROGRAMS}

\subsection{Overview and Rationale for Selected Strategic Programs}

Given the "hybrid" scope of the Ag. PER, it was important to select a sample of strategic programs for in-depth assessment of the policies-expenditure and result linkages. The theory of change and results framework for the agricultural sector of Mozambique suggests (see Chapter 2) there are three programs which will play a strategic role in promoting agricultural transformation, and which align with international experience in other developing countries, namely: agricultural research, agricultural extension and irrigation development.

As stated above, low productivity of the vast majority of farm households characterizes the agricultural sector in Mozambique. Data from the World Development Indicators (WDI), reported by the World Bank, shows that cereal yield averaged 0.8 metric tons (MT) per hectare (ha) in Mozambique during the period 1996 to 2016, well below average yields of 1.4 MT/ha in Tanzania, 1.6 $\mathrm{MT} / \mathrm{ha}$ in Malawi, and $2.0 \mathrm{MT} / \mathrm{ha}$ in Zambia. This low agricultural productivity in Mozambique is associated with limited use of yield-enhancing agricultural inputs such as fertilizer, improved seeds, and pesticides, among other constraints. Data from the nationally representative 2015 Integrated Agricultural Survey (IAI) show that only $3.8 \%$ of the 4.0 million smallholder farmers used chemical fertilizer in the agricultural season $2014 / 2015$, 3.4\% used pesticide, 3.3\% used irrigation, $1.8 \%$ used manure and 5.2\% used maize improved seed with some variation across regions (see Table 5.1). ${ }^{31}$ Data from other IAIs and TIAs illustrate that similar levels of yield-enhancing agricultural inputs usage were registered since the agricultural season 2001/2002. The central region stands out as the region with the largest proportion of smallholder farmers using chemical fertilizer, pesticide, and improved maize seed.

Table 5.1 Use of improved inputs in the agricultural season 2014/2015

\begin{tabular}{lllll}
\hline & \multicolumn{2}{l}{ Region } & & \\
\cline { 2 - 4 } Improved input usage & Northern & Central & Southern & Total \\
\hline Household used chemical fertilizer & $1.8 \%$ & $11.2 \%$ & $2.2 \%$ & $3.8 \%$ \\
Household used pesticide & $3.6 \%$ & $6.0 \%$ & $1.4 \%$ & $3.4 \%$ \\
Household used irrigation & $1.6 \%$ & $4.9 \%$ & $5.1 \%$ & $3.3 \%$ \\
$\begin{array}{l}\text { Household used manure } \\
\text { Household used improved seed }\end{array}$ & $0.7 \%$ & $2.1 \%$ & $3.4 \%$ & $1.8 \%$ \\
$\quad$ Maize & $3.7 \%$ & $14.7 \%$ & $1.3 \%$ & $5.2 \%$ \\
$\quad$ Rice & $0.3 \%$ & $0.1 \%$ & $0.0 \%$ & $0.2 \%$ \\
\hline
\end{tabular}

Source: IAI 2015

On the other hand, data from the Statistics Division of the Food and Agriculture Organization of the United Nations (FAOSTAT) show that fertilizer application rate averaged 5.7 kilograms (Kg) per hectare of arable cropland in Mozambique during the period 2006 to 2015, compared with $6.1 \mathrm{Kg} / \mathrm{ha}$ in

\footnotetext{
${ }^{31}$ Maize and cassava are the two most important crops in terms of both total number of growers and cultivated area. According to data from IAI 2015, the share of smallholder farmers who grew maize in the 2014/2015 agricultural season stand at $73 \%$, and the crop accounted for $33 \%$ of the total cultivated area in the same agricultural season.
} 
Tanzania, $31.7 \mathrm{Kg} / \mathrm{ha}$ in Malawi, and $38.7 \mathrm{Kg} / \mathrm{ha}$ in Zambia. Mozambique's average rate of fertilizer application also lags far behind regional averages: $19.7 \mathrm{Kg} / \mathrm{ha}$ in Sub-Saharan Africa (SSA), $74.5 \mathrm{Kg} / \mathrm{ha}$ in Latin American and Caribbean (LAC) and $189.6 \mathrm{Kg} / \mathrm{ha}$ in Asia over the same period. Furthermore, the average fertilizer application rate in Mozambique fall short of the target of $50 \mathrm{Kg} / \mathrm{ha}$ by 2025 agreed by the African Heads of State in the 2006 ABUJA Declaration on fertilizer for an African green revolution. This commitment has been upheld by the African Head of States in the MALABO Declaration in June 2014.

Recognizing the low agricultural productivity and the paramount importance of improving agricultural productivity given its positive multiplier effects on food security and poverty reduction, the Government of Mozambique (GoM), through the PEDSA (2010-2019), aimed at sustaining an average agricultural growth rate of $7 \%$ per year during, as one of the program development objectives (PDO). Reducing stunting from $44 \%$ in 2008 to $30 \%$ in 2015 and $20 \%$ in 2020 is also among PEDSA's PDOs. Although this PEDSA agricultural growth target is consistent with both the Comprehensive Africa Agriculture Development Program (CAADP) and the 2014 MALABO Declaration targets of at least 6\% agricultural growth rate, it appeared to have been ambitious because registered agricultural growth rates were much lower in Mozambique. According to data from the Mozambique National Institute of Statistics (INE), real agricultural gross domestic product (GDP) grew on average at $2.9 \%$ per year over the period $2010-2017$, while real GDP grew on average at $6.1 \%$ over the same period. Among other targets to induce the 7\% growth rate in the agricultural sector, PEDSA target on fertilizer application was set at $25.0 \mathrm{Kg} / \mathrm{ha}$. As shown above, average fertilizer application rate of $5.7 \mathrm{Kg} / \mathrm{ha}$ is well below this PEDSA target.

In addition to the above-mentioned targets, PEDSA set specific targets for agricultural research and irrigation which were partially achieved during the period 2013-2017. For example, PNISA established a target to release 20 crop varieties (four with high nutritional potential, chicken breeds with tolerance to adverse weather condition, and two goat breeds adapted to different agro-ecological conditions). The target on crop varieties was met as IIAM released 35 crop varieties. However, there was a shortfall in meeting the target for releasing chicken and goat breeds. Additionally, the use of these varieties is still limited due to poor linkages between agricultural research and agricultural extension to make these technologies available to smallholder farmers. Furthermore, under the agricultural irrigation program, PEDSA established a target to increase the area under irrigation 50,000 ha. by 2017 . A significant shortfall was observed for this target, as the irrigated area reached only 20,000 ha. in 2016, less than half of the PEDSA target. On the other hand, the PQG established a target to increase the irrigated area by $75 \%$ from 9.200 ha. in 2014 to 16,000 ha. in 2016, a target which appears to have been achieved.

Regarding agricultural extension, although without specific targets, PEDSA established as a specific objective to provide wider coverage of extension services at provincial and district level to promote agricultural and fishery productivity for food and nutritional security and sustainable use of natural resources. However, the MALABO Declaration established a target of $100 \%$ agricultural extension coverage by 2018. Data from IAI 2015 show that only 4\% of smallholder farmers received extension service in the agricultural season of 2014/2015 revealing a significant shortfall vis-a-vis the MALABO target.

Increased fertilizer adoption (in terms of both the proportion of farmers using fertilizer and the recommended fertilizer application rate), complemented especially with improved seed adoption, irrigation and better land and crop management, play a paramount role in contributing to rapid and 
sustainable growth in agricultural productivity and poverty reduction in Mozambique. Indeed, data from the IAI 2015 show that maize yields are higher among fertilizer and improved maize seed adopters (see Figure 5.1). These data also reveal that maize yield stood at 1,090 Kg/ha among farmers who used improved maize seed but did not use fertilizer, compared with $1,321 \mathrm{Kg} / \mathrm{ha}$ among farmers who used fertilizer but did not use improved maize seed and $3,037 \mathrm{Kg} / \mathrm{ha}$ among farmers who used both maize improved seed and fertilizer. These trends suggest complementarity between fertilizer and improved seed usage. Moreover, the World Bank (2005) documented that agriculture was the sector with the largest contribution to poverty reduction, accounting for a reduction of 11 out of 15 percentage points in poverty between 1996/1997 and 2002/2003.

Achieving a $6 \%$ growth rate in the agricultural sector in a sustainable way requires substantial productivity gains. These gains can be promoted if expenditure is directed towards effective and efficient delivery of services such as agricultural research, extension services and irrigation (through public-private partnerships) to boost smallholder farmers' agricultural productivity and competitiveness to ultimately reduce poverty incidence. Spending on these key public services should be coupled, with improved coordination processes and mechanisms, with well-functioning input and output markets, infrastructure, financial services and enabling environment (in terms of policies and institutions). This chapter assesses patterns and composition of public expenditure in agricultural research, extension and irrigation; and to the extent possible, based on available information/analyses, attempts to link public expenditure in agriculture with realized results, at impact, outcome and output levels.
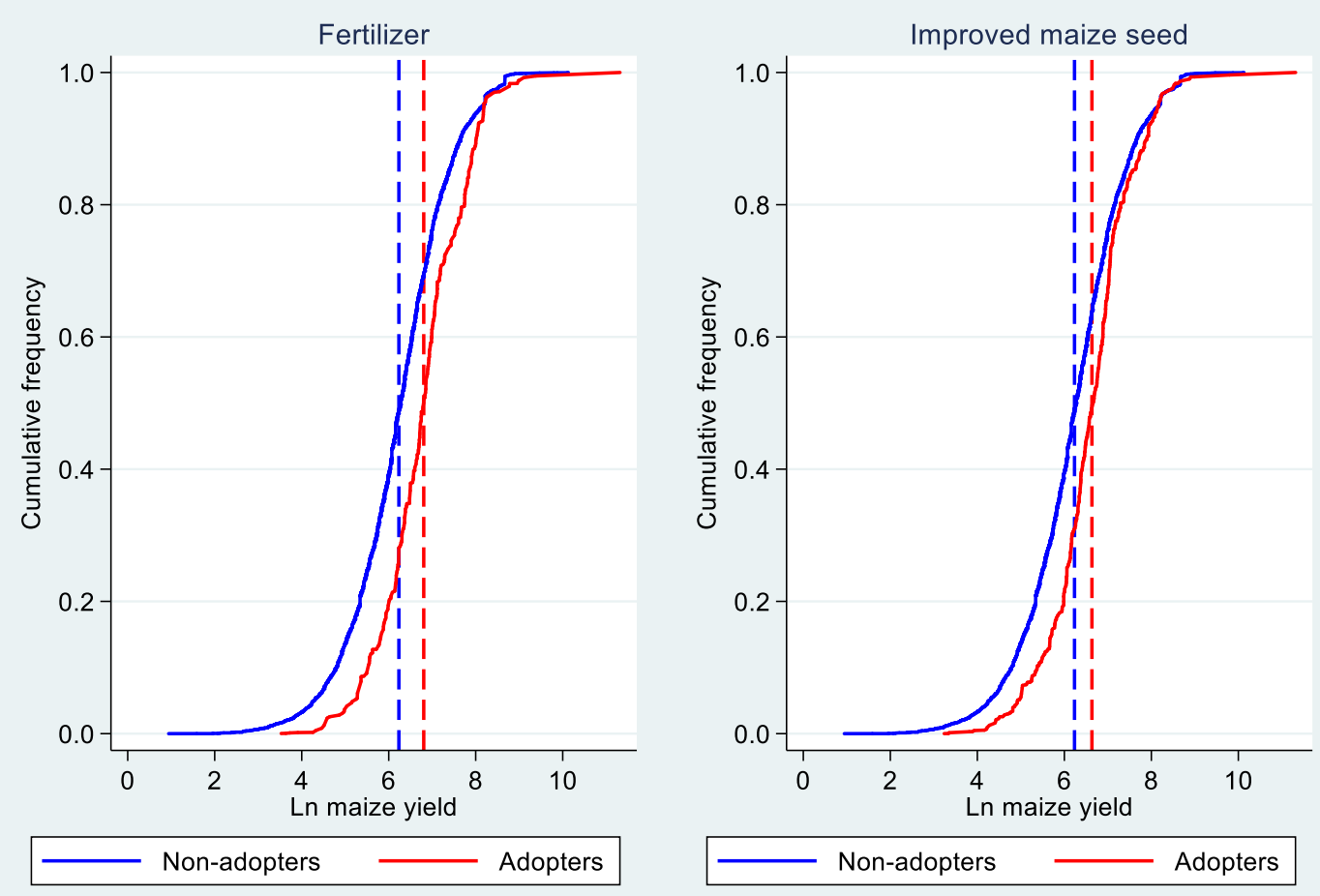

Source: IAI 2015

Figure 5.1 Maize yield among adopters and non-adopters of improved inputs 


\subsection{Agricultural Research}

\subsubsection{Levels of Agricultural Research Expenditure}

The share of agricultural public expenditure accounted for by actual public expenditure in agricultural research has been quite stable, averaging 5\% between 2013 -2017. Over the same period, public expenditure in agricultural research accounted for $17 \%$ of the total public spending in the agricultural production and productivity result area, ranking third within this result area, with agricultural irrigation and cash crops having higher shares (22\% and 19\%, respectively). Table 5.2 summarizes public expenditure in agricultural research by ministry during the same period and shows that public expenditure in agricultural research did not follow a clear trend in real terms over the period 2013 to 2017. After increasing by 33\% between 2013 and 2014, public spending on agricultural research trended downward in real terms, falling from 396 million MZN in 2014 to 258 million MZN in 2017, a reduction of $35 \%$. Expenditure in agricultural research for MASA and MIMAIP followed similar patterns. In real terms, MITADER had negligible expenditure in agricultural research in 2014 and 2015, but their expenditure in agricultural research increased substantially from 285,000 MZN in 2014 to 9 million MZN in 2017. Public spending on agricultural research in real terms averaged 308 million MZN per year between 2013 and 2017. MASA and MIMAIP are undoubtedly the largest contributors to public spending on agricultural research, together accounting for $99 \%$ of the average public spending on agricultural research (MASA accounted for $71 \%$ and MIMAIP for $28 \%$ ) during the same period. Public expenditure in agricultural research totaled 2.1 billion MZN over the period 2013 through 2017, representing about $10 \%$ of the PNISA proposed budget for agricultural research over the same period. This corresponds to a financial gap of $90 \%$. As shown in Figure 5.2 below, the share of the PNISA proposed budget for agricultural research accounted for by actual public expenditure in agricultural research was relatively stable over the period 2013 to 2017, fluctuating between $8 \%$ in 2013 and $11 \%$ in 2014 with an average of $10 \%$.

Table 5.2 Expenditure in agricultural research (real thousand MZN, 2009 = 100)

\begin{tabular}{lllll}
\hline & \multicolumn{2}{l}{ Ministry } & & \\
\cline { 2 - 4 } Year & MASA & MITADER & MIMAIP & Total \\
\hline 2013 & 206,079 & & 90,713 & 296,792 \\
2014 & 288,477 & 285 & 107,277 & 396,040 \\
2015 & 236,215 & 34 & 101,281 & 337,530 \\
2016 & 183,538 & & 66,651 & 250,189 \\
2017 & 184,646 & 8,547 & 64,743 & 257,935 \\
Average & $\mathbf{2 1 9 , 7 9 1}$ & $\mathbf{2 , 9 5 6}$ & $\mathbf{8 6 , 1 3 3}$ & $\mathbf{3 0 7 , 6 9 7}$ \\
\hline
\end{tabular}

Source: e-SISTAFE

This financial gap of $90 \%$ in agricultural research expenditure is substantially large by any standards, making it challenging to realistically achieve the PNISA objectives and targets, especially given that agricultural research is one of the critical channels through which agricultural productivity gains could be realized to sustain annual growth rates of at least 6\% (PEDSA and MALABO Declaration targets) and also to contribute to poverty reduction. Indeed, Alene and Coulibaly (2009) found sizable elasticities of expenditure in agricultural research with respect to agricultural productivity, per capita income and poverty in Sub Saharan Africa (SSA): A $1 \%$ increase in expenditure in agricultural research is expected to result in a $0.38 \%$ increase in agricultural productivity, a $0.95 \%$ growth in per capita income and a $0.60 \%$ reduction in poverty, while considering some lags in these expenditure-result linkages. 


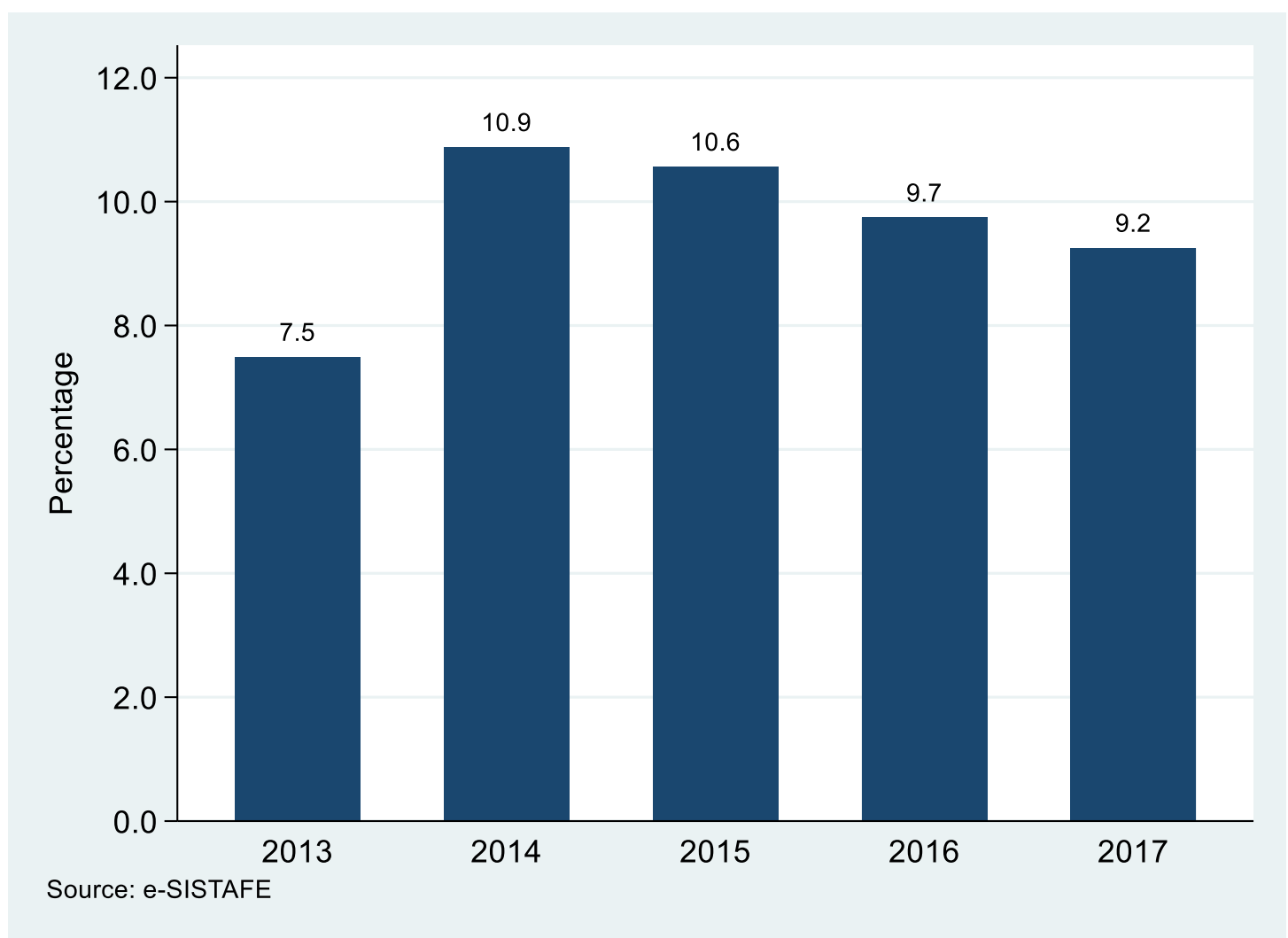

Figure 5.2 Expenditure on agricultural research as share of PNISA proposed budget for research

Estimates of expenditure in agricultural research as a share of agricultural GDP (AgGDP) are summarized in Figure 5.3. Public expenditure in agricultural research relative to AgGDP, commonly known as the agricultural research intensity ratio, averaged $0.31 \%$ over the period $2013-2017$, compared with an average of $0.69 \%$ during the period 1981 to 2008 estimated by Fuglie and Rada (2016). This could suggest that public spending on agricultural research relative to AgGDP declined in Mozambique. This finding reveals that between 2013 and 2017, Mozambique fell short of meeting the important international target of spending at least $1 \%$ of its AgGDP on agricultural research, the target set by the Africa Union (AU) Executive Council in 2006 on its KHARTOUM Decision on Science and Technology. To meet the KHARTOUM Decision, Mozambique would have to increase its public spending on agricultural research by, on average, 979 million MZN, more than doubling the average expenditure level over the period 2013 to 2017. This suggests that Mozambique is underinvesting significantly in agricultural research. However, it is worth noting that the policy and institutional environment under which agricultural research occur, appropriate composition of agricultural research expenditure are as important as levels of expenditure in agricultural research. 


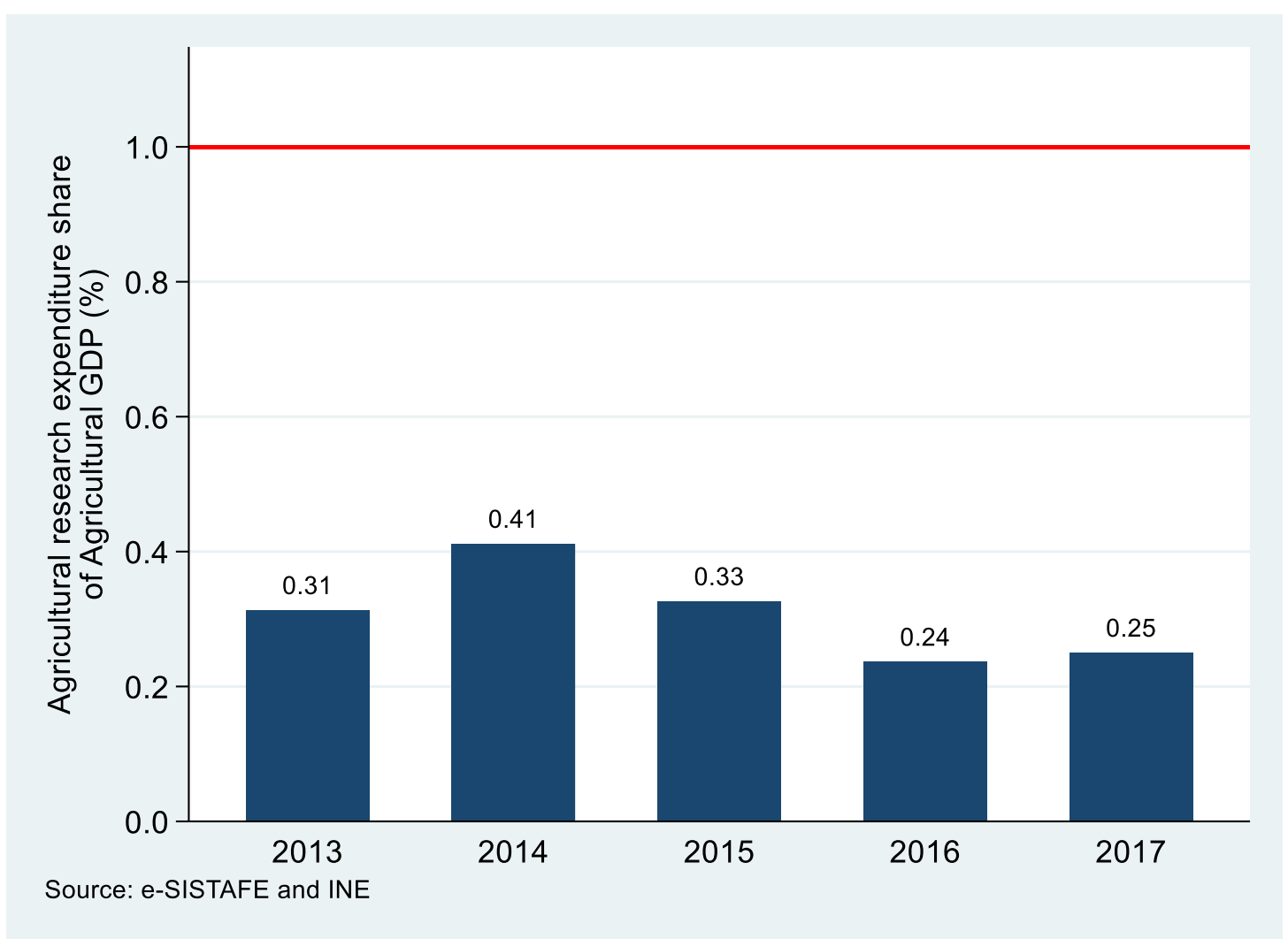

Figure 5.3 Public expenditure in agricultural research as a share of agricultural GDP

\subsubsection{Composition of Agricultural Research Expenditure}

Composition of public expenditure in agricultural research plays a central role in determining the efficiency and effectiveness of agricultural research, and its contribution to sustained agricultural growth and other key impact-level targets. Figure 5.4disaggregates agricultural research public spending by major cost category (wages, operating and other costs, and capital investment). This figure shows that the wage share in public expenditure in agricultural research registered an upward trend, jumping from $44 \%$ in 2013 to $70 \%$ in 2017 . Over this period, 58\% of the total public expenditure in agricultural research was allocated to wages, $29 \%$ to operating and other costs, and $13 \%$ to capital investment. The wage share in agricultural research public expenditure is much higher than the wage share in agricultural public expenditure ( $58 \%$ versus $21 \%)$. This composition indicates that agricultural research entities spent a sizable share of the total expenditure on salary-related expenses and relatively small share on capital investment and non-wage expenses, directly related to running research programs coupled with rehabilitation and development of infrastructure and equipment (58\% versus $13 \%$ ). If research capacity is to be strengthened to more effectively and efficiently contribute to agricultural productivity gains, then a higher share of agricultural research expenditure should be directed towards capital investments (infrastructure and equipment) and non-wage expenses to ensure researchers are productive. However, as argued by Fuglie and Rada (2016), the optimal allocation across cost categories (wages, operating and other costs, and capital investment) should be determined taking into account country size, agroecological diversity, research mandates, and composition of staff. It is recommended that MASA undertake to work out appropriate levels and shares of expenditure, based on efficiency "benchmarks", as the basis for future budgetary requirements/proposals. 


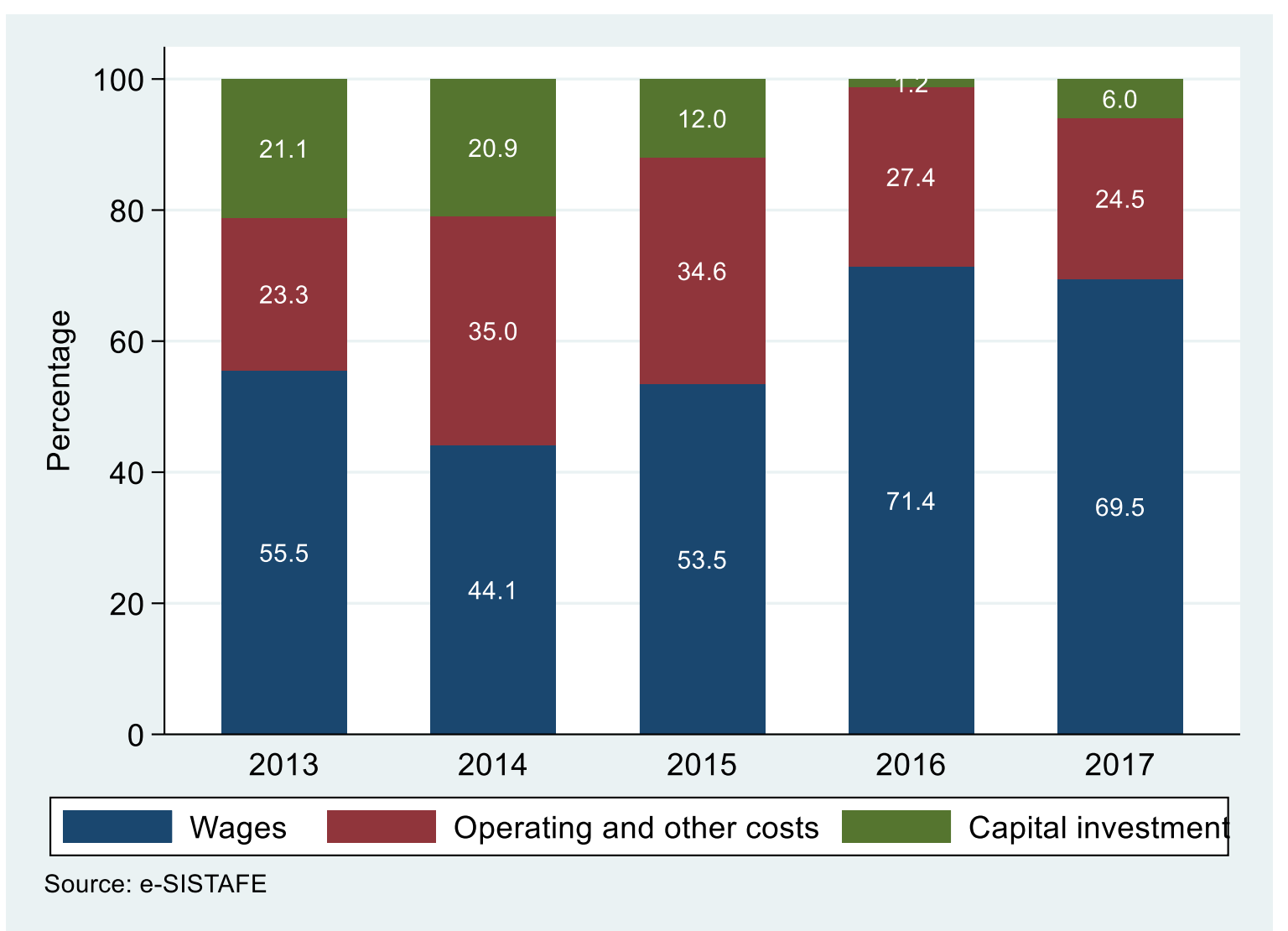

Figure 5.4 Public expenditure in agricultural research by cost categoory

\subsubsection{Funding Source of Agricultural Research Expenditure}

Over the period $2013-2017$, investment expenditure in agricultural research amounted to 819 million MZN, representing $15 \%$ of the total public expenditure in agricultural research. The proportion of total investment expenditure funded by internal sources averaged 85\%, ranging from 69\% in 2016 to $93 \%$ in 2014 (see Figure 5.5). This could be an indication that the GoM gives relatively high priority to agricultural research, but also makes the budgetary allocation to agricultural research more predictable, as discussed earlier, because funding from internal sources has higher budget execution rates than those from external sources ( $80 \%$ versus $38 \%$ ). This higher importance of internal sources is also related to the fact that a substantial share of capital expenditure $(20 \%)$ is spent on paying salaries, as discussed earlier, due to the misclassification of some recurrent expenditure (such as wages) which are classified as capital expenditure in e-SISTAFE. On the other hand, Figure 5.5 illustrates that external sources of capital expenditure are becoming more important in terms of contribution to total capital public expenditure in agricultural research. The share of capital public expenditure accounted for by external sources trended upward, jumping from $8 \%$ in 2013 to $28 \%$ in 2017. 


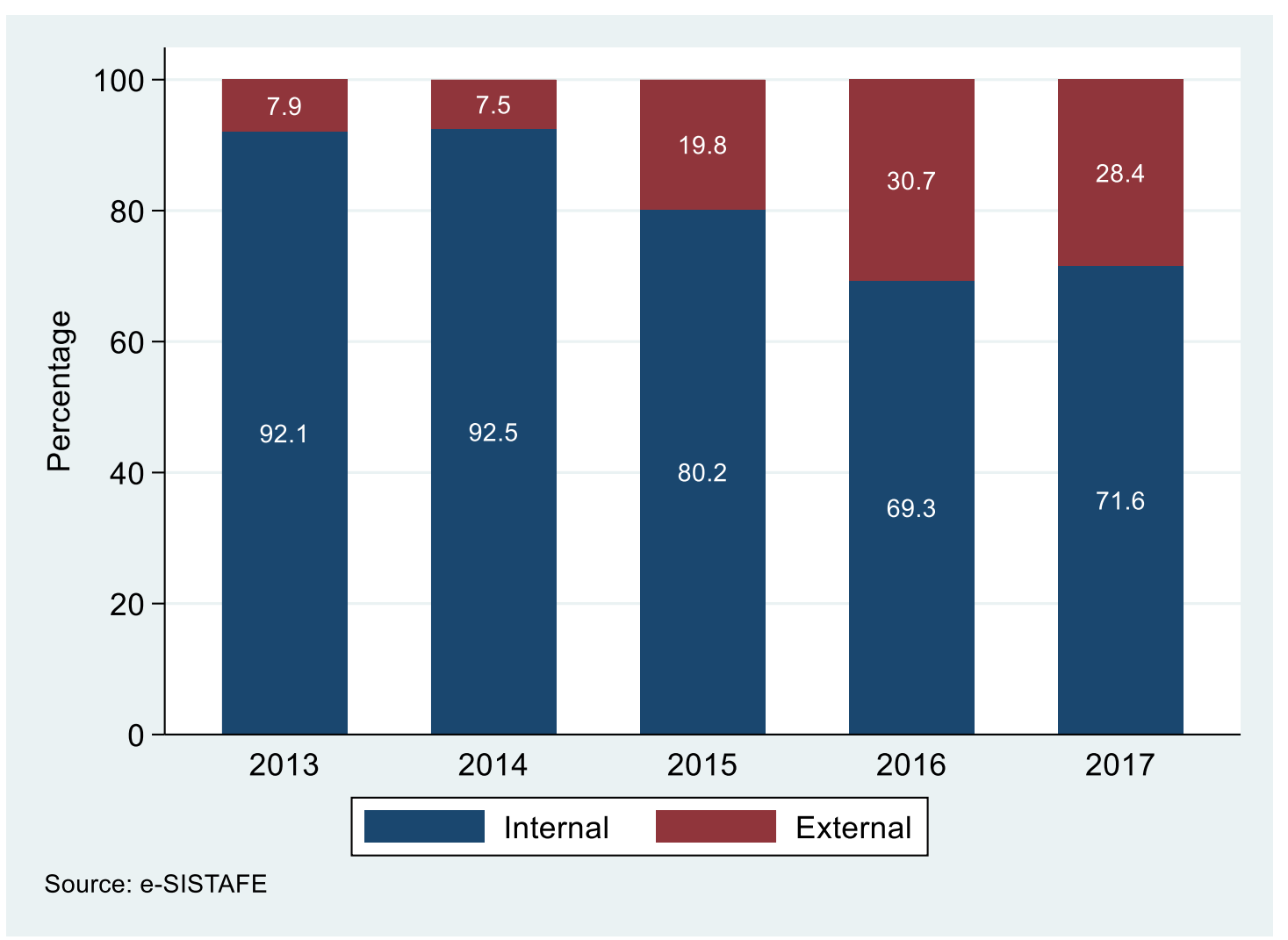

Figure 5.5 Capital public expenditure in agricultural research by funding source

\subsubsection{Agricultural Research Public Expenditure by Administrative Level}

Figure 5.6 breaks down public expenditure in agricultural research by administrative level. This figure illustrates that the share of agricultural research public expenditure accounted for by sub-national government (province level) averaged 39\% over the period 2013 to 2017, and fluctuating between $30 \%$ in 2014 and $44 \%$ in 2013. The sub-national government share of public expenditure in agricultural research is higher than that of the public expenditure in agricultural sector (39\% versus $26 \%$ ). Public expenditure in agricultural research channeled through sub-national government averaged 163 million MZN during the period 2013 to 2017, compared with 256 million MZN channeled through central-level government. These findings suggest higher commitment to decentralization, in terms of both devolution and deconcentration, of public expenditure in agricultural research versus the commitment to meeting expenditure targets for the overall agricultural sector. This is beneficial given that agricultural research should happen on the ground closer to smallholder farmers who are the ultimate agricultural research's target, hence taking into account agro-ecological diversity and specific smallholder farmers' characteristics. 


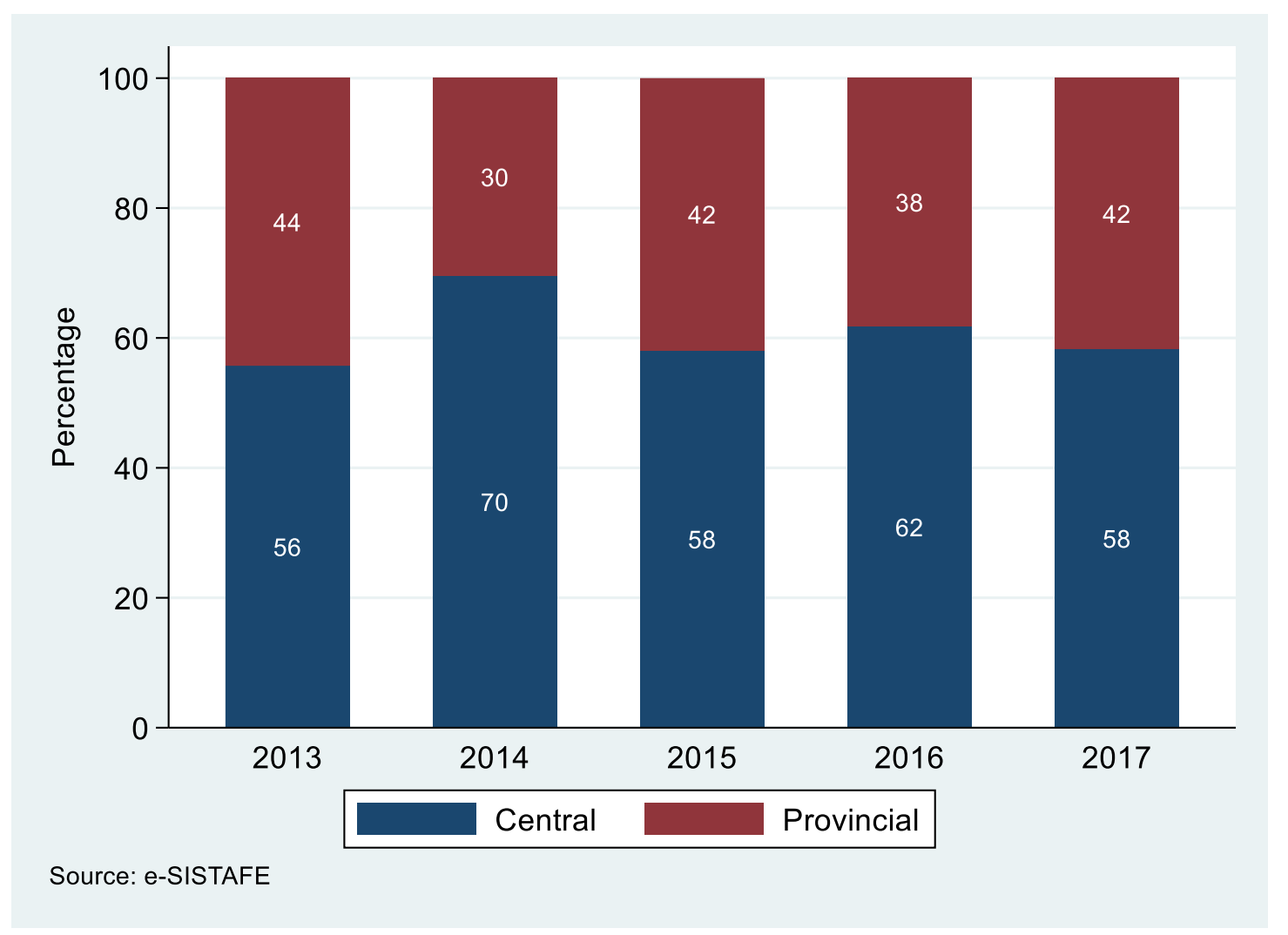

Figure 5.6 Public expenditure in agricultural research by administrative level

\subsubsection{Human Resource in Agricultural Research}

Both the efficiency and effectiveness of agricultural research depend on the availability of physical (such as infrastructure and equipment) and human capital in terms of both quantity and quality. Furthermore, the composition of agricultural researchers in terms of educational level will also play a central role in determining the effectiveness and efficiency with which agricultural research is executed. As indicated earlier, agricultural research is undertaken by MASA predominantly through the Mozambique Agricultural Research Institute (IIAM) and MIMAIP mainly through the Mozambique Fisheries Research Institute (IIP). Table 5.3 summarizes the number of full-time-equivalent (FTE) agricultural researchers by degree. The number of agricultural researchers (FTE) trended upward, increasing by $26 \%$ from 233 in 2013 to 294 in 2016. This increase was complemented with an increase in the intensity of FTE agricultural researchers per smallholder farmers. The number of FTE agricultural researchers per 100,000 smallholder farmers (per one million population) increased from 3.1 (11.4) in 2013 to 3.7 (13.9) in 2017. Table 5.3 also shows that the number of FTE agricultural researchers averaged 258 per year over the period 2013 to 2016 of which $8 \%$ have a Ph.D., $43 \%$ have an M.Sc. and $49 \%$ have a B.Sc.. The numbers of FTE agricultural researchers with all three degrees (Ph.D., M.Sc. and B.Sc.) increased, agricultural researchers with Ph.D. registered the highest percentage increase between 2013 and 2017 (35\%), followed by agricultural researchers with B.Sc. (32\%) and finally those with M.Sc. (18\%). Despite this differential percentage increase in absolute values, the proportions of FTE agricultural researchers accounted for by researchers with each degree (Ph.D., M.Sc. and B.Sc.) remain steady over the period 2013 through 2017: Researchers with Ph.D. accounting, on average, for $8 \%$, researchers with M.Sc. for $43 \%$ and researchers with B.Sc. for $49 \%$ (see Figure 5.7 ). 
Table 5.3Full-time-equivalent (FTE) agricultural researchers by degree

\begin{tabular}{lllll}
\hline & Degree & & & \\
\cline { 2 - 5 } Year & Ph.D. & M.Sc. & B.Sc. & Total \\
\hline 2013 & 20 & 102 & 111 & 233 \\
2014 & 20 & 107 & 116 & 243 \\
2015 & 20 & 112 & 128 & 260 \\
2016 & 27 & 120 & 147 & 294 \\
\hline Average & $\mathbf{2 2}$ & $\mathbf{1 1 0}$ & $\mathbf{1 2 6}$ & $\mathbf{2 5 8}$ \\
\hline
\end{tabular}

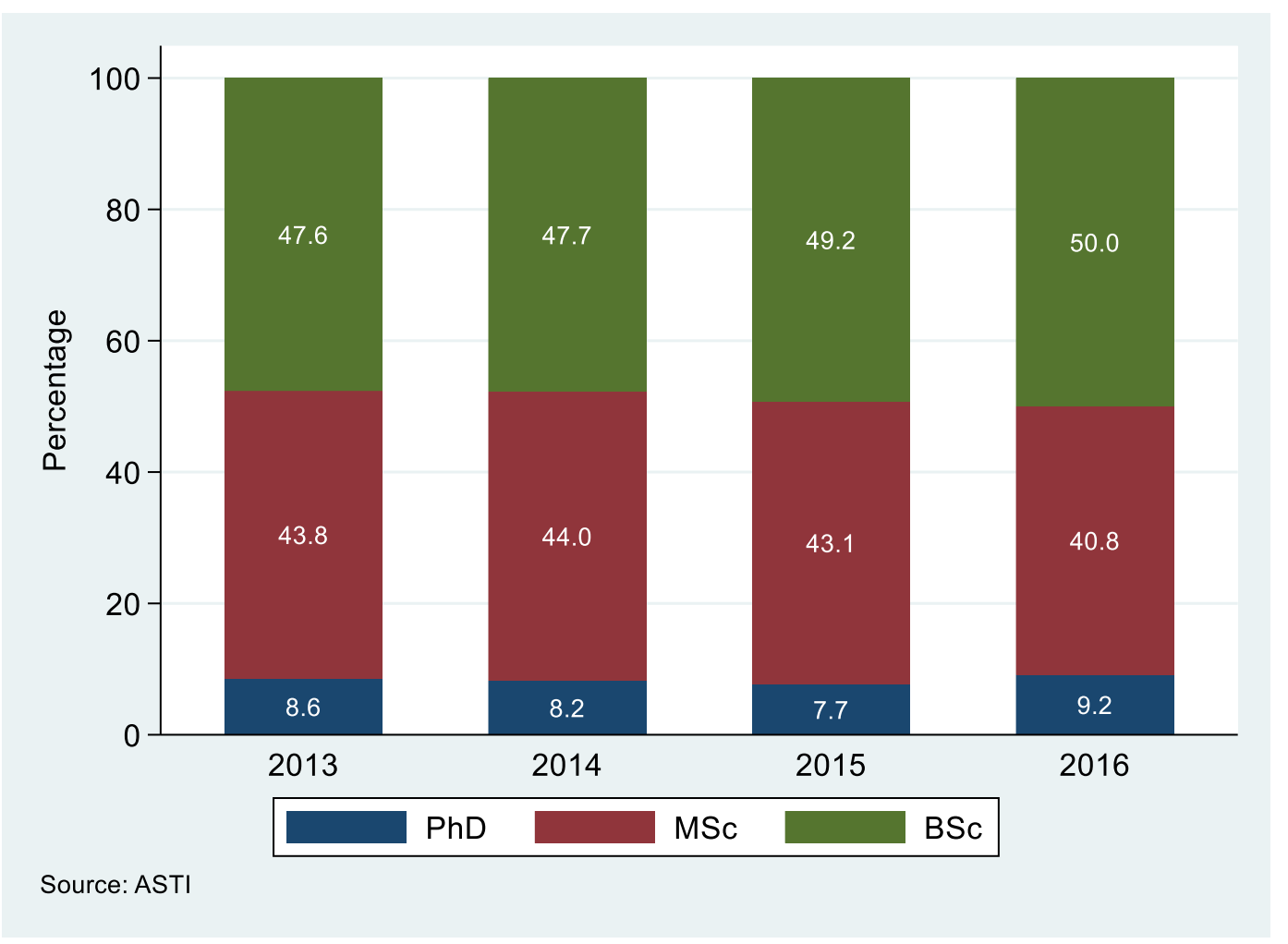

Figure 5.7 FTE agricultural researchers by degree

IIAM, the main institution conducting agricultural research in Mozambique, is divided between its headquarters located in Maputo and three (Four?) Zonal Research Centers (ZRC) located in Gaza, Manica, Nampula and Niassa provinces. Agricultural researchers from IIAM are concentrated in the Northeast ZRC in Nampula (accounting for $26 \%$ of the total FTE agricultural researchers), the headquarters (accounting for 25\%) and Southern ZRC in Gaza (accounting for 23\%). This concentration is associated with better research infrastructure and services at the headquarters, and in the Southern and Northeastern ZRCs. Figure 5.8 illustrates FTE agricultural researchers by ZRC and by degree. This figure shows that between 2008 and 2017, with the exception of the Northwest ZRC (Niassa), the share of agricultural researchers who hold M.Sc. degree in the total agricultural researchers increased in all ZRCs including the headquarters, while the share of researchers with B.Sc. declined. The proportion of agricultural researchers holding M.Sc. increased from $38 \%$ in 2008 to $66 \%$ in 2017 at the headquarters, from $21 \%$ to $37 \%$ in the Southern ZRC, from $6 \%$ to $25 \%$ in Central ZRC and from $24 \%$ to $28 \%$ in Northeast ZRC. This increase in the share of agricultural researchers with M.SC., coupled with slight increased share of researchers with Ph.D., suggests improvements in qualifications to undertake result-oriented research at IIAM. However, agricultural researchers who hold Ph.D. are concentrated 
at the headquarters which accounted for the largest share among the total number of agricultural researchers with a Ph.D. (55\%), with the Central ZRC accounting for the second largest share. The northwest ZRC does not have any agricultural research who hold a Ph.D.

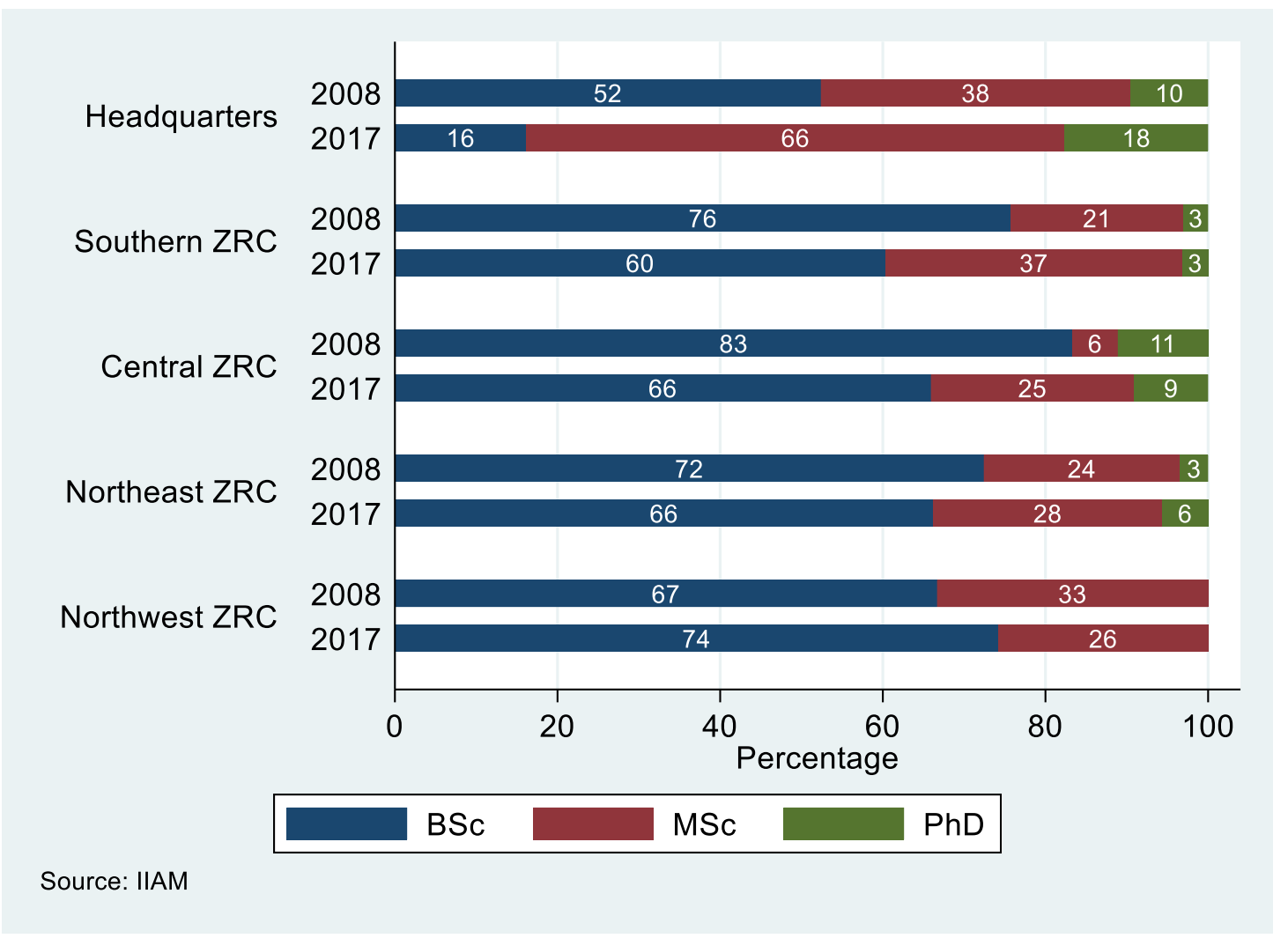

Figure 5.8 FTE agricultural researcher by zonal research center (ZRC) by degree

Figure 5.9 illustrates FTE agricultural researchers by age group. This figure shows the share of agricultural researchers aged 50 years and older increased substantially from $27 \%$ in 2011 to $52 \%$ in 2016 among Ph.D. holders'. A similar increase was registered for B.Sc. holders (6\% in 2011 to $11 \%$ in 2016) and for M.Sc. holders (from 14\% in 2014 to $16 \%$ in 2016). This relatively high proportion of Ph.D.-holders older than 50 years could be an indication that Mozambique could, in the near future, be faced with a retirement wave of well-qualified and experienced agricultural researchers (about $50 \%$ of researchers holding Ph.D.), which could in turn weaken research capacity in terms of human capital in the country. Hence, attention should be given to promoting mentorship and knowledge-sharing mechanisms between young and qualified and experienced researchers and taking advantage of training opportunities available at both national and international higher education institutions. 


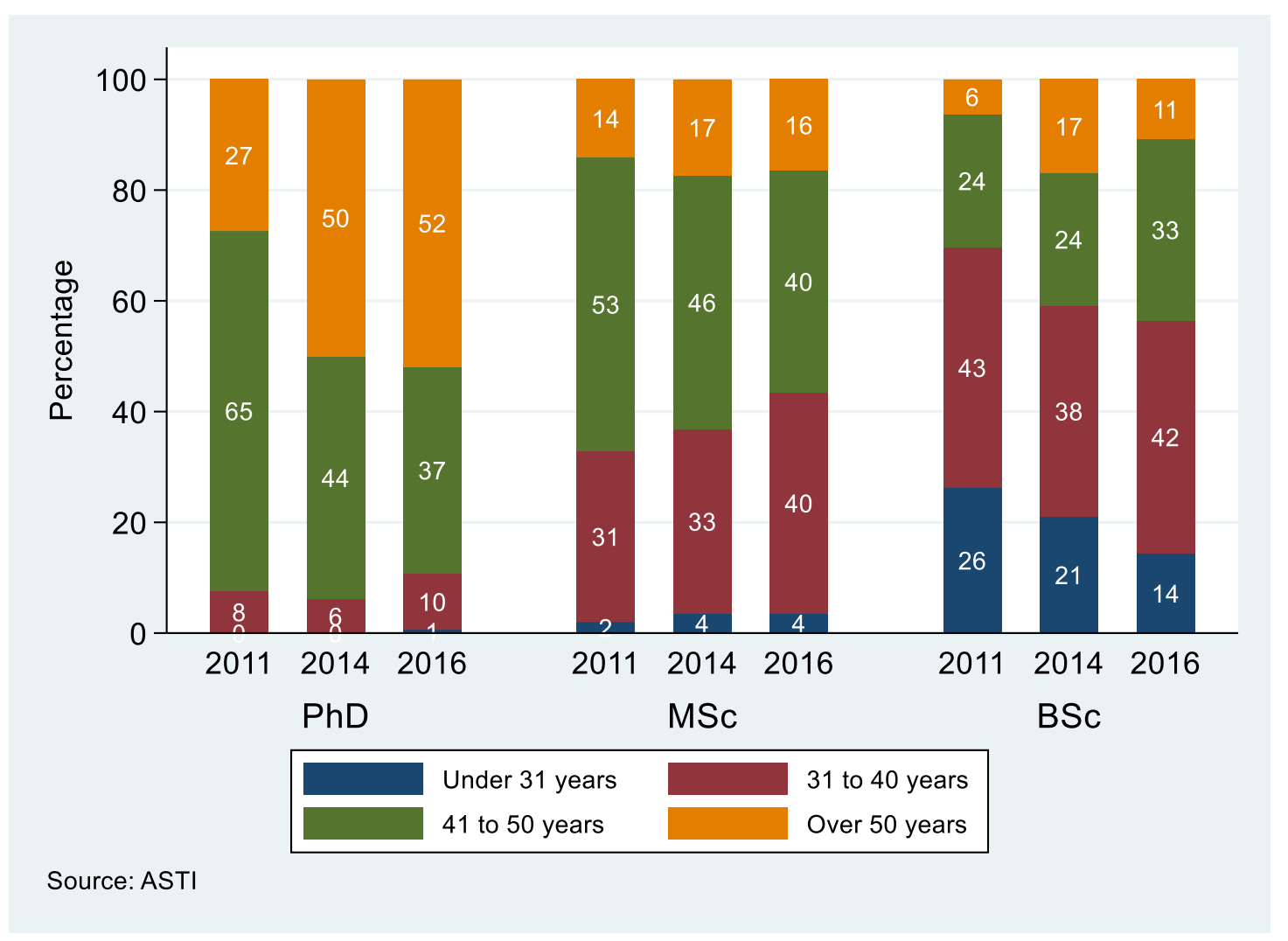

Figure 5.9 FTE agricultural researchers by age group

\subsection{Agricultural Extension}

Similar to agricultural research, expenditure allocations for agricultural extension are erratic and well below the targets outlined in PNISA and by international benchmarks. Given that productivity levels are well below target yields for virtually all food and cash crops, increasing expenditure allocations for agricultural extension and ensuring efficiency improvements should be high priorities actions and will generate substantial tangible benefits.

\subsubsection{Levels of Expenditure in Agricultural Extension}

Public expenditure on agricultural extension averaged 240 million MZN per year between 2013 and 2017, representing 3\% of the average public expenditure in the agricultural sector. The share of agricultural public expenditure accounted for by actual public expenditure on agricultural extension steadily trended upward during the period 2013 to 2017, increasing from 1\% in 2013 to 5\% in 2017. Over the same period, with a share of $10 \%$ of total agricultural expenditure, agricultural extension ranks fifth in terms of the proportion of total public expenditure in the Agricultural Production and Productivity result area, after agricultural irrigation (22\%), cash crops (19\%), agricultural research $(17 \%)$ and fisheries (12\%). Table 5.4 summarizes public expenditure in agricultural extension by ministry between 2013 and 2017. This table shows that public expenditure in agricultural extension increased between 2013 and 2015 by $237 \%$ from 62,000 MZN to 210,000 MZN. It then follows an erratic trend, dropping by $28 \%$ to reach $152,000 \mathrm{MZN}$ in 2016 and then increasing by $78 \%$ to 268,000 MZN in 2017. As mentioned earlier, the reduction in public expenditure in agricultural extension registered in 2016 is associated with DPs' withdrawal from direct support to the State Budget. Expenditure in agricultural extension for MASA followed a similar pattern to that of aggregate public expenditure in agricultural extension. Agricultural extension expenditure for MIMAIP followed a similar pattern up to 2015, but sharply dropped from 63,000 MZN in 2015 to 13,000 MZN in 2017. In 
real terms, MITADER had negligible expenditure in agricultural extension in 2015 and 2017, but their expenditure in agricultural extension dropped substantially from 65,000 MZN in 2015 to 28,000 MZN in 2017.

Public spending on agricultural extension in real terms averaged 168 million MZN per year between 2013 and 2017. MASA and MIMAIP are undoubtedly the largest entities in terms of public expenditure on agricultural extension accounting for $99 \%$ of average public spending in the area (MASA accounted for $86 \%$ and MIMAIP for $14 \%$ ). Public expenditure on agricultural extension totaled 1.2 billion MZN over the period 2013 to 2017, representing approximately 16\% of the PNISA proposed budget for agricultural extension over the same period, a financial gap of $74 \%$, lower than the financial gap for agricultural research that was estimated above at $90 \%$. As shown in Figure 5.10 below, actual public expenditure in agricultural extension relative to PNISA proposed budget for agricultural extension steadily trended upward, rising from $10 \%$ in 2013 to $23 \%$ in 2017.

Although lower than that for agricultural research, the financial gap of $74 \%$ for agricultural extension expenditure is substantially large, making it challenging to realistically achieve PNISA's objectives and strategic targets, that together with agricultural research is critical to achieving the agricultural productivity gains required to sustain annual growth rates of at least $6 \%$ and contribute to poverty reduction. The benefit of agricultural research will not be realized unless improved and appropriate agricultural technologies are developed through agricultural research are indeed adopted by smallholder farmers. Agricultural extension, for example, through demonstration plots in which smallholder farmers can see the benefits of improved agricultural technologies, which could play a central role in increasing adoption rates of improved agricultural technologies. This is because the development of improved agricultural technologies does not always result in their adoption due to a variety of factors.

Table 5.4 Expenditure in agricultural extension (real thousand MZN, $2009=100$ )

\begin{tabular}{lllll}
\hline & \multicolumn{2}{l}{ Ministry } & & \\
\cline { 2 - 4 } Year & MASA & MITADER & MIMAIP & Total \\
\hline 2013 & 57,167 & & 5,117 & 62,284 \\
2014 & 135,185 & & 10,463 & 145,648 \\
2015 & 147,401 & 65 & 62,617 & 210,083 \\
2016 & 121,717 & & 29,899 & 151,616 \\
2017 & 254,604 & 28 & 13,445 & 268,077 \\
Average & $\mathbf{1 4 3 , 2 1 5}$ & $\mathbf{4 7}$ & $\mathbf{2 4 , 3 0 8}$ & $\mathbf{1 6 7 , 5 4 2}$ \\
\hline
\end{tabular}

Source: e-SISTAFE 


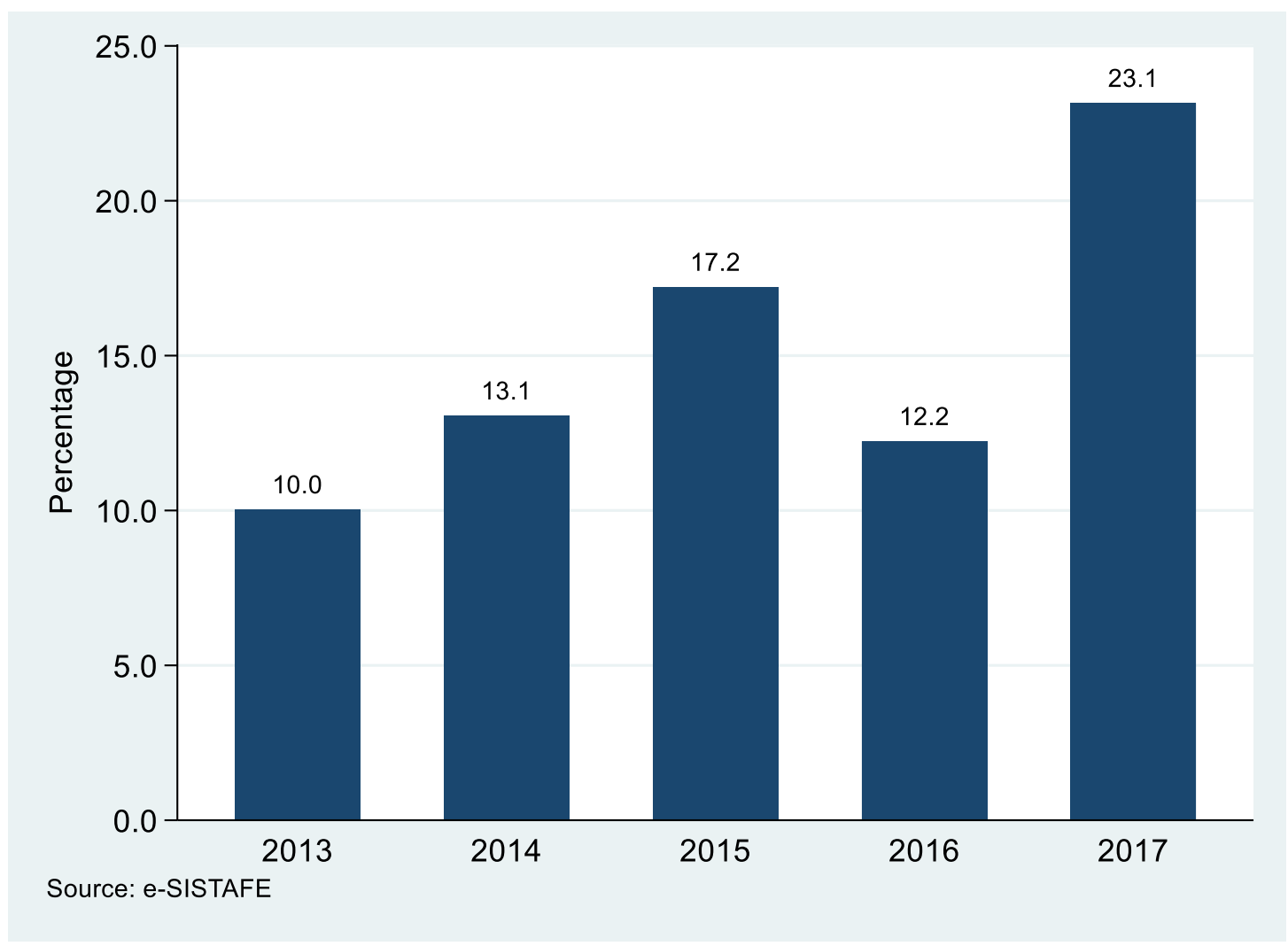

Figure 5.10 Expenditure on agricultural extension as share of PNISA proposed budget for extension

\subsubsection{Composition of Expenditure in Agricultural Extension}

As is the case for agricultural research, the composition of public expenditure plays a central role in determining the efficiency and effectiveness of agricultural extension, and especially in ensuring strong expenditure-result linkages. Figure 5.4 breaks down agricultural extension public spending by cost category (wages, operating and other costs, and capital investment) showing that the wage share of public expenditure in agricultural extension trended downward between 2013 and 2017, falling from $13 \%$ in 2013 to $7 \%$ in 2017 . During the same period, wages contributed to $10 \%$ of the total public expenditure in agricultural extension, while capital investment accounted for $25 \%$ and operating and other costs for $65 \%$. The wage share in public expenditure in agricultural extension was lower than the wage share of public agricultural research expenditure (10\% versus $21 \%)$. This could indicate that a sizable share of public expenditure in agricultural extension is allocated to expenses aimed at directly contributing to effective and efficient delivery of agricultural extension services ( $10 \%$ for wages versus $25 \%$ for capital investment). These trends are contrary to the case of agricultural research, in which a considerable share of expenditure is allocated to wages ( $58 \%$ for wages versus $13 \%$ for capital investment). 


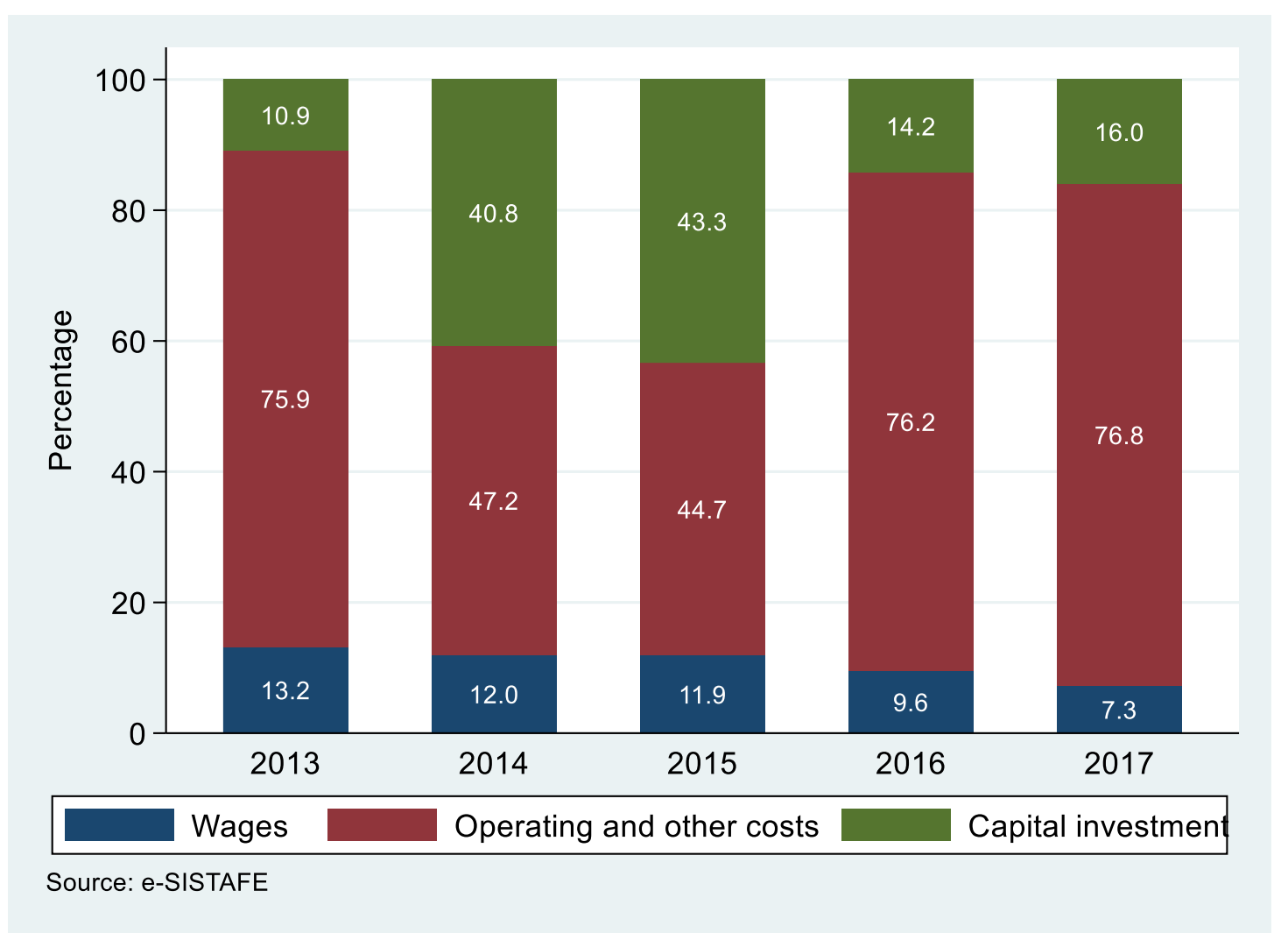

Figure 5.11 Public expenditure in agricultural extension by cost categoory

\subsubsection{Funding Source of Expenditure in Agricultural Extension}

Public investment expenditure in agricultural extension amounted to 1.2 billion MZN over the period 2013 to 2017 . This represents $99 \%$ of the total public expenditure in agricultural extension. Figure 5.12 breaks down public investment expenditure in agricultural extension by funding source. This figure illustrates that the proportion of total public investment expenditure in agricultural extension was funded by internal sources, averaging 32\%, and ranging from $23 \%$ in 2016 to $70 \%$ in 2013 . This finding, combined with findings from the agricultural research public expenditure, could be an indication that the GoM gives relatively lower priority to agricultural extension compared with agricultural research (internal sources contributed to $32 \%$ of investment public expenditure in agricultural extension and $85 \%$ of investment public expenditure in agricultural research). However, the higher dependence on external sources reflects lower budget predictability in public expenditure in agricultural extension. The lower significance of internal sources is also related to the fact that a relatively lower share of public capital expenditure in agricultural extension (10\% for agricultural extension versus $20 \%$ for agricultural research) is spent on paying salaries due to budget misclassification in e-SISTAFE, especially if they are funded by external sources. Furthermore, Figure 5.12 illustrates that external sources of public capital expenditure are steadily becoming more important in terms of its contribution to total public capital expenditure in agricultural extension. The share of public capital expenditure accounted for by external sources trended upward, increasing from 30\% in 2013 to $73 \%$ in 2017. 


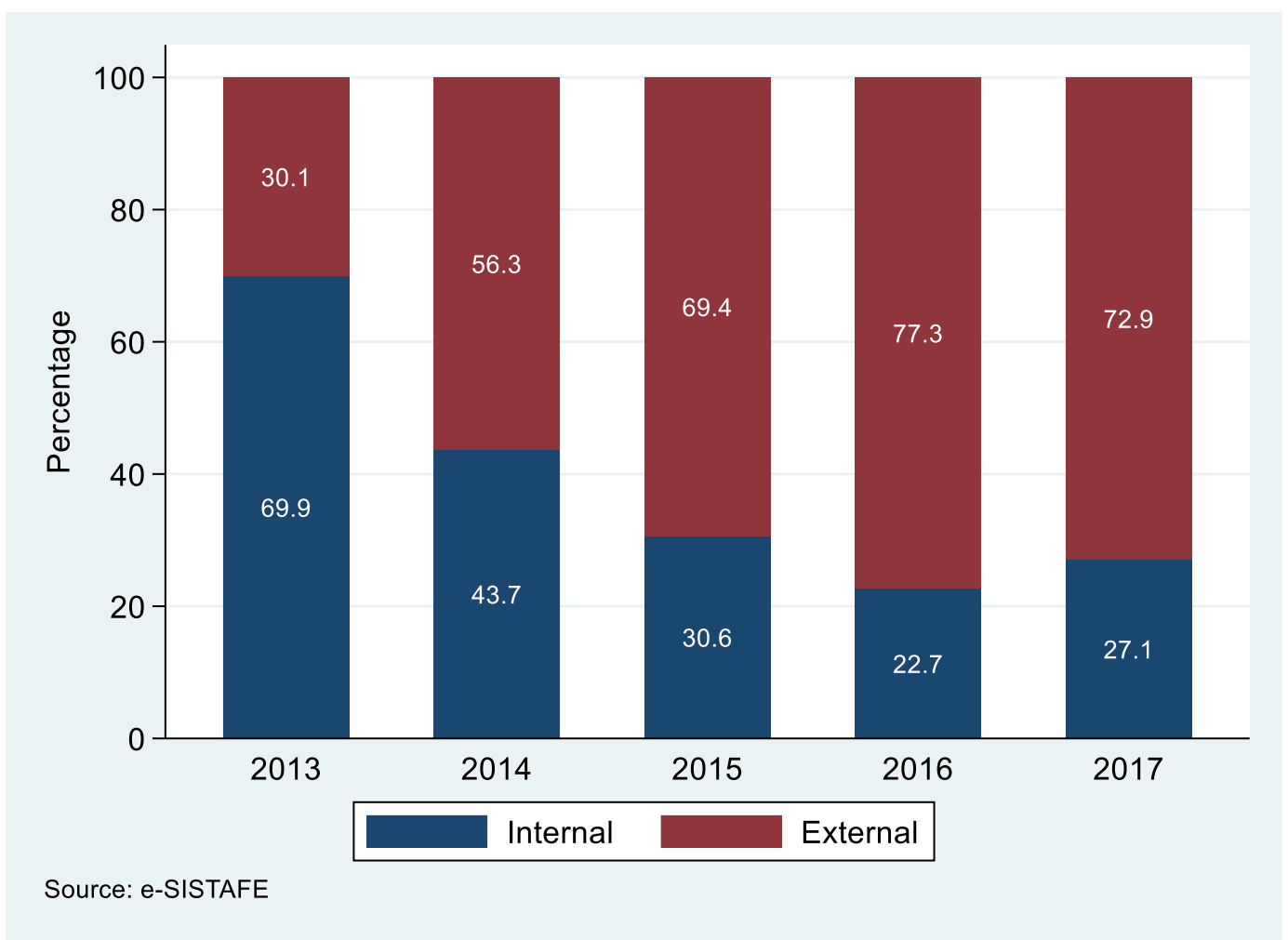

Figure 5.12 Capital public expenditure in agricultural extension by funding source

\subsubsection{Agricultural Extension Public Expenditure by Administrative Level}

The proportion of public expenditure in agricultural extension by central and sub-national government is summarized in Figure 5.13. This figure shows that the share of public expenditure in agricultural extension by sub-national government was relatively stable averaging of $23 \%$ during the period 2013 and 2017 and ranging from 20\% in 2016 to $34 \%$ in 2014. Sub-national government public expenditure in agricultural extension averaged 56,000MZN over the period 2013 to 2017. Compared with agricultural research, agricultural extension is less decentralized in terms of share of public expenditure channeled through sub-national government (23\% versus $39 \%$ ). However, the level of decentralization in agricultural extension is comparable to that in agricultural sector as whole $(23 \%$ versus $26 \%$ ). 


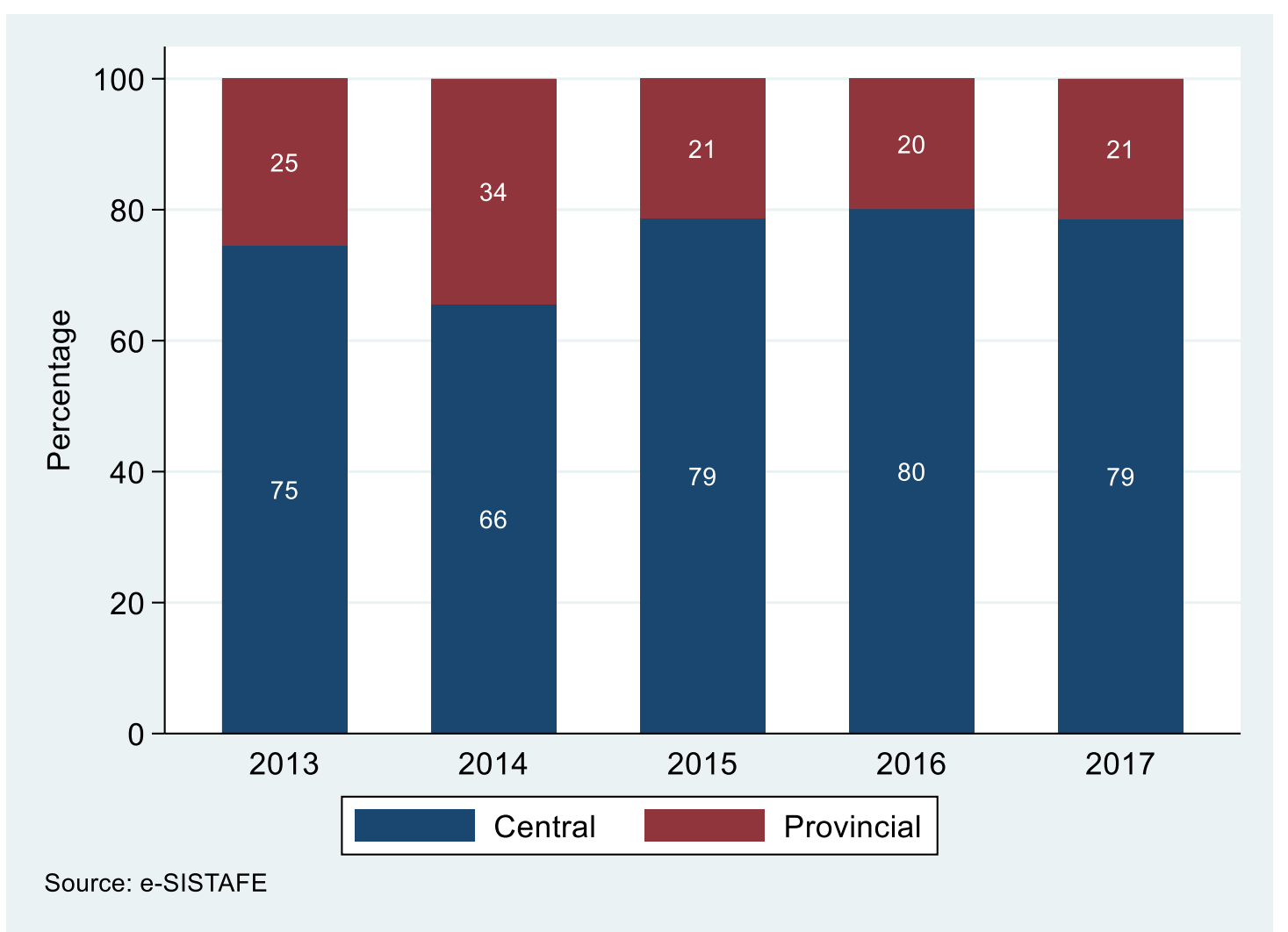

Figure 5.13 Public expenditure in agricultural extension by administrative level

\subsubsection{Human Resource in Agricultural Extension}

The stock of human capital, in terms of both quantity and quality, conditions the effective and efficient delivery of extension services. Figure 5.14 shows the number of extension officers by service provider indicating that the government is the main provider of extension officers. However, Government share of the total number of extension officers varied between $47 \%$ in 2015 and $62 \%$ in 2014, with no clear patterns between 2013 and 2017. However, the number of government extension officers steadily trended upward, increasing by 45\% from 1,137 in 2013 to 1,653 in 2017. The numbers of extension officers from NGOs and the private sector fluctuated and demonstrated no clear patterns. Data from the National Directorate of Agricultural Extension (DNEA) show that of the total number of extension officers from government in $2017,10 \%$ had primary level of education, $76 \%$ had secondary level and $14 \%$ had higher education, suggesting that extension officers are qualified to assist farmers to boost their agricultural productivity. The number of assisted farmers per government extension officer declined by 31\% from 603 in 2013 to 419 in 2017, as illustrated in Figure 5.15. Although still higher than the recommended coverage of 250 farmers per extension officer, it is moving in the right direction and if the trend continues, Mozambique would reach the recommend coverage of 250 farmers per extension officer by 2023. However, the share of farmers assisted by the government extension officers is small and efforts should be made to increase this share. Furthermore, the number of demonstration plots installed per extension officers also dropped from 5 in 2013 to 4 in 2017, despite the sizable increase in the number of extension officers. This small reduction in the number of demonstration plots installed by extension officers is associated with the low coverage of farmers. 


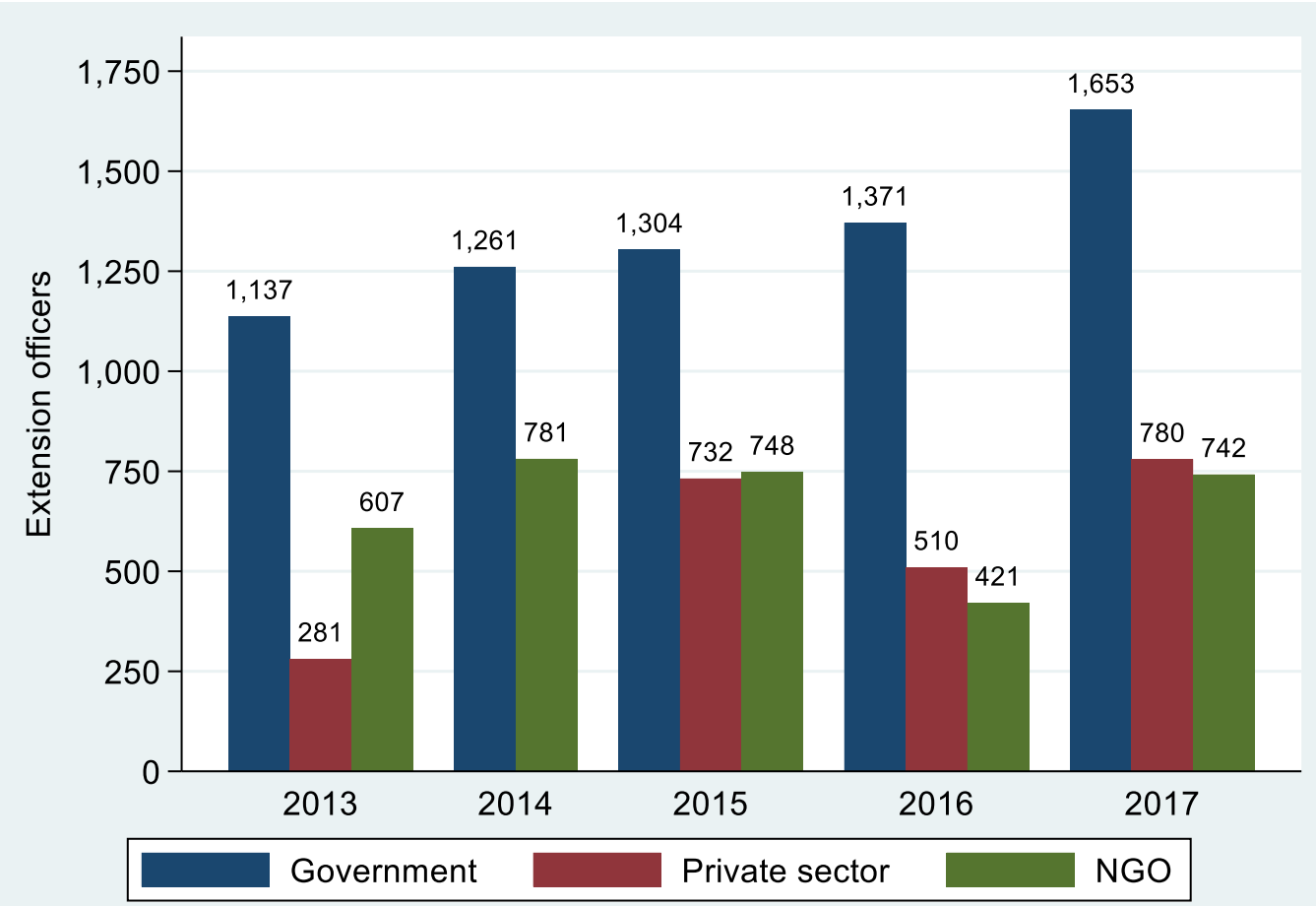

Source: DNEA

Figure 5.14 Number of extension officers by service provider

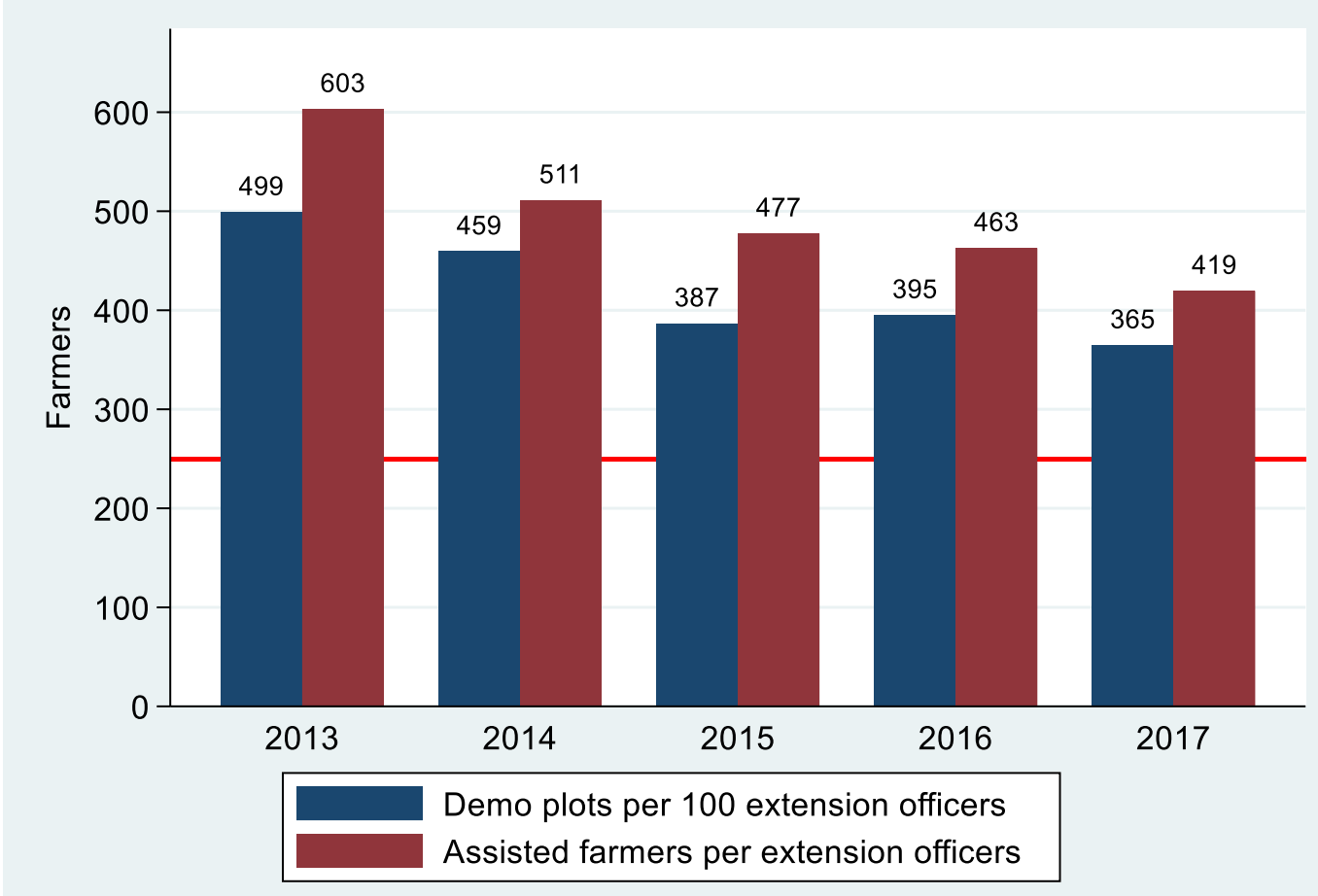

Source: DNEA

Figure 5.15 Demonstration plots and assisted farmers per extension officer 


\subsection{Agricultural Research and Extension Linkages}

The agricultural research and extension linkages represent the flow and feedback of information between researchers and extension agents with the goal of benefitting the end users (the farmers). Ttraditionally, research and extension linkage have tended to be largely based on a 'top-down' oneway communication model with information flowing from researchers to end users. This model has led to a situation where farmers had limited options in making decisions on the technologies appropriate to their specific farming needs and the low adoption of technologies due to the fact that they didn't respond to or were inappropriate to their needs and didn't produce directly measurable results or perceived benefits. This limitation led policy-makers, the academic community and development practitioners to recognize the central role of farmers in the technology development and transfer/adoption process in the late 1980s, leading to the substitution of the top down model with a demand-driven model, customized to local conditions and needs, and responsive to farmers' pressing problems.

Functional linkages between agricultural research and extension are critical for agricultural transformation, and weaknesses in these linkages are major factors in limiting the flow of information, knowledge, useful new technologies, and resources between stakeholders in the technology-delivery utilization system in developing countries.

In Mozambique, research and extension linkages are promoted by two institutions, namely the Mozambican Agricultural Research Institute and the National Directorate of Extension Services at MASA. Both institutions are represented at national level. As noted above, the Mozambican Agricultural Research Institute has four zonal centers covering the main agricultural conditions of the country The National Directorate for Extension is represented by Departments for Extension Services in the Provincial Directorates for Agriculture and Food Security, by District Services for Economic Activities, and by extension agents at community level. Besides public extension platforms, there are private extension agents. Mozambique currently has a total of 3,399 extension agents of which 1,951 (57\%) are public agents and 1,448 (43\%) private extension agents.

The presence of both research and extension services countrywide is crucial for the existence of functional research/extension linkages at all levels. However, there are two main research and extension linkage mechanisms in Mozambique namely (a) the Periodic Technology Review meetings (REPETEs) and (b) On-farm trials. The REPETEs bring together the two platforms (agricultural research and agricultural extension) to analyse best practices in technology supply, based on demands, and plan strategically for the production, dissemination and adoption of technologies. The REPETEs are conducted bi-annually at national level and annually at provincial level. They are rarely organized at district levels. On-farm trials are realised at community level and are conducted jointly by extension agents and researchers. and aim to introduce improved technologies and processes that can be transferred to farmers. However, the results of on-farm trials are not always communicated to the extension agents which limits the identification and dissemination of improved technologies and processes. The Mozambique Agricultural Research Institute has a department for documentation and technology transfer. However, this department is not effectively operational in terms of technology transfer. Besides these limitations, existing research and extension linkages do not include the major stakeholders in agricultural transformation, namely the farmers, the private sector and academia.

Other aspects that negatively impact on effective research and extension linkages in Mozambique include: (a) insufficient numbers of knowledgeable, trained extension workers, meaning extension has 
been unable to systematize recommendations to the producers; (b) few extension officers have the needed technological, market and agribusiness knowledge and technical skills, as well as the right attitude to be effective group facilitators; (c) limited attributable impact of extension and research on the reduction of rural poverty, which is also due to poor monitoring and evaluation systems; (d) a lack of cost-benefit studies of present and new profitable technologies for smallholders, also due to a weak linkage with research, both institutionally as well as technologically; and (e) a high turnover of personnel mainly due to poor incentives, and consequently the most qualified staff leave for NGOs, for higher pay, once they gain some experience within the public system.

In order to improve research and extension linkages, experience from other countries such as Ethiopia suggest the creation of inclusive research and extension linkages mechanisms such as (a) Research Extension Liaison Committees (RELCs) and (b) Research-Extension Advisory Councils (REACs) at both national, provincial and district levels. The establishment of the national RELCs was believed to provide a suitable forum for consultation among different stakeholders and the zonal RELCs were responsible for the testing of improved technologies recommended by zonal research centres before they were released to farmers. The zonal RELCs were also commissioned to design training programs for specialists and development agents on improved technologies to be disseminated to farmers, to review and approve research proposals submitted by research centers, and to serve as a forum where the views of extension workers were considered in identifying research problems for the formulation of research topics. The main objectives of the Research-Extension Advisory Councils (REACs) were to (i) review research programs, (ii) develop technology packages for extension work, and (iii) provide technical backstopping through facilitation of training to extension workers. At the grass roots level, the strategy adopted by Ethiopia, for example to make agricultural research and extension systems responsive and relevant, was to involve small farmers in the selection of research and extension priorities and in research planning and implementation through the establishment of Farmer Research Groups. Farmer Research Groups are groups that farmers voluntarily form to undertake experimentation (research and extension) on their own fields.

\subsection{Agricultural Irrigation}

Similar to agricultural research and extension, levels and quality of expenditure for agricultural irrigation are well below the PNISA original targets and expectations in terms of results. The relatively higher cost of irrigation investments warrants judicious planning and efficient and effective implementation, and effective operation and maintenance.

\subsubsection{Levels of Expenditure in Agricultural Irrigation}

Accounting for $6 \%$ of the average actual public expenditure in the agricultural sector during the period 2013 to 2017, public expenditure in agricultural irrigation averaged 385 million MZN per year. The proportion of agricultural irrigation public expenditure in total agricultural public expenditure has trended downward from $6 \%$ in 2013 to $2 \%$ in 2016. It then increased substantially to $11 \%$ in 2017. Public expenditure in agricultural irrigation relative to that for the agricultural production and productivity result area stood at 22\% between 2013 and 2017, ranking first within this result area, followed by cash crops accounting for $19 \%$ and agricultural research at $17 \%$ in the third place.

Table 5.5 summarizes public expenditure in agricultural irrigation by ministry between 2013 and 2017 showing that the MASA is the only ministry through which public expenditure in agricultural irrigation is executed and that public expenditure decreased from 408 million MZN in 2013 to 88 million MZN 
in 2016, a reduction of 79\%. It then sharply increased to 576 million MZN in 2017, an increase of 558\% and a record-high between 2013 and 2017. Once again, the substantial drop in public expenditure in agricultural irrigation is related to DPs' withdrawal from direct budget support. Public expenditure in agricultural irrigation amounted to 2.7 billion MZN over the period 2013 - 2017, representing about $11 \%$ of the PNISA proposed budget for irrigation over the same period. This corresponds to a financial gap of $89 \%$, which is comparable to that of agricultural research $(90 \%)$ and higher than that of agricultural extension (74\%).

Figure 5.16 shows public expenditure in agricultural irrigation as a share of the PNISA proposed budget for agricultural irrigation and indicates that expenditure was stable at about 10\% between 2013 and 2015 before substantially dropping to 3\% in 2016 before recovering to reach. 25\% in 2017.

This financial gap of $89 \%$ in agricultural irrigation public expenditure is substantial making it challenging to realistically achieve the PNISA objectives and targets, and given that agricultural irrigation, coupled with expanded and improved quality of agricultural research and extension, is a critical channels through which agricultural productivity gains could be realized to sustain annual growth rates of at least $6 \%$ and to contribute to poverty reduction, is of concern. Increasing usage of agricultural irrigation is central to improving agricultural productivity given that the vast majority of smallholder farmers depend on rain-fed agricultural production systems. Data from IAI 2015 show that only $3 \%$ of smallholder farmers used agricultural irrigation in the agricultural season 2014/2015.

Table 5.5 Expenditure in agricultural irrigation (real million MZN, $2009=100$

\begin{tabular}{lll}
\hline Year & MASA & Total \\
\hline 2013 & 408 & 408 \\
2014 & 459 & 459 \\
2015 & 396 & 396 \\
2016 & 88 & 88 \\
2017 & 576 & 576 \\
Average & 385 & 385 \\
\hline
\end{tabular}

Source: e-SISTAFE 


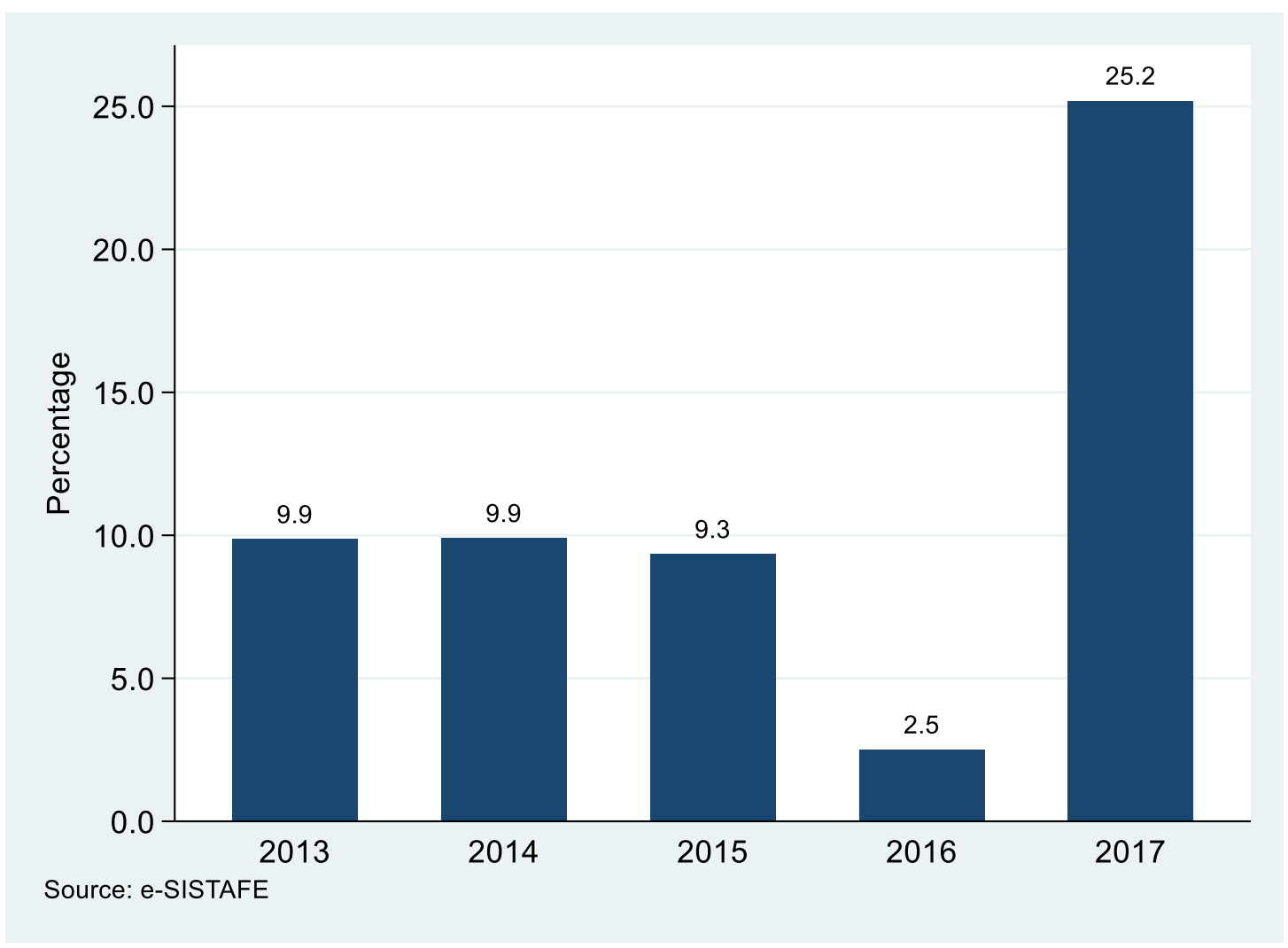

Figure 5.16 Expenditure on agricultural irrigation as share of PNISA proposed budget for irrigation

\subsubsection{Composition of Expenditure in Agricultural Irrigation}

As is the case for agricultural research and extension, the composition of public expenditure in agricultural extension plays a central role in determining the efficiency and effectiveness of agricultural irrigation. Figure 5.4 breaks down public expenditure in agricultural irrigation by cost category (wages, operating and other costs, and capital investment). This figure shows that the wage share of public expenditure in agricultural irrigation trended upward between 2013 and 2017, increasing from $1 \%$ in 2013 to $10 \%$ in 2017 . The share of capital investment in public expenditure in agricultural irrigation also trended upward, increasing from $53 \%$ in 2013 to $81 \%$ in 2017 . During the same period, wages represented $6 \%$ of the total public expenditure in agricultural irrigation, operating and other costs to $24 \%$ and capital investment to $70 \%$. The wage share in public expenditure in agricultural irrigation was lower than the wage share of agricultural extension public expenditure and of agricultural research public expenditure (6\% versus $10 \%$ versus $21 \%$ ). This could indicate that like agricultural extension, a sizable share of public expenditure in agricultural irrigation is allocated to expenses aimed at directly contributing to capital infrastructure with the aim of effective and efficient delivery of agricultural irrigation (6\% for wages versus $70 \%$ for capital investment); in contrast, expenditures for agricultural research are dominated by human capital, in which considerable share is allocated to wages (i.e., $58 \%$ for wages versus $13 \%$ for capital investment). 


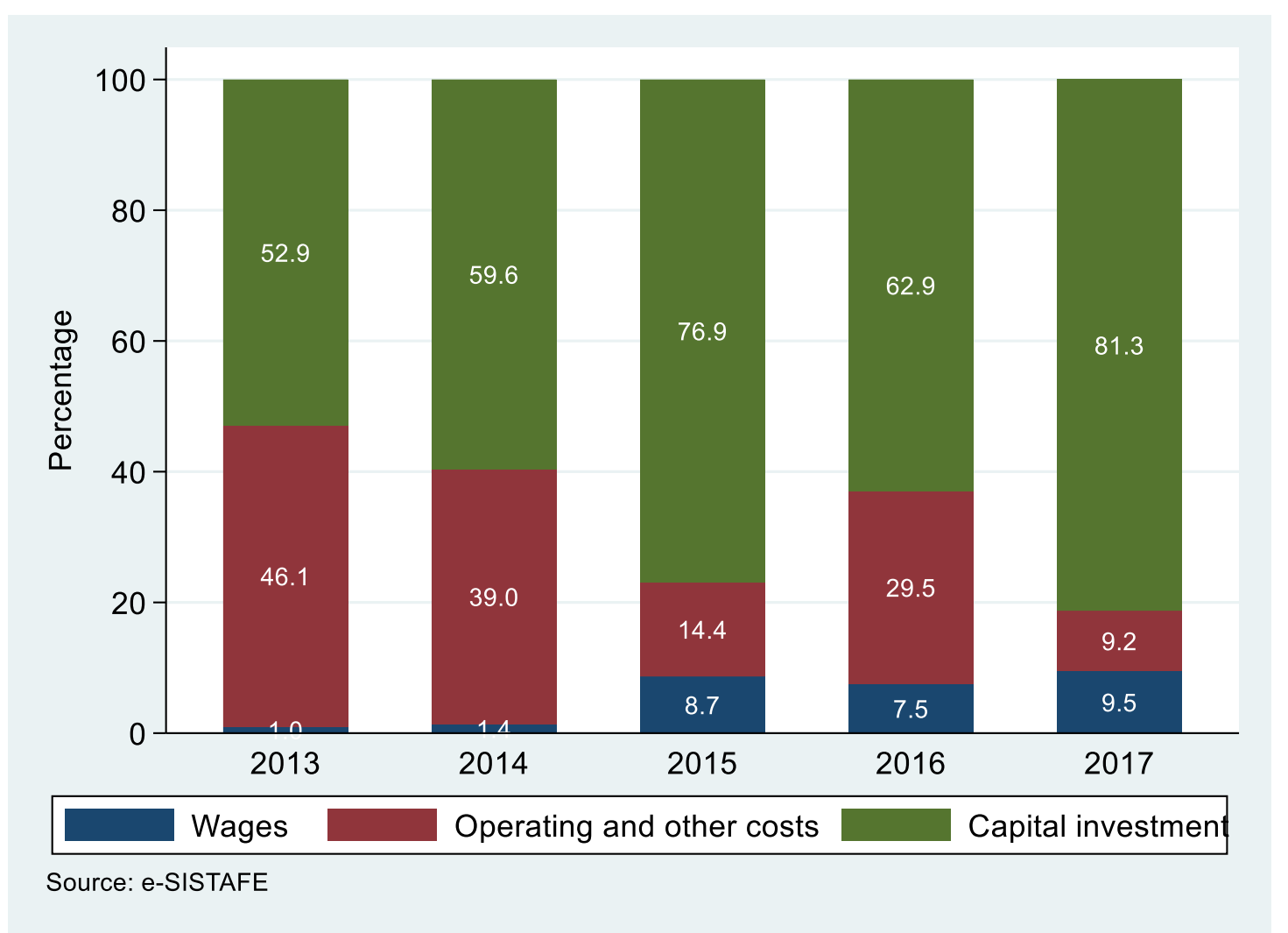

Figure 5.17 Public expenditure in agricultural irrigation by cost categoory

\subsubsection{Funding Source of Expenditure in Agricultural Irrigation}

Investment public expenditure in agricultural irrigation totaled 2.7 billion MZN over the period 2013 through 2017, representing 99\% of the total public expenditure in agricultural irrigation. Figure 5.18 breaks down investment public expenditure in agricultural irrigation by funding sources. This figure illustrates that the share of investment expenditure in agricultural irrigation using internal financial sources averaged 53\% between 2013 and 2017, fluctuating between $24 \%$ in 2017 and 100\% in 2016 . This finding, combined with finding from the agricultural research and extension public expenditure, could be an indication that the GoM gives relatively lower priority to agricultural irrigation compared with agricultural extension and research (internal sources contributed to $24 \%$ in agricultural irrigation, $32 \%$ of investment public expenditure in agricultural extension and $85 \%$ of investment public expenditure in agricultural research). However, as in the case of agricultural extension, this higher dependence on external sources is associated with lower budget predictability in public expenditure in agricultural irrigation. This lower importance of internal sources is also related to the fact that a relatively lower share of public capital expenditure in agricultural irrigation (5\% for agricultural irrigation versus $10 \%$ for agricultural extension versus $20 \%$ for agricultural research) is spent on paying salaries. Moreover, Figure 5.18 shows that as in the case of agricultural extension, external sources of public capital expenditure steadily become more important in terms of contribution to total public capital expenditure in agricultural irrigation. The share of public capital expenditure in agricultural irrigation using external financing sources was stable between 2013 and 2015 at about 35\% and but substantially increased to $76 \%$ in 2017. It is worth pointing out that public capital expenditure in agricultural irrigation was sourced only from internal sources in 2016. As mentioned earlier, this is related to the withdrawal of development partners from direct budget support due to revelations of hidden debt. 


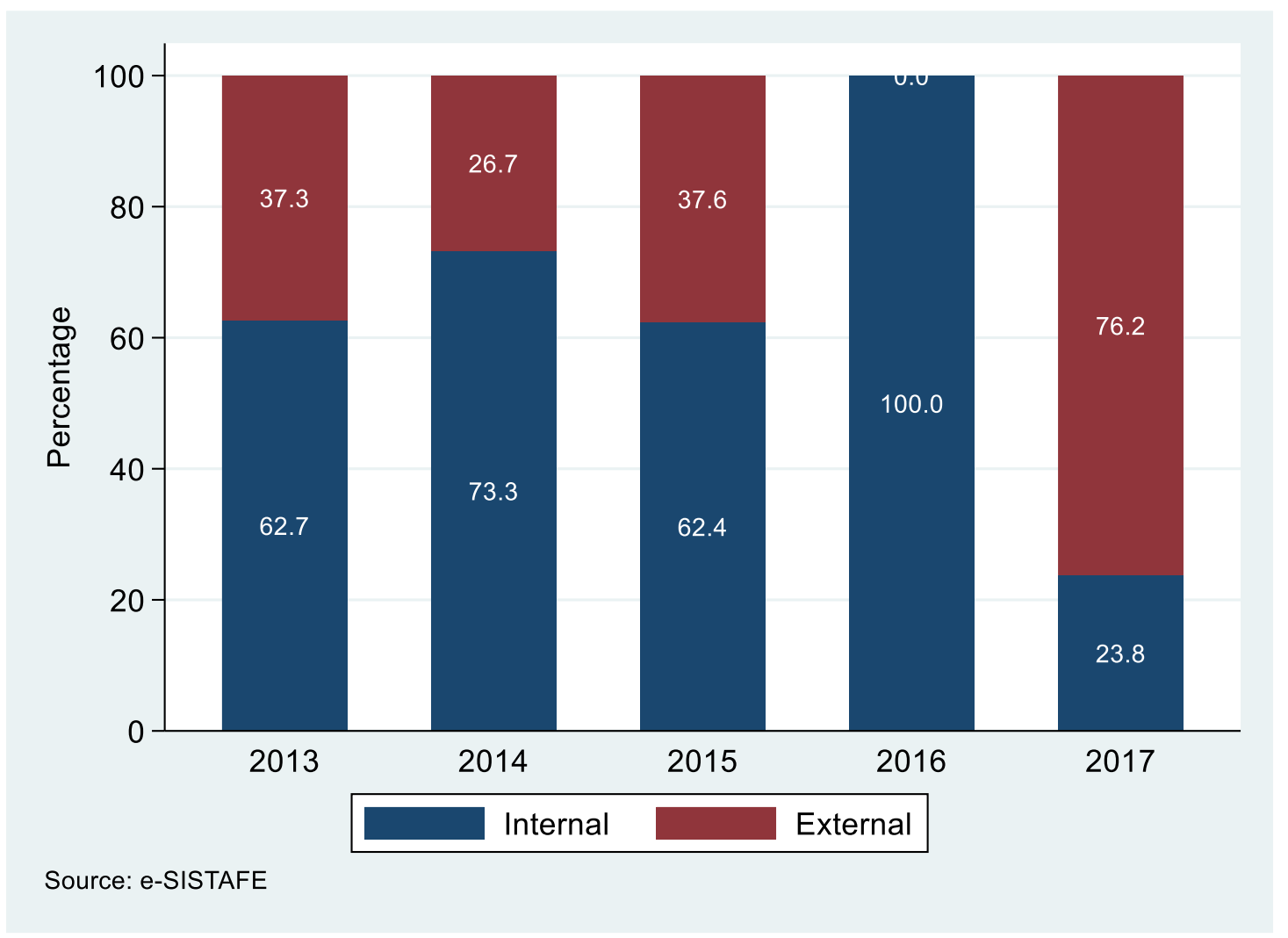

Figure 5.18 Public capital expenditure in agricultural irrigation by funding source

\subsubsection{Agricultural Irrigation Public Expenditure by Administrative Level}

Figure 5.19 breaks down public expenditure in agricultural irrigation by administrative level. With an average of $16 \%$ over the period 2013 to 2017 , the proportion of public expenditure on agricultural irrigation by sub-national government did not followed a clear trend, fluctuating considerably between $4 \%$ in 2017 and 54\% in 2016. Sub-national government public expenditure in agricultural irrigation averaged $88,000 \mathrm{MZN}$ over the period 2013 to 2017 . Agricultural research ranks first in terms of the proportion of public agricultural expenditure executed by sub-national government for each program (63\%), followed by agricultural extension (23\%) and agricultural irrigation with $16 \%$. This suggests that agricultural irrigation is less decentralized compared with agricultural research and extension. 


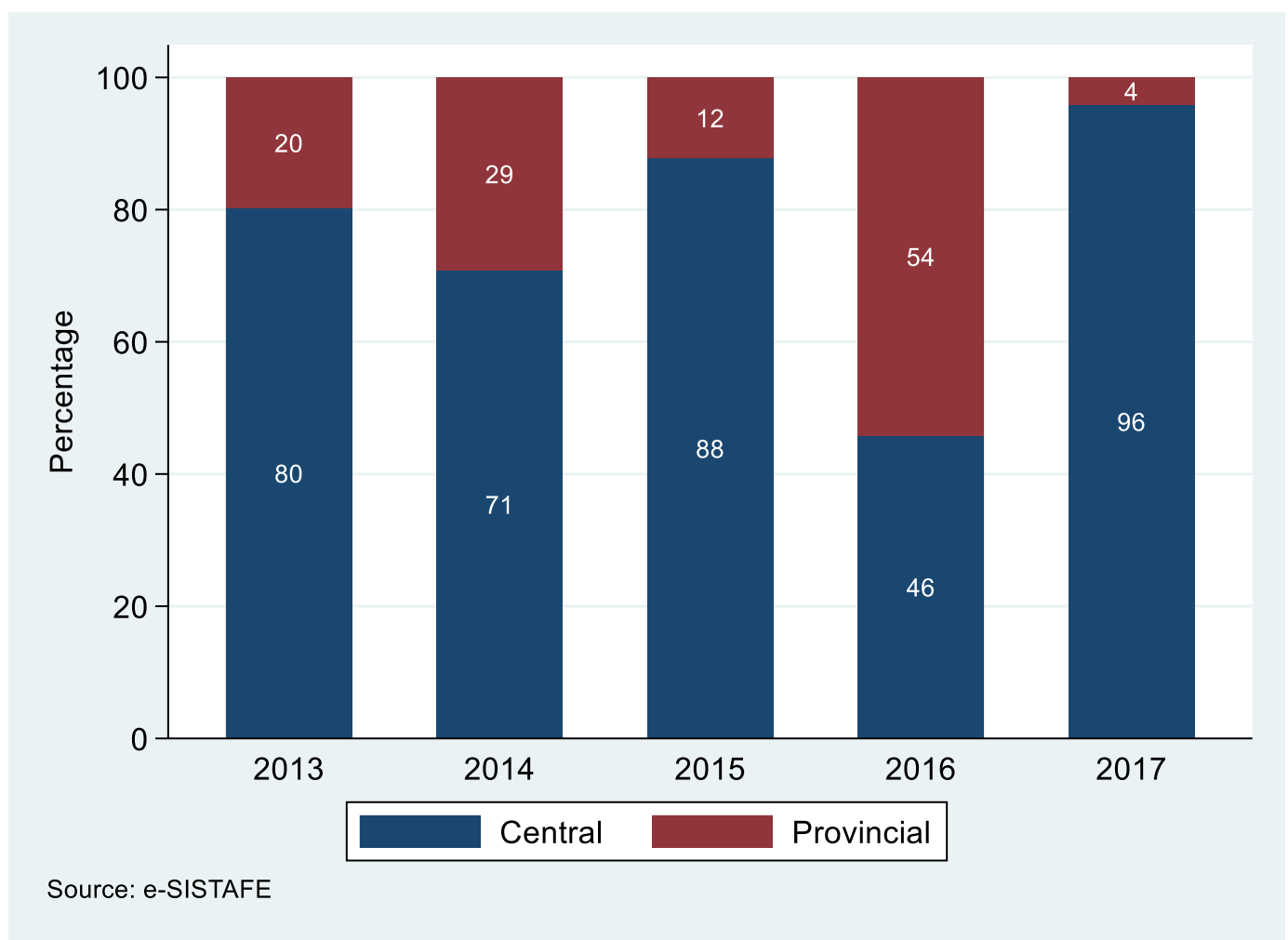

Figure 5.19 Public expenditure in agricultural irrigation by administrative level

\subsubsection{Framework of Emerging Benefits from Irrigation Investments}

The tangible benefits generated by irrigation investments in Mozambique are summarized in a recent project document for Smallholder Irrigated Agriculture and Market Access. ${ }^{32}$ Based on completed and on-going irrigation projects in Mozambique, the project document assesses the quantitative (gross margins per ha. of improved irrigation land) and qualitative benefits arising from improved irrigation infrastructure and supporting agricultural services, resulting in significant improvements in agricultural productivity, production, increased farm household incomes and reduced poverty levels. More specifically, these benefits will be achieved by: (a) improved access to irrigation water; (b) adoption of new improved technologies by farmers, enabled by the irrigation supplies; (c) investments in value addition by small and medium enterprises (linked to the irrigation services); improved access to technical assistance/extension to farmers, demonstrating strong synergies between irrigation and improved and adopted agricultural technologies; (d) improved access to input and output markets for farmers, enabled by the irrigation investments and supporting project-supported services.

This project is providing efficiency-based investments, for rehabilitated and new irrigation facilities. These unit costs can be used a benchmark for other irrigation investments, adjusted to specific types and locational factors.

\footnotetext{
32See World Bank-financed Project: Smallholder Irrigated Agriculture and Market Access Project IRRIGA), Project Appraisal Document, May 30, 2018, World Bank.
} 
Furthermore, the Project is providing technical support for ensuring efficient and effective O\&M of irrigation facilities, also based on efficiency-based O\&M costs and arrangements, for the different types of irrigation investments. It is recommended that these O\&M costs (per ha. of different types of irrigation facilities) be used as a benchmark for other irrigation schemes in Mozambique, with appropriate adjustments ${ }^{33}$. Also, the project is providing improved approaches to carrying out O\&M activities, with farmer beneficiaries and supporting Water User Associations taking the main O\&M responsibility for these irrigation schemes. This approach provides a useful model for scaling up for the country's irrigation system.

In summary this chapter has highlighted:

(a) The significant and erratic underfunding of three strategic programs (agricultural research, extension and irrigation);

(b) Agricultural research funding is dominated by wage expenditure, suggesting an imbalance with respect to required capital expenditure to ensure targeted results;

(c) Agricultural extension funding reflects dominance of external funding, thereby posing sustainability risks;

(d) Limited use of efficiency-based financial and technical indicators to help ensure efficient and effective expenditure programs.

33

The issue of O\&M costs for irrigation schemes is a high priority subject in developing countries. A useful reference document is: O\&M Spending Levels in Third World Irrigation Systems: Exploring Economic Alternatives, by Peter F. M. McLoughlin. Water Resources Bulletin, Paper No. 87116, June 1988. 


\section{FINANCING OF AGRICULTURAL EXPENDITURE}

\subsection{Overview of Financing Strategy and Main Sources}

The Government of Mozambique (GoM) approved two strategic documents to guide management and reforms of public finance for both the agricultural and non-agricultural sectors: Public Finance Vision 2011 - 2025 (known by its Portuguese acronym VFP Visão de Finanças Públicas) and the Strategic Plan for Public Finance 2016 - 2019 ((PEFP -Plano Estratégico das Finanças Públicas). The PEFP draws on the experience of of the implementation of the VFP. . PEFP sets out seven objectives with 18 strategic actions and 53 indicators, including targets for each indicator. PEFP strategic objectives include:

- To stimulate private saving and investment in the country (two strategic actions and nine indicators);

- To improve government revenue collection (two strategic actions and six indicators);

- To ensure criterion-based government budget allocations (two strategic actions and six indicators);

- To increase public budget execution efficiency (four strategic actions and 14 indicators);

- To strengthen management of government assets (two strategic actions and three indicators);

- To ensure sustainability of public debt (four strategic actions and six indicators);

- To improve management of government resources and availability of statistical economic and financial information about public finance (two strategic actions and nine indicators);

Although there is room for improvements in budget planning, execution, reporting and accounting (see Chapter 3) and internal and external auditing, public finance management (PFM) in Mozambique has made considerable progress. This progress could be attributed, to a large extent, to the GoM's efforts to implement recommendations which emerged from the PFM assessments, using the Public Expenditure and Financial Accountability (PEFA) methodology. ${ }^{34}$ All PFM assessments undertaken in Mozambique using the PEFA methodology report both improvements and a consolidation of improvements in many PFM indicators, while also pointing out areas of deficiency.

The GoM executes expenditure in the agricultural and non-agricultural sectors using funds that are channeled through on- and off-budget processes. On-budget expenditure are executed using both internal and external financial sources. Internal sources principally include revenue collected by the GoM, while external sources consist of funds obtained from various development partners and channeled through the GoM State Budget (Orçamento do Estado,OE). In additional to on-budget financing, donors also support expenditure in the agricultural and non-agricultural sectors using funds not registered in the $\mathrm{OE}$, which is referred to as "off-budget" expenditure. Both the domestic and international private sector also execute expenditure in the agricultural sector, although gathering data and information on this, is challenging because the private sector either does not keep records of its expenditure or is reluctant to share this information due to its sensitivity.

\footnotetext{
${ }^{34}$ PEFA is a partnership program managed by seven international development partners and outlines a methodological framework for assessing and reporting of strengths and weaknesses of PFM. PEFA main objective is to strengthen countries' capacities to assess their PFM systems and develop a practical sequence of PFM reforms and capacity development actions. Four PFM assessments have been carried out in Mozambique. The first PFM assessment was conducted in 2005 covering the period 2002 through 2005, the second in 2008 for the period 2004 - 2006; the third in 2010 for the period 2007 - 2009; and the fourth in 2015 for the period $2012-2014$.
} 
An important feature of both on-budget and off-budget financing from development partners is that since early 1990s, Government has not pursued the use of multi-donor funded sector-based programs (or projects) for the agriculture sector (although PRO-AGRI exhibited some features of a sector-wide program, funded by various DPs). Rather, there continues to be a project-by-project approach in financing the agrarian sector, sometimes involving two DPs. The Malabo Declaration, and supporting AU guidelines, encourage Governments to adopt program-based financing approaches, mobilizing several development partners. The next planning cycle for the national agrarian sector investment program provides an opportunity to adopt these approaches, which will also facilitate coordination at the operational level, and reduce the level of fragmentation that characterizes the sector.

\subsection{On-budget Financing}

Government revenues are undoubtedly the main source of financing for on-budget public expenditure in agriculture. On-budget public expenditure in agriculture totaled 46 billion MZN over the period 2013 to 2017 of which, $67 \%$ came from government revenues, $19 \%$ from external borrowing and $14 \%$ from external grants. The relative importance of each source of financing varies over the period 2013 to 2017 (see Figure 6.1). The government revenue share of on-budget public expenditure in agriculture was stable at about 74\% between 2013 and 2016 before dropping to 52\% in 2017. On the contrary, the proportion of on-budget public expenditure in agriculture accounted for by external borrowing increased from $8 \%$ in 2013 to $19 \%$ in 2015 , and to $32 \%$ in 2017. Moreover, the relative importance of external grants in terms of contribution to total on-budget public expenditure in agriculture dropped from $20 \%$ in 2013 to $8 \%$ in 2015 and 2016, followed by an increase to $16 \%$ in 2017. This increased dependence on external borrowing, coupled with a reduction in reliance on government revenue and external grants, is associated with withdrawal of DPs from direct budget support in 2015. 


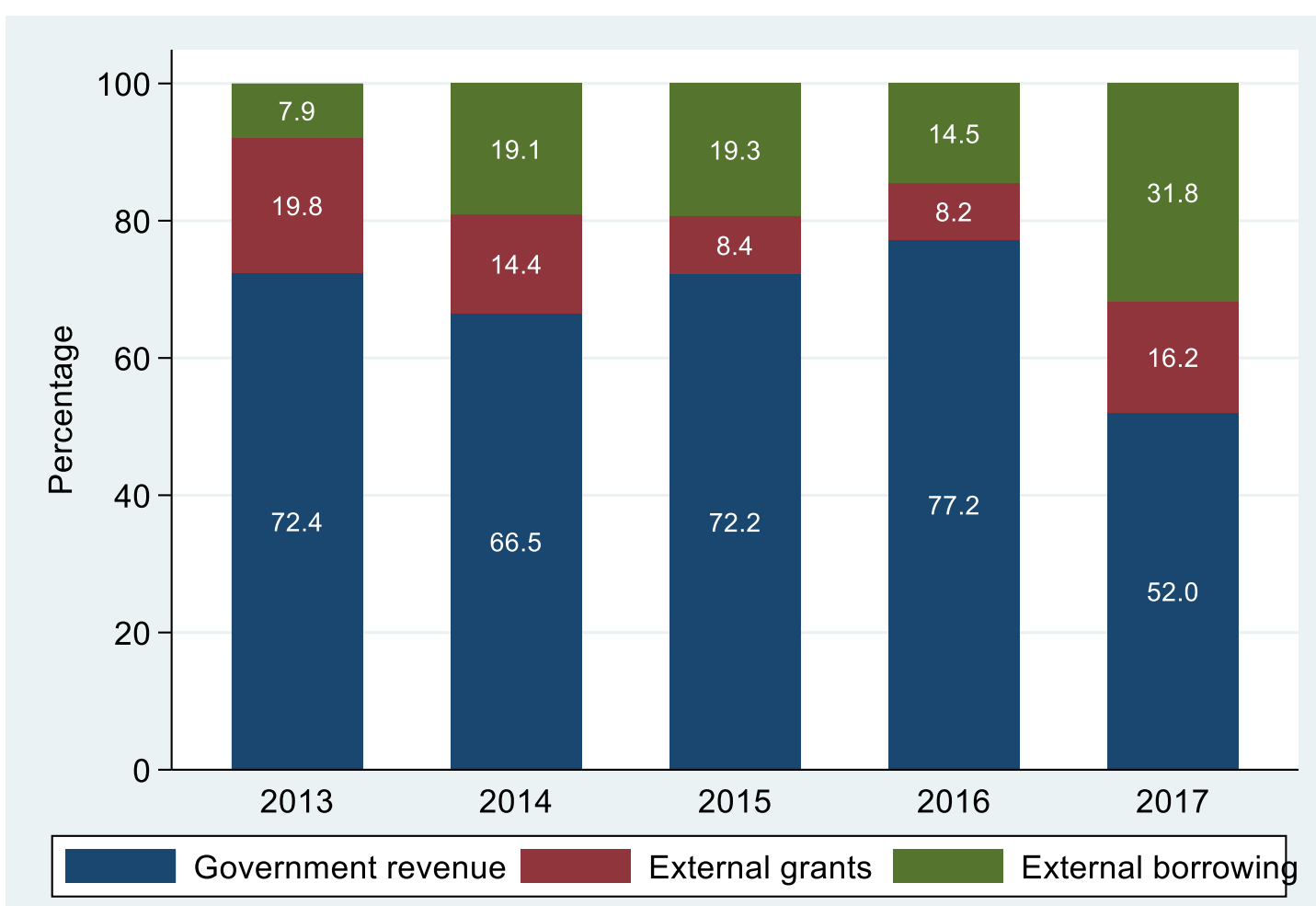

Source: e-SISTAFE

Figure 6.1 On-budget public expenditure in agriculture by financing source

The relative importance of each source of financing varies across ministries as illustrated in Figure 6.2. With $90 \%$ and $84 \%$ respectively, MIC and MASA are the ministries with the largest reliance on government revenue over the period 2013 through 2017. MITADER with $30 \%$, MOPHRH with $24 \%$, and MIMAIP with $22 \%$, are among the ministries with the largest dependence on external grants. These findings are consistent with those presented in Chapter 4 showing similar patterns in terms of relative importance of internal and external sources of funding. These differences in the relative importance of each source of funding across ministries could suggest that ministries have different strategies to mobilize funds to implement their annual activities which in turn implies that there is scope for ministries to learn from each other on how to diversify their sources of financing. 


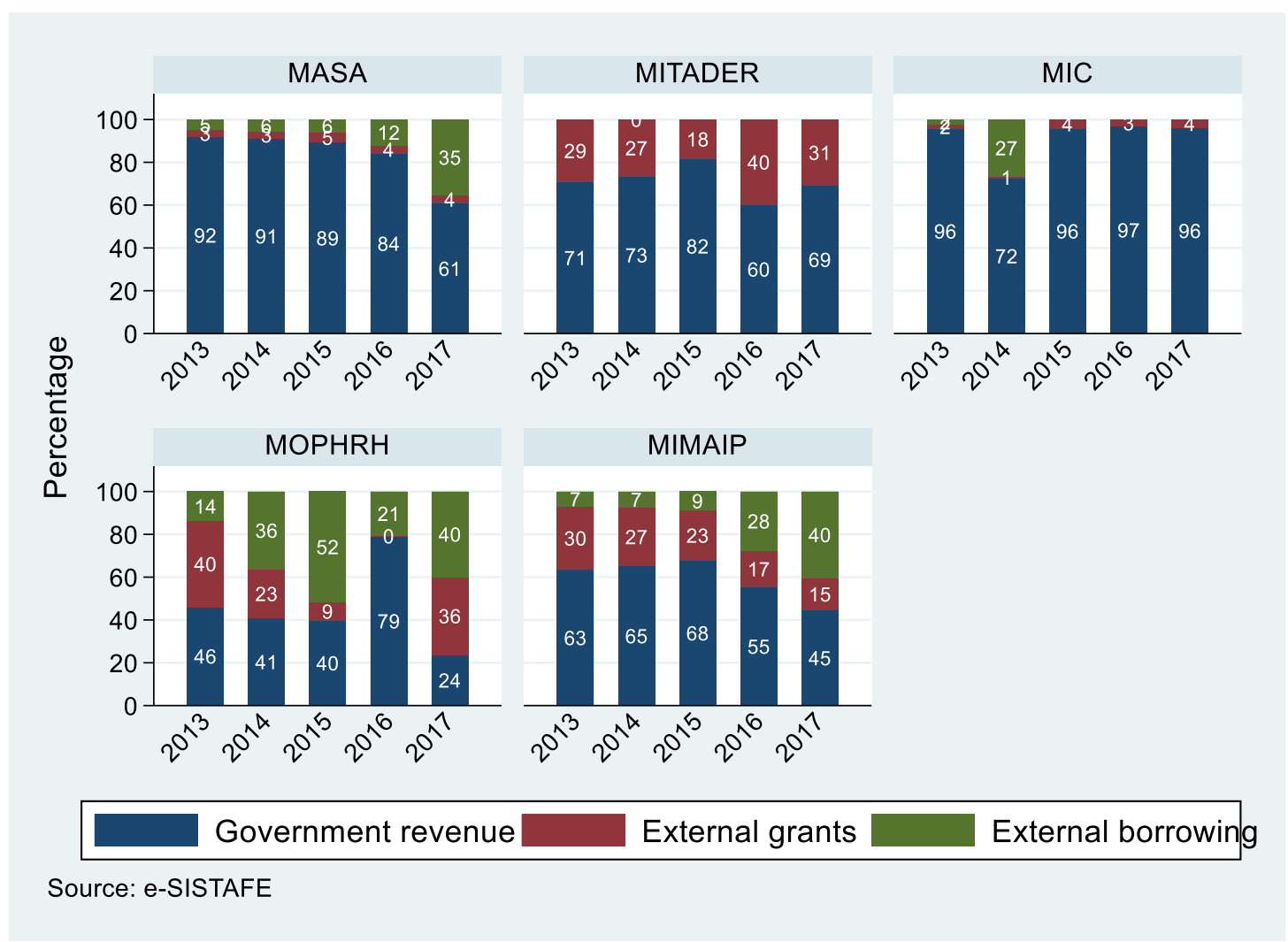

Figure 6.2 On-budget agricultural public expenditure by source of financing by ministry

Table 6.1 summarizes government revenue by source and shows that total government revenue collection does not follow a clear pattern between 2013 and 2017. After increasing by $22 \%$ between 2013 and 2014 and reaching an historical high over the period 2013 to 2017 of 188 billion MZN in 2014, total government revenue collection has trended downwards in real terms between 2014 and 2016, falling to 154 billion MZN in 2016. It then increased to 165 billion MZN in 2017.

Government revenue collected from internal and external sources followed a similar pattern of that of total government revenue collection but with different magnitude. Approximately three quarters of total Government revenues is generated by internal sources, a proportion which is relatively stable between 2013 and 2017. This serves to introduce greater predictability in revenue collection. The sizable share of internally collected revenues as a proportion of total government revenue reflects the GoM's efforts to increase revenue by strengthening the collection of customs, fiscal and non-fiscal revenues, and taxes in capital gains from the resale of exploration rights in the extractive industry. This is consistent with one of the strategic objectives of PEFP 2016 - 2019. Nevertheless, the predictability of revenue generation could be further strengthened if government were to put in place more effective and efficient mechanisms to strengthening domestic revenue collection.

Table 6.1 Government revenue collection (real million MZN, 2009 = 100)

\begin{tabular}{llll}
\hline & \multicolumn{2}{l}{ Source } & \\
\cline { 2 - 3 } Year & Internal & External & Total \\
\hline 2013 & 105,820 & 48,656 & 154,476 \\
2014 & 129,044 & 59,328 & 188,372 \\
2015 & 125,897 & 37,898 & 163,795 \\
2016 & 119,065 & 35,294 & 154,359
\end{tabular}




\begin{tabular}{llll}
2017 & 128,781 & 36,034 & 164,815 \\
\hline Average & $\mathbf{1 2 1 , 7 2 1}$ & $\mathbf{4 3 , 4 4 2}$ & $\mathbf{1 6 5 , 1 6 3}$ \\
\hline
\end{tabular}

Source: National Accounts

The study findings reveal that actual collected government revenue as a share of forecasted revenue dropped from $97 \%$ in 2013 to $93 \%$ in 2016 before increasing to $109 \%$ in 2017 . This share averaged $98 \%$ over the period 2013 to 2017 suggesting that the government's forecasts for revenue collection are quite reliable. However, domestic sources of revenue appear more predictable than external sources. For domestic sources, collected revenue falls short of forecasted revenue in only two out of five years (in 2015 by 3\% and in 2016 by 7\%), whilst for external sources, collected revenue falls short of the forecast in all five years, with shortfalls ranging from 16\% in 2013 to 8\% in 2016 and 2017 (see Figure 6.3). The greater unpredictability of revenue from external sources appears consistent with findings presented in Chapter 4 that also showed that execution rates were lower for funding from external sources than from internal sources (ranging from $98 \%$ to $75 \%$ for internal sources and from $71 \%$ to $28 \%$ for external sources). Similarly, and as noted in Chapter 4 , the higher unpredictability of funding from external sources makes it difficult to implement activities as planned, and usually leads to ad-hoc decision-making when considerable portions of funding are not forthcoming.

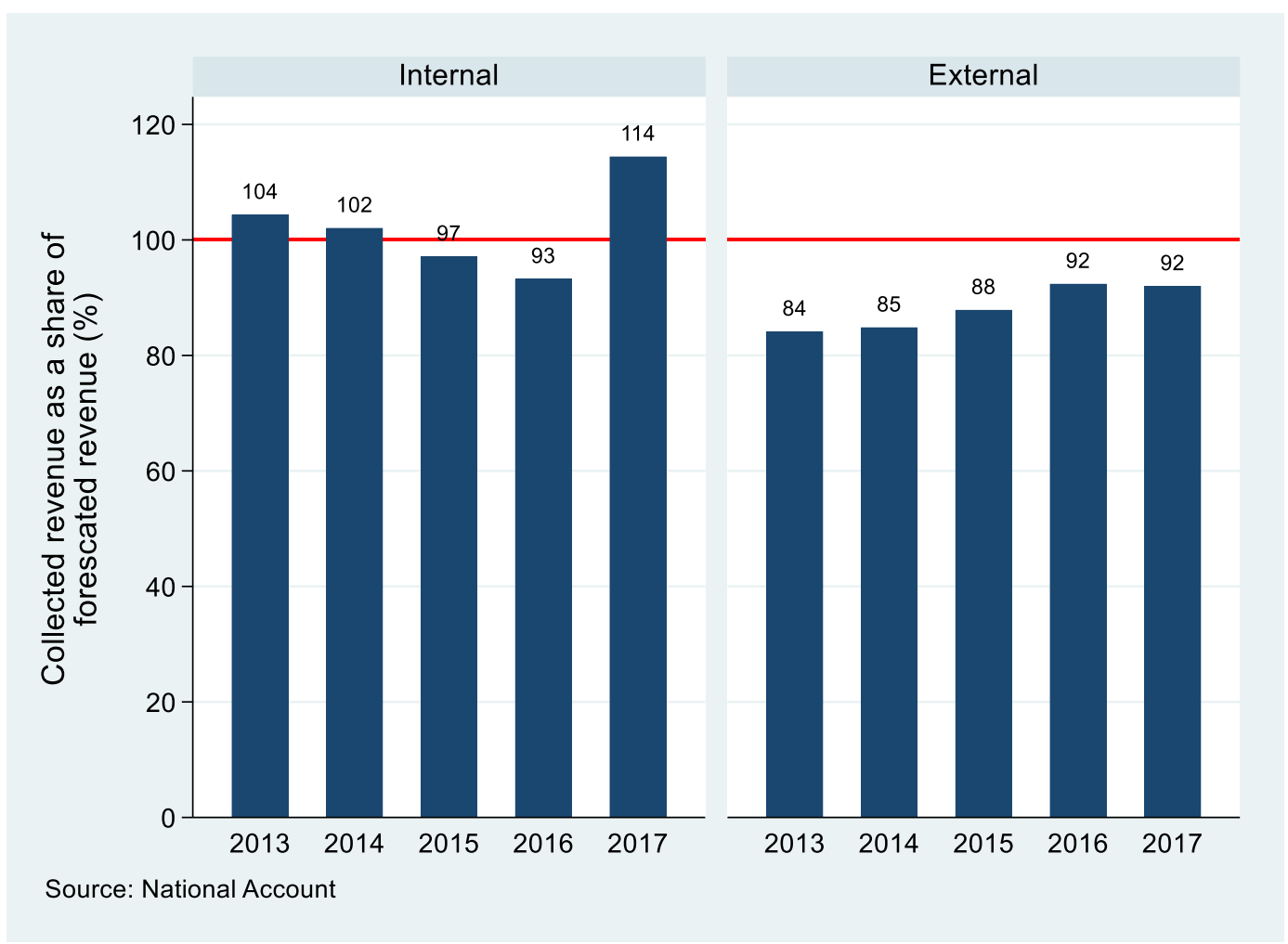

Figure 6.3 Actual collected revenue as a share of government forescated revenue

\subsection{Off-budget Financing}

While the previous section focused on on-budget financing, this section analyses off-budget expenditure in agriculture. The study team obtained off budget expenditure from the Official 
Development Assistance Database for Mozambique (ODAMOZ) ${ }^{35}$. Official Development Assistance (ODA) funds for agriculture are channeled through both on-budget and off-budget processes, both of which are reported in ODAMOZ. Figure 6.4 breaks down ODA funds by on budget versus off budget illustrating that the proportion of ODA funds channeled through off-budget has trended downwards, falling from $42 \%$ in 2013 to $32 \%$ in 2015 before increasing to $41 \%$ in 2017.

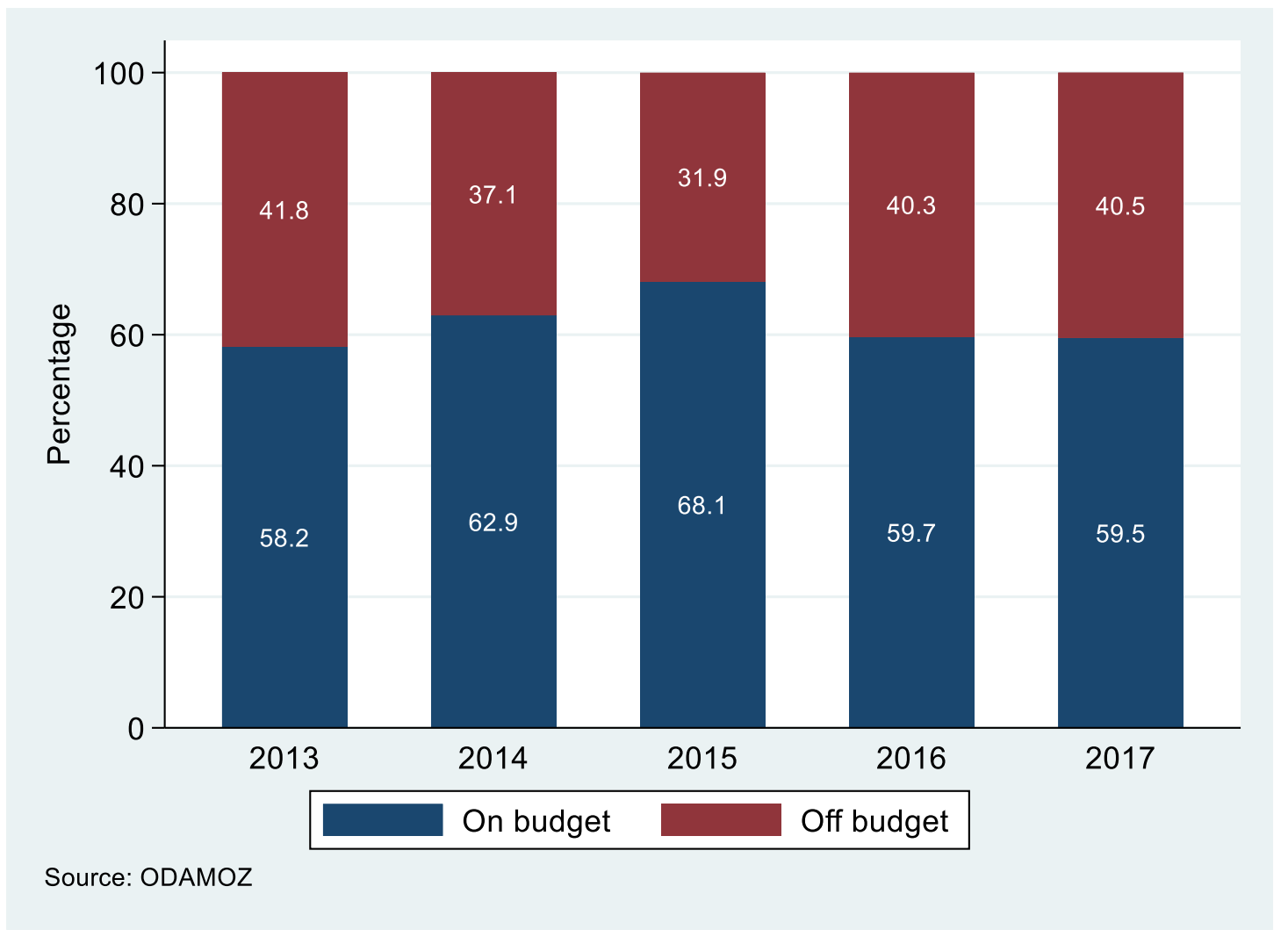

Figure 6.4 Agricultural expenditure funded by donors by funding chanel

The downward trend in the share of ODA expenditure channeled through off-budget processes is consistent with government efforts to increase the proportion of external funds channeled through on-budget and ON-CUT processes, a stated objective of the PEFP 2016 - 2019. PEFP targets seek to increase the share of ODA funds that are ON-CUT from an estimated $44 \%$ in 2015 to $50 \%$ in 2017. Data from ODAMOZ show that ODA ON-CUT expenditure as a share of total ODA on-budget expenditure almost doubled from $27 \%$ in 2013 to $41 \%$ in 2014. It then steadily trended downward dropping to $6 \%$ in 2016 and to $4 \%$ in 2017; with an average of $17 \%$ over the period 2013 to 2017 . This suggests that the 50\% PEFP target is unlikely to be achieved. However, the low share of ODA funds put ON-CUT could be associated with the DPs' decision to withdraw from direct budget support in 2015.

Off-budget expenditure in agriculture did not follow a clear pattern over the period 2013 to 2017 (see Table 6.2). In real terms, off-budget spending on agriculture decreased by $47 \%$, from 1.9 billion MZN in 2013 to 1.0 billion MZN in 2015 but then doubling reaching 2.0 billion MZN in 2016, and before falling to 1.3 billion MZN in 2017, a 37\% reduction. Furthermore, Table 6.2 shows that off-budget

35 ODAMOZ database emerged in response to the Paris Declaration with the main objective of strengthening coordination and harmonization among donors and alignment between donors' and the Government of Mozambique's initiatives. 
expenditure in the agriculture sector represents a sizable share of total public expenditure, varying between $13 \%$ in 2015 and $47 \%$ in 2016. Off-budget agriculture expenditure averaged 1.5 billion MZN during the period 2013 to 2017, representing $23 \%$ of average public agricultural expenditure during the same period. Off-budget expenditure in agriculture relative to total government expenditure averaged $1 \%$ between 2013 and 2017 . The share of total off-budget expenditure accounted for by offbudget expenditure in agriculture did not follow a clear pattern during the period 2013 to 2017, fluctuating between $12 \%$ in 2014 and $20 \%$ in 2016.

Figure 6.5 shows the share of off-budget expenditure in agriculture by development partner over the period 2013 to 2017 . Sweden with a $22 \%$ share is clearly responsible for the largest proportion of offbudget expenditure in agriculture in the period 2013-17, followed by USA (15\%), Switzerland (11\%), and Finland and Norway, each with $7 \%$. This Figure 6.5 suggests that off-budget expenditure in the agricultural sector is highly fragmented, raising questions about effective coordination among partners and with regard to alignment between the GoM's policy framework and total expenditure (on and off budget sources) in the agricultural sector.

Table 6.2 Off-budget and government expenditure in agriculture (real million MZN, 2009 $=100$ )

\begin{tabular}{|c|c|c|c|c|}
\hline Year & $\begin{array}{l}\text { Off-budget } \\
\text { expenditure in } \\
\text { agriculture }\end{array}$ & $\begin{array}{l}\text { Public expenditure } \\
\text { in agriculture }\end{array}$ & $\begin{array}{l}\text { Off-budget } \\
\text { expenditure as share } \\
\text { of public expenditure } \\
\text { in agriculture }\end{array}$ & $\begin{array}{l}\text { Off-budget agriculture } \\
\text { expenditure as share of } \\
\text { total off-budget } \\
\text { expenditure }\end{array}$ \\
\hline 2013 & 1,900 & 7,178 & $26.5 \%$ & $14.3 \%$ \\
\hline 2014 & 1,427 & 9,114 & $15.7 \%$ & $11.9 \%$ \\
\hline 2015 & 1,002 & 7,702 & $13.0 \%$ & $14.5 \%$ \\
\hline 2016 & 2,041 & 4,364 & $46.8 \%$ & $19.1 \%$ \\
\hline 2017 & 1,278 & 5,420 & $23.6 \%$ & $15.4 \%$ \\
\hline Average & 1,530 & 6,756 & $22.6 \%$ & $15.0 \%$ \\
\hline
\end{tabular}

Source: e-SISTAFE and ODAMOZ 


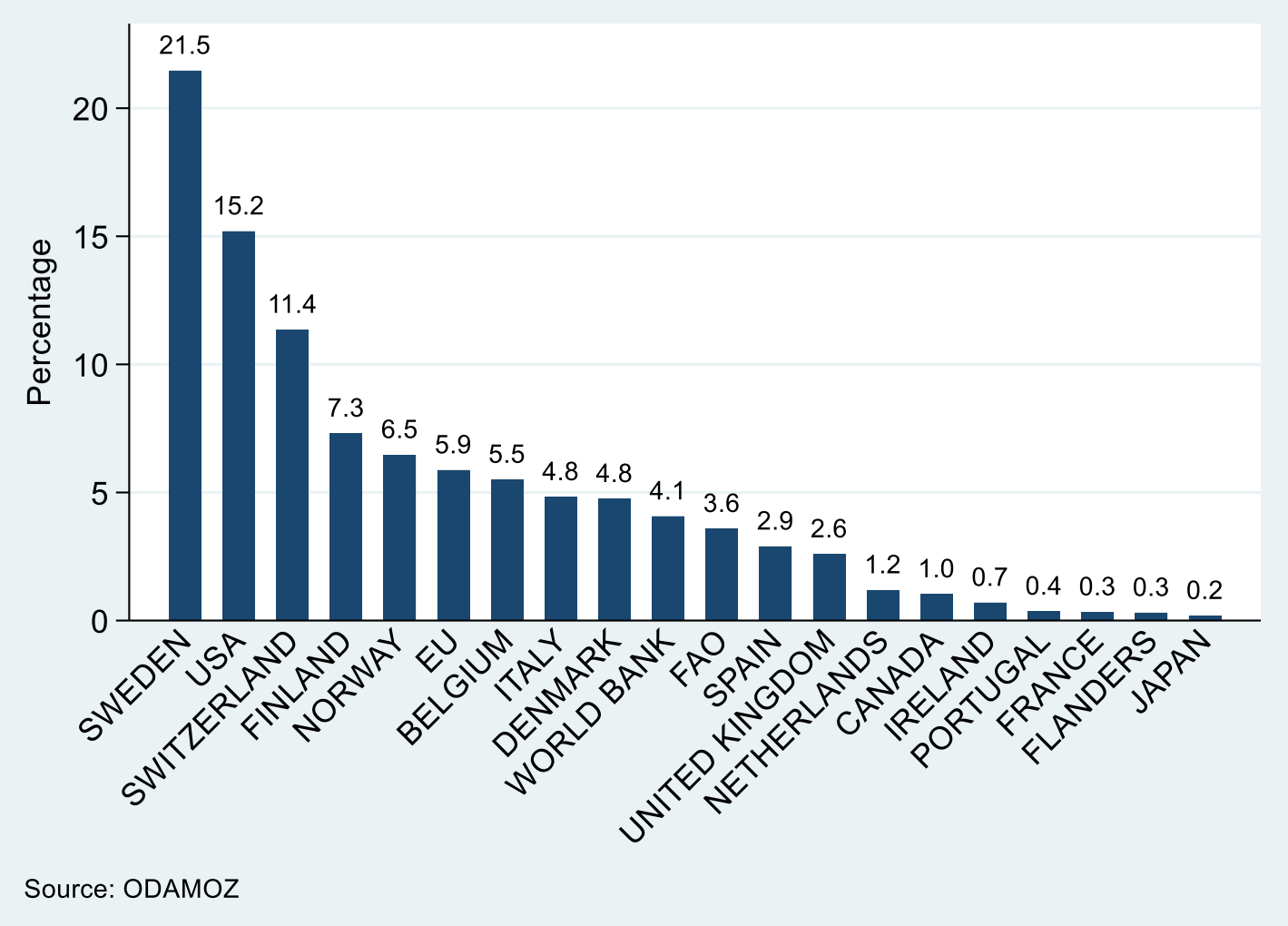

Figure 6.5 Breakdown of off-budget expenditure in agriculture during 2013 to 2017

\subsection{Private Sector Financing: Levels, Sources, Constraints and Emerging Strategy for Expanded Private Sector Role}

The vital role of financing for food, agriculture and rural development is widely recognized, especially in countries, like Mozambique, where agriculture is the main pillar of the economy. Investments are needed to improve smallholder farmers' production and productivity, coupled with the development of infrastructure to increase trade capacity and enhancement of post-harvest technologies including agro processing at both farm and community levels. Empirical evidence suggests that the financing of agriculture, especially through small- and medium-scale enterprises (SMEs), is essential for promoting growth in agricultural and non-agricultural sectors through multiplier effects. The World Economic Forum (WEF) has found that access to financing was the most problematic factor for doing business in Mozambique during the period 2013-2017 (see Figure 6.6). Other problematic factors include corruption, inefficient government bureaucracy, and inadequate supply of infrastructure. 


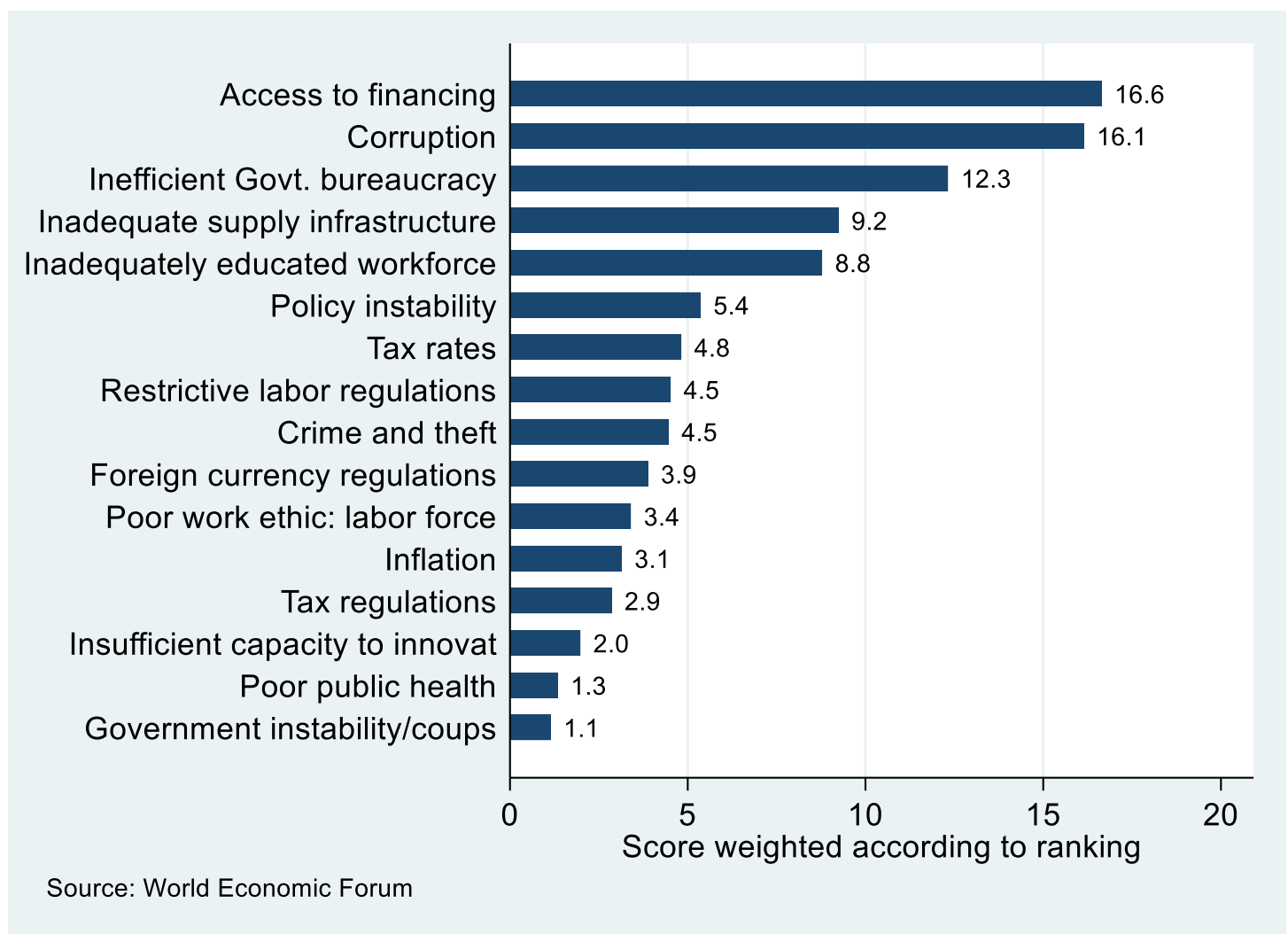

Figure 6.6 Most problematic factors for doing business in Mozambique: 2013 - 2017

Commercial and specialized banks are one of the channels through which the private sector can access financing for the agricultural sector. However, the lack of financial services in rural areas and high interest rates are among the key constraints faced by private sector when seeking access to financing. Data from Mozambique's Central Bank (Banco de Moçambique, BM), indicate that banks' average annual interest rates for rose from $20 \%$ in 2013 to $28 \%$ in 2017, averaging $22 \%$. Coupled with the informality of a large share of SMEs and the lack of financial institutions especially in rural area, this could explain why a large proportion of SMEs opt for informal sources for development capital. Other challenges include the higher risks in the agriculture sector, lack of collateral, low loaned amounts, and high default rates.

Data from BM reveals that credit in the economy as a whole has seen an upward trend, increasing in real terms from 110 billion MZN in 2013 to 181 billion MZN in 2016 before dropping by 25\% to reach 136 billion MZN in 2017. Between 2013 and 2017, annual credit allocated to the agricultural sector ranged from 4 billion MZN in 2014 to 11 billion MZN in 2016. During the same period, agricultural sector credit relative to total credit in the economy fluctuated between 4\% in 2013 and 3\% in 2015 . . Figure 6.7 reveals the share of total credit by selected sectors ${ }^{36}$ and shows that the agricultural sector

\footnotetext{
${ }^{36}$ Selected sectors include agriculture, industry, construction, tourism, trade, and transport; which are key sectors in the economy. These selected sectors together accounted for $52 \%$ of the total credit allocated to the economy between 2013 and 2017. The data do not allow further disaggregation of the sectors benefiting from credit, rather than the selected sectors, because all other sectors are classified as "others" in the data. This lumped category contributed to the remaining $48 \%$ of the total credit supplied to the economy from 2013 through 2017.
} 
has amongst the smallest share of total credit among the selected sectors ranging from $6 \%$ in 2015 to $8 \%$ in 2013 and averaging 6\% between 2013 and 2017. This suggests that despite the importance of the agriculture sector in terms of its contribution to GDP, it receives a smaller share of the total credit in the economy. As discussed earlier, the agricultural sector contributes an estimated 25\% to GDP and even higher if multiplier effects are considered.

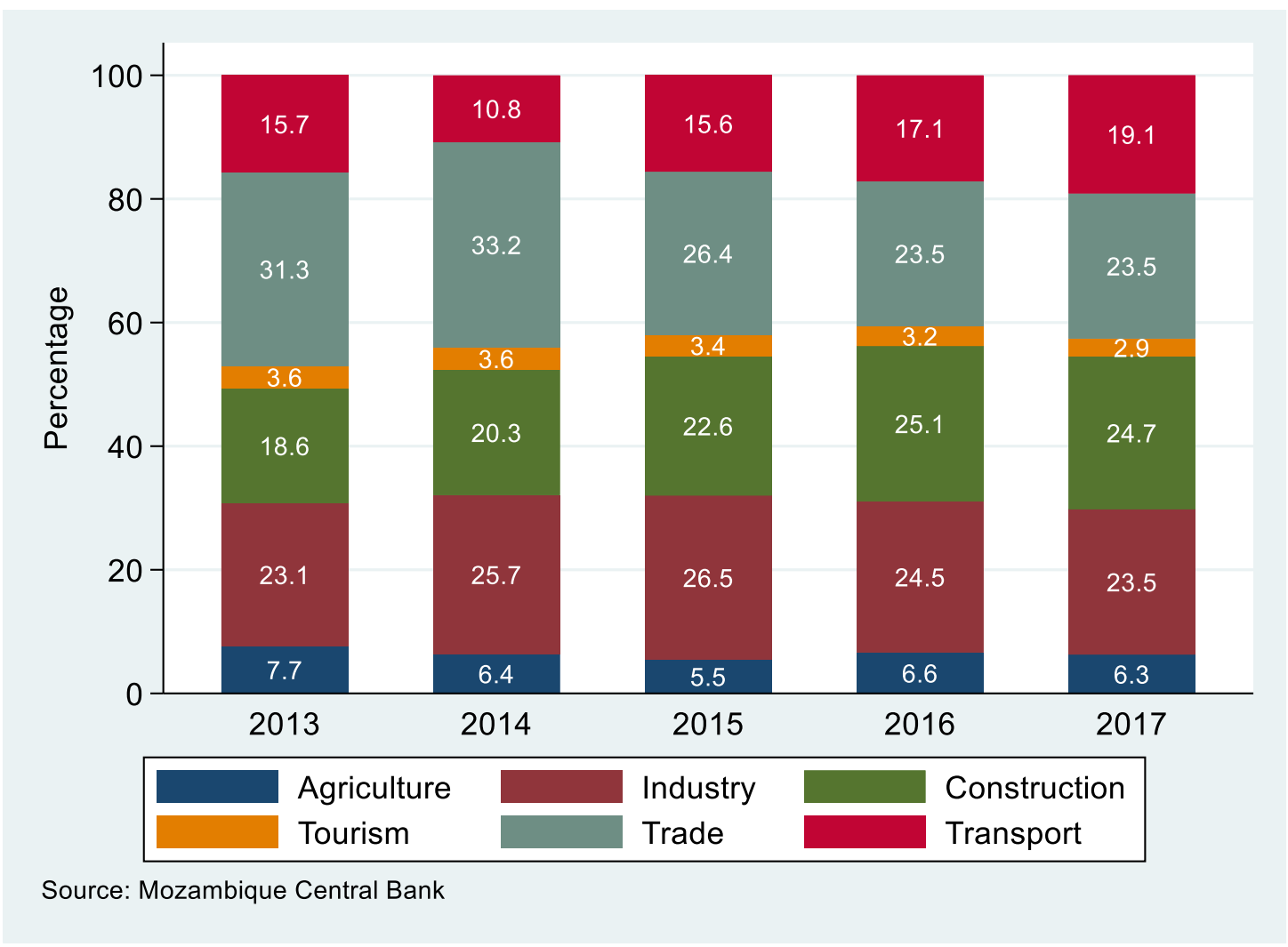

Figure 6.7 Contribution of selected sectors to total credit among those sectors

Figure 6.8 \%disaggregates agricultural credit by sub-sector during the period 2013 to 2017 and shows that the subsectors that receive the greats amount of credit are crops (67\% of total credit), fishery $(19 \%)$, and livestock (9\%). Further analysis of the data shows that in the sub-sector crops, for the period 2013 to 2017, the crops that were able to secure the greatest levels of credit were mainly cash crops including (: cotton (13\% of crop credit), cashew nuts (10\%), tea $(9 \%)$, and sugarcane $(5 \%)$. These four cash crops together accounted for $37 \%$ of the total credit allocated to crops. This suggests a sizable proportion of agricultural sector credit allocated to the crop subsector is allotted to cash crops. 


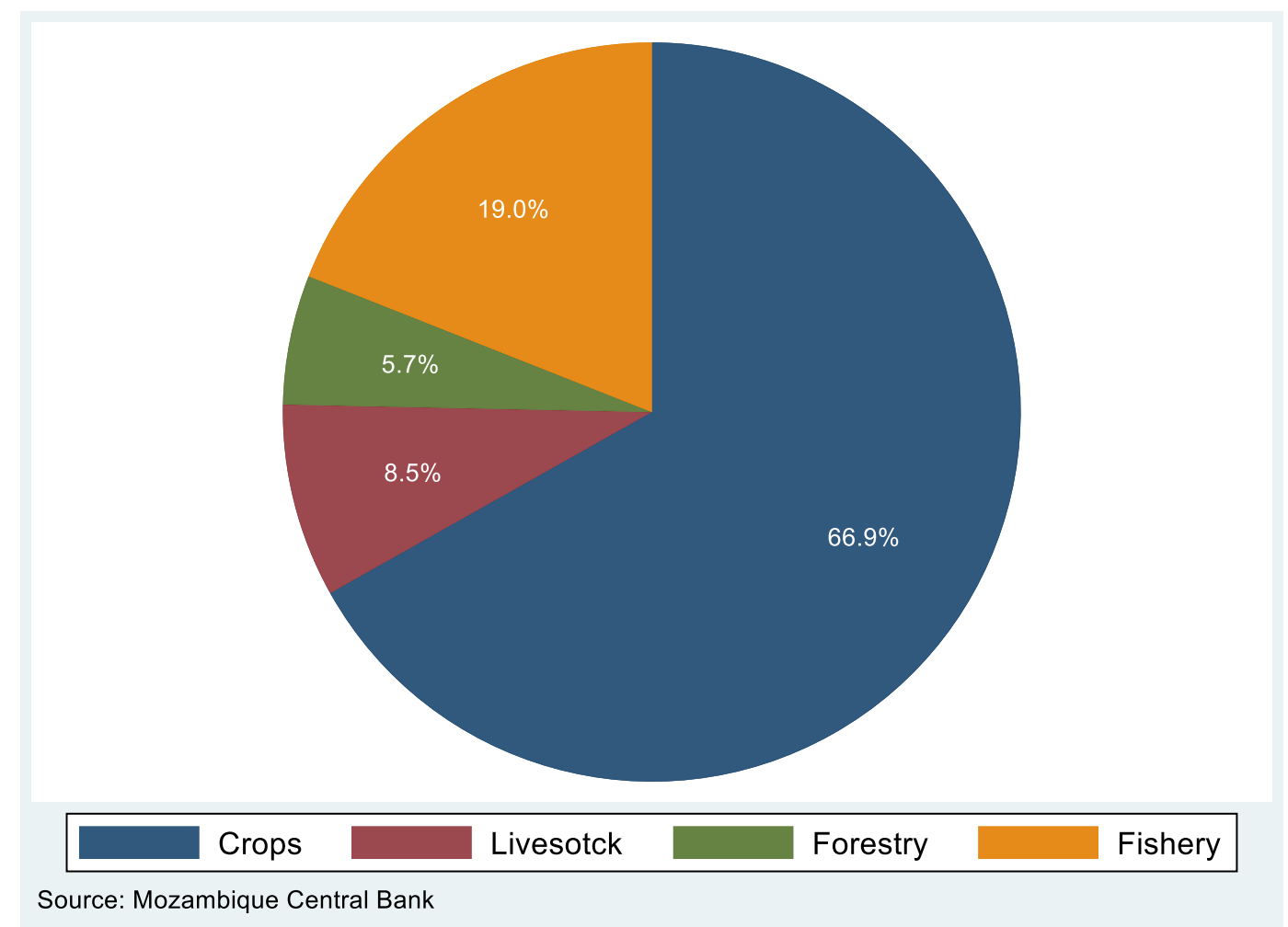

Figure 6.8 Agricultural sector credit by agricultural subsector between 2013 and 2017

Data from MASA indicates that in 2016, 14 official institutions, including MASA, provided credit for the agriculture sector with interest rates varying from $0 \%$ to $60 \%$. During the period 2013-2017, apart from private banks ( $\mathrm{BCl}, \mathrm{BIM}$, Banco Terra and Standard Bank), farmers accessed financing through public and private institutions and non-governmental organizations (NGOs) such as, but not limited to, the Agricultural Development Fund (FDA), District Development Funds (FDD), the Office for the Promotion of Investment (GAPI), the Investment Promotion Centre (CPI), the Institute for Promotion of Small and Medium-scale Enterprises (IPEME), the Africa Management Services Company (AM.SC.O), the Caixa Comunitária de Microfinanças (CCOM), Support to Private Sector Initiatives in the Agriculture Sector (ADIPSA), and the Enterprise Fund for Portuguese Cooperation (FECOP).

Foreign Direct Investment (FDI) is another channel through the private sector can finance investments in the agricultural sector. Data from the Mozambique Investment and Export Promotion Agency (APIEX) show that FDI amounted in real terms to 195 billion MZN over the period 2013 to 2017, with an annual average of 39 million MZN (illustrated in Table 6.3). Between 2013 and 2017, the most important sectors in terms of FDI are industry, with an average of 13 billion MZN per year, services 7 billion MZN per year, construction with 5 billion MZN per year, and agriculture with 5 billion MZN per year. South Africa accounted for $65 \%$ of the total FDI channeled to the agricultural sector between 2013 and 2014, and is undoubtedly the main source of FDI for the agricultural sector (see Figure 6.9). 
Table 6.3 Foreign direct investment by sector (real million MZN, $2009=100$ )

\begin{tabular}{|c|c|c|c|c|c|c|c|c|c|}
\hline \multirow[b]{2}{*}{ Year } & \multicolumn{8}{|l|}{ Sector } & \multirow[b]{2}{*}{ Total } \\
\hline & $\begin{array}{l}\text { Agricultu } \\
\text { re }\end{array}$ & $\begin{array}{l}\text { Industr } \\
\mathrm{y}\end{array}$ & $\begin{array}{l}\text { Constructi } \\
\text { on }\end{array}$ & $\begin{array}{l}\text { Servic } \\
\text { e }\end{array}$ & $\begin{array}{l}\text { Transpo } \\
\text { rt }\end{array}$ & $\begin{array}{l}\text { Touris } \\
\mathrm{m}\end{array}$ & $\begin{array}{l}\text { Bankin } \\
\mathrm{g}\end{array}$ & Other & \\
\hline & & & & & & & & & 33,31 \\
\hline \multirow[t]{2}{*}{2013} & 6,880 & 10,417 & 3,980 & 5,113 & 1,476 & 5,413 & 0 & 38 & 7 \\
\hline & & & & & & & & 16,79 & 60,15 \\
\hline \multirow[t]{2}{*}{2014} & 8,594 & 3,929 & 5,200 & 9,137 & 14,839 & 1,524 & 134 & 4 & 2 \\
\hline & & & & & & & & & 28,93 \\
\hline \multirow[t]{2}{*}{2015} & 2,694 & 14,006 & 6,338 & 4,589 & 472 & 520 & 312 & 0 & 0 \\
\hline & & & & & & & & & 28,21 \\
\hline \multirow[t]{2}{*}{2016} & 2,539 & 8,153 & 5,343 & 8,376 & 512 & 1,930 & 83 & 1,280 & 6 \\
\hline & & & & & & & & & 44,83 \\
\hline 2017 & 2,309 & 26,926 & 3,150 & 8,964 & 2,382 & 1,098 & 4 & 0 & 2 \\
\hline Averag & & & & & & & & & 39,08 \\
\hline e & 4,603 & 12,686 & 4,802 & 7,236 & 3,936 & 2,097 & 107 & 3,622 & 9 \\
\hline
\end{tabular}

Source: APIEX

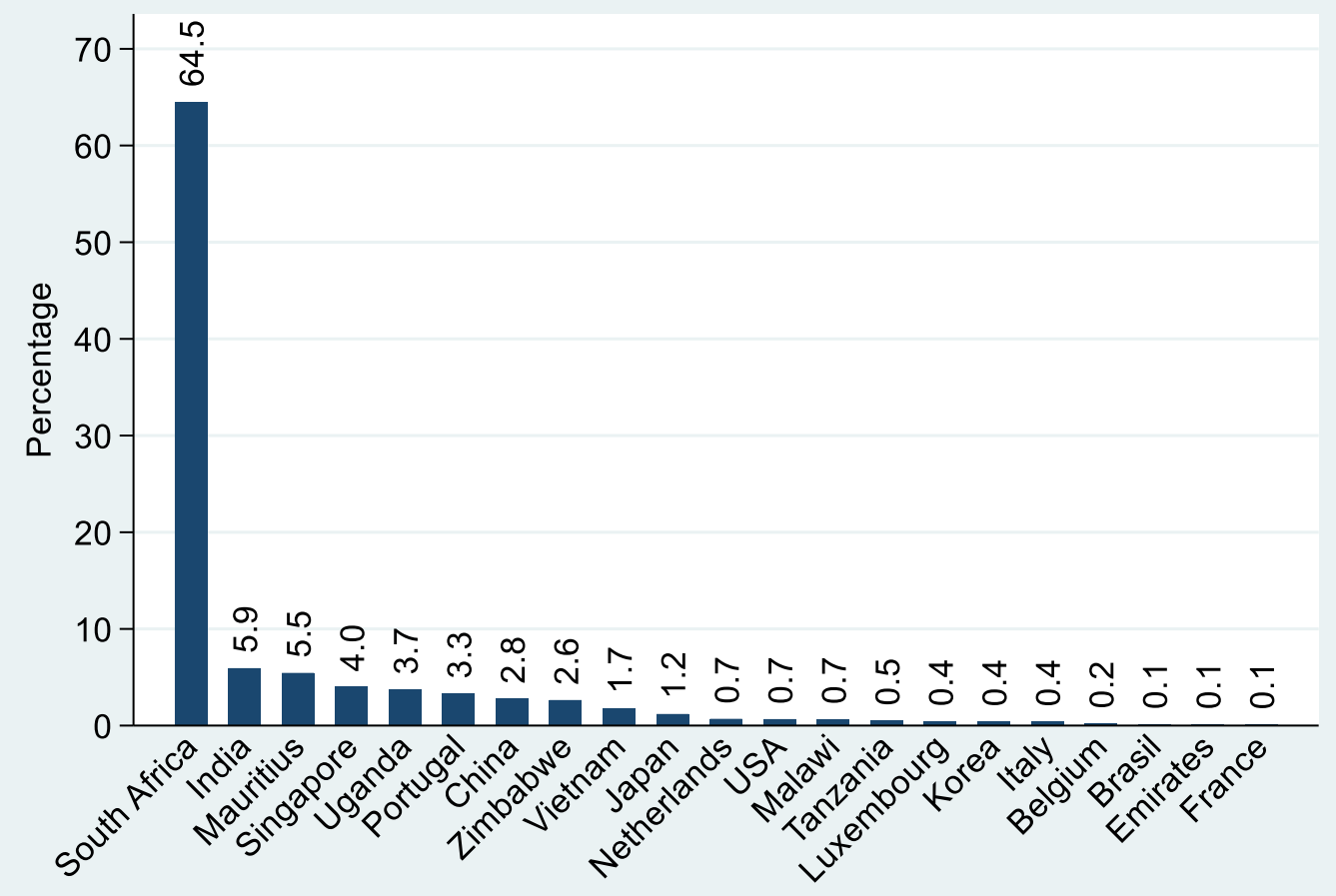

Source: APIEX

Figure 6.9 Foreign direct investment in agriculture by country of origin between 2013 and 2017 


\subsection{Framework for Expanded Role of Private Sector for Promoting Agrarian Sector Transformation}

There companion study "strategy for expanding the role of an inclusive private sector to help transform the agrarian sector of Mozambique" ${ }^{37}$ comprises seven strategic outcome areas, operationalized through prioritized actions which are inter-linked and exhibit a strong resultsorientation:

1) Improved Policy/Regulatory Environment: Improve the business "environment" through an appropriate revision/strengthening of relevant market-based policies and regulations, clearer roles for the public and private sectors, and characterized by greater transparency and consistency in their application;

2) Increased Smallholder Intensification/Performance: Increase smallholder incomes through improved and appropriate intensified, diversified, profitable and climate-smart agricultural technologies (for key subsectors: crops, livestock, fisheries), expanded farmer adoption rates, enabled by expanded access to efficient and competitive input and output markets for key commodities;

3) Strengthened Value Chain Competitiveness: strengthen value chain competitiveness for key commodities through the application of appropriate and sustainable incentives, and strengthening the linkages between the various actors, including the provision of prioritized rural infrastructure (especially rural roads and electrification);

4) Expanded Land Access/Security: Improve land security and utilization, consistent with the other key complementary strategies;

5) Expanded Access to Finance: Enhance access to affordable, inclusive and sustainable finance, with strong linkages to the competitive value chains;

6) Expanded Private Sector Participation: Attract expanded private sector participation in agricultural transformation through the sale or leasing of currently sub-utilized public assets, and/or their integration into sustainable Public Private Partnerships, while demonstrating appropriate roles of public and private sectors;

7) Effective Institutional Arrangements/Mechanisms: Strengthen/establish the most appropriate institutional arrangements and processes to ensure transparent, accountable and results-oriented coordination and dialogues/platforms (e.g., CCSA, relevant private sector platforms), supported by a strengthened monitoring and evaluation system of key performance indicators for the private sector strategy.

For each of these 7 core strategy elements, the private sector strategy includes prioritized actions and a supporting Action Plan. It will be important for the users of this Ag. PER findings and recommendations also to utilize the recommendations of the private sector strategy in order to generate strong synergies from using both documents.

In summary, the significant underfunding of the agrarian sector reveals:

(a) Erratic levels and sources of budgetary and development partner funding;

\footnotetext{
${ }^{37}$ See: Strategy for Expanding the Role of the Private Sector in Transforming Mozambique's Agrarian Sector (SERPS), draft dated May, 2019 (carried out by a World Bank consultant team, and funded by DFID).
} 
(b) The low level of domestic commercial bank credit allocated to agrarian sector vis a vis its importance to national economy;

(c) The low level of FDI allocated to agrarian sector relative to its importance in agrarian sector national economy, with dominant share coming from South Africa;

(d) The major source of agrarian sector growth and poverty reduction will be driven by the private sector. However, there is an absence of coherent and explicit strategy for expanding the role of the private sector for accelerating agrarian sector transformation. The companion study regarding the private sector strategy (with its seven strategic objectives and supporting priority actions) provides a relevant and timely framework for expanding the role of the private sector. 


\section{ASSESSMENT OF FORWARD AGRICULTURAL EXPENDITURE ALLOCATIONS}

\subsection{Overview of MTEFF/CFMP Processes and Emerging Issues}

The Medium-term Expenditure Fiscal Framework (MTEFF) elaborated in the context of the State System for Financial Administration (SISTAFE), aims to support the elaboration of the Medium-Term Fiscal Scenario (CFMP: Cenário Fiscal de Médio Prazo). The CFMP is a three-year rolling instrument for budgetary planning (at national and provincial levels), which proposes allocations for public revenue and expenditure for the State Budget (OE), and which allocates public funds to priority activities for the annual Economic and Social Plan (PES). The objectives of the CFMP are clearly captured in the SISTAFE Regulations 3 and 4, as well as in the methodology for the elaboration of the CFMP updated and issued each year.

Specifically, the objectives of the CFMP are: (i) to define the macroeconomic context and parameters (e.g., fiscal ceilings) for the forthcoming budget; (ii) to explain the fiscal policy adopted, in the light of the macroeconomic context and the PQG; (iii) to forecast the envelope/ceiling of financial resources/revenues, including the respective sources; and (iv) to forecast a 3-year allocation of resources consistent with the policy and goals of PQG and PES. These objectives are consistent with international good practice as they emphasize predictability, clear links to policy and other strategic documents at national and sub-national levels and key sectors, and consider comprehensive and internally consistent coverage of revenues, expenditure and debt.

The process of drafting the CFMP covers all government institutions at central and sub-national levels (provincial, district and municipalities). This process is coordinated by the Ministry of Economy and Finance (MEF). The process starts in January with the provision of the methodology to all government institutions which stresses the need to forecast revenues to be generated by each sector and the respective resources (own revenues, donations, credit among others), and to estimate the recurrent and investment expenses. The methodology also indicates the criteria for prioritizing activities, although these tend to be quite general and vary from year to year. For example, the CFMP (20152017) prioritized the allocation of $68 \%$ of the total resources (excluding interest and debt and financial transactions) to priority sectors of the Action Plan for the Reduction of Poverty and the CFMP (20182020), and recommends ensuring that at least $77 \%$ of the financial resources be allocated to the priorities of the PQG. Figure 7.1 below summarize the driving factors and the objectives of the CFMP.

Although the total financial resources are limited and insufficient to cover the high demand, the criteria are general in nature and do not indicate explicit criteria to follow for prioritizing activities to be undertaken for the key sectors. The absence of explicit prioritization criteria allows government institutions to produce spending and revenue scenarios using differentiated prioritization criteria, which are generally based on ad-hoc judgements by the planning officials, which they submit to MEF by May of each year ${ }^{38}$. It is important to note that within government institutions at all levels, the participating staff are committed to the formulation of CFMP as it is also a requirement to obtain fiscal resources as it is used to establish the institutional annual budgetary ceilings. It is generally agreed

38 From 2013 to 2017, the CFPM covering the period from 2016 to 2018 was not produced and published. 
that the CFMP provides a good basis for planning over the medium term and it is used to define the annual PES targets. Without the CFMP, the annual plans and budget would lack strategic and fiscal coherence. Government stakeholders also report that the CFMP is important as an instrument for mobilizing funds from development partners. However, most Government planning/budget officers find the CFMP process frustrating, since they prepare the CFMP with ceilings that they receive in December, but then lower ceilings are issued by MEF for the OE in May, requiring budgetary planning officers to re-work the data for the elaboration of PES.

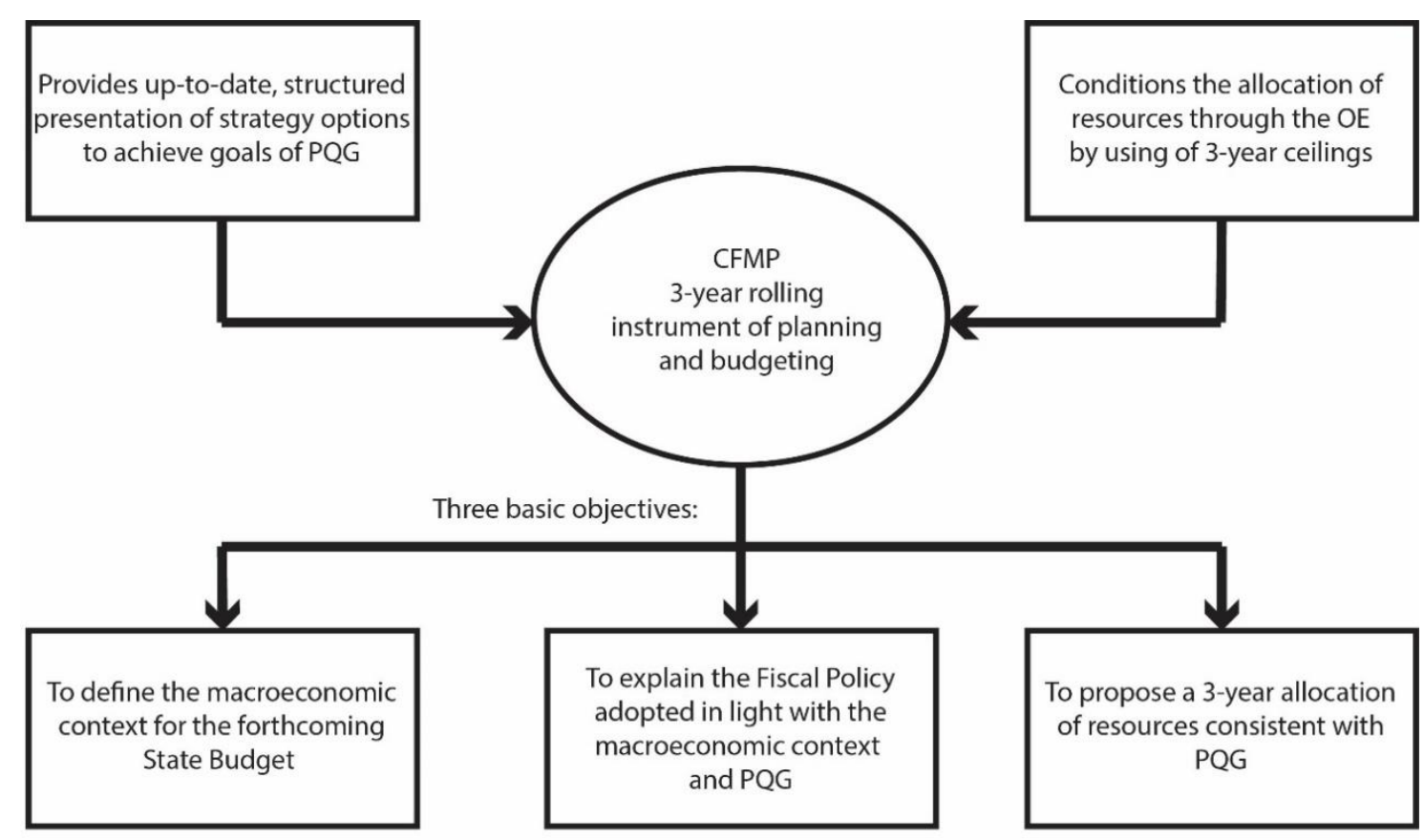

Source: World Bank (2016)

\section{Figure 7.1 The driving factors and the objectives of CFMP}

Accordingly, the ceilings established in the CFMP tend to be significantly higher (generally about 15 $35 \%)$ than the limits in the approved budget, requiring Ministries/agencies to revise their annual PES, taking into account the financial resources actually available. Table 7.1 below presents the forecasted and approved budget. Various versions of the rolling CFMP reveal that there are differences in the forecasted budgets for any given year. This might be due to the influence of macroeconomic conditions which affect directly the establishment of budget ceilings, coupled with the lack of accuracy for the expenditure and revenue assumptions of the macroeconomic projections. Furthermore, the CFMP, as a financial management tool, is limited because there are significant changes during the budget formulation process, which make the CFMP values diverge widely from the approved budget. As shown in Table 7.1below, during the period analyzed the actual budget was at least $12 \%$ lower than the approved budget, except in 2014. These results suggest the need of a robust framework for predicting the ceiling, and the need to design and implement clear "Policy Anchors", such as fiscal adjustment targets to guide the framework and subsequent adjustments. 
Table 7.1 Forecasted and actual budget (million MZN)

\begin{tabular}{llllll}
\hline Description & 2013 & 2014 & 2015 & 2016 & 2017 \\
\hline CFMP (2012-2014) & 169,286 & 186,556 & & & \\
CFMP(2013-2015) & 181,200 & 201,472 & 225,903 & & \\
CFMP (2014-2016) & & 190,212 & 211,763 & 239,253 & \\
CFMP (2015-2017) & & & 248,807 & 252,170 & 289,139 \\
CFMP (2017-2019) & & & & & 272,289 \\
Last previewed value in CFMP & 181,200 & 190,212 & 248,807 & 252,170 & 272,289 \\
Actual budget & 160,132 & 199,327 & 171,670 & 220,588 & 177,138 \\
Actual as \%age of predicted (\%) & $88.4 \%$ & $104.8 \%$ & $69.0 \%$ & $87.5 \%$ & $65.1 \%$ \\
\hline
\end{tabular}

Source: CFMP and e-SISTAFE

Furthermore, the CFMP is ambitious as it aims to be both a fiscal and a budget framework, and these two objectives are pursued simultaneously, coupled with scarce resources and the limited familiarity with the techniques and practices of good forecasting. Additionally, the policy anchors of the Fiscal Strategy are not clear in the absence of Fiscal Rules or medium-term adjustment targets. These limitations suggest the need for MEF to adopt five steps to improve the efficiency and effectiveness of CFMP framework (illustrated in Figure 7.2).

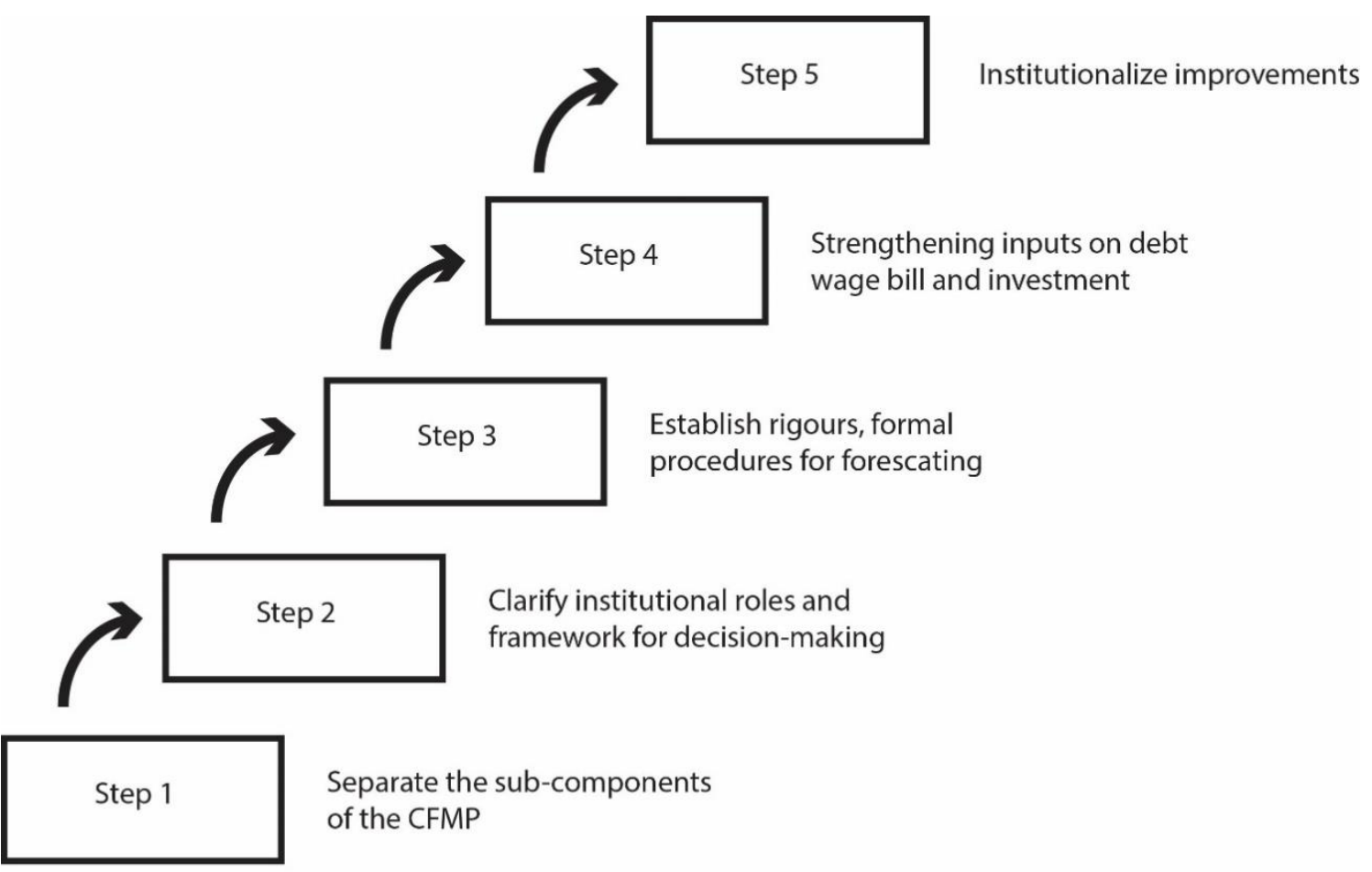

Source: World Bank (2016)

Figure 7.2 The five steps for the improvement of CFMP

The first step requires allowing more time for the development of CFMP by separating the fiscal and the budgetary frameworks, and by allowing the first to start and complete to provide useful information in terms of reliable predictions to feed the second component. 
The second step calls for: a) strengthening internal coordination and quality control within MEF: b) strengthening the fiscal foundations of the Plano Económico Social (PES); and c) improving communication and public consultation on the Fiscal Strategy.

The third step requires that all forecasting processes for fiscal aggregates - revenue, debt, expenditure \& its key sub-components, and budget financing - should be based on systematic application of two principles, namely: (i) forecast from a defined baseline towards a target, backed by appropriate policy measures and; (ii) all forecasts independently checked, agreed by a technical committee, and signed off by a MEF Manager.

The fourth step needs improving debt, wage bill and pensions forecasting and planning and budgeting of public investment projects.

The fifth and last step requires that institutional measures are introduced to ensure that improvements to the CFMP will be sustained, and this should include both short-term and mediumterm measures to ensure that "quick wins" are consolidated and that the improved CFMP is sustained over the long term. These measures include the establishment of a fiscal technical committee, to agree on action plan and establish periodically reviews.

These proposed improvements to the CFMP process could be considered by the agricultural sectoral ministries including: (a) applying the above principles, adjusted to their ministry/sector; (b) formulate agreed explicit prioritization criteria; (c) consider High, Medium and Low scenarios to facilitate the process of adjustment; (d) ensure there is coordination of priorities amongst the sectoral ministries (say, through periodic working session(s) convened by the directors/senior budgetary planning staff of the Planning Departments of each of the sectoral ministries) to help ensure strong alignment, complementarity, coherence and consistency and budgetary allocations with the agreed and explicit prioritization criteria (as recommended in this report).

\subsection{Assessment of MTEFF at the Sector Ministry Level}

Overview. As explained in above, the MTEFF framework is used to preview the budget, taking into account the macroeconomic context and working assumptions. This process is led by MEF, with inputs from government institutions. Within a given government institution, each beneficiary management unit ("Unidade Gestora Benefeciária, UGB)"), prepares its CFMP and submits to the ministry-level Directorate of Planning for aggregation. The process of preparing the CFMP is supposed to be interactive and involve the main actors (planners and technical staff) as well as interaction among the different UGBs for alignment. Although this process involves planning and technical staff, there is no alignment among the different UGBs and institutions. This alignment is key, and it is recommended to ensure complementarity, and therefore, efficient and effective use of limited fiscal resources.

Forecasted Investments. This CFMP framework is crucial for planning investments in the agricultural sector. Table 7.2 shows the forecasted total investment budget from the recent CFMP (2019-2021) by each sectoral Ministry. The results reveal that among the analyzed Ministries, MOPHRH has the highest forecasted investment budget as it is associated to the construction of public and costly infrastructure, such as roads, water supply, hydraulic works, and bridges. The trend of forecasted budget for investment is increasing for MASA, but there is not a clear trend for the other Ministries. 
The increase of $8.5 \%$ from 2019 to 2020 in MASA is not aligned with the average agricultural growth rate of $3.2 \%$ in the period from 2013 to 2017 , which implies that the budgetary allocations for the agriculture sector are not aligned with realized benefits in the sector, although the contribution of the agricultural sector to total GDP is an estimated $25 \%$. In contrast to MASA, the forecasted investment budget is decreasing for MITADER and MIMAIP. This scenario might be reflecting the general budgetary cuts being faced by government institutions.

Table 7.2 Forecasted total investment by ministry (million MZN)

\begin{tabular}{lllllll}
\hline \multirow{2}{*}{ Year } & Ministries & \multicolumn{5}{c}{} \\
\cline { 2 - 6 } & MASA & MITADER & MIMAIP & MIC & MOPHRH & Total \\
\hline 2019 & 996 & 2,011 & 2,165 & 297 & 66,272 & 71,741 \\
2020 & 1,081 & 1,638 & 1,761 & 315 & 35,991 & 40,785 \\
2021 & 4,674 & 1,588 & 776 & 310 & 40,215 & 47,563 \\
\hline
\end{tabular}

Source: MEF (2019)

Sources of Funding. Considering the funding sources of the forecasted investment budget, the results reveal that it differs among ministries (Table 7.3). The results in Table 7.3 reveal that the main source of forecasted investment budget is external in MOPHRH and it is internal for MASA. The fact that the majority of forecasted investment funds for MASA are internal might limit the effective implementation of activities due to financial constraints that are resulting budget cuts in Mozambique. Therefore, there is a need for MASA to design and implement an action plan for mobilizing additional financial resources, building on lessons derived from other Ministries such as MIMAIP, MOPHRH and MITADER.

Table 7.3 Share of internal and external predicted investment by ministry (\%)

\begin{tabular}{|c|c|c|c|c|c|c|c|c|c|c|}
\hline \multirow[b]{3}{*}{$\begin{array}{l}\text { Yea } \\
r\end{array}$} & \multicolumn{10}{|c|}{ Ministries } \\
\hline & \multicolumn{2}{|c|}{ MASA } & \multicolumn{2}{|c|}{ MITADER } & \multicolumn{2}{|c|}{ MIMAIP } & \multicolumn{2}{|l|}{$\mathrm{MIC}$} & \multicolumn{2}{|c|}{ MOPHRH } \\
\hline & $\begin{array}{l}\text { Intern } \\
\text { al }\end{array}$ & $\begin{array}{l}\text { Extern } \\
\text { al }\end{array}$ & $\begin{array}{l}\text { Intern } \\
\text { al }\end{array}$ & $\begin{array}{l}\text { Extern } \\
\text { al }\end{array}$ & $\begin{array}{l}\text { Intern } \\
\text { al }\end{array}$ & $\begin{array}{l}\text { Extern } \\
\text { al }\end{array}$ & $\begin{array}{l}\text { Intern } \\
\text { al }\end{array}$ & $\begin{array}{l}\text { Extern } \\
\text { al }\end{array}$ & $\begin{array}{l}\text { Intern } \\
\text { al }\end{array}$ & $\begin{array}{l}\text { Extern } \\
\text { al }\end{array}$ \\
\hline 201 & & & & & & & & & & \\
\hline $\begin{array}{l}9 \\
202\end{array}$ & 100.0 & 0.0 & 44.8 & 55.2 & 6.4 & 94.0 & 47.7 & 52.3 & 11.0 & 89.0 \\
\hline 0 & 100.0 & 0.0 & 62.2 & 37.8 & 8.7 & 92.0 & 50.9 & 49.1 & 22.3 & 77.7 \\
\hline 202 & & & & & & & & & & \\
\hline 1 & 100.0 & 0.0 & 63.4 & 36.6 & 24.6 & 80.3 & 58.5 & 41.5 & 21.3 & 78.7 \\
\hline
\end{tabular}

Source: MEF (2019)

\subsection{Synthesis of Good Practices and Lessons from Selected African Countries}

In general, there is limited experience and few examples of good practice in sectoral ministries in Sub Saharan Africa (SSA) in terms of preparing sound medium-term expenditure frameworks. However, 
the Ag. Public Expenditure reviews for ten African countries, funded by the Gates Foundation, included some limited experiences and the main conclusions and lessons can be summarized as follows: ${ }^{39}$

- MTEFs are budgetary planning tools which are gaining strong acceptance and use by Ministries of Finance in most countries of SSA;

- Most countries in SSA are experiencing capacity constraints to prepare and use quality MTEFs by Ministries of Finance, sectoral ministries, and especially at the sub-national level;

- Very few countries are using budgetary planning scenarios (high, medium and low) and explicit prioritization criteria. This does not mean that these aspects are not recognized as being important but reflects the relatively new introduction of MTEFs as a standard planning tool and practice.

- Although there are very few countries (probably less than two) in SSA which have adopted multi-ministerial joint planning meetings to formulate their budgetary allocations, preferably facilitated by the MEF, this reflects the deep-rooted practice/habit of working in a fragmented and uncoordinated manner. Clearly, weak coordination arrangements and supporting mechanisms in the budgetary cycle among sectoral ministries, especially at the sub-national level, are a common major challenge in most SSA countries. With the support of the WB/Gates Foundation, in 2014, a specialized study was carried out to assess the medium-term expenditure framework and associated processes. One of the good practices identified in Togo was the establishment of a Sectoral Technical Working Group which worked together in the formulation and use of the MTEF for the agricultural sector. It is not known if this TWG is still operating, nor is it known if other countries in SSA use this TWG mechanism. With effective leadership, this coordination mechanism can be effectively used, with tangible benefits.

- There is a need to develop a good practice "platform" among SSA countries, including sectoral ministries (and not just MEFs), to share good practices of budgetary training modules and experiences in the budgetary cycle (covering MTEFs and annual budgetary processes). The World Bank and IMF could work together to facilitate such a platform (web-based, and periodic workshops to encourage cross-country sharing), involving country level/macro and major sectors. With the completion of the Gates Foundation Ag PER assessment project, the African Union (together with NEPAD) has endeavored to continue some aspects of tracking these experiences, but capacity and financial constraints have limited the institutionalization of these practices, and are more limited to meeting the biennial reporting requirements of CAADP.

\subsection{Alignment between Priority Targets and Programs and Proposed Forward Budgetary Proposals}

The process of preparing the CFMP is supposed to be based on sound and updated agricultural sector strategy documents such as the National Agriculture Investment Plan (PNISA), the National Development Strategy, among other relevant documents. The current guiding strategic document in

\footnotetext{
${ }^{39}$ Strengthening National Comprehensive Agricultural Public Expenditure in Sub-Sahara Africa (funded by the Gates Foundation, executed by the World Bank, in close collaboration with AUC/NEPAD in support of CAADP, implemented during the period of 2010 - 2016). The other document which provides additional inputs with respect to "Light" Ag. PERs refers to: Guide for Carrying Out "Light" Agricultural Public Expenditure Reviews (World Bank, in collaboration with AUC/NEPAD, in support of CAADP, 2017.
} 
Mozambique's agricultural sector is PEDSA and especially the PNISA, and therefore this section assesses the alignment of the CFMP (2019-2021) with the PNISA. Table 7.4 below presents the forecasted investment budget by result area for the agricultural sector.

The results are clear in terms of the mandate of each ministry in leading the five results areas. For example, MASA and MIMAIP allocate their investment resources mainly for agricultural production and productivity (RA 1). MITADER and MOPHRH allocate their investment budget mainly for natural resource management and access to markets, respectively (RAs 2 and 3). The amount allocated by MIC to the five result areas is relatively smaller compared to other ministries, but there is clear tendency for MIC to allocate the majority of its investment budget to the Result Area 2 (Access to Markets). Therefore, under the envisioned revived and strengthened CCSA, the leadership/coordination of the agricultural sector's technical affairs should be distributed according to result areas and programs as follows: MASA and MIMAIP to lead agricultural production and productivity; MITADER to lead Natural Resource Management; MASA and MIC to lead food security and MOPHRH and MIC to lead access to markets. The yearly relative importance of each result area in terms of the allocation of the forecasted investment budget under the CFMP (2019-2021) is shown in the last column of Table 7.4 below. The results indicate a consistent yearly pattern of forecasting relatively high budget for the Result Area 2 (Access to Market) followed by Result Area 1 (Production and Productivity).

Table 7.4 Forecasted investment budget by result area in the agricultural sector (2019 2021)

\begin{tabular}{|c|c|c|c|c|c|c|c|c|}
\hline \multirow[b]{2}{*}{ Years } & \multirow[b]{2}{*}{ Result Area (5 RAs comprise 21 programs) } & \multicolumn{5}{|l|}{ Ministries } & \multirow[b]{2}{*}{ Total } & \multirow{2}{*}{$\begin{array}{l}\text { Relative } \\
\text { importance } \\
\text { (\%) }\end{array}$} \\
\hline & & MASA & MITADER & MIMAIP & MIC & MOPHRH & & \\
\hline \multirow{6}{*}{2019} & 1) Agricultural Production and Productivity & 458.63 & 1.00 & 715.79 & & & $1,175.42$ & $16.0 \%$ \\
\hline & 2) Access to Markets & & & 221.57 & 55.03 & $3,048.01$ & $3,324.61$ & $45.2 \%$ \\
\hline & 3) Food Nutritional Security & 536.91 & & & & & 536.91 & $7.3 \%$ \\
\hline & 4) Natural Resources Management & & $1,086.66$ & & 1.50 & & $1,088.16$ & $14.8 \%$ \\
\hline & 5) Institutional Reform and Strengthening & & & $1,227.64$ & 2.50 & & $1,230.14$ & $16.7 \%$ \\
\hline & Subtotal & 995.54 & $1,087.66$ & $2,165.00$ & 59.03 & $3,048.01$ & $7,355.24$ & $100.0 \%$ \\
\hline \multirow{6}{*}{2020} & 1) Agricultural Production and Productivity & 470.22 & 1.20 & 601.20 & & & $1,072.62$ & $18.4 \%$ \\
\hline & 2) Access to Markets & & & 169.77 & 76.42 & $1,939.30$ & $2,185.49$ & $37.4 \%$ \\
\hline & 3) Food Nutritional Security & 610.37 & & & 0.79 & & 611.17 & $10.5 \%$ \\
\hline & 4) Natural Resources Management & & 975.82 & & & & 975.82 & $16.7 \%$ \\
\hline & 5) Institutional Reform and Strengthening & & & 990.06 & 2.38 & & 992.44 & $17.0 \%$ \\
\hline & Subtotal & $1,080.59$ & 977.02 & $1,761.03$ & 79.59 & $1,939.30$ & $5,837.54$ & $100.0 \%$ \\
\hline \multirow{6}{*}{2021} & 1) Agricultural Production and Productivity & $2,471.15$ & 1.40 & 444.82 & & & $2,917.37$ & $34.8 \%$ \\
\hline & 2) Access to Market & & & 50.22 & 81.55 & $1,911.81$ & $2,043.57$ & $24.4 \%$ \\
\hline & 3)Food Nutritional Security & $2,203.30$ & & & 0.93 & & $2,204.23$ & $26.3 \%$ \\
\hline & 4) Natural Resources Management & & 942.05 & & & & 942.05 & $11.2 \%$ \\
\hline & 5) Institutional Reform and Strengthening & & & 281.27 & 2.80 & & 284.07 & $3.4 \%$ \\
\hline & Subtotal & $4,674.45$ & 943.45 & 776.31 & 85.28 & $1,911.81$ & $8,391.29$ & $100.0 \%$ \\
\hline
\end{tabular}

Source: MEF (2019)

For a further understanding of the alignment of the actual forecasted budget with the relative importance of PNISA Result Areas as established in PNISA, Table 7.5 shows the relative importance of 
the five result areas under the CFMP (2019-2021) and the PNISA. These results suggest a relatively small misalignment in the allocation of resources. The result area 1 (agricultural production and productivity), which was ranked number 1 in terms of budget allocation under PNISA, is ranked number 2 under the CFMP (2019-2021), while the result area 2, ranked number 2 under the PNISA, is ranked number 1 under the CFMP (2019-2021). The result area 4 (food and nutritional security) which was ranked 5 under PNISA is ranked 3 under CFMP (2019-2021) and above the result area 4 (natural resource management). This shows the commitment of the government to reduce malnutrition which has been high and static over the years. Therefore, the design of the new agricultural sector strategic documents should take into account this new paradigm by analyzing the possibilities for allocating more resources for supporting increased productivity (RA 1) and Food Nutritional Security (RA compared to the previous strategic documents.

Table 7.5 Forecasted investment budget by result area (2019 - 2021)

\begin{tabular}{|c|c|c|c|c|c|c|c|}
\hline \multirow[b]{2}{*}{ Result Areas } & \multicolumn{3}{|l|}{ Years } & \multirow[b]{2}{*}{ Total } & \multirow{2}{*}{$\begin{array}{l}\text { Relative } \\
\text { importance } \\
(\%)\end{array}$} & \multirow{2}{*}{$\begin{array}{l}\text { Rank } \\
\text { CFMP }\end{array}$} & \multirow{2}{*}{$\begin{array}{l}\text { Rank } \\
\text { PNISA }\end{array}$} \\
\hline & 2019 & 2020 & 2021 & & & & \\
\hline 1) Agricultural Production and Productivity & 1,175 & 1,073 & 2,917 & 5,165 & $25.8 \%$ & 2 & 1 \\
\hline 2) Access to Market & 3,325 & 611 & 2,044 & 5,979 & $29.9 \%$ & 1 & 2 \\
\hline 3)Food Nutritional Security & 537 & 611 & 2,204 & 3,352 & $16.8 \%$ & 3 & 5 \\
\hline 4) Natural Resources Management & 1,088 & 976 & 942 & 3,006 & $15.0 \%$ & 4 & 4 \\
\hline 5) Institutional Reform and Strengthening & 1,230 & 992 & 284 & 2,507 & $12.5 \%$ & 5 & 3 \\
\hline Total & 7,355 & 4,263 & 8,391 & 20,010 & $100.0 \%$ & - & - \\
\hline
\end{tabular}

Source: MEF (2019)

It is also important to note that PNISA presents the budget for each result area which should be considered as a reference during the production of CFMP. Figure 7.3 below compares the forecasted annual budget for each result area with the annual budget for each result area, as stated in the PNISA. The results reveal a huge misalignment for the result area 1 (agricultural production and productivity), where the annual PNISA budget is significantly superior to the forecasted budget for the CFMP (20192021). This result suggests that the production of the CFMP is ad-hoc, without consulting and reflecting consistently the relevant sectoral strategic documents, coupled with criteria for prioritization and poor performance of the agricultural sector (e.g., stagnant crop yields). Therefore, it is recommended to use/apply consistently the existing strategic documents (PNISA, PNISA Assessment Report, Programa Estrela/SUSTENTA) for the formulation of the CFMP, coupled with making improvements in its implementation, as discussed in the above section.

Another important conclusion from this broad assessment of alignment, is the importance of ensuring an increased level and quality of expenditure for each of the component programs, totaling 21 programs for the 5 RAs. In general, there is continued underfunding of each of these programs, reflecting macro-fiscal constraints. There has been limited progress in improvements in the quality of the composition of expenditure for most of the programs. Accordingly, this brief mini-assessment of the forward budget suggests that the recommendations arising from the past expenditure are largely and equally applicable for forward expenditures. 


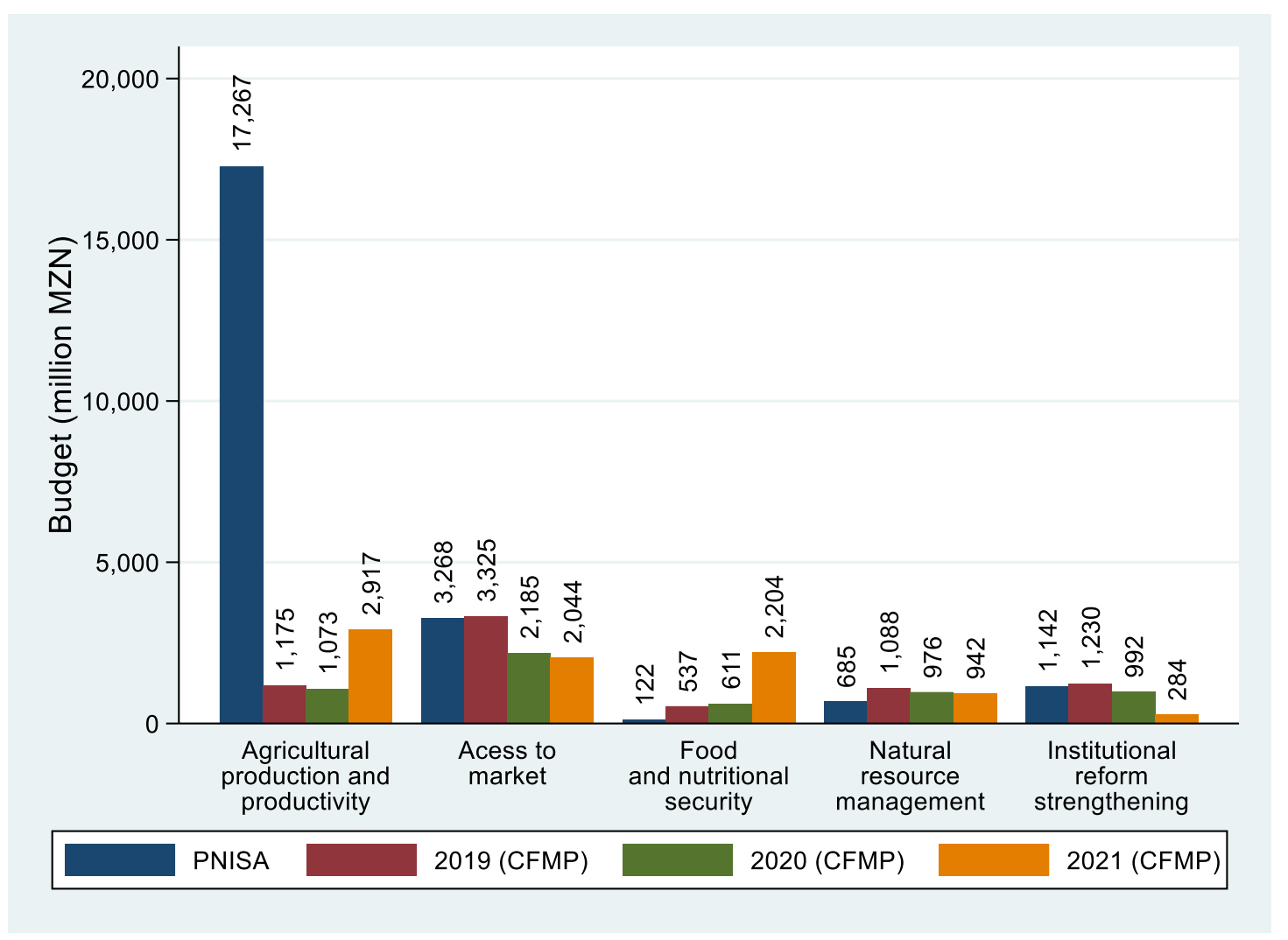

Figure 7.3 PNISA budget and CFMP budget by PNISA result area

\subsection{Main Findings and Recommendations}

The current MTEFF process is ambitious as it aims to be both a fiscal and a budget framework, with these two objectives being pursued simultaneously, coupled with scarce resources and the limited familiarity with the techniques and practices of good forecasting as well as the lack of fiscal rules or medium-term adjustment targets. These constraints make the process frustrating as the fiscal ceilings are revised during the budgetary planning process, requiring planning officials to continuously make uninformed adjustments to the PES. Additionally, the CFMP is not prepared in coordination with the various units within the Ministry, or with different Ministries comprising the agricultural sector. Moreover, there is limited use of agricultural strategic documents, coupled with the lack of prioritization criteria, which yields differences between the relative importance of each result area established in the strategic documents and the relative importance of these result areas resulting from the CFMP.

Therefore, there is a need for improvements of the CFMP processes, including:

(a) Allowing more time for the development of CFMP by separating the fiscal and the budgetary frameworks, and by allowing the first to start and complete providing useful information in terms of reliable predictions to feed into the second component;

(b) Improve the forecasting processes for fiscal aggregates - revenue, debt, expenditure and its key sub-components, and budget financing, and establish baseline and realistic and consistent expenditure and result targets; 
(c) Improve institutional processes, and particularly improved coordination, within the ministry and between ministries, including the establishment of a Sectoral Technical Working Group (enabled by effective leadership), and agree on an annual action plan, and establish mid-year and yearly reviews;

(d) Use agricultural sector strategic documents as key inputs for the preparation of CFMP and formulate agreed explicit prioritization criteria (as proposed in this report, with relevant adjustments);

(e) Consider high, medium and low expenditure scenarios (for the medium-term and annual), to facilitate the process of adjustment with actual budgetary ceilings;

(f) Ensure there is coordination of priorities amongst the sectoral ministries (say, through periodic working session(s) convened by the directors/senior budgetary planning staff of the Planning Departments of each of the sectoral ministries) to help ensure strong alignment, complementarity, coherence and consistency and budgetary allocations with the agreed prioritization criteria. Use commonly agreed M\&E performance indicators and corresponding targets to help ensure alignment among different ministries. 


\section{ROADMAP: STRATEGIC CONCLUSIONS, PRIORITIZED RECOMMENDATIONS AND WAY FORWARD}

This Agricultural Public Expenditure Review (AgPER) has generated 8 strategic core messages, with supporting priority recommendations, in line with the objectives of this exercise. The basic premise of this Ag. PER is that the Government has developed over time sound and improved medium-term and annual expenditure frameworks and processes, but agricultural sector Ministries and Provinces need to enhance the management and application of these tools and processes during the entire expenditure cycle, with a focus on achieving sharper prioritization, accountability and strategic results. Especially in the light of fiscal constraints, it is vital to ensure the agricultural public expenditure also catalyze increased and inclusive investments from an expanded private sector.

Moreover, the adoption, implementation and accountability of the core agreed recommendations by key stakeholders, especially by the sectoral Ministries, guided and reinforced through the reactivated CCSA, can help translate the study's recommendations into tangible and sustainable results. The section below synthesizes these 8 core messages and supporting recommendations in the form of a roadmap for paving the way forward, using especially the budgetary cycle and supporting appropriate tools, processes and approaches outlined in the report. Annex 0 provides further details of a proposed results-focused agricultural PER Action Plan ("RAPEAP") as a tool to help generate strategic results from the efficient and effective implementation and accountability of the agreed priority recommendations.

Figure 8.1 illustrates the inter-connections between the 8 core messages/strategic outcomes, or expenditure pillars, such that phased adoption and effective implementation of their supporting priority_actions will enhance significantly the level, quality and strategic results of Mozambique's agricultural public expenditures. For each of these 8 strategic outcomes, the section below highlights the relevant context and "core" and the secondary recommended actions. Further details are outlined in the Action Plan (Annex E). 


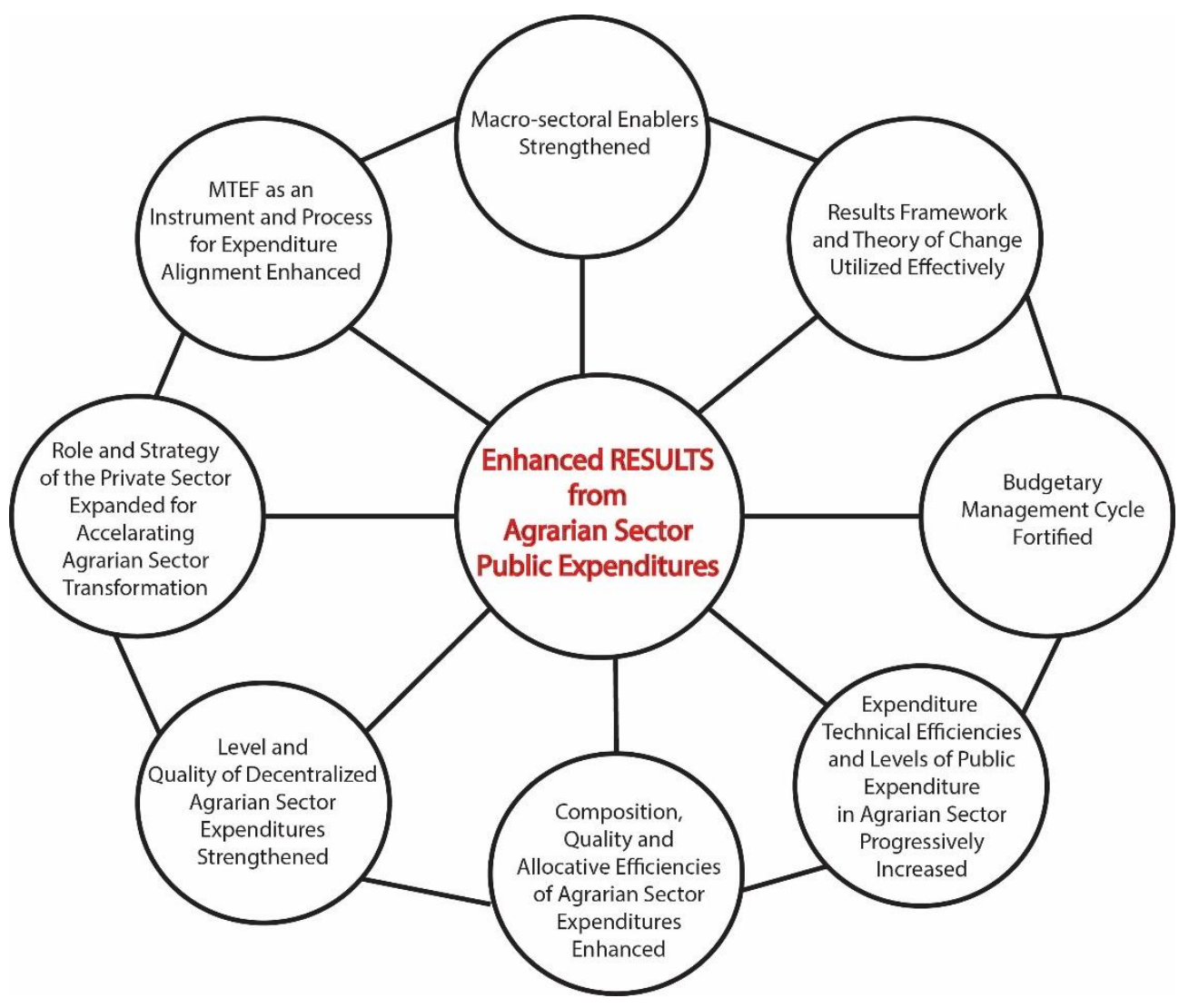

Figure 8.1 Interconnectivity and Synergies of Core Elements of Agricultural Sector Expenditure

1) Macro-Sectoral Enablers Strengthened. Sound policy framework at both macro and sectoral levels and clear and effective institutional roles will determine the scope and pace of agrarian sector transformation [Chapter 1]

\section{Core Recommendations:}

a) Ensure updated and effective implementation of the PQG \& MTEF as guiding planning and expenditure tools for each sectoral ministry, also reflecting high priority for agrarian sector;

b) Ensure formulation, approval and implementation of updated agrarian sector policy, strategy and investment program

\section{Secondary Recommendations:}

a) Improve agrarian sector performance to be more consistent and to achieve realistic targets, while addressing the relevant constraints. The study highlighted Mozambique's important macro-economic structural factors and trends (e.g., fluctuating economic growth rates; rising inflation rates, and growing fiscal imbalances) and structural constraints in the agricultural and rural sectors. These factors pose significant challenges to achieving accelerated and inclusive growth in the agricultural sector and sustained rural employment generation and poverty reduction; 
b) Revitalize the role of the agrarian sector to contribute to core objectives of the Government's PQG and targets. The agricultural sector performance has been erratic and well below targets, due to various constraints, including: limited generation of, and access to, enhanced and climate-resilient agricultural technologies, together with limited research and extension linkages; limited access to financial resources, coupled with its inappropriate allocation; uneven capacities and variable efficiencies and effectiveness of both public and private sector institutions, especially with respect to coordination;

c) Tap underutilized potential for intensifying and diversifying Mozambique's sources of growth. There is significant underutilized potential for intensifying and diversifying Mozambique's sources of growth, with respect to agricultural production and associated agro-processing potential, coupled with enhanced market competitiveness, to be driven by an expanded and inclusive private sector development, which is currently in its infant stage;

d) Promote stronger institutional coherence fragmentation in the agrarian sector. The institutional fragmentation of the agricultural sector highlights the urgency of ensuring appropriate, efficient and effective coordination of policies, institutional roles and public and private sector investments at various levels (national and sub-national) for the agricultural sector, rather than a "traditional" institutional and narrow approach;

e) Expand the role of an inclusive private sector to accelerate agrarian sector transformation. From other successful country experiences, agrarian transformation will be driven primarily by an inclusive private sector, which will need to exhibit resilient capacities and competitive value chains;

f) Update and track appropriate and prioritized investments by both public and private sectors to help realize strategic sector targets. There is an urgent need to update and intensify formulation, implementation and tracking of appropriate and prioritized investments by both public and private sectors to help realize strategic sector targets. Most of these targets (ref. PNISA) are being significantly underachieved, due to a combination of constraints identified above, including absence of sound and explicit prioritization criteria, coupled with limited funding;

g) Tap the large poverty elasticity of the agrarian sector. The agricultural sector has the largest poverty elasticity $(-2.6 \%)$, more than three times higher than other sectors, and consistent with global developing country experience. This implies the need for expanding strategic and prioritized level and composition of public investments in the agricultural sector.

\section{2) Results Framework (RF) and Theory of Change (ToC) Utilized Effectively for Assessing and} Prioritizing the Efficiency and effectiveness of Sectoral Public Expenditure [Chapters 2 and 3]

\section{Core Recommendation:}

Ensure effective use of sound RF and other relevant tools to:

- formulate updated agrarian policy, strategy and investment program

- mid-term reviews of on-going and design of proposed projects

\section{Secondary Recommendations:}

While this tool has been absent, the sharpening and operationalization of a sound RF provides planners, decision-makers and implementors a powerful and dynamic tool to accelerate the performance of the agricultural sector since it provides a roadmap to agrarian transformation. It is recommended that MASA, through its Department of Planning and International Cooperation (DPCI), together with the leadership of MASA's Minister, other senior managers, working closely together with the other sectoral Ministries, take a proactive role to: 
a) Engage with MEF. Engage with key counterparts in the relevant departments from the Ministry of Economy and Finance (MEF) to understand fully relevant macro-economic-fiscal policies and expenditure programs, and to derive sound strategic and operational implications for promoting transformation of the agrarian sector, utilizing effectively the Medium-Term Expenditure Framework and annual budgetary processes/PES;

b) Work Together. Work closely with the other sectoral Ministries (MITADER, MIC, MOPHRH and MIMAIP, and their relevant specific departments) and key stakeholders (especially inclusive private sector, development partners/DPs, civil society/academia), to pursue a perspective and "lens" of an integrated "agrarian sector" (in line with AU guidelines); and

c) Jointly Update Key Policies, Strategies and Investments. Carry out, together with twinning arrangements with other Ministries, academia and local organizations, relevant analyses and consultations, to advocate for the formulation, implementation and tracking of updated and sound agrarian sector policies, regulations and investments (both public and private sector) which can contribute to the key macro-economic and sectoral objectives and targets (especially the PQG) ${ }^{40}$.

\section{3) Budget Management Cycle Fortified: Sound Process and Prioritization Criteria Applied and Effective Sectoral Coordination to Ensure Strategic Results [Chapters 3, 4, 5 and 7]}

The main findings include: (i) There is a gap between the theory and practice of the agricultural budgetary cycle and supporting processes (managed/coordinated by MASA and other sectoral ministries, coordinated by MEF). Accordingly, there are important technical, analytical and management capacity constraints which need to be addressed at various levels - national and subnational; (ii) The budgetary process and institutional roles at national and sub-national levels are: (a) Elaborate and similar at both levels and (b) There are greater capacity constraints at sub-national levels, and hence quality is more variable, especially as expenditure are increased at sub-national levels as part of on-going decentralization; (iii) There is a comprehensive budgetary cycle process, which exhibits uncertain and changing budgetary ceilings, resulting in challenges, frustration and lack of clear priorities, especially with the lower ceilings arising from fiscal constraints.

\section{Core Recommendations:}

(a) Apply enhanced prioritization criteria, at each stage of the budgetary cycle for agrarian sector, namely (i) Strength of alignment with relevant PQG and agrarian sector objectives and targets, (ii) Contribution to inclusive sources of agricultural growth and poverty reduction, especially with respect to increased crop yields and value chain development, increased climate change resilience and consistent with "public" goods and services to ensure appropriate roles, (iii) Contribution to "catalyzing" expanded and inclusive private agrarian sector investments, including strategic public goods and services (e.g. enhanced technologies, productive rural infrastructure) and (iv) Demonstrated evidence of good institutional performance and governance including functional M\&E systems;

(b) Ensure effective functioning of a strengthened CCSA

\section{Secondary Recommendations:} 40
MASA, in consultation with other stakeholders, has prepared a framework TOR for formulating during 2019
Mozambique's Three Pillars of Agrarian Sector Transformation: Policy, Strategy and Investment Program. 
Strengthen the agrarian sector level budgetary management cycle, supported by enhanced processes, capacities, performance and accountabilities at various levels, to help translate allocations into sharper priorities and strategic results, at key stages of the budgetary cycle:

a) Planning Phase:

(i) Adequate Time and Scenarios. Request MEF (at National and Provincial levels) to issue the call for budget proposals (medium-term and annual) with adequate time (length and sequence) for technical preparation and for consultations with stakeholders, and with 3 budgetary scenarios (High, Medium, Low), varying according to resource availabilities and Government agrarian sector priorities;

(ii) Strengthen Capacities and Use of Relevant Tools. Request MEF and strengthen sectoral Ministries (at National and Provincial levels) to introduce, in the call for budget, and apply consistently sound planning tools and explicit prioritization criteria (can use a simple weighting method to help rank projects/activities, using the above prioritization criteria);

(iii) Sound Prioritization with final ceilings. Sectoral Ministries to ensure sound prioritization of the final proposed allocations, in the light of the changing budgetary ceilings issued by MEF;

(iv) Assure Alignment and Adjustment with Development Partners: Organize annual meetings with partners to review investment proposals based on enhanced prioritization criteria, with objective to promote strong alignment between activities developed/proposed/re-aligned by development partners and those proposed by the government and private sector.

(v) Reactivated Sectoral Coordination/CCSA. Government, through the leadership of the sectoral Ministers, to ensure the establishment and effective functioning of improved agrarian sector coordination mechanisms and processes at various levels (e.g. re-activation and effective functioning of the CCSA, at national and provincial levels, with the support of a proposed Executive Technical Secretariat/ETS). This reactivated mechanism is to review and adjust the proposed budgetary allocations of the relevant institutions (national and sub-national levels), in the light of the changing ceilings, from the perspective of ensuring strong complementarity of allocations between institutions, with respect to achieving agricultural sector objectives and priority targets;

(vi) Expand Private Sector Role. Ensure appropriate support for an expanded and inclusive private sector for promoting agricultural development, consistent with appropriate roles between public and private sectors. There is a parallel study which has identified 7 strategic components and supporting priority actions which can provide a roadmap.

b) Implementation Phase:

(i) Effective Functioning of CCSA. Ensure the effective functioning of the enhanced CCSA, coupled with the required technical support (e.g. ETS), supported by periodic meetings (semesterly for high level CCSA, and quarterly for the technical level and program-based reviews), and ensure timely implementation and follow-up of the agreed actions, as part of enhanced accountability;

(ii) Streamline Procurement and financial management. Streamline procurement and financial management/Financial Management/FM processes to ensure a strengthened Government procurement system is functional at national and sub-national levels, and helps ensure efficient execution of the budgetary allocations;

(iii) Ensure Development Partners (DPs) Alignment and Harmonization. Align and harmonize development partner (DP) procurement and financial management requirements with strengthened Government systems at national and sub-national levels; 
(iv) Provide Interim Technical Support. In the interim, to ensure adequate technical procurement and financial management support is provided to the implementing agencies, with a strong capacity building orientation.

c) M\&E Phase:

(i) Enhance Sectoral M\&E Systems. Ensure effective strengthening, functioning and utilization of the ministerial and sectoral M\&E systems at the national, sub-national and sectoral levels, especially for the 5 Ministries comprising the CCSA;

(ii) Operationalize Performance Indicators. Develop and use the relevant performance indicators for promoting enhanced efficiencies, effectiveness and value-for-money of public expenditure, to support effective and timely implementation and enhanced coordination of prioritized public expenditure (including mid-year adjustments and rolling 3-year plans, and resulting sound annual plans), and

(iii) Strengthen Expenditure Data/e-SISTAFE Systems. Identify and ensure improvements in the quality and reliability of expenditure data for the e-SISTAFE disaggregated expenditure database, at national and provincial levels, and ensure other relevant data is compiled to support the enhanced sectoral M\&E system;

(iv) Ensure Effective Use of M\&E Results. Ensure the relevant findings of the M\&E systems are utilized as strategic inputs for the planning cycle (rolling 3-year and annual plans) by the relevant ministries/directorates for the agricultural sector, at national and sub-national levels; and

(v) Conduct Strategic Studies. Identify relevant strategic studies to be carried out which will assess strategic expenditure issues (e.g. subsidies in the agricultural sector; effectiveness of the agricultural technology systems; strategies for promoting competitive value chain development, and other strategic issues arising from the M\&E reports).

\section{4) Expenditure Technical efficiencies and levels of public expenditure in the agrarian sector progressively increased [Chapter 4, 5 and 6]}

Agricultural Sector Exhibits Major Underfunding. The study findings suggest that the agricultural sector was significantly underfunded during the period 2013 - 2017 (with an average of only $6.5 \%$ of total government budget allocation, and $5^{\text {th }}$ in allocations relative to other government functions/sectors), especially considering the following factors:

a) Relative Importance of Agricultural Sector. the agricultural sector contributes about $23 \%$ of $\mathrm{GDP}$, and when considering the indirect contributions, agricultural and related agro-based activities and services, the broader agricultural sector probably contributes about $50 \%$ of GDP);

b) Agricultural Sector with High Poverty Expenditure Elasticity. The agricultural sector, by far, has the highest poverty expenditure elasticity $(-2.5 \%)$ compared with any other sectors of the economy;

c) Mozambique Well Below the Maputo/Malabo Expenditure Target of 10\%. Mozambique fell significantly below the MAPUTO/MALABO Declaration targets of allocating at least $10 \%$ of total government expenditure to the agricultural sector. Even with the inclusion of off-budget expenditures, the share of expenditure for the agricultural sector is still well below the $10 \%$ expenditure target (about 6.5\%).

\section{Core Recommendation:}


Improve the execution rates and especially prioritization in order to ensure better quality of expenditure allocations in agrarian sector, as pre-condition to increase expenditure levels in the agrarian sector (towards the Maputo Declaration expenditure target of $10 \%$ );

\section{Secondary Recommendation:}

Develop Efficiency-Based Unit Costs/Benchmarks. The sectoral Ministries to develop "efficiencybased" unit costs for major goods and services, which should be used to improve value for money, and procurement and implementation efficiencies and performance (e.g., cost per hectare for different types of irrigation facilities; cost per kilometer for different types of rural roads; cost per agricultural extension agent and agricultural researcher with respect to identified outputs, and other key agricultural services);

\section{5) Composition, Quality and Allocative Efficiencies of Agrarian Sector Expenditure Significantly Enhanced [Chapters 4, 5, and 6]}

a) Composition Matters. The study highlighted the overall conclusion that the composition of agricultural public expenditure matters as much as the amount actually spent. Allocations and expenditure in different functions can result in very different outcomes in terms of both performance of the agricultural sector and ultimately on the impact of rural households. Currently, there are relatively weak processes and systems in place to ensure consistent highquality expenditure in the agricultural sector, including the application of explicit sound prioritization criteria (see above).

b) Use Expenditure Classification Systems. There are 4 different expenditure classification systems which were assessed, with each system demonstrating varying "mixed" results in terms of "appropriate" balance: (a) by economic classification; (b) by source of funding; (c) by administrative level; and (d) by PNISA result area and program. While there is a limited empirical basis to determine precisely the "appropriate level" of expenditure to be allocated according to each of these classification systems, based on international standards/practices, the findings suggest there is scope for improving the balance of the expenditure and their corresponding composition, in order to generate stronger results (e.g., excessive allocations for wages, and insufficient funds for operating expenses and capital expenditures, limits the effectiveness and results of the goods and services, such as research, with concentration on wages, and limited operational funds to generate relevant research outputs; excessive dependency on external sources of funding threatens the sustainability of providing key agricultural services; underfunding programs which promote agricultural productivity and resilience to climate change, such as funding key public goods such as agricultural research and extension, and low cost irrigation facilities; the risk of increasing expenditure allocations for "private" goods (e.g., fertilizer subsidies), rather than addressing underlying key constraints to low input usage and low productivity levels).

c) Significant Underfunding of 3 Strategic Programs. The study found that there was substantial public underfunding of the 3 strategic programs which will contribute to the agrarian sector transformation - agricultural research, extension and irrigation infrastructure - well below PNISA targets and established international standards/targets (e.g., agricultural research expenditure intensity of $0.43 \%$ of AgGDP, vs. the AU target of $1 \%$ of Ag. GDP; imbalance in the allocations for recurrent and capital expenditures, especially to ensure the agricultural researchers and extension workers, and irrigation schemes have adequate operational funds and capital "assets" to perform productively and to generate the expected results). 
d) Risks of Reliance on External Funding. The study findings also highlighted some of the risks in some programs relying excessively on external funding sources $(40 \%$ to $60 \%$ of some programs), which could jeopardize the sustainability of core services (e.g., agricultural research, extension, irrigation, rural roads, institutional strengthening).

\section{Core Recommendations:}

(a) Apply the agreed enhanced four (4) prioritization criteria:

(i) Strength of alignment with relevant PQG and agrarian sector objectives and targets;

(ii) Contribution to inclusive sources of agricultural growth and poverty reduction;

(iii) Contribution to "catalyzing" expanded inclusive private agrarian sector investments; and

(iv) Demonstrated evidence of good institutional performance and governance;

(b) Strengthen and effectively Use Agrarian Sector M\&E system (ministry, provincial and sectoral levels)

\section{Secondary Recommendations:}

a) Develop/Use Efficiency-based Expenditure for Achieving Sound "Balance" and Unit Costs. Each of the sectoral Ministries work out "efficiency-based" expenditure balance and unit cost targets for the 4 expenditure categories, especially for their major expenditure activities, and to use these "benchmarks" as a guide for formulating the composition of their expenditures, in their medium and annual expenditure plans, and ensuring cost-effectiveness during the procurement and implementation processes. This approach recognizes that there is no fixed proportion or composition to be followed by all ministries for all programs, but this expenditure balance and benchmarks need to be worked out by each Ministry, focusing on the MAJOR expenditure items which generate strategic results, and to use the international benchmarks as guides to ensure a sound composition of expenditures. This exercise will need to be monitored, and to provide periodic adjustments on the composition benchmarks, based on actual experience and evaluation findings. Efforts should be made to compile and use as a reference relevant and comparable cross-country information and experiences in these benchmarks.

b) Increase Funding for 3 Strategic Programs. MASA, with MEF support, endeavor to increase progressively the funding levels for 3 strategic programs assessed in this study (agricultural research, extension and irrigation) based on their updated agricultural research agenda, agricultural extension operational strategy, prioritized irrigation facilities, taking into account relevant targets and performance indicators.

c) Strengthen/Use Ministerial and Sectoral M\&E Systems. Each of the sectoral ministries to strengthen and to use effectively their M\&E systems, including:

(i) the operationalization of relevant performance indicators (at output, outcome and impact levels), building on good country practices, and consistent with the strategic indicators implied in the RF;

(ii) conducting mid-year budgetary reviews which should focus on assessing the performance of major programs, including proposing budgetary reallocations, based on performance and strategic requirements;

(iii) the carrying out of periodic evaluations of strategic issues and major programs, as outlined above (3c); and

(iv) the use of the findings of these performance indicators, mid-year assessments, and thematic evaluations as inputs for improving the design features and budgetary allocations of these 
programs (medium term, annual and mid-year budgetary processes), and the next phase of PEDSA (2020) \& PNISA (2020-2024);

d) Enhance Quality and Results of 3 Strategic Programs. MASA, together with relevant entities at national and sub-national levels, ensure increased budgetary allocations and sustainable improved quality of these 3 strategic programs (research, extension and irrigation), especially for agricultural research and extension staff, including adequate and periodic training and age composition of agricultural staff (e.g., including promoting mentorship and knowledge sharing mechanisms between young and qualified and experienced researchers).

\section{6) Level and Quality of Decentralized Agricultural Expenditures Significantly Strengthened [Chapters 4, 5 and 6]}

Decentralization policies and expenditure are in their early stages of implementation, and there is significant scope for proactively strengthening the quality and effectiveness of decentralized programs and their expenditures, especially for strategic programs in the agrarian sector (consistent with the RF).

a) Increasing Share of Provincial Expenditures. The Provincial government share of total government budget allocation for agriculture expenditure increased from 28\% in 2013 to $40 \%$ in 2016, before falling in 2017. These erratic trends show that Mozambique is still in transition to devolution and deconcentration, which in the meantime, could negatively influence the efficiency and effectiveness with which relevant services are delivered to sustainably increase agricultural productivity and promote agrarian sector transformation.

b) Misalignment Between Expenditure Allocations and Agricultural Potential. As another measure of expenditure efficiency, the study team analyzed expenditure in agriculture disaggregated by province to assess whether expenditure in agriculture were aligned with agricultural "potential". The study revealed an "uneven" alignment between agricultural potential and the relative share of expenditure in agriculture.

\section{Core Recommendation:}

Align annual and medium term strategic agrarian sector provincial expenditure plans in line with enhanced prioritization criteria and timeline

\section{Secondary Recommendations:}

During the budgetary planning phase and cycle, MEF and sectoral ministry budgetary officers need to give increased attention to ensuring:

a) Improve Stability of Funding Levels and Shares. More stable funding levels and shares between central and provincial governments, in line with the decentralization policies, and the above cited "balance" of expenditures;

b) Improve Alignment between Sectoral Allocations and Importance/Potential. Aligned budgetary allocations to Provinces so that the share of agriculture expenditure reflects the relative importance of the agricultural sector, with respect to the Province's share of Ag.GDP and share of the labor force employed in agriculture; and

c) Strengthen Technical Capacities. Strengthened capacities of core staff involved in the budgetary cycle, especially including:

(i) planning officers in the use of enhanced and relevant planning and implementation tools and application of prioritization criteria (to be consistent with national entities): and 
(ii) M\&E officers in the design and implementation of M\&E systems at various levels, and relevant performance indicators (consistent with the sectoral results framework).

\section{7) Role and Strategy of the Private Sector Expanded for Accelerating Agrarian Sector Transformation [Chapter 6]}

There is a VITAL need to improve the financing strategies and diversify/increase the sources for the agrarian sector, especially to better align off-budget funding and to expand the role of an inclusive private sector to help accelerate the transformation of the agrarian sector.

a) Risks of External Funding. While there is a dominance of Government funding for expenditure in the agriculture sector (derived from Government revenues) there is a growing proportion of funding for the sector coming from external sources - grant and loan sources. This poses risks in terms of ensuring sustainable levels of funding for key services and productive rural infrastructure.

b) Misalignment of Off-Budget Funding. On-budget funding is the largest share, although there is a substantial share which is non-budget (about $40 \%$ ), provided primarily on a grant basis by a large number of mostly bilateral development partners. There are concerns that these offbudget resources exhibit weak alignment with Government priorities, and especially since the sectoral ministries are not using explicit prioritization criteria to guide the alignment processes for budgetary allocations.

c) Constraints to, and Limited Funding for, and from, the Private Sector. There is an expanding share of total financing for the agricultural sector which is being provided by the private sector vis-à-vis the public sector. However, there are significant constraints for farmers, traders, agro-processors to gain access to finance, and therefore, the agricultural sector obtains a relatively small share (only about $6 \%$ ) of total private sector finance vis-à-vis the share obtained by other sectors. Also, there is a relatively small share of foreign direct investment (FDI) which is allocated to the agricultural sector (ranks 4th, relative to other sectors), and below potential for increased private sector investments.

d) Private Sector is a "Game Changer" but in an infant Stage. Other country experiences exhibit that the "game-changer" in catalyzing sustained agrarian transformation is driven by an inclusive private sector. In Mozambique, the private sector is still at an infant stage, comprised primarily of subsistence farmers, and a very small number of agro-processors and other stakeholders.

\section{Core Recommendation:}

Approve, Adopt and Implement Proposed Private Sector Strategy for Agrarian Sector. MASA, MIMAIP, MITADER, MIC and MOPHRH, together with other stakeholders, to review, validate/update, adopt and implement the emerging recommendations of the parallel private sector strategy for agrarian sector transformation. This emerging strategy complements the Ag. PER, is comprised of seven inter-linked strategic objectives/outcomes, and is to be operationalized through prioritized supporting strategic actions, with a strong results-orientation:

(i) Improved Policy/Regulatory Environment: Improve business "environment" through an appropriate revision/strengthening of relevant market-based policies and regulations, clearer roles of the public and private sectors, and characterized by greater transparency and consistency in their application;

(ii) Increased Smallholder Intensification/Performance: Increase smallholder incomes through improved and appropriate intensified, diversified, profitable and climate- 
smart agricultural technologies (for key subsectors: crops, livestock, fisheries), expanded farmer adoption rates, enabled by expanded access to efficient and competitive input and output markets for key commodities;

(iii) Strengthened Value Chain Competitiveness: strengthen value chain competitiveness of key commodities through the application of appropriate and sustainable incentives, and strengthening the linkages between the various actors, including the provision of prioritized rural infrastructure (especially rural roads and electrification);

(iv) Expanded Land Access/Security: Improve land security and utilization, consistent with the other key complementary strategies;

(v) Expanded Access to Finance: Enhance access to affordable, inclusive and sustainable finance, with strong linkages to the competitive value chains;

(vi) Strengthened Public-Private Partnerships (PPPs): Attract expanded private sector participation in agricultural transformation through the sale or leasing of currently sub-utilized public assets, and/or their integration into sustainable Public Private Partnerships, while demonstrating appropriate roles of the public and private sectors;

(vii) Effective Institutional Arrangements/Mechanisms: Strengthen/establish the most appropriate institutional arrangements and processes to ensure transparent, accountable and results-oriented coordination and dialogues/platforms (e.g., CCSA, relevant private sector platforms), supported by a strengthened monitoring and evaluation system of key performance indicators for the private sector strategy.

\section{Secondary Recommendation:}

Strengthen Expenditure Alignment During Budgetary Cycle to catalyze expanded private sector investment. MEF, together with the sectoral ministries, encourage development partners, especially those providing large allocations of on and off-budget funds, to align their medium-term assistance programs with the Government's priorities, and to use the budgetary cycle (CFMP and annual/PES) and explicit prioritization criteria for the sector to help ensure strengthened alignment. For on-going projects, Government should take the initiative to encourage re-allocations and retrofitting, if relevant, toward stronger alignment and expenditure priorities, using mid-term reviews as an avenue for such enhancements. The PNISA assessment highlighted other recommendations for strengthening the alignment of the current portfolio of DP assistance, which will help ensure strong alignment for future support.

\section{8) MTEF as an Instrument and Process for Expenditure Alignment Enhanced [Chapters 3 and 7]}

The Medium Term Fiscal Framework (CFMP) is a powerful but underutilized planning and budgetary cycle tool for promoting enhanced levels and composition of expenditures, and there is scope for substantial improvement in the effective application and use of the CFMP, at national and sub-national levels, to help ensure better alignment with agrarian sector expenditure and strategic results.

a) MTEF as Strategic Expenditure Tool and Process. The CFMP provides a good basis for budgetary planning, used to define the medium term and annual PES targets, and also provides an important instrument to mobilize donor funding. The main challenges include:

(i) Changing and uncertain ceilings require several iterations in the preparation of medium-term and annual budgets by national and sub-national governments, and the challenges of ensuring the final allocations reflect sound priorities; 
(ii) Indicative ceilings established by MEF, based on CFMP, are well above the actual budgets; the absence of clear prioritization criteria and the actual allocations do not reflect sound expenditure priorities;

(iii) The CFMP is ambitious as it aims to be both a fiscal and a budget framework - there is need to reconcile these objectives.

b) Misalignment between CFMP and PNISA. There is a misalignment between CFMP and PNISA in the Forward Budget, including:

(i) The result area 1 (agricultural production and productivity), which was ranked number 1 in terms of budget allocation under PNISA, is ranked number 2 under the CFMP (2019-2021); reflects emphasis on value chain development projects;

(ii) Food and nutritional security is getting more attention in terms of forecasted funds under CFMP.

\section{Core Recommendation:}

Ensure each sectoral ministry strengthens the quality and effective use of its MTEF, including application of enhanced prioritization criteria and of expenditure scenarios (High, Medium, Low)

\section{Secondary Recommendations:}

Improve the CFMP processes (by MEF and sectoral ministries), including:

a) Separate Fiscal and Budgetary Frameworks while ensuring complementary. Allowing more time for the development of CFMP by separating the fiscal and the budgetary frameworks, and by allowing the first to start and complete getting useful information in terms of reliable forecasting of revenues to feed the second component;

b) Improve Revenue Forecasting and Use Expenditure Scenarios (High, Medium and Low). Improve the forecasting processes for fiscal aggregates (revenue, debt, expenditure and its key sub-components, and budget financing) and establish realistic baseline and targets (using High, Medium and Low scenarios);

c) Strengthen Institutional Coordination/Reactivate CCSA. Improve institutional measures, and strengthen coordination mechanisms within the ministry and among ministries, including the establishment of an activated CCSA, supported by a Technical Secretariat, and "fueled" by supporting program-based working groups, based on evidenced-based action plans and periodic and transparent multi-stakeholder reviews;

d) Use Program Working Groups. Ensure there is coordination of priorities amongst the sectoral ministries (say, through periodic working session(s) - by program - to be convened by the directors/senior budgetary planning staff/focal persons of the Planning Departments of each of the sectoral ministries). This approach will help ensure strong alignment, complementarity, coherence and consistency and budgetary allocations with the agreed prioritization criteria. 
Table 8.1: Summary Roadmap for Enhanced Results-Focused Agrarian Expenditure Management (Annex E provides further details in the form of an action plan).

\begin{tabular}{|c|c|c|c|}
\hline $\begin{array}{l}\text { Strategic Outcomes (8) } \\
\text { \& Rationale } \\
\text { (also will generate sectoral "synergies") }\end{array}$ & $\begin{array}{c}\text { Core Priority Actions (11) } \\
\text { (see Action Plan for other key } \\
\text { actions) }\end{array}$ & Timeframe & Main Responsibility \\
\hline \multirow[t]{2}{*}{$\begin{array}{l}\text { 1.0 Macro-Sectoral "Enablers" } \\
\text { Strengthened. Appropriate Macro and } \\
\text { Sectoral Trends and "Enablers" will } \\
\text { influence significantly the scope and } \\
\text { pace of agrarian sector transformation }\end{array}$} & $\begin{array}{l}1.1 \text { Ensure updated and effective } \\
\text { implementation of the PQG \& } \\
\text { MTEF as guiding expenditure tool } \\
\text { for each sectoral ministry, also } \\
\text { reflecting high priority for agrarian } \\
\text { sector; }\end{array}$ & By end of 2019 & MEF \\
\hline & $\begin{array}{l}1.2 \text { Ensure formulation, approval } \\
\text { and implementation of updated } \\
\text { agrarian sector policy, strategy and } \\
\text { investment program }\end{array}$ & $\begin{array}{l}\text { Formulation and } \\
\text { approval by end } \\
\text { of } 2019\end{array}$ & $\begin{array}{l}\text { MEF, with guidance } \\
\text { by CCSA }\end{array}$ \\
\hline $\begin{array}{l}\text { 2.0 Results Framework and ToC Utilized } \\
\text { Effectively. A sound results } \\
\text { framework/RF, underpinned by a solid } \\
\text { theory of change, provides a useful } \\
\text { TOOL for assessing the efficiencies and } \\
\text { effectiveness of sectoral public } \\
\text { expenditures, for both backward } \\
\text { assessments and forward-looking } \\
\text { proposals. }\end{array}$ & $\begin{array}{l}2.1 \text { Ensure use of sound RF and } \\
\text { other tools to: } \\
\text { - formulate updated agrarian } \\
\text { policy, strategy and investment } \\
\text { program } \\
\text { - mid-term reviews of on-going } \\
\text { and design of proposed projects }\end{array}$ & $\begin{array}{l}\text { - During } 2019 \\
\text { - During } 2019 \\
\text { and beyond }\end{array}$ & $\begin{array}{l}\text { MASA, in close } \\
\text { collaboration with } \\
\text { sectoral ministries }\end{array}$ \\
\hline \multirow{2}{*}{$\begin{array}{l}\text { 3.0 Budget Management Cycle Fortified: } \\
\text { Sound Prioritization Criteria Applied } \\
\text { Effectively and Effective Sectoral } \\
\text { Coordination Fostered }\end{array}$} & $\begin{array}{l}\text { 3.1: Apply enhanced prioritization } \\
\text { criteria, at each stage of the } \\
\text { budgetary cycle for agrarian sector }\end{array}$ & $\begin{array}{l}\text { Budgetary cycle } \\
\text { of each year, } \\
\text { beginning with } \\
\text { FY20 budget }\end{array}$ & $\begin{array}{l}\text { MEF, reinforced by } \\
\text { CCSA members }\end{array}$ \\
\hline & $\begin{array}{l}\text { 3.2: Ensure Effective Functioning of } \\
\text { CCSA }\end{array}$ & $\begin{array}{l}\text { By June } 2019, \\
\text { and meets twice } \\
\text { per year (or as } \\
\text { needed) }\end{array}$ & $\begin{array}{l}\text { CCSA members, with } \\
\text { support from } \\
\text { Technical Secretariat }\end{array}$ \\
\hline $\begin{array}{l}\text { 4.0 Expenditure technical efficiencies } \\
\text { and levels of public expenditure in } \\
\text { agrarian sector progressively increased }\end{array}$ & $\begin{array}{l}4.1 \text { Improve the execution rates } \\
\text { and prioritization and quality of } \\
\text { expenditure allocations in agrarian } \\
\text { sector, as pre-condition to increase } \\
\text { expenditure levels in the agrarian } \\
\text { sector (towards the Maputo exp. } \\
\text { target of } 10 \% \text { ); }\end{array}$ & $\begin{array}{l}\text { By mid-year } \\
\text { expenditure } \\
\text { review (2019), } \\
\text { and annual } \\
\text { budgetary } \\
\text { allocations } \\
\text { (FY20 and } \\
\text { beyond) }\end{array}$ & $\begin{array}{l}\text { Sectoral Ministries, } \\
\text { under oversight and } \\
\text { guidance of CCSA }\end{array}$ \\
\hline $\begin{array}{l}5.0 \text { Composition, Quality and Allocative } \\
\text { Efficiencies of Agrarian Sector } \\
\text { Expenditures Significantly Enhanced }\end{array}$ & $\begin{array}{l}5.1 \text { Adopt/Apply the agreed } \\
\text { enhanced prioritization criteria: } \\
\text { (i) Strength of alignment with } \\
\text { relevant PQG and agrarian sector } \\
\text { objectives and targets; } \\
\text { (ii) Contribution to inclusive } \\
\text { sources of agricultural growth and } \\
\text { poverty reduction; } \\
\text { (iii) Contribution to "catalyzing" } \\
\text { expanded inclusive private agrarian } \\
\text { sector investments; and }\end{array}$ & $\begin{array}{l}\text { Budgetary cycle } \\
\text { of each year }\end{array}$ & $\begin{array}{l}\text { Each sectoral } \\
\text { Ministry, under } \\
\text { oversight \& guidance } \\
\text { of CCSA }\end{array}$ \\
\hline
\end{tabular}




\begin{tabular}{|c|c|c|c|}
\hline & $\begin{array}{l}\text { (iv) Demonstrated evidence of } \\
\text { good institutional performance } \\
\text { and governance }\end{array}$ & & \\
\hline & $\begin{array}{l}5.2 \text { Strengthen/Use Agrarian } \\
\text { Sector M\&E system }\end{array}$ & $\begin{array}{l}\text { By end of 2019, } \\
\text { and beyond } \\
\text { (with updated } \\
\text { improvements) }\end{array}$ & $\begin{array}{l}\text { MASA, together with } \\
\text { other sector } \\
\text { Ministries, and active } \\
\text { use by CCSA }\end{array}$ \\
\hline $\begin{array}{l}\text { 6.0 Level and Quality of Decentralized } \\
\text { Agricultural Expenditures Significantly } \\
\text { Strengthened }\end{array}$ & $\begin{array}{l}\text { 6.1 Align annual and medium-term } \\
\text { strategic agrarian. sector provincial } \\
\text { expenditure plans in line with } \\
\text { enhanced prioritization criteria and } \\
\text { timeline }\end{array}$ & $\begin{array}{l}\text { FY } 20 \text { budgetary } \\
\text { cycle and } \\
\text { beyond }\end{array}$ & $\begin{array}{l}\text { MEF, together with } \\
\text { the overall guidance } \\
\text { and oversight by } \\
\text { CCSA (national \& } \\
\text { approval) }\end{array}$ \\
\hline $\begin{array}{l}\text { 7.0 Role and Strategy of the Private } \\
\text { Sector Expanded for Accelerating } \\
\text { Agrarian Sector Transformation }\end{array}$ & $\begin{array}{l}\text { 7.1 Strengthen the alignment and } \\
\text { prioritization of agrarian sector } \\
\text { public expenditure during the } \\
\text { budgetary cycle to expand the } \\
\text { private sector role, based on } 7 \\
\text { Core Elements (see (7) (b) }\end{array}$ & $\begin{array}{l}\text { FY20 budgetary } \\
\text { cycle and } \\
\text { beyond, with } \\
\text { periodic updates }\end{array}$ & $\begin{array}{l}\text { CCSA, with active } \\
\text { roles of MASA/FDA } \\
\text { and MITADER/FNDS }\end{array}$ \\
\hline $\begin{array}{l}\text { 8.0 MTEF as an Instrument and Process } \\
\text { for Expenditure Alignment Enhanced }\end{array}$ & $\begin{array}{l}8.1 \text { Ensure each sectoral ministry } \\
\text { strengthens the quality and } \\
\text { effective use of its MTEF, including } \\
\text { application of enhanced } \\
\text { prioritization criteria and of } \\
\text { expenditure scenarios (H, M, L) }\end{array}$ & $\begin{array}{l}\text { FY20 budgetary } \\
\text { cycle, and } \\
\text { beyond (with } \\
\text { improvements } \\
\text { each year) }\end{array}$ & $\begin{array}{l}\text { Each sectoral } \\
\text { ministry, in close } \\
\text { collaboration with } \\
\text { MEF, and oversight } \\
\text { by CCSA }\end{array}$ \\
\hline
\end{tabular}




\section{REFERENCES}

Alene, A. D., and O. Coulibaly. 2009. The Impact of Agricultural Research on Productivity and Poverty in sub-Saharan Africa. Food Policy 34 (2), 198-209.

African Union. 2016. Guide for Improved Level and Quality of Agricultural Public Expenditures.

Fuglie, K. O., and N. Rada. 2016. Economies of size in national agricultural research systems, in J. Lynam, N. M. Beintema, J. Roseboom and O. Badiane eds., Agricultural reseach in Africa: Investing in future harvests. International Research Food Policy Institute (IFPRI), Washington, DC.

Instituto Nacional de Estadistica. 2019. Macro-economic data.

Ministry of Agriculture and Food Security. 2017. PNISA Assessment

Maschietto, R. H. 2016. Decentralisation and local governance in Mozambique: The challenges of promoting bottom-up dynamics from the top down. Conflict, Security \& Development 16 (2), 103-23.

Mogues, T., M. Morris, L. Freinkman, A. Adubi, E. Simeon, C. Nwoko, O. Taiwo, C. Nege, P. Okonji, and L. Chete. 2008. Agricultural public spending in Nigeria. IFPRI Discussion Paper 00789. International Food Policy Research Institute (IFPRI), Wasingthon D.C.

World Bank, 2005. Mozambique Country Economic Memorandum: Sustaining Growth and Reducing Poverty. Report 32615-MZ. World Bank, Washington D.C.

World Bank. 2017. Country Partnership Strategy.

World Bank. 2019. Mozambique: Rural Income Diagnostics Study. 


\section{ANNEXES}




\section{A. Strategic objectives and targets for the agricultural sector: PQG (2015-2019) and PNISA (2013 - 2017)}

\begin{tabular}{|c|c|c|c|c|c|c|}
\hline PQG (Strategic & & & & & & Performance \\
\hline $\begin{array}{l}\text { objectives/results for } \\
\text { the ag sector: 2015- } \\
\text { 2019) }\end{array}$ & Indicator & $\begin{array}{l}\text { PQG } \\
\text { targets }\end{array}$ & $\begin{array}{l}\text { Agricultural sector strategic } \\
\text { objectives (PNISA 2013- } \\
\text { 2017): Impact level }\end{array}$ & Strategic indicator & $\begin{array}{l}\text { Initial strategic targets (cumulative } \\
\text { by the end of period) }\end{array}$ & Estimated actual (by the end of 2017) \\
\hline \multirow{5}{*}{$\begin{array}{l}\text { Improving the living } \\
\text { conditions of the } \\
\text { Mozambican people, } \\
\text { increasing } \\
\text { employment, } \\
\text { productivity and } \\
\text { competitiveness, } \\
\text { creating wealth and } \\
\text { generating a } \\
\text { development }\end{array}$} & $\begin{array}{l}\text { Households living in } \\
\text { absolute poverty } \\
\text { (\%) }\end{array}$ & & \multirow{5}{*}{$\begin{array}{l}\text { Enhanced food security and } \\
\text { nutrition, increased income } \\
\text { and profitability of } \\
\text { agricultural producers, and } \\
\text { the rapid, competitive and } \\
\text { sustainable increases in } \\
\text { market-oriented agricultural } \\
\text { production }\end{array}$} & $\begin{array}{l}\text { Annual agricultural } \\
\text { sector growth rate }\end{array}$ & $\begin{array}{l}\text { Average growth rate of } 7 \% \text { per year } \\
\text { for the next } 10 \text { years (PNISA). } \\
\text { Growth rate of at least } 6 \% \text { from 2015 } \\
\text { to } 2025 \quad \text { (MALABO). } \\
\text { Average growth rate of } 7 \% \text { per year } \\
\text { for the next } 10 \text { years (PNISA). } \\
\text { Growth rate of at least } 6 \% \text { from 2015 } \\
\text { to } 2025 \text { (MALABO). }\end{array}$ & $\begin{array}{l}\text { 1. Average agriculture growth rate for the } \\
\text { period from } 2013 \text { to } 2016 \text { was } 3.1 \% \text { per year. } \\
\text { Significant and consistent shortfalls in } \\
\text { achieving the ambitious target. } \\
\text { 2. Major reasons include significant } \\
\text { underfunding of PNISA (public and } \\
\text { development partners) coupled with PNISA's } \\
\text { limited scope in mobilizing funds, promoting } \\
\text { and achieving an expanded private sector role. }\end{array}$ \\
\hline & $\begin{array}{l}\text { Households with } \\
\text { adequate } \\
\text { consumption (\%) }\end{array}$ & 75 & & $\begin{array}{l}\text { Reduction rate of } \\
\text { poverty headcount } \\
\text { ratio }\end{array}$ & $\begin{array}{l}\text { Reduce poverty level by at least } 50 \% \\
\text { at national poverty line, from the year } \\
2015 \text { to the year } 2025\end{array}$ & $\begin{array}{l}\text { Modest reduction in poverty ( } 54.7 \% \text { in } 2009 \text { to } \\
49.2 \% \text { in } 2015 \text { ) reflects a larger reduction in } \\
\text { urban poverty with modest decrease in rural } \\
\text { poverty ( } 9 \% \text { versus } 3 \% \text { ), coupled with relatively } \\
\text { low agricultural sector growth rate trends. }\end{array}$ \\
\hline & $\begin{array}{l}\text { Households with } \\
\text { chronic malnutrition } \\
\text { (\%) }\end{array}$ & 16 & & $\begin{array}{l}\text { Prevalence of } \\
\text { wasting (under five } \\
\text { children) }\end{array}$ & $\begin{array}{l}\text { Bring down wasting to } 5 \% \text { or less by } \\
\text { the year } 2025 \text { (MALABO and not } \\
\text { specified by PNISA). }\end{array}$ & $\begin{array}{l}\text { Achieved: } 8 \% \text { in } 2009 \text { (IOF), } 11.3 \% \text { in } 2013 \\
\text { (SETSAN) and } 4.9 \% \text { in } 2015 \text { (IOF) }\end{array}$ \\
\hline & $\begin{array}{l}\text { Households with } \\
\text { adequate } \\
\text { consumption (\%) }\end{array}$ & 75 & & $\begin{array}{ll}\text { Prevalence } & \text { of } \\
\text { stunting (\% } & \text { of } \\
\text { under-five } & \\
\text { children) } & \end{array}$ & $\begin{array}{l}\text { Reduce from } 44 \% \text { in } 2008 \text { to } 30 \% \text { in } \\
2015 \text { and } 20 \% \text { in } 2020 \text {. Targets for } \\
\text { intermediate years were not defined }\end{array}$ & $\begin{array}{l}\text { Very unlikely to be met based on modest } \\
\text { increase from } 45.7 \% \text { in } 2009 \text { (IOF) to } 47.9 \% \text { in } \\
2013 \text { (SETSAN) and modest decrease to } 43.6 \% \\
\text { in } 2015 \text { (IOF) }\end{array}$ \\
\hline & $\begin{array}{l}\text { Incidence of chronic } \\
\text { malnutrition in } \\
\text { children under } 5 \\
\text { years old (\%) }\end{array}$ & 35 & & & & \\
\hline
\end{tabular}




\section{B. The AgPERs in Sub Saharan Africa: Synthesis of Relevant Challenges, Lessons and Good Practices}

\begin{tabular}{|c|c|}
\hline Strategic Challenges & Lessons Learned and Good Practices \\
\hline $\begin{array}{l}\text { 1) Sound definition of "agricultural } \\
\text { sector" }\end{array}$ & $\begin{array}{l}\text { 1) Define the "agricultural sector" (= "agrarian sector"), } \\
\text { based on relevant guidelines and methodologies, including } \\
\text { indicators, findings and recommendations, customized to } \\
\text { country requirements (e.g., AU Guide on Level and Quality } \\
\text { of Agricultural Expenditures, 2016). }\end{array}$ \\
\hline $\begin{array}{l}\text { 2) Lack of clarity on sound agric. } \\
\text { expenditure-result linkages, and on } \\
\text { the pathways for cause-effect } \\
\text { relationships; }\end{array}$ & $\begin{array}{l}\text { 2) Ensure and apply sound results framework to enable } \\
\text { appropriate assessment and prioritization of expenditures }\end{array}$ \\
\hline $\begin{array}{l}\text { 3) Sound and streamlined conceptual } \\
\text { framework(s) to help focus evidenced } \\
\text {-based analyses }\end{array}$ & $\begin{array}{l}\text { 3) Sound formulation, including realistic scope and depth } \\
\text { of TOR, and consensus by key stakeholders, throughout } \\
\text { the key stages of the analytical exercise. }\end{array}$ \\
\hline $\begin{array}{l}\text { 4) Absence of agricultural sector } \\
\text { model (to help assess the expenditure } \\
\text { implications and scenarios) (funding } \\
\text { from Shear) }\end{array}$ & $\begin{array}{l}\text { 4) Strong ownership by key counterparts, enabled by } \\
\text { focusing on relevant expenditure issues and promoting } \\
\text { enhanced "professionalism" and technical capacities of } \\
\text { participating officers. }\end{array}$ \\
\hline $\begin{array}{l}\text { 5) Availability of reliable and } \\
\text { consistent expenditure data, } \\
\text { sufficiently disaggregated and } \\
\text { integrated (according to national/sub- } \\
\text { national and strategic programs) }\end{array}$ & $\begin{array}{l}\text { 5) Identify and merge data requirements and availabilities } \\
\text { at various levels and institutions (national/sub-national, } \\
\text { relevant ministries and departments), together with } \\
\text { preparation of template tables, in the early stages of the } \\
\text { exercise; the aim should be to envision template tables } \\
\text { which can be institutionalized as part of periodic } \\
\text { expenditure analyses, in support of the budgetary cycle, } \\
\text { coupled with recommendations to enhance expenditure } \\
\text { data consistencies and reliability; }\end{array}$ \\
\hline $\begin{array}{l}\text { 7) Fragmentation of the agricultural } \\
\text { sector among many different } \\
\text { ministries and other entities, coupled } \\
\text { with weak institutional coordination } \\
\text { arrangements, processes and } \\
\text { mechanisms, coupled with absence of } \\
\text { leadership, to engage stakeholders } \\
\text { and provide effectively and timely } \\
\text { prioritization and guidance during the } \\
\text { expenditure review and cycle. }\end{array}$ & $\begin{array}{l}\text { 7) Ensure active engagement and coordination by relevant } \\
\text { stakeholders at key stages of the expenditure exercise, } \\
\text { which also would help ensure ownership and utilization of } \\
\text { the findings and recommendations of the Ag. PER during } \\
\text { the annual budgetary planning and implementation } \\
\text { phases; recommend improved institutional coordination } \\
\text { processes and mechanisms for enhanced management } \\
\text { expenditure cycle (building on existing and/or proposed } \\
\text { sector coordination initiatives) }\end{array}$ \\
\hline
\end{tabular}




\section{Functions and Apportionment}

The scope and methodological aspects of this expenditure review are summarized in the text. Below are further details.

The agrarian sector includes the following functions, known as COFOG "plus", which together contributes to agricultural development:

- Food and Nutritional Security;

- Rural/feeder roads;

- Rural Land Administration;

- Natural Resource Management and Climate Change Adaptation for Sustainability;

- Agricultural Development (including sustainable forestry);

- Multi-Sectoral and Multi-Purpose Development Projects;

- Mandated Functions of the State-owned enterprises (SOEs) for agricultural development;

- Agriculture Marketing;

- Capacity Development for Agriculture Development (up to the technical level);

- Rural Electrification for Agriculture;

- Information and communication technology (ICT) for Agriculture;

- Sub National expenditure (which are on-budget and off-budget, and which directly benefit the agricultural sector);

In the above functions are carried out by five central government ministries and provincial governments. Error! Reference source not found. shows the expenditure apportionment assumptions employed in this report with respect to Mozambique's relevant government entities and their respective functions/mandates, taking into account apportionment assumptions in other countries in Sub-Sahara Africa. 


\begin{tabular}{|c|c|c|c|}
\hline Government entity & Function/Mandate & Apportionment (\%) & Rationale \\
\hline MASA & $\begin{array}{l}\text { - Fostering the production, agro-industrialization and competitiveness of agricultural products; } \\
\text { - Promote sustainable development through administration, management, protection, } \\
\text { - } \text { - Promservation and rational use of essential resources for agriculture and food security; } \\
\text { - Promotion of research, extension, and technical assistance in agriculture and food security; } \\
\text { - Promote, monitor and evaluate programs, projects and plans in the agricultural sector and food } \\
\text { - } \quad \text { Licensing of agricultural activities, agro-forestry planning and food safety. }\end{array}$ & 100 & $\begin{array}{l}\text { All expenditure } \\
\text { contribute directly to } \\
\text { agricultural growth } \\
\text { and rural poverty } \\
\text { reduction }\end{array}$ \\
\hline MITADER & $\begin{array}{l}\text { - Planning and territorial ordination for sustainable development; } \\
\text { - } \quad \text { Formulation of integrated development policy and strategies related to land, environment, } \\
\text { - } \quad \text { Lanservation manageas, forestry, wildlife and rural development; } \\
\text { - Administration, management and sustainable use of wildlife and forestry; } \\
\text { - Administration and management of national conservation areas; } \\
\text { - Planning, coordination and promotion of sustainable rural development. } \\
\text { - Promotion of knowledge development in land, environment, rural development and related } \\
\text { - } \quad \text { Guareas } \\
\text { - Ind rural development; } \\
\text { development. }\end{array}$ & 50 & $\begin{array}{l}\text { Functions include } \\
\text { expenditure for } \\
\text { various sectors }\end{array}$ \\
\hline MIMAIP & $\begin{array}{l}\text { - Exercise of the State authority over the sea, inland waters and fisheries; } \\
\text { - Authorize and supervise the planning, research and other activities that demand the use of the } \\
\text { sea, inland waters and their ecosystems, in articulation with other institutions; } \\
\text { - Promote the use and exploitation of the resources of the sea, inland waters and their ecosystems; } \\
\text { - Promote and coordinate the regulation of the sustainable use of water, the prevention and } \\
\text { reduction of the pollution of the aquatic environment, and improvement of the state of } \\
\text { respective ecosystems. }\end{array}$ & 100 & $\begin{array}{l}\text { All expenditure } \\
\text { contributes directly to } \\
\text { agricultural growth } \\
\text { and rural poverty } \\
\text { reduction }\end{array}$ \\
\hline
\end{tabular}




\section{Institutional roles and Budgetary Planning documents}

Table D.1 The roles of the different institutions involved in the budgetary process

\begin{tabular}{|c|c|}
\hline Institution & Roles \\
\hline $\begin{array}{l}\text { Provincial/district } \\
\text { institutions }\end{array}$ & $\begin{array}{l}\text { - Provide inputs for the design of the government five-year plan; } \\
\text { - Design and implement the provincial strategies and plans; } \\
\text { - Provide inputs in the design of the provincial social and economic plan; } \\
\text { - } \quad \text { Present and defend the provincial social and economic plan to the provincial parliament } \\
\text { - } \text { and other actors such as private sector, civil society through the respective platforms; } \\
\text { - Prepare and submit to MEF the medium-term fiscal and expenditure framework; } \\
\text { - } \text { - Exepare and submit to MEF the yearly budget based on the medium-term fiscal expenditure } \\
\text { - Present and defend the balance of the social and economic plan to the provincial } \\
\text { parliament and other actors such as private sector, civil society through the respective } \\
\text { platforms. }\end{array}$ \\
\hline $\begin{array}{l}\text { Central } \\
\text { institutions: } \\
\text { Ministries }\end{array}$ & $\begin{array}{l}\text { - Provide inputs for the design of the government five-year plan; } \\
\text { - Design and implement the sector strategies and plans; } \\
\text { - } \quad \text { Design the sector economic and social plan and submit to MEF; } \\
\text { by MEF; } \\
\text { - Prepare and submit to MEF the medium-term fiscal and expenditure framework; } \\
\text { - } \quad \text { Prepare and submit to MEF the yearly budget based on the medium-term fiscal expenditure } \\
\text { - } \quad \text { framework; } \\
\text { - } \quad \text { Present the balance of the social and economic plan to the national parliament. }\end{array}$ \\
\hline $\begin{array}{l}\text { Coordinating } \\
\text { institution: } \\
\text { Ministry } \\
\text { Economy } \\
\text { Finance }\end{array}$ & $\begin{array}{l}\text { - } \quad \text { Produce the national social and economic plan; } \\
\text { - } \quad \text { Submit the national and economic plan to the council of ministers; } \\
\text { - } \quad \text { Present and defend the social and economic plan to the council of minister; } \\
\text { - } \quad \text { Establish budget ceiling and communicate to the respective institutions; } \\
\text { - } \quad \text { Produce the national budget and submit to the council of ministers; } \\
\text { - } \quad \text { Present and defend the national budget to the council of ministers; } \\
\text { - } \quad \text { Produce and implement financial and budgetary rules and regulations with coordination of } \\
\text { - } \quad \text { other institutions (provincial and central levels); } \\
\text { - } \quad \text { Allocate and disburse funds to implementing institutions. }\end{array}$ \\
\hline
\end{tabular}


Table D.2 Key Strategic Documents Supporting Budgetary Processes in Mozambique

\begin{tabular}{|c|c|c|}
\hline Key Strategic Document & $\begin{array}{l}\text { Coordinating } \\
\text { Institution }\end{array}$ & Timeline \\
\hline & Central & \\
\hline Government Five Year Plan & Government & $2015-2019$ \\
\hline National Development Strategy & Government & 2015-2035 \\
\hline Law N.9/2002 on State Financial Management System (SISTAFE) & MEF & 2002- up to now \\
\hline Law N. 8/2003 on Legal Framework for the State Local Organs (OLEs) & MEF & 2003-up to now \\
\hline Public Finance Strategic Plan & MEF & 2016-2019 \\
\hline Law N. 9/2002 on State Financial Administration System & MEF & 2002 \\
\hline Resolution N. 40/2012 on Decentralization Policy and Strategy & MAEFP & 2012 \\
\hline Food and Nutrition Security Strategy and Action Plan & MASA & $2008-2015$ \\
\hline Multisectoral Action Plan for Reduction of Chronic Malnutrition in Mozambique & MASA & 2011-2015 \\
\hline Strategic Plan for the Development of Agricultural Sector & MASA & 2011-2020 \\
\hline National Agriculture Investment Plan & MASA & $2013-2017$ \\
\hline Irrigation Strategy & MASA & $2010-2020$ \\
\hline National Irrigation Program & MASA & $2016-2040$ \\
\hline Agricultural Extension Master Plan & MASA & 2007-2016 \\
\hline Agricultural Extension National Program & MASA & $2007-2014$ \\
\hline Mozambique Agricultural Research Institution Strategy & MASA & 2011-2015 \\
\hline Rural Development Strategy & MITADER & $2007-2025$ \\
\hline Rural Finance Strategy & MITADER & 2011-2016 \\
\hline National Strategy for Sustainable Development & MITADER & $2015-2030$ \\
\hline National Sustainable Development Fund Strategic Plan & MITADER & $2017-2021$ \\
\hline Fisheries Master Plan & MIMAIP & $2010-2019$ \\
\hline Sea Policy and Strategy & MIMAIP & 2017 \\
\hline Integrated Plan for Agricultural Commercialization & MIC & $2013-2020$ \\
\hline Agricultural Commercialization Operational Plan & MIC & 2017 \\
\hline
\end{tabular}




\section{E. Results-Focused Agrarian Sector Public Expenditure Action Plan ("RASPEAP")}

Annex E: Results-focused Agrarian Sector Public Expenditure Action Plan ("RASPEAP")

\begin{tabular}{|c|c|c|c|c|c|c|}
\hline \multirow{2}{*}{ Strategic Outcomes } & \multirow{2}{*}{$\begin{array}{l}\text { Recommended Priority Actions } \\
\text { (core priorities shown in bold) }\end{array}$} & \multirow{2}{*}{ Expected Strategic Results } & \multicolumn{2}{|c|}{ Responsible Actors } & \multirow{2}{*}{$\begin{array}{c}\text { Timeline } \\
\text { (during budget } \\
\text { cycle) }\end{array}$} & \multirow{2}{*}{$\begin{array}{l}\text { Required Resources to } \\
\text { Implement Priority Actions }\end{array}$} \\
\hline & & & Coordinator & Other Actors & & \\
\hline \multirow{9}{*}{$\begin{array}{l}\text { 1.0 Macro-Sectoral } \\
\text { "Enablers" } \\
\text { Strengthened }\end{array}$} & $\begin{array}{l}\text { 1.1 Ensure updated and effective implementation } \\
\text { of the PQG \& MTEF as guiding expenditure tool } \\
\text { for each sectoral ministry, also reflecting high } \\
\text { priority for agrarian sector; }\end{array}$ & $\begin{array}{c}\text { PQG and MTEF elaborated and } \\
\text { effectively implemented taking } \\
\text { into acccount the macro } \\
\text { economic context }\end{array}$ & MEF & $\begin{array}{l}\text { MASA, MIMAIP, } \\
\text { MOPHRH, MIC, } \\
\text { MITADER }\end{array}$ & $\begin{array}{l}\text { December } 2019 \text { for } \\
\text { PQG and March } \\
2020 \text { onward for } \\
\text { MTEF }\end{array}$ & $\begin{array}{l}\text { Adequate human and financial } \\
\text { resources }\end{array}$ \\
\hline & $\begin{array}{l}\text { l.2 Ensure formulation, approval and } \\
\text { implementation of updated agrarian sector } \\
\text { policy, strategy and investment program }\end{array}$ & $\begin{array}{c}\text { Agrarian sector policy, strategy } \\
\text { and investment program } \\
\text { formulated, approved and } \\
\text { implemented }\end{array}$ & MASA & $\begin{array}{l}\text { MIMAIP, MITADER, } \\
\text { MIC, MOPHRH, and MEF }\end{array}$ & December, 2019 & $\begin{array}{l}\text { Adequate human and financial } \\
\text { resources }\end{array}$ \\
\hline & $\begin{array}{l}\text { 1.3 Improve agrarian sector performance to be more } \\
\text { consistent and to achieve realistic targets, while } \\
\text { addressing the relevant constraints; }\end{array}$ & $\begin{array}{l}\text { Indicators developed and } \\
\text { evidence-based targets set }\end{array}$ & MASA & $\begin{array}{l}\text { MIMAIP, MITADER, } \\
\text { MIC, MOPHRH, and MEF }\end{array}$ & December, 2019 & $\begin{array}{l}\text { Adequate human and financial } \\
\text { resources }\end{array}$ \\
\hline & $\begin{array}{l}\text { 1.4 Revitalize the role of the agrarian sector to } \\
\text { contribute to core objectives of the Government's } \\
\text { PQG and targets; }\end{array}$ & $\begin{array}{c}\text { CCSA revitalized and } \\
\text { effectively and efficiently } \\
\text { working } \\
\end{array}$ & MASA & $\begin{array}{l}\text { MIMAIP, MITADER, } \\
\text { MIC, MOPHRH, and MEF }\end{array}$ & December, 2019 & $\begin{array}{l}\text { Adequate human and financial } \\
\text { resources }\end{array}$ \\
\hline & $\begin{array}{l}\text { 1.5 Tap underutilized potential for intensifying and } \\
\text { diversifying Mozambique's sources of growth; }\end{array}$ & $\begin{array}{c}\text { Agrarian resources (land, water, } \\
\text { etc) effectively used coupled } \\
\text { with enhanced use of improved } \\
\text { agricultural technologies }\end{array}$ & MASA & $\begin{array}{l}\text { MIMAIP, MITADER, } \\
\text { MIC, MOPHRH, and MEF }\end{array}$ & $\begin{array}{l}\text { September } 2019 \\
\text { onwards }\end{array}$ & $\begin{array}{l}\text { Adequate human and financial } \\
\text { resources }\end{array}$ \\
\hline & $\begin{array}{l}\text { 1.6 Promote stronger institutional coherence } \\
\text { fragmentation in the agrarian sector }\end{array}$ & $\begin{array}{c}\text { CCSA revitalized and } \\
\text { effectively and efficiently } \\
\text { working }\end{array}$ & MASA & $\begin{array}{l}\text { MIMAIP, MITADER, } \\
\text { MIC, MOPHRH, and MEF }\end{array}$ & December, 2019 & $\begin{array}{l}\text { Adequate human and financial } \\
\text { resources }\end{array}$ \\
\hline & $\begin{array}{l}\text { 1.7 Expand role of an inclusive private sector to } \\
\text { accelerate agrarian sector transformation; }\end{array}$ & $\begin{array}{l}\text { Private Sector Strategy for } \\
\text { Agrarian Sector approved, } \\
\text { adopted and effectively } \\
\text { implemented }\end{array}$ & $\begin{array}{c}\text { MIC in collaboration } \\
\text { with MASA/FDA }\end{array}$ & $\begin{array}{l}\text { MIMAIP, MITADER, } \\
\text { MOPHRH, and MEF }\end{array}$ & $\begin{array}{l}\text { December, } 2019 \\
\text { onwards }\end{array}$ & $\begin{array}{l}\text { Adequate human and financial } \\
\text { resources }\end{array}$ \\
\hline & $\begin{array}{l}1.8 \text { Update and track appropriate and prioritized } \\
\text { investments by both public and private sectors to } \\
\text { help realize strategic sector targets }\end{array}$ & $\begin{array}{l}\text { Agrarian sector investment } \\
\text { identified and prioritized }\end{array}$ & $\begin{array}{l}\text { MASA in } \\
\text { collaboration MIC }\end{array}$ & $\begin{array}{l}\text { MIMAIP, MITADER, } \\
\text { MOPHRH, and MEF }\end{array}$ & December, 2019 & $\begin{array}{l}\text { Adequate human and financial } \\
\text { resources }\end{array}$ \\
\hline & $\begin{array}{l}\text { 1.9 Tap the large poverty elasticity of the agrarian } \\
\text { sector }\end{array}$ & $\begin{array}{l}\text { Poverty reduced through } \\
\text { agrarian sector enhanced } \\
\text { performance }\end{array}$ & MASA & $\begin{array}{l}\text { MIMAIP, MITADER, } \\
\text { MIC, MOPHRH, and MEF }\end{array}$ & December, 2020 & $\begin{array}{l}\text { Adequate human and financial } \\
\text { resources }\end{array}$ \\
\hline
\end{tabular}




\begin{tabular}{|c|c|c|c|c|c|c|}
\hline \multirow{2}{*}{ Strategic Outcomes } & \multirow{2}{*}{$\begin{array}{l}\text { Recommended Priority Actions } \\
\text { (core priorities shown in bold) }\end{array}$} & \multirow{2}{*}{ Expected Strategic Results } & \multicolumn{2}{|c|}{ Responsible Actors } & \multirow{2}{*}{$\begin{array}{c}\text { Timeline } \\
\text { (during budget } \\
\text { cycle) }\end{array}$} & \multirow{2}{*}{$\begin{array}{l}\text { Required Resources to } \\
\text { Implement Priority Actions }\end{array}$} \\
\hline & & & Coordinator & Other Actors & & \\
\hline \multirow{4}{*}{$\begin{array}{l}2.0 \text { Results Framework } \\
\text { (RF) and Theory of } \\
\text { Change (ToC) utilized } \\
\text { effectively for assessing } \\
\text { and prioritizing the } \\
\text { efficiency and } \\
\text { effectiveness of sectoral } \\
\text { public expenditure }\end{array}$} & $\begin{array}{l}2.1 \text { Ensure effective use of sound RF and other } \\
\text { relevant tools to: }\end{array}$ & & & & & \\
\hline & $\begin{array}{l}\text { (i) formulate updated agrarian policy, strategy and } \\
\text { investment program }\end{array}$ & \begin{tabular}{|c|} 
Agrarian sector policy, strategy \\
and investment program \\
formulated, approved and \\
implemented
\end{tabular} & MASA & $\begin{array}{l}\text { MIMAIP, MITADER, } \\
\text { MIC, MOPHRH, and MEF }\end{array}$ & December, 2019 & $\begin{array}{l}\text { Adequate human and financial } \\
\text { resources }\end{array}$ \\
\hline & $\begin{array}{l}\text { (ii) support mid-term reviews of on-going and } \\
\text { design of proposed projects }\end{array}$ & \begin{tabular}{|c|}
$\begin{array}{c}\text { Mid-term project review reports } \\
\text { elaborated and new projects } \\
\text { designed }\end{array}$ \\
\end{tabular} & MASA & $\begin{array}{l}\text { MIMAIP, MITADER, } \\
\text { MIC, MOPHRH, and MEF }\end{array}$ & $\begin{array}{l}\text { December, } 2019 \\
\text { onwards }\end{array}$ & $\begin{array}{l}\text { Adequate human and financial } \\
\text { resources }\end{array}$ \\
\hline & $\begin{array}{l}\text { 2.2 MASA together with other sectoral ministries, } \\
\text { take a proactive role to: (i) engage with MEF and (ii) } \\
\text { work together }\end{array}$ & \begin{tabular}{|} 
Working plan to enhanced \\
linkages between sectorial \\
ministries and MEF generated
\end{tabular} & MASA & $\begin{array}{l}\text { MIMAIP, MITADER, } \\
\text { MIC, MOPHRH, and MEF }\end{array}$ & December, 2019 & $\begin{array}{l}\text { Adequate human and financial } \\
\text { resources }\end{array}$ \\
\hline
\end{tabular}




\begin{tabular}{|c|c|c|c|c|c|c|}
\hline \multirow{2}{*}{ Strategic Outcomes } & \multirow{2}{*}{$\begin{array}{l}\text { Recommended Priority Actions } \\
\text { (core priorities shown in bold) }\end{array}$} & \multirow{2}{*}{ Expected Strategic Results } & \multicolumn{2}{|c|}{ Responsible Actors } & \multirow{2}{*}{$\begin{array}{c}\text { Timeline } \\
\text { (during budget } \\
\text { cycle) }\end{array}$} & \multirow{2}{*}{$\begin{array}{l}\text { Required Resources to } \\
\text { Implement Priority Actions }\end{array}$} \\
\hline & & & Coordinator & Other Actors & & \\
\hline & $\begin{array}{l}\text { 3.1 Assure Strong Alignment of Financing and TA } \\
\text { Assistance from Development Partners (DPs) with } \\
\text { Strategic Priorities: } \\
\text { (a) Apply sound prioritization criteria during the } \\
\text { budgetary cycle process (see text for } 4 \text { proposed } \\
\text { criteria); } \\
\text { (b) Organize annual meetings with DPs to review \& } \\
\text { align investment proposals (on-going and new), } \\
\text { based on enhanced prioritization criteria }\end{array}$ & $\begin{array}{l}\text { Recurrent comunication } \\
\text { between the Government and its } \\
\text { partners established as well as } \\
\text { alignment between Government } \\
\text { and DP programs to ensure } \\
\text { coherence and consistency }\end{array}$ & $\begin{array}{l}\text { (a) MASA (in close } \\
\text { coordination with } \\
\text { MEF) } \\
\text { (b) MASA }\end{array}$ & $\begin{array}{l}\text { (a) MEF, MITADER, } \\
\text { MIC, MIMAIP, MOPHRH } \\
\text { and Agrarian Sector } \\
\text { Development Partners } \\
\\
\text { (b) MITADER, MIC, } \\
\text { MIMAIP, MOPHRH, } \\
\text { MEF and Agrarian Sector } \\
\text { Development Partners }\end{array}$ & $\begin{array}{l}\text { (a) and (b): March } \\
\text { every year (in } \\
\text { accordance with } \\
\text { budgetary cycle) }\end{array}$ & $\begin{array}{l}\text { (a) Adequate human resources in } \\
\text { MASA and other Ministries, and } \\
\text { Planning Departments at the } \\
\text { national, provincial and district } \\
\text { levels } \\
\text { (b) Financial resources for } \\
\text { meetings. The required amounts } \\
\text { must be defined by the } \\
\text { responsible ministry as part of } \\
\text { budgetary cycle }\end{array}$ \\
\hline & $\begin{array}{l}\text { 3.2 Ensure Adequate Time for Budgetary Processes } \\
\text { and Provide } 3 \text { Budgetary Scenarios (e.x., High (H), } \\
\text { Medium (M) and Low (L)): } \\
\text { (a) Prepare budget proposals with scenarios (H, M, } \\
\text { L), with clear indication of financing sources; } \\
\text { (b) Assure adeuate time for budgetary processes and } \\
\text { the sound application of prioritization criteria for } \\
\text { each scenario (H, M, L). }\end{array}$ & $\begin{array}{l}\text { Sound application of relevant } \\
\text { budgetary Instruments (for } \\
\text { CFMP, PES and Budgeting), } \\
\text { with evidence of improvement } \\
\text { of priorities and the strategic } \\
\text { results }\end{array}$ & (a) MEF & $\begin{array}{l}\text { (a) and (b) MASA, } \\
\text { MITADER, MIC, } \\
\text { MIMAIP, MOPHRH }\end{array}$ & $\begin{array}{l}\text { (a) and (b) March } \\
\text { every year }\end{array}$ & $\begin{array}{l}\text { (a) and (b) Adequate human } \\
\text { resources at MEF and sector's } \\
\text { ministries, and planning } \\
\text { departments at national, } \\
\text { provincial and district levels }\end{array}$ \\
\hline & $\begin{array}{l}\text { 3.3 Apply enhanced prioritization criteria at } \\
\text { each stage of budgetary cycle for agrarian sector } \\
\text { Agree/Adjust/Update prioritization criteria } \\
\text { (annually) }\end{array}$ & $\begin{array}{l}\text { Enhanced prioritization criteria } \\
\text { elaborated, agreed, } \\
\text { disseminated, applied and } \\
\text { contributing to improved results }\end{array}$ & MEF & $\begin{array}{l}\text { MASA, MITADER, MIC, } \\
\text { MIMAIP, MOPHRH }\end{array}$ & $\begin{array}{l}\text { Budgetary cycle of } \\
\text { each year, beginning } \\
\text { with FY20 budget }\end{array}$ & $\begin{array}{l}\text { Adequate human resources at } \\
\text { MEF and sector's Ministries, and } \\
\text { planning departments at national, } \\
\text { provincial and district levels }\end{array}$ \\
\hline
\end{tabular}




\begin{tabular}{|c|c|c|c|c|c|c|}
\hline \multirow{2}{*}{ Strategic Outcomes } & \multirow{2}{*}{$\begin{array}{l}\text { Recommended Priority Actions } \\
\text { (core priorities shown in bold) }\end{array}$} & \multirow[b]{2}{*}{ Expected Strategic Results } & \multicolumn{2}{|c|}{ Responsible Actors } & \multirow{2}{*}{$\begin{array}{c}\text { Timeline } \\
\text { (during budget } \\
\text { cycle) }\end{array}$} & \multirow{2}{*}{$\begin{array}{l}\text { Required Resources to } \\
\text { Implement Priority Actions }\end{array}$} \\
\hline & & & Coordinator & Other Actors & & \\
\hline \multirow[t]{3}{*}{$\begin{array}{l}\text { 3.0 Budget } \\
\text { Management Cycle } \\
\text { Fortified: Sound } \\
\text { Processes and } \\
\text { Prioritization } \\
\text { Criteria Applied and } \\
\text { Effective Sectoral } \\
\text { Coordination to } \\
\text { Ensure Strategic } \\
\text { Results }\end{array}$} & $\begin{array}{l}\text { 3.4 Ensure Efective Functioning of CCSA } \\
\text { (a) Recruit an adequate number of human resources } \\
\text { to assure the functioning of the CCSA secretariat } \\
\text { (b) Organize two meetings every year with all CCSA } \\
\text { members and other key stakeholders with a } \\
\text { significative agenda } \\
\text { (c) Monitor and ensure accountability on agreed } \\
\text { action plan and its accomplishments }\end{array}$ & $\begin{array}{l}\text { Reactivated CCSA generating } \\
\text { strategic results for agrarian } \\
\text { sector }\end{array}$ & $\begin{array}{l}\text { (b) MASA } \\
\text { (c) CCSA members }\end{array}$ & $\begin{array}{l}\text { (a) MIMAIP, MOPHRH, } \\
\text { MEF, MIC, MITADER } \\
\text { (b) MIMAIP, MIC, } \\
\text { MOPHRH, MITADER, } \\
\text { MEF, CCSA members and } \\
\text { other key stakeholders } \\
\text { (c) CCSA members }\end{array}$ & $\begin{array}{l}\text { (b) First and third } \\
\text { trimesters of each } \\
\text { year } \\
\text { (c) Third trimester of } \\
\text { each year }\end{array}$ & $\begin{array}{l}\text { (a) Adequate human resources } \\
\text { for CCSA secretariat (initially } \\
\text { with AGRA funding, and to be } \\
\text { sustained by Government) } \\
\text { (b) Financial Resources for } \\
\text { CCSA meetings. Budget to be } \\
\text { estimated by MASA } \\
\text { (c) Relevant members of CCSA } \\
\text { to represent major stakeholders }\end{array}$ \\
\hline & $\begin{array}{l}\text { 3.5 Provide Technical Support to Planning Officers } \\
\text { of planning departments at national and provincial } \\
\text { levels: } \\
\text { (a) Review and ensure that adequate human } \\
\text { resources are allocated planning departments } \\
\text { (National and provincial levels) assuring an effective } \\
\text { management of the budget cycle } \\
\text { (b) Provide annual training for improvement of } \\
\text { annual budget planning to planning officers from } \\
\text { ministries, provincial directorates and districts }\end{array}$ & $\begin{array}{l}\text { Planning and budgetary cycle } \\
\text { functioning effectively and } \\
\text { budgeting, contributing to } \\
\text { improved and monitored results }\end{array}$ & (b) MEF & $\begin{array}{l}\text { (a) MASA, MIMAIP, } \\
\text { MOPHRH, MIC, } \\
\text { MITADER } \\
\text { (b) MASA, MIMAIP, } \\
\text { MOPHRH, MIC, } \\
\text { MITADER }\end{array}$ & $\begin{array}{l}\text { (a) December, } 2019 \text {, } \\
\text { with annual reviews } \\
\text { and adjustments } \\
\text { (b) February each } \\
\text { year }\end{array}$ & $\begin{array}{l}\text { (a) Adequate human resources at } \\
\text { MEF and other Ministries, and } \\
\text { planning departments at national, } \\
\text { provincial and district levels } \\
\text { (b) Adequate human resources to } \\
\text { assure training and financial } \\
\text { resources to pay for trainings. } \\
\text { Budget estimated by responsible } \\
\text { ministry and to be included in } \\
\text { budgetary requirements }\end{array}$ \\
\hline & $\begin{array}{l}3.6 \text { Improve M\&E Systems, and supporting } \\
\text { performance indicators: } \\
\text { (a) Formulate improved sectoral M\&E system with } \\
\text { relevant agrarian sector key efficiency and } \\
\text { effectiveness indicators for each ministry, province } \\
\text { and district } \\
\text { (b) Use M\&E results to support annual and mid-term } \\
\text { budget planning as well as mid-term reviews and } \\
\text { adjustments. }\end{array}$ & $\begin{array}{l}\text { M\&E systems that include } \\
\text { relevant indicators from } \\
\text { strategic documents as well as } \\
\text { indicators of efficiency and } \\
\text { effectiveness of resource usage, } \\
\text { with evidence of improvement } \\
\text { of strategic results, and used to } \\
\text { support enhanced decision- } \\
\text { making; }\end{array}$ & (a) MASA & $\begin{array}{l}\text { (a) MIMAIP, MOPHRH, } \\
\text { MIC, MITADER, MEF } \\
\\
\text { (b) MASA, MIMAIP, } \\
\text { MOPHRH, MIC, } \\
\text { MITADER, MEF }\end{array}$ & $\begin{array}{l}\text { (a) December } 2019 \\
\text { with annual meetings }\end{array}$ & $\begin{array}{l}\text { (a) e (b) Adequate human } \\
\text { resources from MEF and other } \\
\text { ministries, and planning } \\
\text { departments at national, } \\
\text { provincial and district levels }\end{array}$ \\
\hline
\end{tabular}




\begin{tabular}{|c|c|c|c|c|c|c|}
\hline \multirow[b]{2}{*}{ Strategic Outcomes } & \multirow{2}{*}{$\begin{array}{l}\text { Recommended Priority Actions } \\
\text { (core priorities shown in bold) }\end{array}$} & \multirow[b]{2}{*}{ Expected Strategic Results } & \multicolumn{2}{|c|}{ Responsible Actors } & \multirow{2}{*}{$\begin{array}{c}\text { Timeline } \\
\text { (during budget } \\
\text { cycle) } \\
\end{array}$} & \multirow{2}{*}{$\begin{array}{l}\text { Required Resources to } \\
\text { Implement Priority Actions }\end{array}$} \\
\hline & & & Coordinator & Other Actors & & \\
\hline \multirow{4}{*}{$\begin{array}{l}\text { 4.0 Expenditure } \\
\text { Technical } \\
\text { Efficiencies and } \\
\text { Level of Public } \\
\text { Expenditures in the } \\
\text { Agrarian Sector } \\
\text { Progressively } \\
\text { Increased }\end{array}$} & $\begin{array}{l}4.1 \text { Inprove consistently the budget's technical } \\
\text { efficiency including, execution rates of agriculture } \\
\text { expenditures: } \\
\text { (a) Monitor execution rates as key indicator } \\
\text { (b) Develop a biannual action plan to improve the } \\
\text { budget execution rates of the Agrarian Sector } \\
\text { (national and provincial levels) }\end{array}$ & $\begin{array}{l}\text { Budget execution rates above } \\
95 \% \text {, accompained by a regular } \\
\text { monthly flow disembursment }\end{array}$ & (a) and (b) MEF & $\begin{array}{l}\text { (a) and (b) MASA, } \\
\text { MIMAIP, MOPHRH, } \\
\text { MIC, MITADER }\end{array}$ & $\begin{array}{l}\text { December } 2019 \text { with } \\
\text { yearly updates }\end{array}$ & $\begin{array}{l}\text { Human resources: Adequate } \\
\text { budgetary officers at national and } \\
\text { provincial levels, tracking } \\
\text { expenditure execution rates. }\end{array}$ \\
\hline & $\begin{array}{l}\text { 4.2 Improve the execution rates and } \\
\text { prioritization and quality of expenditure } \\
\text { allocations in agrarian sector, as pre-conditon to } \\
\text { increase expenditure levels in the agriculture } \\
\text { sector; } \\
\text { (a) Use and monitor relevant indicators for efficient } \\
\text { allocation of financial resources of the Agrarian } \\
\text { Sector }\end{array}$ & \begin{tabular}{|l|} 
Prioritization criteria and \\
efficient allocation of financial \\
resources applied to promote \\
improved and expanded results \\
of public expenses at the \\
Agrarian Sector
\end{tabular} & (a) MEF & $\begin{array}{l}\text { MASA, MIMAIP, } \\
\text { MOPHRH, MIC, } \\
\text { MITADER }\end{array}$ & $\begin{array}{l}\text { December } 2019 \text { with } \\
\text { yearly updates }\end{array}$ & $\begin{array}{l}\text { Human resources: Adequate } \\
\text { planning officers at national and } \\
\text { provincial levels, applying } \\
\text { prioritization criteria and } \\
\text { ensuring efficient allocation of } \\
\text { expenditures. }\end{array}$ \\
\hline & $\begin{array}{l}\text { 4.3 Progressive increase of the level of public } \\
\text { expenditures in the Agrarian Sector: } \\
\text { (a) Annual monitoring of the percentage of agrarian } \\
\text { sector expenditures as a \% of Total Government } \\
\text { Expenditures }\end{array}$ & $\begin{array}{l}\text { Increase of the level of } \\
\text { expenditures on the Agrarian } \\
\text { Sector, based on prioritization } \\
\text { criteria to improve the sector's } \\
\text { performance/results }\end{array}$ & (a) $\operatorname{CCSA}$ & $\begin{array}{l}\text { MEF, MASA, MIMAIP, } \\
\text { MOPHRH, MIC, } \\
\text { MITADER }\end{array}$ & $\begin{array}{l}\text { September } 2019 \text { as } \\
\text { well as subsequent } \\
\text { years }\end{array}$ & $\begin{array}{l}\text { Human resources: CCSA } \\
\text { members and planning and } \\
\text { finance officers, at national and } \\
\text { provincial levels }\end{array}$ \\
\hline & $\begin{array}{l}\text { 4.4 Improve the M\&E system in physical and } \\
\text { financial execution: } \\
\text { a) Develop and useefficiency based unit } \\
\text { cost/banchmark; } \\
\text { (b) Assure the use of an improved M\&E system that } \\
\text { tracks prioritization and application of relevant } \\
\text { technical and financial indicators }\end{array}$ & $\begin{array}{l}\text { Analytical PES balances } \\
\text { produced using strategic } \\
\text { documents indicators as well as } \\
\text { an efficent and effective use of } \\
\text { financial resources to improve } \\
\text { the performance of the Agrarian } \\
\text { Sector }\end{array}$ & (a) MASA & $\begin{array}{l}\text { MEF, MIMAIP, } \\
\text { MOPHRH, MIC, } \\
\text { MITADER }\end{array}$ & $\begin{array}{l}\text { December } 2020 \text { as } \\
\text { well as subsequent } \\
\text { years }\end{array}$ & $\begin{array}{l}\text { Adequate human resources, } \\
\text { especially M\&E officers at the } \\
\text { national and provincial levels. }\end{array}$ \\
\hline
\end{tabular}




\begin{tabular}{|c|c|c|c|c|c|c|}
\hline \multirow[b]{2}{*}{ Strategic Outcomes } & \multirow{2}{*}{$\begin{array}{l}\text { Recommended Priority Actions } \\
\text { (core priorities shown in bold) }\end{array}$} & \multirow[b]{2}{*}{ Expected Strategic Results } & \multicolumn{2}{|c|}{ Responsible Actors } & \multirow{2}{*}{$\begin{array}{c}\text { Timeline } \\
\text { (during budget } \\
\text { cycle) }\end{array}$} & \multirow{2}{*}{$\begin{array}{l}\text { Required Resources to } \\
\text { Implement Priority Actions }\end{array}$} \\
\hline & & & Coordinator & Other Actors & & \\
\hline \multirow{4}{*}{$\begin{array}{l} \\
5.0 \\
\text { Composition/quality } \\
\text { and Allocative } \\
\text { Efficiencies of } \\
\text { Agrarian Sector } \\
\text { Expenditures } \\
\text { Significantly } \\
\text { Enhanced } \\
\end{array}$} & $\begin{array}{l}\text { 5.1 Adopt/Apply the agreed enhanced four (4) } \\
\text { prioritization criteria; }\end{array}$ & $\begin{array}{l}\text { Increase the levels of } \\
\text { expenditures for the Agrarian } \\
\text { Sector, driven by application of } \\
\text { enhanced prioritization criteria, } \\
\text { to improve the sector's results }\end{array}$ & MASA & $\begin{array}{l}\text { MASA, MITADER, MIC, } \\
\text { MOPHRH \& MIMAIP, } \\
\text { MEF }\end{array}$ & $\begin{array}{l}\text { Budgetary cycle of } \\
\text { each year }\end{array}$ & $\begin{array}{l}\text { (a) Adequate human resources in } \\
\text { MASA and other ministries, at } \\
\text { their planning and program } \\
\text { departments, at national, } \\
\text { provincial and distrital levels }\end{array}$ \\
\hline & $\begin{array}{l}\text { 5.2 Strenghten/Use M\&E systems of Agrarian } \\
\text { Sector's Ministries: } \\
\text { (a) Develop and apply improved M\&E systems, } \\
\text { including indicators for the tracking and } \\
\text { improvement of efficient allocation of financial } \\
\text { resources (at national and subnational levels) }\end{array}$ & $\begin{array}{l}\text { Compostion and allocative } \\
\text { efficiency of the Agrarian } \\
\text { Sector's budget improved }\end{array}$ & MASA & $\begin{array}{l}\text { MEF, MITADER, MIC, } \\
\text { MOPHRH \& MIMAIP }\end{array}$ & $\begin{array}{l}\text { July and December } \\
2019 \text {, with mid-year } \\
\text { and annual updates }\end{array}$ & $\begin{array}{l}\text { Adequate Human Resources: } \\
\text { Adequate technical and planning } \\
\text { officers (from Planning and } \\
\text { program departments). }\end{array}$ \\
\hline & $\begin{array}{l}\text { 5.3 Increase progressively the investment in the } 3 \\
\text { strategic programs (agricultural research, extension, } \\
\text { irrigation), and simultaneosly improve their } \\
\text { performance and results: } \\
\text { (a) Develop an action plan to improve the results of } \\
\text { agrarian research and extension system, supported } \\
\text { by relevant performance and results indicators, as } \\
\text { well as monitoring and periodic evaluations. } \\
\text { (b) Increase progressivly budgetary allocations for } \\
\text { the } 3 \text { strategic programs }\end{array}$ & $\begin{array}{l}\text { Improved compositon and } \\
\text { allocation of financial resources } \\
\text { to the } 3 \text { strategic programs, and } \\
\text { their enhanced results }\end{array}$ & MASA & $\begin{array}{l}\text { MEF, MITADER, MIC, } \\
\text { MOPHRH \& MIMAIP }\end{array}$ & $\begin{array}{l}\begin{array}{l}\text { For each budget } \\
\text { cycle, beginning with } \\
\text { cycle for FY20 }\end{array} \\
\text {. }\end{array}$ & $\begin{array}{l}\text { Adequate Human Resources: } \\
\text { Adequate technical and planning } \\
\text { officers (from Planning and the } 3 \\
\text { program departments) }\end{array}$ \\
\hline & $\begin{array}{l}5.4 \text { Formulate/Use Enhanced "Balance" of } \\
\text { Expenditures and efficiency-based Unit Costs of } \\
\text { major expenditures: } \\
\text { (a) Estimate efficiency indicators based on unit } \\
\text { costs for key expenditures of the Agrarian Sector } \\
\text { (e.g.,cost per km of rural roads, cost per inigated } \\
\text { area (ha)) }\end{array}$ & $\begin{array}{l}\text { Indicators of efficiency and } \\
\text { effectiveness for financial } \\
\text { resources use produced in all } \\
\text { sectors, especially for public } \\
\text { expenditures in agriculture for } \\
\text { improved results }\end{array}$ & MASA & $\begin{array}{l}\text { MEF, MITADER, MIC, } \\
\text { MOPHRH \& MIMAIP }\end{array}$ & $\begin{array}{l}\text { For each budget } \\
\text { cycle, beginning with } \\
\text { cycle for FY21 }\end{array}$ & $\begin{array}{l}\text { Human Resources: Adequate } \\
\text { technical officers (combination } \\
\text { of planning, budgeting and } \\
\text { program officers) }\end{array}$ \\
\hline
\end{tabular}




\begin{tabular}{|c|c|c|c|c|c|c|}
\hline \multirow{2}{*}{ Strategic Outcomes } & \multirow{2}{*}{$\begin{array}{l}\text { Recommended Priority Actions } \\
\text { (core priorities shown in bold) }\end{array}$} & \multirow{2}{*}{ Expected Strategic Results } & \multicolumn{2}{|c|}{ Responsible Actors } & \multirow{2}{*}{$\begin{array}{c}\text { Timeline } \\
\text { (during budget } \\
\text { cycle) }\end{array}$} & \multirow{2}{*}{$\begin{array}{l}\text { Required Resources to } \\
\text { Implement Priority Actions }\end{array}$} \\
\hline & & & Coordinator & Other Actors & & \\
\hline \multirow{6}{*}{$\begin{array}{l}\text { 6.0 Level and } \\
\text { Quality of } \\
\text { Descentralized } \\
\text { Agriculture } \\
\text { Expenditures } \\
\text { Significantly } \\
\text { Strenghthen }\end{array}$} & $\begin{array}{l}6.1 \text { Improve the stability: of the level and proportion } \\
\text { of ag. sector public expenditurees at provincial } \\
\text { level; and a balance betweem the proportion of ag. } \\
\text { public expenditures between central and provincial } \\
\text { levels: } \\
\text { (a) Inccrease expenditures to the provinces compared } \\
\text { with the central level for the descentralized programs }\end{array}$ & $\begin{array}{l}\text { Provincial budgetary } \\
\text { allocations reflect adequately } \\
\text { the relative importance of the } \\
\text { s }\end{array}$ & MASA & $\begin{array}{l}\text { MEF, MITADER, MIC, } \\
\text { MOPHRH \& MIMAIP }\end{array}$ & $\begin{array}{l}\text { December } 2019 \text {, and } \\
\text { each subsequent } \\
\text { budgetary cycle }\end{array}$ & $\begin{array}{l}\text { Human Resources: Adequate } \\
\text { technical officers (combination } \\
\text { of planning, budgeting and } \\
\text { program officers) }\end{array}$ \\
\hline & $\begin{array}{l}6.2 \text { Improve the alignment between sectoral } \\
\text { allocation and importance with the prioritization } \\
\text { criteria agro-ecological potential: } \\
\text { (a) Develop and apply enhanced prioritization } \\
\text { criteria and key indicators for consistent allocation } \\
\text { of public expenditures for the Agrarian Sector in } \\
\text { each province }\end{array}$ & \begin{tabular}{|l|} 
Results from efficiency and \\
effectiveness used for \\
budgetary allocations at central \\
and provincial levels
\end{tabular} & MASA & $\begin{array}{l}\text { MEF, MITADER, MIC, } \\
\text { MOPHRH \& MIMAIP }\end{array}$ & $\begin{array}{l}\text { December } 2019 \text { with } \\
\text { annual updates }\end{array}$ & $\begin{array}{l}\text { Human resources: Technical } \\
\text { officiers with adequate skills for } \\
\text { forecasting revenues and } \\
\text { formulating ag. sector } \\
\text { expenditures. }\end{array}$ \\
\hline & $\begin{array}{l}6.3 \text { Improve the efficiency of budgetary ceiling } \\
\text { communications: }\end{array}$ & & & & & \\
\hline & $\begin{array}{l}\text { (a) MEF should comunicate the Agrarian Sector } \\
\text { about the budget ceilings based on the three scenario } \\
(\mathrm{H}, \mathrm{M}, \mathrm{L}) \text { in coordination with the sector's ministries; } \\
\text { (b) Sector's Ministeries should coordinate budgetary } \\
\text { planning and allocations with provinces during the } \\
\text { budget cycle }\end{array}$ & $\begin{array}{l}\text { Orientation instruments used } \\
\text { for CFMP are consistent with } \\
\text { the budget cycle at the Agrarian } \\
\text { Sector }\end{array}$ & (a) MEF & $\begin{array}{l}\text { (a) MASA, MITADER, } \\
\text { MIC, MOPHRH \& } \\
\text { MIMAIP. } \\
\text { (b) Agrarian Sector (MEF, } \\
\text { MITADER, MIC, } \\
\text { MOPHRH \& MIMAIP). }\end{array}$ & $\begin{array}{l}\text { (a) and (b) December } \\
2019, \text { and each } \\
\text { budgetary cycle } \\
\text { thereafter }\end{array}$ & $\begin{array}{l}\text { Ensure adequate technical } \\
\text { officers serve as focal persons for } \\
\text { each sector Ministry and } \\
\text { Province, in close collaboration } \\
\text { wth relevant budget officers from } \\
\text { MEF }\end{array}$ \\
\hline & $\begin{array}{l}\text { 6.4 Align annual and medium term strategic ag. } \\
\text { sector provincial expenditure plans in line with } \\
\text { enhanced prioritizatioin criteria and timeline: }\end{array}$ & & & & & \\
\hline & $\begin{array}{l}\text { (a) alignment and prioritization criteria reflected in } \\
\text { the annual and medium term expenditures for } \\
\text { agriculture sector; } \\
\text { (b) Strategic plans reflected in the core agrarian } \\
\text { sector indicators in budget plans }\end{array}$ & $\begin{array}{l}\text { District and provincial plans } \\
\text { and strategies aligned with the } \\
\text { national plans and prioritization } \\
\text { criteria, generating strategic and } \\
\text { sustainable results }\end{array}$ & (a) MEF & $\begin{array}{l}\text { (a) MASA, MITADER, } \\
\text { MIC, MOPHRH \& } \\
\text { MIMAIP } \\
\text { (b) MEF, MITADER, } \\
\text { MIC, MOPHRH \& } \\
\text { MIMAIP }\end{array}$ & $\begin{array}{l}\text { December } 2019 \text {, and } \\
\text { each budgetary cycle } \\
\text { thereafter }\end{array}$ & $\begin{array}{l}\text { Human resources: Budgeting and } \\
\text { Planning officers from sector's } \\
\text { ministries work in collaboration } \\
\text { with planning and budgetary } \\
\text { officers from MEF }\end{array}$ \\
\hline
\end{tabular}




\begin{tabular}{|c|c|c|c|c|c|c|}
\hline \multirow{2}{*}{ Strategic Outcomes } & \multirow{2}{*}{$\begin{array}{l}\text { Recommended Priority Actions } \\
\text { (core priorities shown in bold) }\end{array}$} & \multirow{2}{*}{ Expected Strategic Results } & \multicolumn{2}{|c|}{ Responsible Actors } & \multirow{2}{*}{$\begin{array}{c}\text { Timeline } \\
\text { (during budget } \\
\text { cycle) }\end{array}$} & \multirow{2}{*}{$\begin{array}{l}\text { Required Resources to } \\
\text { Implement Priority Actions }\end{array}$} \\
\hline & & & Coordinator & Other Actors & & \\
\hline \multirow{2}{*}{$\begin{array}{l}7.0 \text { Role and } \\
\text { Strategy of the } \\
\text { Private Sector } \\
\text { Expanded for } \\
\text { Accelerating } \\
\text { Agrarian Sector } \\
\text { Transformation }\end{array}$} & $\begin{array}{l}7.1 \text { Strengthen the alignment and prioritization } \\
\text { of ag. sector public expenditures during the } \\
\text { budgetary cycle to expand the private sector role, } \\
\text { based on the PSS 7 Core Elements: } \\
\text { (a) Apply } 7 \text { elements/action plan for expanded role } \\
\text { of private sector (see PSS report) as key input for } \\
\text { prioritizing and aligning annual and medium term } \\
\text { agrarian sector public expenditures; } \\
\text { (b) Incorporate in the prioritization criteria for } \\
\text { agrarian sector public expenditures the relevant } \\
\text { points from the action plan for expanded role of the } \\
\text { private sector }\end{array}$ & $\begin{array}{l}\text { Taking into account the action } \\
\text { plan for expanded role of } \\
\text { private sector, include in annual } \\
\text { PES priorized expenditures for } \\
\text { investment and services of the } \\
\text { Agrarian Sector that catalizes } \\
\text { the participation and } \\
\text { investments of the private } \\
\text { sector in agriculture, and which } \\
\text { will contribute to enhanced } \\
\text { agrarian sector growth }\end{array}$ & (a) and (b): MASA & $\begin{array}{l}\text { (a) and (b) MEF, } \\
\text { MITADER, MIC, } \\
\text { MOPHRH \& MIMAIP }\end{array}$ & $\begin{array}{l}\text { December 2019, and } \\
\text { each budgetary cycle } \\
\text { thereafter }\end{array}$ & $\begin{array}{l}\text { Human Resources: Adequate } \\
\text { technical officers (combination } \\
\text { of planning and program } \\
\text { officers) }\end{array}$ \\
\hline & $\begin{array}{l}\text { 7.2 Approve, adopt and implement private sector } \\
\text { strategy and action plan (7 elements) for } \\
\text { expanded role of the private sector for agrarian } \\
\text { sector transformation } \\
\text { 7.3 Arrange periodic updates of the action plan for } \\
\text { private sector expanded role in agriculture, based on } \\
\text { implementation experiences and evaluation results }\end{array}$ & $\begin{array}{l}\text { Formulated, approved and } \\
\text { implemented strategy for } \\
\text { private sector expanded role in } \\
\text { agriculture, catalized by } \\
\text { prioritized public expenditures } \\
\text { in the Agrarian Sector }\end{array}$ & MASA & $\begin{array}{l}\text { Agrarian Sector (MEF, } \\
\text { MITADER, MIC, } \\
\text { MOPHRH \& MIMAIP). }\end{array}$ & $\begin{array}{l}\text { By mid-2019, and } \\
\text { each budgetary cycle } \\
\text { thereafter }\end{array}$ & $\begin{array}{l}\text { Human Resources: Adequate } \\
\text { technical officers (combination } \\
\text { of planning and program } \\
\text { officers) }\end{array}$ \\
\hline
\end{tabular}




\begin{tabular}{|c|c|c|c|c|c|c|}
\hline \multirow{2}{*}{ Strategic Outcomes } & \multirow{2}{*}{$\begin{array}{l}\text { Recommended Priority Actions } \\
\text { (core priorities shown in bold) }\end{array}$} & \multirow{2}{*}{ Expected Strategic Results } & \multicolumn{2}{|c|}{ Responsible Actors } & \multirow{2}{*}{$\begin{array}{c}\text { Timeline } \\
\text { (during budget } \\
\text { cycle) }\end{array}$} & \multirow{2}{*}{$\begin{array}{l}\text { Required Resources to } \\
\text { Implement Priority Actions }\end{array}$} \\
\hline & & & Coordinator & Other Actors & & \\
\hline \multirow[b]{7}{*}{$\begin{array}{l}8.0 \mathrm{MTF} \text { as an } \\
\text { Instrument and } \\
\text { Process for } \\
\text { Expenditure } \\
\text { Alignment Enhanced }\end{array}$} & $\begin{array}{l}\text { 8.1 Ensure each Sectoral Ministry Strenghthen the } \\
\text { Quality and Effective Use of Its MTEF Icluding: }\end{array}$ & & & & & \\
\hline & a) Application of enhanced prioritization criteria & $\begin{array}{l}\text { Prioritization criteria agreed, } \\
\text { socialized and implemented }\end{array}$ & MEF & $\begin{array}{l}\text { MASA, MIMAIP, } \\
\text { MOPHRH, MIC, } \\
\text { MITADER }\end{array}$ & December, 2019 & $\begin{array}{l}\text { Adequate human and financial } \\
\text { resources }\end{array}$ \\
\hline & b) Formulation of expenditure scenario (H,M, L) & CFMP with scenario developed & MEF & $\begin{array}{l}\text { MASA, MIMAIP, } \\
\text { MOPHRH, MIC, } \\
\text { MITADER }\end{array}$ & December, 2019 & $\begin{array}{l}\text { Adequate human and financial } \\
\text { resources }\end{array}$ \\
\hline & $\begin{array}{l}\text { 8.1 Strengthen Institutional Coordination and } \\
\text { Reactivate an Effective CCSA: }\end{array}$ & & & & & \\
\hline & $\begin{array}{l}\text { (a) Recruit an adequate number of human resources } \\
\text { to assure an effective functioning of CCSA } \\
\text { secretariat } \\
\text { (b) Organize two meetings in each year with all } \\
\text { CCSA members and other key stakeholders, based } \\
\text { on a strategic agenda }\end{array}$ & $\begin{array}{l}\text { Reactivated CCSA generating } \\
\text { strategic results for agrarian } \\
\text { sector }\end{array}$ & $\begin{array}{l}\text { (a) MASA } \\
\text { (b) MASA }\end{array}$ & $\begin{array}{l}\text { (a) MIMAIP, MOPHRH, } \\
\text { MEF, MIC, MITADER } \\
\text { (b) MIMAIP, MOPHRH, } \\
\text { MEF, MIC, MITADER, } \\
\text { CCSA members and key } \\
\text { stakeholders }\end{array}$ & $\begin{array}{l}\text { (a) July, } 2019 \\
\text { (b) First and third } \\
\text { trimesters of each } \\
\text { year }\end{array}$ & $\begin{array}{l}\text { (a) Adequate human resources } \\
\text { for CCSA secretariat (initial } \\
\text { funding provided by AGRA) } \\
\text { (b) Financial resources to pay for } \\
\text { CCSA meetings. Budget must be } \\
\text { estimated by MASA }\end{array}$ \\
\hline & $\begin{array}{l}\text { (c) Monitor implementation and ensure } \\
\text { accountability on the agreed action plan }\end{array}$ & & (c) CCSA members & (c) CCSA members & $\begin{array}{l}\text { (c) Third trimesters } \\
\text { of each year }\end{array}$ & $\begin{array}{l}\text { (c) Adequate and diversified } \\
\text { members of CCSA (to represent } \\
\text { key stakeholder groups) }\end{array}$ \\
\hline & $\begin{array}{l}\text { 8.2 Separate fiscal and budgeting processes, assuring } \\
\text { complementarity: } \\
\text { (a) Estimate fiscal and budget expenditures based on } \\
\text { three scenarios (H, M, L) } \\
\text { (b) Reconciliate fiscal and budget expenditures } \\
\text { based on } 3 \text { scenarios, especially on time of defining } \\
\text { budget ceilings for ministries, provinces and districts }\end{array}$ & $\begin{array}{l}\text { Budgetary Orientation } \\
\text { instruments produced for } \\
\text { processes (i) fiscal and (ii) } \\
\text { budgeting, to ensure that budget } \\
\text { proposals are based on realistic } \\
\text { fiscal parameters }\end{array}$ & (a) and (b): MEF & $\begin{array}{l}\text { (a) and (b): MASA, } \\
\text { MIMAIP, MOPHRH, } \\
\text { MIC, MITADER }\end{array}$ & $\begin{array}{l}\text { December 2019, } \\
\text { forward }\end{array}$ & $\begin{array}{l}\text { Adequate human resources from } \\
\text { MEF, including budgetary } \\
\text { department officers to serve as } \\
\text { focal points for agrarian sector } \\
\text { ministries }\end{array}$ \\
\hline
\end{tabular}




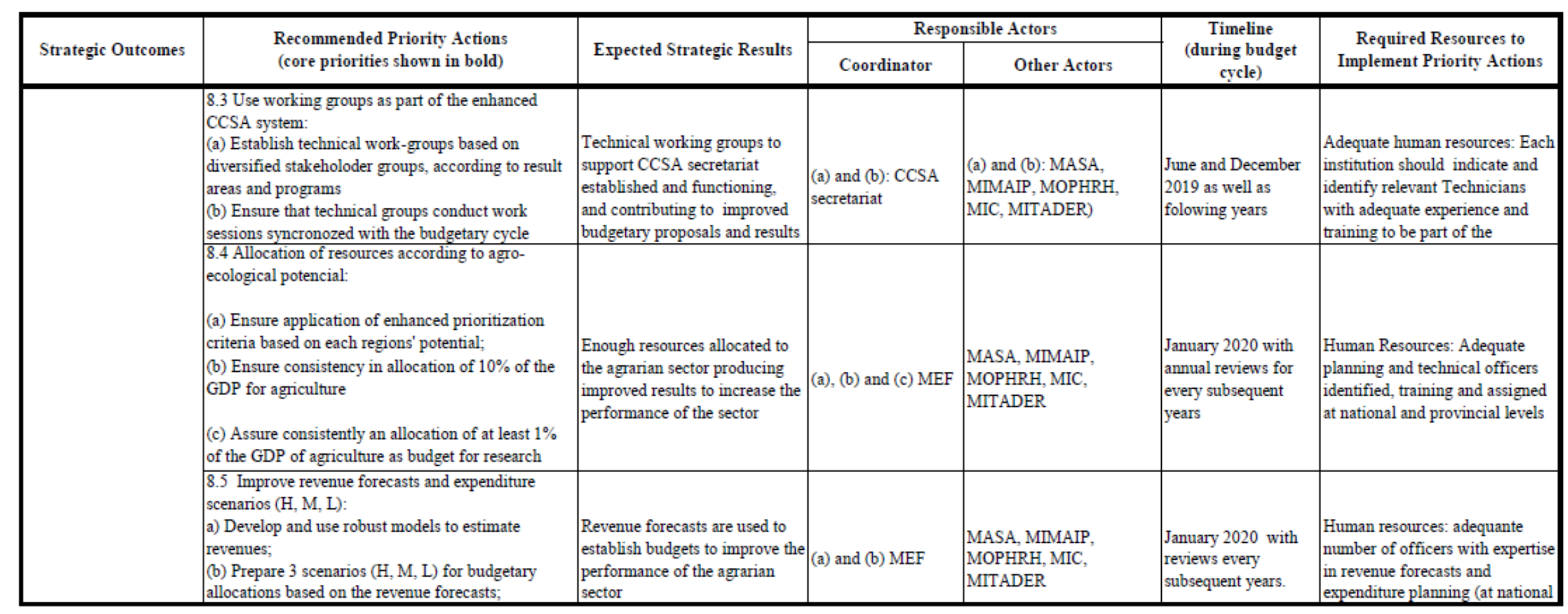

